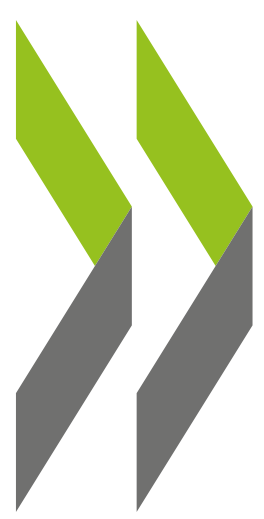

Starting Strong

\title{
Starting Strong VI
}

SUPPORTING MEANINGFUL INTERACTIONS IN EARLY CHILDHOOD EDUCATION AND CARE

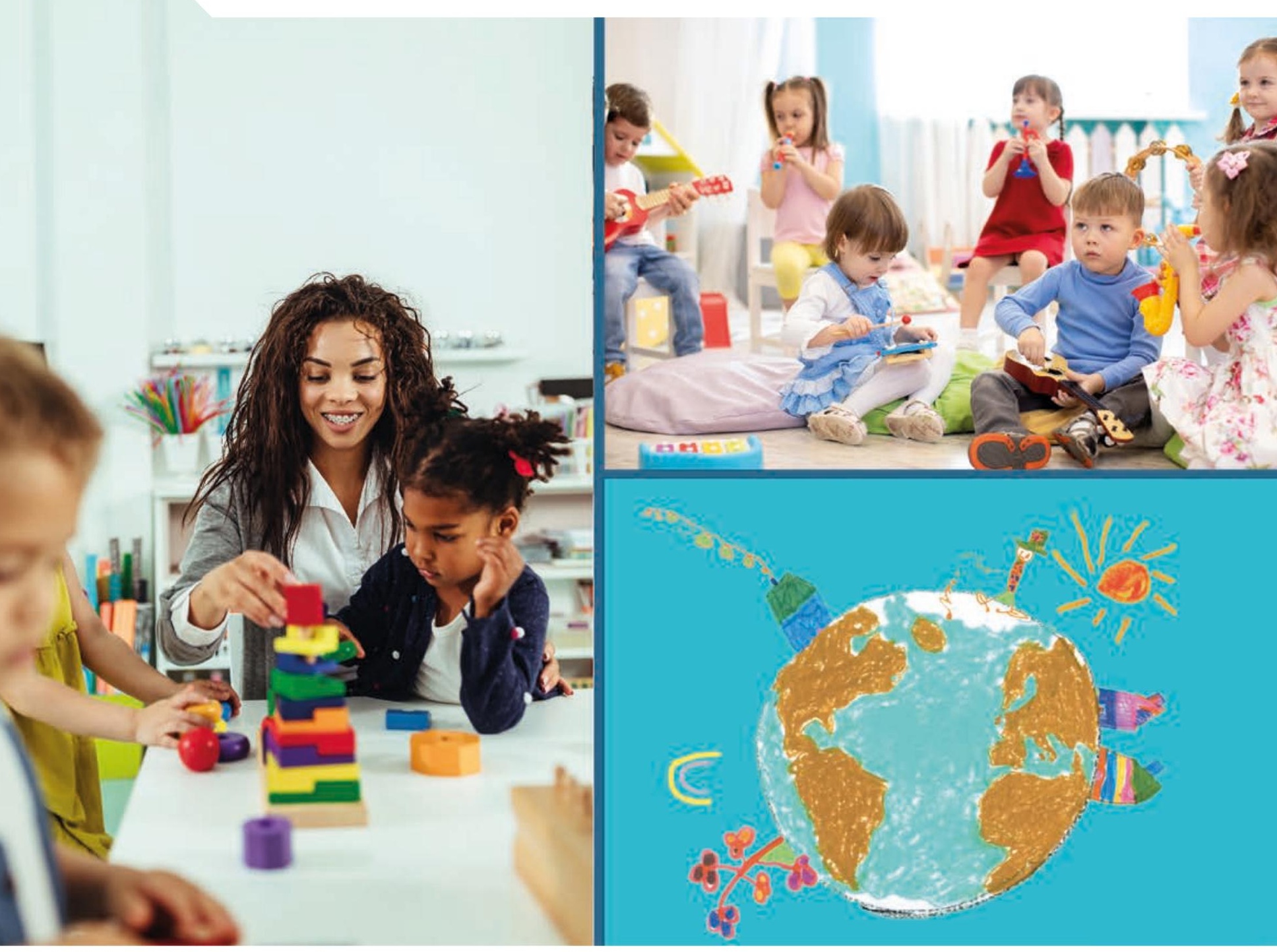

()OCD 



\title{
Starting Strong VI
}

\author{
SUPPORTING MEANINGFUL INTERACTIONS \\ IN EARLY CHILDHOOD EDUCATION AND CARE
}

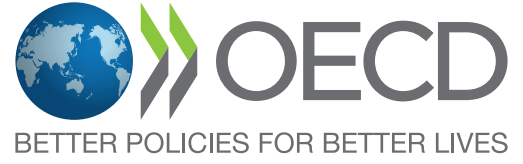


This work is published under the responsibility of the Secretary-General of the OECD. The opinions expressed and arguments employed herein do not necessarily reflect the official views of OECD member countries.

This document, as well as any data and map included herein, are without prejudice to the status of or sovereignty over any territory, to the delimitation of international frontiers and boundaries and to the name of any territory, city or area.

The statistical data for Israel are supplied by and under the responsibility of the relevant Israeli authorities. The use of such data by the OECD is without prejudice to the status of the Golan Heights, East Jerusalem and Israeli settlements in the West Bank under the terms of international law.

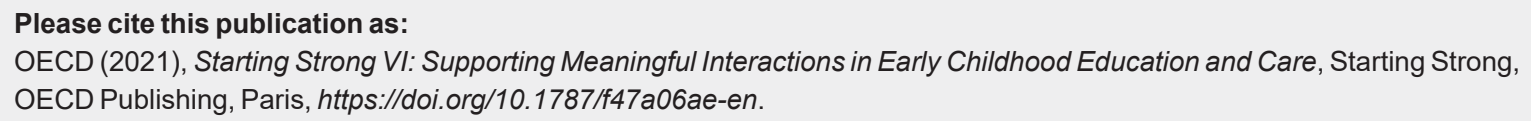

ISBN 978-92-64-32747-4 (print) ISBN 978-92-64-88865-4 (pdf)

Starting Strong

ISSN 2521-6023 (print)

ISSN 2521-6031 (online)

Photo credits: Cover @ Shutterstock/Oksana Kuzmina; @ Shutterstock/bbernard. 


\section{Foreword}

Some of the workplace skills that we value most, whether it's curiosity and creativity, or an ability to think independently while still working collaboratively, are best developed in the earliest years of life. Early childhood education and care (ECEC), as children's first experience outside the home environment, holds immense promise for guiding children towards a positive and rich life-long learning and development path. However, this role of ECEC is coupled with great responsibility in not only ensuring access to but also quality of services.

Historically, policies on ECEC have focussed on setting norms to safeguard the safety of young children, such as the formulation of standards on buildings, materials or staff-to-child group ratios. However, it is the quality of interactions which children experience, known as process quality, that matters most for their development, learning and well-being. This leads to two key questions:

1. Which policies set the best conditions for children to experience high quality interactions in ECEC settings?

2. To what extent are existing policies in OECD countries supportive of high quality interactions in ECEC settings?

Fostering process quality involves designing policies in a way that best facilitates meaningful interactions in ECEC settings, going beyond simply a regulatory nature. This was the focus of the Quality beyond Regulations policy review, which the OECD developed to help countries and jurisdictions better support the different dimensions of quality in ECEC. This report summarises the main findings of the policy review and is accompanied by a website that presents policy indicators in participating countries and jurisdictions, clarifying their links to process quality.

The report identifies five policy levers that are instrumental to the quality of children's everyday interactions: 1) quality standards, governance and funding; 2) curriculum and pedagogy; 3) workforce development; 4) monitoring and data; and 5) family and community engagement. It gives particular attention to two of them, curriculum and pedagogy, and workforce development.

Curriculum and pedagogy are powerful tools to shape interactions within ECEC settings. The former sets the principles and goals that ECEC staff use to foster children's development, learning and well-being, while the latter refers to the strategies and techniques implemented by staff to offer these opportunities. Perhaps one of the most important observations of this report is the vast variety of approaches to curriculum and pedagogy that exist across countries and jurisdictions, and the at times complex nature of ECEC landscapes within a country or jurisdiction. For example, multiple curricula may exist for a specific age group or setting, while the youngest age group ( 0 to 2 year olds) is not always covered by a curriculum. Some countries adopt a very comprehensive approach to children's development with a curriculum framework for after-school activities, while other countries consider it to be outside the scope of policies to foster child development.

The ECEC workforce encompasses professionals who interact with children and families in ECEC settings, reconciling formal objectives with community expectations. Countries often use qualification requirements to set standards on workforce quality. However, such a one-sided indicator is not always sufficient as 
features like the inclusion of a practicum and pre-service trainings on early childhood and curriculum implementation are essential to prepare staff to interact in a rich and informed way with children. Policies on staff initial education vary significantly across countries and jurisdictions, and many are evaluated based on their capacity to better regulate the quality of these initial education programmes for different staff categories. Participation in professional development is crucial for all staff to refine and expand their knowledge and skills, as well as to bring new research-based practices to life in the classroom or playgroup. However, facilitating participation for all categories of employees is a challenge for many countries and jurisdictions, with many implementing requirements on the number of yearly training hours, but few following up with monitoring the quality of trainings provided.

The realisation of this report and its accompanying website was possible due to the continued collaboration with participating OECD ECEC Network countries and jurisdictions, who shared their insights and provided an inside look into their systems and policies. The project has highlighted the complexity of the sector and the difficulty to compare ECEC systems across countries, even though it is often successfully done for primary and secondary school education. It provides a solid basis to better understand how system level policies, when designed carefully, support process quality; and provides a multiplicity of examples of good policies, while also highlighting areas for improvement. Overall, it demonstrates that carefully designed policies can support meaningful interactions for all children as part of their ECEC experience - this is where focus should be placed.

Andreas Schleicher,

Director for Education and Skills

Special Advisor on Education Policy to the OECD Secretary-General 


\section{Acknowledgements}

This report, Starting Strong VI: Supporting meaningful interactions in early childhood education and care, represents the culmination of the Quality beyond Regulations policy review undertaken between 2018 and 2021.The development of this report and of the policy review was guided by OECD Early Childhood Education and Care Network and has benefited from contributions of its members throughout the project. Annex $D$ of this report lists the various individuals and institutions that contributed to the preparation of the report.

The development of this report was guided by Andreas Schleicher and Yuri Belfali and led by Stéphanie Jamet. Elizabeth Shuey wrote Chapter 1, Victoria Liberatore was the lead author of Chapter 2, and Chapter 3 was prepared by Joana Cadima, Vera Coelho, Carolina Guedes, and Gil Nata (external consultants), and by Stéphanie Jamet and Thomas Radinger. Authors of the report also prepared the country notes with contributions from Alix Got. Andrea Konstantinidi supported report preparation, production, project co-ordination and communications with contributions from Mernie Graziotin in the first phase of the project. The report builds on preparatory work led by Clara Barata, Arno Engel, Victoria Liberatore, Elizabeth Shuey and Miho Taguma. Cassandra Davis, Henri Pearson, and Taline Shahinian also provided support for report production and communications. Julie Harris edited the report.

Statistical analyses and outputs were co-ordinated by Elisa Duarte and Thomas Radinger with contribution from Vanessa Denis and Victoria Liberatore. Thomas Radinger led the development of the accompanying online platform, Starting Strong: Mapping quality in early childhood education and care with Andrea Konstantinidi. Bruno Pérez, and Sébastien Conejo and Ismaël Guerrib (external consultants) developed the online platform. Simon Normandeau contributed to the development of the policy questionnaire. 


\section{Table of contents}

Foreword 3

Acknowledgements 5

$\begin{array}{ll}\text { Reader's guide } & 9\end{array}$

Abbreviations and acronyms 14

Executive summary 15

1 Trends shaping early childhood education and care 17

2 Curriculum frameworks, pedagogy and process quality in early childhood education and care

3 Workforce and process quality in early childhood education and care 96

Annex A. Reference tables 146

Annex B. Technical annex 155

Annex C. List of tables available on line 166

Annex D. Network member contributors 167

Tables

Table 2.1. ECEC curriculum framework coverage 54

Table 3.1. Most prevalent qualification required of ECEC staff to enter the profession 101

Table A A.1. Overview of ECEC curriculum frameworks and reference numbers for tables and figures, 2019146

Table A A.2. Overview of age groups covered by ECEC settings and types of provision of ECEC settings, 2019

Table A B.1. Countries and jurisdictions having responded to the policy questionnaire

Figures

Figure 1.1. Change in enrolment rates in early childhood education and care services and primary education, 3 to 5 year-olds 
Figure 1.2. Share of enrolment by type of institution and education level (2018) 24

Figure 1.3. Total expenditure on pre-primary education 25

Figure 1.4. Five policy areas to support high-quality early childhood education and care 27

Figure 1.5. Change in enrolment rates of children under 3 years of age in early childhood education and care settings meeting ISCED Level 0 criteria

Figure 1.6. Gaps in pre-primary education participation by students' socio-economic background

Figure 1.7. Association between mothers' labour market participation and early childhood education and care enrolment rates

Figure 1.8. Strategies to support children's transitions

Figure 2.1. Specification of developmental and learning goals in curriculum frameworks covering children aged 0 to 5

Figure 2.2. Specification of developmental and learning goals in curriculum frameworks covering children aged

3 to 5

Figure 2.3. Stated goals in curriculum frameworks

Figure 2.4. Developmental and learning areas specified in curriculum frameworks

Figure 2.5. Specification of pedagogical approaches in curriculum frameworks

Figure 2.6. Pedagogical approaches specified in curriculum frameworks

Figure 2.7. Pedagogical guidance and support for staff as provided in curriculum frameworks

Figure 2.8. Stakeholders involved in curriculum framework design

Figure 2.9. Scope of stakeholders' involvement in the design of curriculum frameworks covering ages 0 to 5

Figure 2.10. Implementation guides or documents accompanying curriculum frameworks

Figure 2.11. Audiences targeted by implementation guides or documents accompanying curriculum

frameworks

Figure 2.12. Inclusion of families and communities in curriculum frameworks

Figure 2.13. Mandatory external monitoring of curriculum framework implementation

Figure 2.14. Responsibility for monitoring the implementation of curriculum frameworks

Figure 2.15. Frequency of external monitoring of the curriculum framework implementation

Figure 2.16. Methods for external monitoring of curriculum frameworks' implementation

Figure 2.17. Interactions monitored in external monitoring of curriculum frameworks' implementation

Figure 3.1. Educational attainment of staff and content of initial training

Figure 3.2. Practicum requirements as part of ECEC professionals' initial education and training

Figure 3.3. Breadth of content required as part of ECEC professionals' initial education to obtain the minimum qualification

Figure 3.4. Requirements of ECEC professionals' initial education in terms of content areas

Figure 3.5. Inclusion of curriculum framework implementation in teachers' initial education

Figure 3.6. Formal recognition and accreditation of professional development activities for teachers

Figure 3.7. Assessment of the quality of professional development for teachers

Figure 3.8. Time incentives for teachers to participate in professional development activities

Figure 3.9. Assessment of teachers' professional development needs

Figure 3.10. Assessment of barriers to teachers' participation in professional development 123

Figure 3.11. Pre-primary teachers' statutory salaries at different points in teachers' careers 125

Figure 3.12. Measures in place to support promotions or wage increases associated with teacher performance 128

Figure 3.13. Activities for which ECEC staff are given protected time 129

Figure 3.14. Extent of protected time for activities without children 131

Figure 3.15. Minimum educational requirements for ECEC centre leaders 133

Figure 3.16. Content requirements for leaders' initial training 135

Figure 3.17. Pedagogical leadership as a content requirement of leaders' initial training 136

\section{Boxes}

Box 1.1. Research highlights the benefits of participation in early childhood education and care 22

Box 1.2. The Quality beyond Regulations project

Box 1.3. Learning from countries: Early childhood education and care responses to the COVID-19 pandemic and lessons for the future

Box 2.1. Quality beyond Regulations policy review: Coverage and methodology

Box 2.2. Supporting inclusion, diversity and multilingualism through curriculum frameworks and guidelines

Box 2.3. Pedagogical approaches in early childhood education and care

Box 2.4. Consultation and collaborative approaches to the design and revision of curriculum frameworks

Box 2.5. Guidance for ECEC staff to engage families and communities in ECEC 
Box 2.6. Developing monitoring tools for curriculum frameworks' implementation and process quality

Box 3.1. Quality beyond Regulations policy review: Coverage and methodology concerning indicators related to the workforce

Box 3.2. Ensuring quality and consistency across initial education programmes through standards

Box 3.3. Supporting cultural diversity and multilingualism through initial education and professional development

Box 3.4. Professional development opportunities for curriculum implementation 


\section{Reader's guide}

The OECD Starting Strong series provides comparable international information on early childhood education and care (ECEC) to support countries and jurisdictions in their review and redesign of policies to strengthen their delivery of quality services.

This volume of the series, Starting Strong VI: Supporting Meaningful Interactions in Early Childhood Education and Care, represents the culmination of the Quality beyond Regulations policy review undertaken between 2018 and 2021 to foster an understanding of the different dimensions of quality in ECEC, focusing on process quality in particular, as part of the OECD's long-term strategy to develop ECEC. Process quality encompasses children's daily interactions through their ECEC settings - including with other children, staff and teachers, space and materials, their families and the wider community - which are directly linked to their development, learning and well-being. A primary goal of the policy review was to identify and discuss the main policy levers that can enhance process quality and provide countries with concrete examples of policies. Building on a multidimensional approach to quality in ECEC, the review focused on the following policy levers, with the first two being the main focus of the present report:

1. curriculum and pedagogy

2. workforce development

3. family and community engagement

4. quality standards, governance, and financing

5. monitoring and data.

An online platform, Starting Strong: Mapping quality in early childhood education and care, complements this report. This platform provides a visualisation of the policy levers that countries can draw on to promote (process) quality in ECEC. Its multidimensional map allows users to explore the interrelation between process quality and policy levers, and to access related indicators and visuals, as well as the underlying data. The platform is available at:

\section{https://quality-ecec.oecd.org}

A series of brief country profiles summarises the key findings related to policies and practices for process quality in countries that decided to engage in the policy review in greater depth, namely Australia, Canada, Ireland, Japan, Luxembourg and Switzerland. The country profiles are available at https://oe.cd/3N6.

All information related to the Quality beyond Regulations project, and the OECD Network on Early Childhood Education and Care, is available at www.oecd.org/edu/earlychildhood.

\section{Methodology, data and content of the report}

The first phase of the Quality beyond Regulations policy review culminated in a literature review and meta-analysis of the links between different dimensions of quality and children's learning, development 
and well-being, published under the title Engaging Young Children: Lessons from Research about Quality in Early Childhood Education and Care (OECD, 2018).

In the second phase of the project, members of the OECD's Early Childhood Education and Care Network were invited to share information on policies that have been shown by research to matter for process quality by completing a questionnaire. In addition, six countries participated in the project by completing in-depth country background reports.

Together, these two sources of information, developed specifically for the Quality beyond Regulations policy review, provide the data for the main analyses presented in this publication. The comparative data and the country background reports were collected before the coronavirus (COVID-19) pandemic.

Findings from the aforementioned data sources were supplemented by data from other OECD projects, such as the Starting Strong Teaching and Learning International Survey (TALIS Starting Strong), the Programme for International Student Assessment (PISA) and Education at a Glance, exploring synergies to provide a more comprehensive picture of the ECEC sector.

This report includes three chapters. The first chapter discusses the main trends and issues shaping the ECEC sector. Chapters 2 and 3 are dedicated to specific themes: curriculum and pedagogy and workforce development. These thematic chapters discuss policies that support process quality for the two areas of focus while also touching upon linkages between them and other policy levers, namely family and community engagement and monitoring and data. Each chapter builds on research to identify the policy levers that contribute to process quality and discusses how these policies are developed in participating countries and jurisdictions according to information provided in the Quality beyond Regulations policy questionnaire and country background reports.

\section{Policy questionnaire}

Between April and October 2019, the OECD Secretariat distributed a policy questionnaire to the OECD's Early Childhood Education and Care Network, a unique knowledge-sharing platform for national, regional and local policy makers working on developing ECEC policies.

In total, 26 countries completed the policy questionnaire, resulting in a rich database of information on ECEC systems around the world and their efforts to promote high-quality ECEC as of the year 2019. Given the complex architecture of ECEC systems, the review collected information for different curriculum frameworks (56 in total) and ECEC settings (121 in total) in place within participating countries and jurisdictions.

Guided by the project's data collection framework, the questionnaire included questions organised around the focal policy levers of curriculum and pedagogy and workforce development. The last section aimed to capture key contextual information shaping the two priority areas to enhance process quality.

Overall, information was collected on the following areas:

- background information on settings and curricula

- curriculum and pedagogy

- initial education, professional development and working conditions of the ECEC workforce

- contextual information (e.g. governance, standards and funding).

Annex $B$ provides more detailed information about the collection and treatment of data through this policy questionnaire. 


\section{Country background reports}

Complementary country background reports (CBRs) were completed by six countries that provided additional support to the project: Australia, Canada, Ireland, Japan, Luxembourg and Switzerland. These background reports responded to a common set of issues and questions, and followed a common framework to facilitate comparative analysis and maximise knowledge-sharing opportunities. These reports were undertaken by the respective national governments, as well as provincial governments in Canada. The CBRs are available at https://oe.cd/3N6.

\section{Scope}

\section{Country coverage}

ECEC systems are often decentralised, with authority for different types of settings or particular aspects of ECEC provision falling to different levels of governance. In federal countries, the mix of responsibilities between national governments and sub-national entities (e.g. provinces, states, cantons) can make understanding ECEC systems even more complex from the perspective of international comparisons.

Given the goal of providing internationally comparative data, the Quality beyond Regulations policy review focused on collecting national data from all countries. However, in federal systems where sub-national data was deemed invaluable given variations in policies for indicators, their jurisdictions are clearly noted in the analysis of the Starting Strong VI report.

\section{Settings, curricula and age groups}

Consistent with previous OECD work on ECEC, the data collection for the Quality beyond Regulations policy review included all settings belonging to countries' regulated ECEC systems: childcare, crèches, kindergarten, nursery or preschool, integrated centre-based ECEC, and home-based care. Countries were asked to report information on all settings regardless of type, funding, opening hours or programme content, provided that they were subject to certain rules, minimum standards or were otherwise regulated.

Standardised age groups were assigned to the different settings and curricula to facilitate analysis and comparisons across age groups within and across countries and jurisdictions. Depending on their coverage, settings and curricula were classified as belonging to the following age groups: 1) Age 0 to 2; 2) Age 3 to 5/primary school entry; 3 ) Integrated for age 0 to 5/primary school entry. Information was then aggregated across settings or curricula for indicators where information was the same or very similar within these standardised age groups (e.g. for a country with several curricula for the same age group).

To understand the actual age groups covered in settings under the standardised age groups in countries and jurisdictions, readers should consult the dedicated reference table in Annex A. For further details on the collection and treatment of data from the policy questionnaire, readers should see Annex $B$.

\section{Staff roles and development in setting types}

The professionals working in ECEC systems have many different roles and titles, including pre-primary school teachers, pedagogues, care workers, educators and counsellors. To address the workforce development policy lever of the Quality beyond Regulations policy review, it was deemed necessary to consider these different staff roles and the different types of ECEC settings in which they work.

To collect data that are meaningful across countries and address the different roles of staff across settings, the policy questionnaire asked countries to report on workforce development policies based on the structure of their ECEC systems. That is, countries with an integrated system serving children ages 0 to 5/primary school entry were asked to report on workforce development policies for centre-based ECEC 
within this integrated system. While countries with a split system were asked to report policies relevant for centre-based ECEC settings separately, first for those serving children under the age of 3 and second for those serving children aged 3 to 5/primary school entry. All countries were asked to report on workforce development policies relevant for home-based or family childcare settings.

In addition, countries were asked to report on workforce development policies for three categories of staff: teachers, assistants and leaders. Although these staff categories are not exhaustive, they capture the majority of staff within ECEC centres across countries and jurisdictions and are consistent with the primary categories used in the TALIS Starting Strong survey.

When a detailed breakdown of information was not possible, either by type of ECEC setting or by staff category, countries had the option to report policy information at an aggregate level.

\section{Figures}

\section{Symbols}

Certain symbols are used to denote non-reported information:

- a: "no, not regulated or not required", "not applicable". For instance, in countries and jurisdictions where no external monitoring process for curriculum implementation is in place, information on related items, such as the frequency of inspection, is classified as "not applicable".

- $\quad$ m: "missing".

\section{Interpretation of data}

For the use and display of data in comparative figures and tables, both in the present publication and the interactive website Starting Strong: Mapping quality in early childhood education and care, information was aggregated across settings and curricula, within the same age groups, treating all settings and curricula of equal importance. For further details on the method of aggregation, readers should consult Annex B.

Throughout the report, in figures showing the distribution of a response across countries and jurisdictions, the share of settings and curricula is based on the full set of curricula or settings within an age group or across all settings/curricula across age groups, including those for which information is "not applicable" or "missing". Figures, however, only display the names of countries and jurisdictions with information available for at least one setting or curriculum (within an age group or across all age groups). As a result, readers should be careful in interpreting figures and in particular in drawing conclusions for the level of countries and jurisdictions. A category that is shown for a country or jurisdiction in a figure may, for instance, only apply to one of several settings or curricula within a country, but not all of the settings or curricula. At the same time, countries and jurisdiction may appear in different categories within the same age group in the same figure, representing different settings of that country.

For figures showing the percentage of response categories that apply for a country or jurisdiction, the percentage represents the simple value where information is the same across settings or curricula within an age group in that country. Where information differs, the figure shows the average calculated for that country across settings or curricula, again within the same age group. For some figures showing the percentages of response categories, the value presented for a country with sub-national information is the average of all jurisdictions. Again, readers should interpret with caution these averages and the extent to which they allow for the drawing of conclusions regarding the level of the country or jurisdictions. Full data tables are available for download from the Starting Strong: Mapping quality in early childhood education and care website at https://quality-ecec.oecd.org. 


\section{StatLinks}

This report has OECD StatLinks available at the bottom of the tables and figures. To download the matching Excel® spreadsheet for each table or figure, type the link into your Internet browser, starting with the http://dx.doi.org prefix, or click on the link from the e-book version.

The results referred to in this volume can be found in Annex $C$ and through the OECD StatLinks at the bottom of the tables and figures throughout the report. 


\section{Abbreviations and acronyms}

\begin{tabular}{l|l}
\hline CBR & Country background report \\
\hline COVID-19 & Coronavirus disease 2019 \\
\hline ECEC & Early childhood education and care \\
\hline EPPSE & Effective Pre-school, Primary and Secondary Education \\
\hline ICT & Information and communication technology \\
\hline ISCED & International Standard Classification of Education \\
\hline OECD & Organisation of Economic Co-operation and Development \\
\hline PIAAC & Programme for the International Assessment of Adult Competencies \\
\hline PISA & Programme for International Student Assessment \\
\hline PPP & Purchasing power parity \\
\hline SARS & Severe Acute Respiratory Syndrome \\
\hline TALIS & Teaching and Learning International Survey \\
\hline
\end{tabular}




\section{Executive summary}

High-quality early childhood education and care (ECEC) holds tremendous potential for children, families and societies, laying the groundwork for the success of future generations. Specifically, children's daily interactions through their ECEC settings - with other children, staff and teachers, space and materials, their families and the wider community - reflect the quality of ECEC they experience. Together, these interactions are known as "process quality" and are the most proximal drivers of children's development, learning and well-being. This report explores how policies create constructive conditions that ensure all children benefit from rich interactions as part of their ECEC experience and investigates the full potential of these policies beyond their regulatory nature. It stresses that quality, as a multidimensional construct, requires multifaceted policy solutions.

Policy makers increasingly recognise the importance of safeguarding children's access to equitable opportunities and experiences that favourably kick-start their educational careers. In this context, enrolment in ECEC is growing and is near-universal in several OECD countries for children aged 3 to 5 . Yet, investments in the sector remain below public spending for later stages of education, a critical factor that could hinder access and updated service quality. In addition, although enrolment of children under age 3 in ECEC is increasing, it is still more variable compared to the participation of older children. The coronavirus (COVID-19) pandemic may further exacerbate inequitable enrolment, especially for the youngest children, signalling the potential risk that more children may miss out on the benefits of participating in ECEC.

International comparisons of ECEC systems, as seen in Starting Strong VI, provide evidence to inform policy developments and meet the aforementioned rising demand and expectations for ECEC services. The observations and policy implications set out in this report stem from data collected across 26 countries and 41 jurisdictions that provided information on 56 different curriculum frameworks and 120 different types of ECEC settings, highlighting the complexity of the sector and the variability in approaches across and within countries.

Five policy levers, or drivers, are identified as instrumental tools for building ECEC systems that can foster quality in children's everyday interactions. The levers are: 1) quality standards, governance and funding; 2) curriculum and pedagogy; 3) workforce development; 4) monitoring and data; and 5) family and community engagement.

The present report conceptualises the linkages between these policy levers and process quality, with a particular focus on curriculum and pedagogy and workforce development, while noting the cross-cutting nature of the remaining levers, principally family and community engagement.

\section{Curriculum and pedagogy}

Curriculum frameworks set the principles, standards, guidelines and approaches that staff could use to foster children's development, learning and well-being. They are more likely to be mandatory for children aged 3 to 5 than those aged 0 to 2 . In almost $25 \%$ of participating countries and jurisdictions, there is more than one curriculum in place per age group; yet in $14 \%$ of participating countries and jurisdictions, there is 
no specific curriculum framework for the youngest age group, aged 0 to 2 . A curriculum is a powerful tool to create alignment and encourage co-ordination across stages of education. Thus, an absence of concrete curricula or multiple curricula for the same age group can result in differences in the quality of ECEC across ages and settings and can make transitions within pre-primary and to primary education more challenging.

The implementation of curriculum frameworks is tightly linked with pedagogy, which denotes the foundation of a curricular approach. It also outlines the strategies and techniques implemented by staff to provide opportunities for young children's development within a particular social and material context. Most curricula across age groups in the study suggest the use of multiple pedagogical approaches and are accompanied by guidelines for implementation that provide staff with examples of practices and highlight the importance of co-operation with families, as a pillar of children's broader development outside the ECEC setting in the community context.

Monitoring of curriculum implementation is mandatory in most countries and jurisdictions, with inspections acting as the most common method of external monitoring, coupled with staff self-assessments. More than one-third of countries and jurisdictions conduct external monitoring of curriculum implementation at least once a year in all age groups, and $23 \%$ of them decide to monitor based on the previous year's results. Countries and jurisdictions monitor process quality, but they often focus on only some particular types of interactions. For example, less than $40 \%$ of participating countries and jurisdictions monitor interactions between ECEC staff and parents.

Both curriculum and pedagogy are important drivers of process quality and need to be embedded in staff's initial education and training, and professional development.

\section{Workforce development}

ECEC staff require comprehensive initial education programmes, ongoing professional development during employment and supportive working conditions to effectively engage in high-quality interactions and have the confidence to innovate in their sector. ECEC leaders play an important role in shaping organisational conditions and strategies for ensuring quality, and themselves need access to appropriate training and support structures to be most effective.

Qualification requirements for teachers vary considerably across participating countries, though a bachelor's degree or equivalent (ISCED [International Standard Classification of Education] Level 6) is the most common requirement. On the other hand, qualification requirements for assistants are more homogeneous, generally insisting on an upper secondary education degree (ISCED Level 3). Work-based learning during initial education is required for teachers of most settings covering ages 3 to 5 , but less so for settings covering ages 0 to 2 and for assistants. The breadth of content included in ECEC staff's initial education varies sharply across countries and jurisdictions, but most settings expect teachers to have knowledge of child development, playful learning aspects, and curriculum and pedagogy. Linking ECEC and home-learning activities is one of the least covered topics.

To enhance process quality, trainings must be of high quality and adapted to the needs and interests of staff, which vary based on their initial preparation, experience and role. While several countries have requirements or objectives for participation in professional development, most participating countries and jurisdictions do not regulate either the assessment of staff professional needs or barriers to participation, or the monitoring of the quality of professional development.

In addition to salary and career progression, hours worked and time allocation are important elements of staff's working conditions and well-being and affect the quality of their daily work with children. Countries and jurisdictions differ in their regulations of protected time for activities performed without children, such as professional development opportunities, but coincide because protected time tends to be more common for teachers than for assistants across settings and for all age groups. 


\section{Trends shaping early childhood education and care}

This report is based on findings from the Quality beyond Regulations policy review, which was initiated to support countries and jurisdictions in understanding and enhancing quality in early childhood education and care (ECEC) settings. This chapter introduces the findings from the policy review and provides context for the results presented in subsequent chapters by summarising key issues and trends in the field of ECEC. Focus is given to curriculum and pedagogy, and to workforce development as key policy levers to enhance quality, with attention to three additional policy levers: governance, standards and funding; data and monitoring; and family and community engagement. 


\section{Key messages}

- Early childhood education and care (ECEC) can give a strong start to all children by providing equitable opportunities and experiences that support development. Participation in ECEC is typical and universal, or near-universal, in several OECD countries, for children aged 3 to 5 years.

- The coronavirus (COVID-19) pandemic may exacerbate inequitable enrolment in ECEC and mean that more children miss opportunities to participate in ECEC. Children from socio-economically disadvantaged families continue to be less likely than their more advantaged peers to participate in ECEC. In addition, although enrolment of children under age 3 in ECEC is increasing, it is still more variable than participation of older children.

- There is more variability in approaches to ECEC governance, oversight and funding than at most other levels of education. The 26 countries and 41 jurisdictions that participated in the Quality beyond Regulations policy questionnaire reported on 56 different curriculum frameworks. They provided information on staff training requirements and working conditions across more than 120 different types of ECEC settings.

- Despite growing ECEC enrolment and recognition of the value of high-quality ECEC, investments in this sector remain below public spending for later stages of education.

- Approximately one-third of children attending ECEC in OECD countries are in private institutions, whereas public institutions are more common at other levels of education.

- The concept of quality in ECEC is multidimensional. Children's daily interactions through their ECEC settings, including with other children, staff and teachers, space and materials, their families and the wider community, reflect the quality of ECEC they experience. Together, these interactions are known as process quality, and are key to supporting children's learning, development and well-being.

- Curriculum frameworks support process quality through several mechanisms, including their content, routines, activities, resources and encouragement of interactions. Articulating a curriculum framework and its links to pedagogy are important policy strategies for enhancing process quality in ECEC.

- Curriculum is a powerful tool to create alignment and encourage co-ordination across stages of education. A majority of the curricula covered in Quality beyond Regulations include facilitation of continuity and transitions among their goals. However, with the exception of providing information materials for parents on transitions, fewer than half of ECEC settings covered by the data systematically employ strategies to support transitions.

- ECEC staff need strong initial preparation, opportunities to participate in ongoing professional development and supportive working conditions to engage in high-quality interactions with young children. ECEC leaders play an important role in shaping organisational conditions and strategies for ensuring quality, and they themselves need access to appropriate training and support structures to be most effective.

\section{Introduction}

Early childhood education and care (ECEC) holds tremendous potential for children, families and societies when it is of high quality. With expanding access to ECEC, policy makers, practitioners and researchers alike are shifting their focus from expanding the sector's size to ensuring that all children are in settings 
that support their development, learning and well-being. The benefits of high-quality ECEC are wide-ranging, as are the policy approaches needed to equitably support this sector, which sits at the intersection of education, labour, health and social welfare.

The COVID-19 pandemic underscores the myriad ways in which ECEC matters for individuals and societies. Even as schools closed to limit the spread of COVID-19, in many places, ECEC continued to operate, providing ongoing services at least for children of essential workers (OECD, 2021 [1] ). Discussions about re-opening economies hinge on the capacity of ECEC systems to support parents' participation in the labour force. In this context, continuing government commitment to quality is imperative to promote children's development, learning and well-being throughout and following the crisis, in addition to supporting parental employment.

International comparisons of ECEC systems provide rich information to inform policy developments and meet the rising demand and expectations for ECEC services. The Quality beyond Regulations project was launched to support countries and jurisdictions to better understand different dimensions of quality in ECEC and the policies that can enhance quality, going beyond minimum standards and requirements. The project and this publication focus on two policy areas within ECEC - curriculum and pedagogy and workforce development - that offer strong opportunities for countries to learn from one another, even in the context of highly heterogeneous ECEC systems. Moreover, these policy areas represent core aspects of children's daily experiences in ECEC, making them important for understanding quality beyond the complex governance and regulatory systems surrounding ECEC.

\section{Recognition of the value of early childhood education and care is widespread}

Research innovations and social changes over recent decades have converged to make policy attention to ECEC widespread. Factors driving this attention include a recognition of the role of ECEC in supporting young children's rights and well-being, commitments to equal opportunities for women in the labour force and clear evidence from fields as diverse as neuroscience and economics that demonstrates the benefits of high-quality early childhood experiences. Policy makers worldwide recognise the myriad advantages of ECEC, and in this context, enrolment in ECEC is growing. Among children aged 3 to 5 years, participation in ECEC is typical, and universal or near-universal, in several OECD countries (Figure 1.1). 
Figure 1.1. Change in enrolment rates in early childhood education and care services and primary education, 3 to 5 year-olds

Percentage of children enrolled in early childhood education and care (ISCED Level 0) or primary education (ISCED Level 1), 3 to 5 year-olds, 2005-18

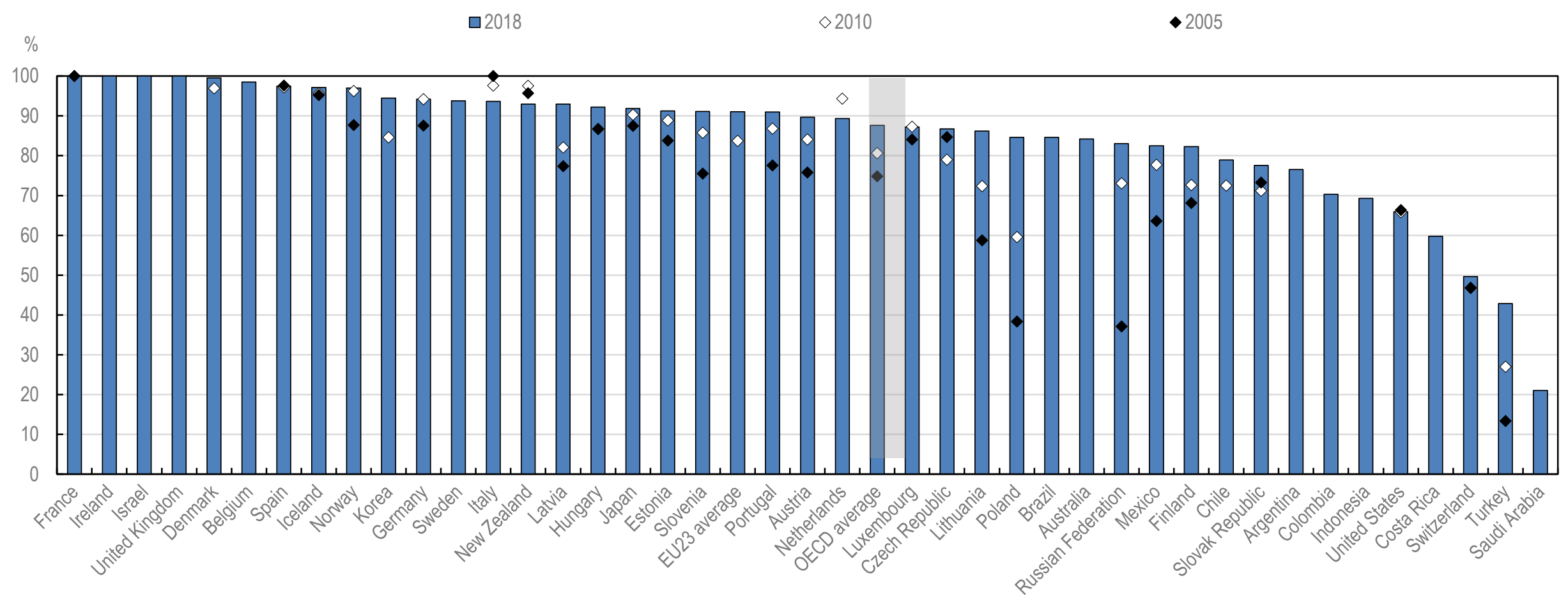

Countries are ranked in descending order of the enrolment rates of 3 to 5 year-olds in 2018.

Source: OECD (2020[2]), Education at a Glance 2020: OECD Indicators, Table B2.2, https://dx.doi.org/10.1787/69096873-en.

StatLink ताIS https://doi.org/10.1787/888934248692 
Young children are developing and learning rapidly, setting the foundations for their understanding of the world. ECEC can give a strong start to all children by providing equitable opportunities and experiences that support development, promote well-being and connect families to one another and to resources in the community. Participation in ECEC is linked with both short- and long-term benefits that range across domains. In the short term, these benefits include providing children with opportunities to enjoy exploring their own interests and growing capabilities while developing a sense of belonging. In addition, ECEC helps ensure children have the skills and confidence to transition smoothly into primary school. Families and society also benefit from ECEC in the short term, notably through stronger parental labour market participation.

Children's early learning and development is closely connected across domains. Cognitive, social and emotional, and self-regulatory skills grow together during early childhood, with gains in one area contributing to concurrent and future growth in other areas (OECD, 2020[3]). Participation in high-quality ECEC supports children's development in all of these areas, with implications for learning beyond early childhood. For example, children in Denmark who participated in higher quality ECEC performed better on a written exam at the end of lower secondary schooling (ten years after their ECEC participation) than their peers whose ECEC experiences were of lower quality (Bauchmüller, Gørtz and Rasmussen, 2014[4]). Similarly, findings from the United Kingdom show that participation in higher quality ECEC is associated with stronger performance at the end of compulsory schooling, enough to imply a $4.3 \%$ increase in gross lifetime earnings per individual (Cattan, Crawford and Dearden, 2014[5]). In addition to educational and economic benefits, quality ECEC can support social and emotional well-being: in a sample from the United States, at age 15, adolescents reported fewer behavioural and emotional problems when they had participated in higher quality ECEC (Vandell et al., 2010[6]).

In the longer term, participation in ECEC positively predicts well-being across a range of indicators in adulthood, including physical and mental health, educational attainment and employment (Belfield et al., 2006[7]; Campbell et al., 2012[8]; García et al., 2020[9]; Heckman and Karapakula, 2019[10]; Heckman et al., 2010[11]; Karoly, 2016[12]; Reynolds and Ou, 2011[13]). In addition to these benefits for individuals, societies benefit in the long term through greater labour market participation and earnings, better physical health and fewer healthcare costs, and lower involvement in criminal activity throughout the life course of individuals who participate in high-quality ECEC (Box 1.1). 


\section{Box 1.1. Research highlights the benefits of participation in early childhood education and care}

Decades of research demonstrate the short- and long-term benefits of high-quality early childhood education and care (ECEC). Although no single study can answer all relevant questions about ECEC and children's development, learning and well-being, evidence from different types of studies provides a robust picture of the outcomes associated with participation in ECEC. The research summarised here gives examples of different methodological approaches to studying ECEC and children's outcomes, highlighting studies that have been influential for informing policy.

\section{Longitudinal studies: The Effective Pre-school, Primary and Secondary Education (EPPSE) Project}

More than 3000 children, their families and schools participated in this longitudinal study in United Kingdom (England) that began in 1997. Children were sampled from a range of ECEC settings where information on quality was collected through observations. A comparison group of children who did not attend ECEC was recruited upon school entry. Researchers followed the entire sample of children through age 16. Findings show the enduring importance of ECEC experiences throughout childhood and adolescence: any participation in ECEC, longer duration of ECEC participation and better quality of ECEC settings all strengthen children's holistic learning, development and well-being, beyond individual and family background characteristics (Sylva et al., 2004[14]). For example, attending ECEC for longer was associated with students being more than four times as likely to pursue a higher academic education versus a vocational training pathway at the end of compulsory schooling (Taggart et al., 2015[15]). Importantly, EPPSE findings show that despite some fadeout in the advantage of ECEC participation for test scores during intermediate levels of schooling, individuals who attended higher quality ECEC programmes showed stronger academic performance and better social and emotional skills at age 16 (Cattan, Crawford and Dearden, 2014 $4_{[5]}$ ). Although results are strictly correlational, longitudinal studies like EPPSE are important for understanding how families with different characteristics engage with ECEC systems and subsequent developmental trajectories of children.

\section{Random assignment studies: Perry preschool}

The Perry Preschool Project was implemented in the United States in the 1960s and involved 123 low-income African-American children. Of these children, 58 were randomly assigned to receive a high-quality preschool programme as well as home visits. Despite the small sample, this study is notable for several reasons. First, the study participants are still being followed, providing a long-term perspective on participation in ECEC. Second, the programme used an experimental design, with random assignment of children to the treatment and control groups. This research design allows strong conclusions about the causal effects of ECEC on outcomes later in life. Although the study participants had many experiences between early childhood and the assessments in adulthood, the one factor that systematically distinguishes them is their status in the treatment versus control groups. Analysis of outcomes for study participants at age 40 suggests that the programme's return-on-investment is USD 7-12 for each dollar invested at age 4. These returns reflect that children who participated in the high-quality preschool programme subsequently had less participation in special education programmes, greater educational attainment, greater employment and earnings and less reliance on social benefits, as well as less engagement in criminal activity (Heckman et al., 2010[11]). Notably, participation in high-quality ECEC also appears to transfer to the second generation, with children of programme participants benefiting as well (Heckman and Karapakula, 2019 ${ }_{[16]}$ ).

\section{Natural experiments: A meta-analysis}

Researchers in the Netherlands conducted a meta-analysis of studies evaluating the effects of universal ECEC on children's outcomes conducted between 2005 and 2017 in Australia, Canada, 
United Kingdom (England), France, Germany, Spain and the United States (Van Huizen and Plantenga, 2018[17]). The studies included in the analysis all took advantage of natural experiments, for example, by using regional variation in the timing of ECEC expansion or by comparing children who participated a year earlier than closely aged peers due to strict age-eligibility thresholds. This research approach better accounts for family selection into ECEC (i.e. all families are not equally likely to enrol their children in ECEC) than is possible in correlational studies such as EPPSE, for example. It also gives an assessment of the value of universal ECEC, rather than targeted programmes (i.e. programmes that serve only some segments of the population by design) such as Perry Preschool. Results from this analysis highlight the heterogeneity in findings from studies of universal ECEC, and in particular show mixed findings on the importance of ECEC starting age. However, the results also show that high-quality ECEC (defined by staff-to-child ratios and staff educational requirements) and public provision of ECEC (versus private) consistently lead to stronger outcomes for children. In addition, children from socio-economically disadvantaged households show greater gains from participation in universal ECEC than their more advantaged peers.

Source: Cattan, S., C. Crawford and L. Dearden (2014 $\left.{ }_{[5]}\right)$, "The economic effects of pre-school education and quality", http://dx.doi.org/10.1920/re.ifs.2014.0099; Heckman, J. and G. Karapakula $\left(2019_{[16]}\right)$, "Intergenerational and intragenerational externalities of the Perry Preschool Project", hceconomics.org; Heckman, J. et al. (2010[11]), "The rate of return to the HighScope Perry Preschool Program", https://doi.org/10.1016/i.jpubeco.2009.11.001; Sylva, K. et al. (2004[14]), "The Effective Provision of Pre-school Education (EPPE) Project: Findings from Pre-school to end of Key Stage 1", https://dera.ioe.ac.uk/18189/2/SSU-SF-2004-01.pdf; Taggart, B. et al. (2015 $[15])$, Effective Pre-school, Primary and Secondary Education Project (EPPSE 3-16+): How Pre-school Influences Children and Young People's Attainment and Developmental Outcomes Over Time, https://assets.publishing.service.gov.uk/government/uploads/system/uploads/attachment data/file/455670/RB455 Effective pre-

school_primary_and_secondary_education_project.pdf.pdf; Van Huizen, T. and J. Plantenga $\left(2018_{[17]}\right)$, "Do children benefit from universal early childhood education and care? A meta-analysis of evidence from natural experiments", https://doi.org/10.1016/i.econedurev.2018.08.001.

Despite growing ECEC enrolment and recognition of the value of high-quality ECEC, investments in this sector remain below those for later stages of education. On average in 2017, OECD countries spent $0.86 \%$ of gross domestic product (GDP) on ECEC compared with $1.46 \%$ and $1.95 \%$ of GDP on primary and secondary education, respectively (OECD, 2020[2]). In some countries, pre-primary education has a shorter duration than primary education, potentially justifying lower overall expenditures; however, the proportion of private spending in total spending is higher for pre-primary education than for primary education, highlighting the gap between funding that is needed in the sector and public investments. Moreover, following rising investments in ECEC during around the turn of the 21st century, expenditures on ECEC levelled off, or even decreased in many countries, between 2013 and 2017 even in the context of overall economic growth during this period (OECD, 2006[18]; 2020[2]). As policy makers commit to implementing high-quality ECEC by building systems that go beyond regulating basic features of ECEC, these issues of spending will require ongoing attention.

The prominent role of private institutions in the ECEC sector further highlights differences with later stages of education. Approximately one-third of children attending ECEC in OECD countries are in private institutions, whereas public institutions are more common at all other levels of education (except post-secondary non-tertiary education; Figure 1.2). The reliance on private institutions to provide ECEC can permit faster expansion of the supply of ECEC settings than would be possible for governments on their own. At the same time, the monitoring and governance of private settings can present challenges for ensuring equitable, affordable access to high-quality ECEC for all children, even when private institutions receive public funding.

The average percentage of children in ECEC in private settings in OECD countries hides important variation both within levels of ECEC and across countries. Regarding levels of ECEC, children under age 3 years are much less likely to attend public ECEC settings than children in pre-primary education. However, in countries that rely heavily on private provision of ECEC, the private sector is also responsible for most pre-primary education as well. For example, more than three-quarters of children attending pre-primary education are in private settings in Australia, Ireland, Japan, Korea and New Zealand (OECD, 2020[2]). 
Expenditure per child in pre-primary education is similar to spending per student in primary school but lower than spending per student at higher levels of education across OECD countries (OECD, 2020[2]). Stronger per-child investments enable conditions that support high quality but must be weighed against

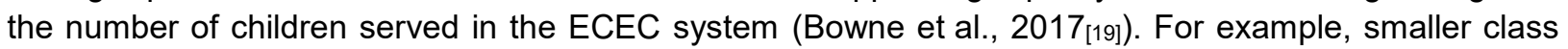
sizes and more favourable child-staff ratios can support staff to interact effectively with individual children. However, the costs of increasing staffing need to be balanced with other strategies to enhance quality, such as investments in staff training and professional development.

Per-child expenditures in pre-primary education vary greatly across OECD countries (Figure 1.3). Several countries, notably Nordic countries, combine strong investments per child with widespread access to ECEC (OECD, 2020[20]). However, differences in per-child expenditures on ECEC across countries do not necessarily reflect lower prioritisation of this sector as a whole. For example, Israel's per-child expenditures on ECEC are below the OECD average, but their expenditure on pre-primary education was $0.96 \%$ of GDP in 2017 , well above the OECD average of $0.63 \%$ (OECD, 2020[2]). The lower per-child expenditures in Israel reflect widespread enrolment of young children in ECEC, particularly among children under age 3. Countries need different policy and investment approaches to ensure high-quality ECEC, considering relevant contexts and related policies, such as women's labour force participation and access to parental leave.

\section{Figure 1.2. Share of enrolment by type of institution and education level (2018)}

Average enrolment of children/students in public and private educational settings across OECD countries, 2018

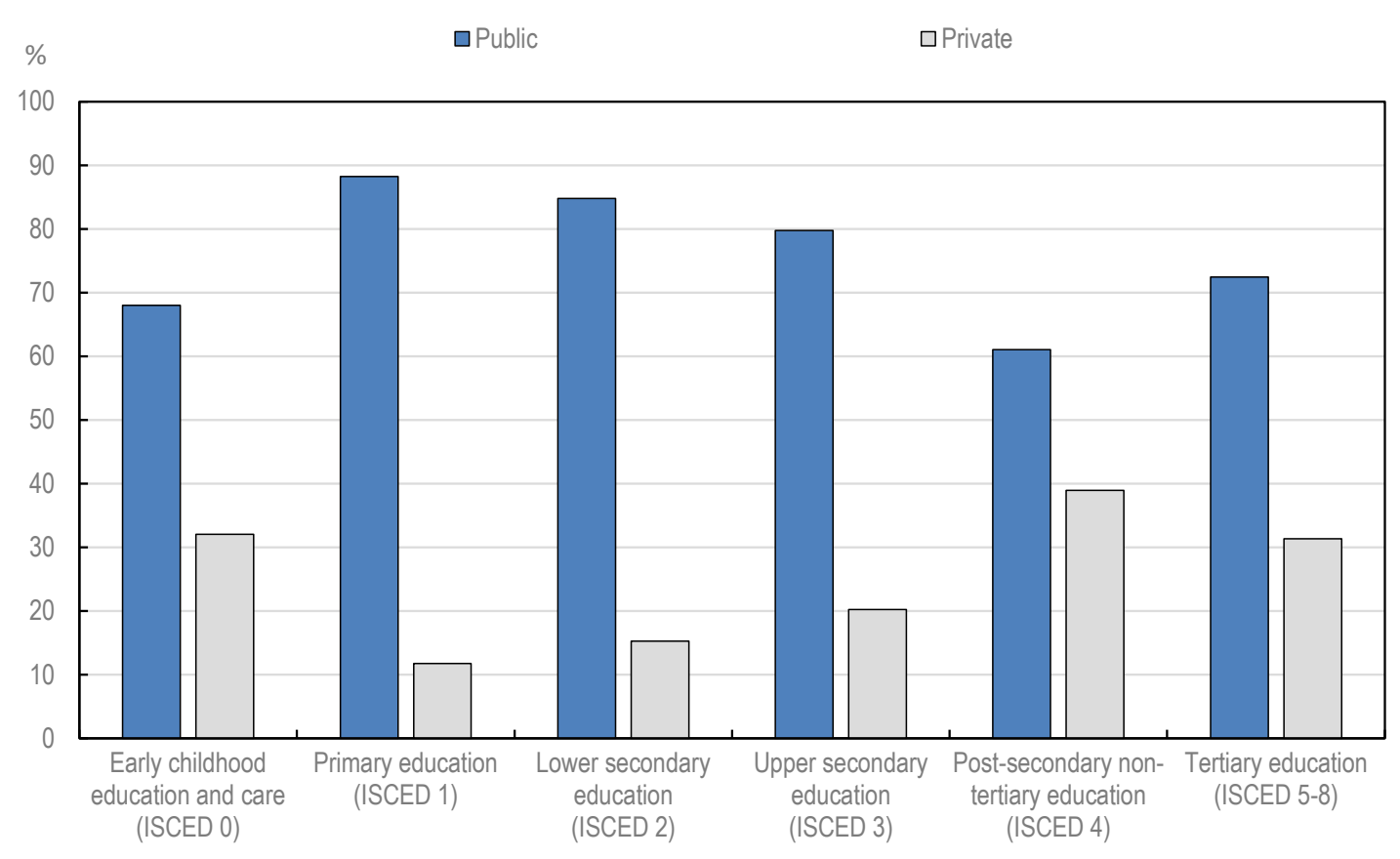

Source: OECD (2020[2]), Education at a Glance 2020: OECD Indicators, https://dx.doi.org/10.1787/69096873-en. 
Figure 1.3. Total expenditure on pre-primary education

Total expenditure on pre-primary education for children aged 3 to 5 years, 2017

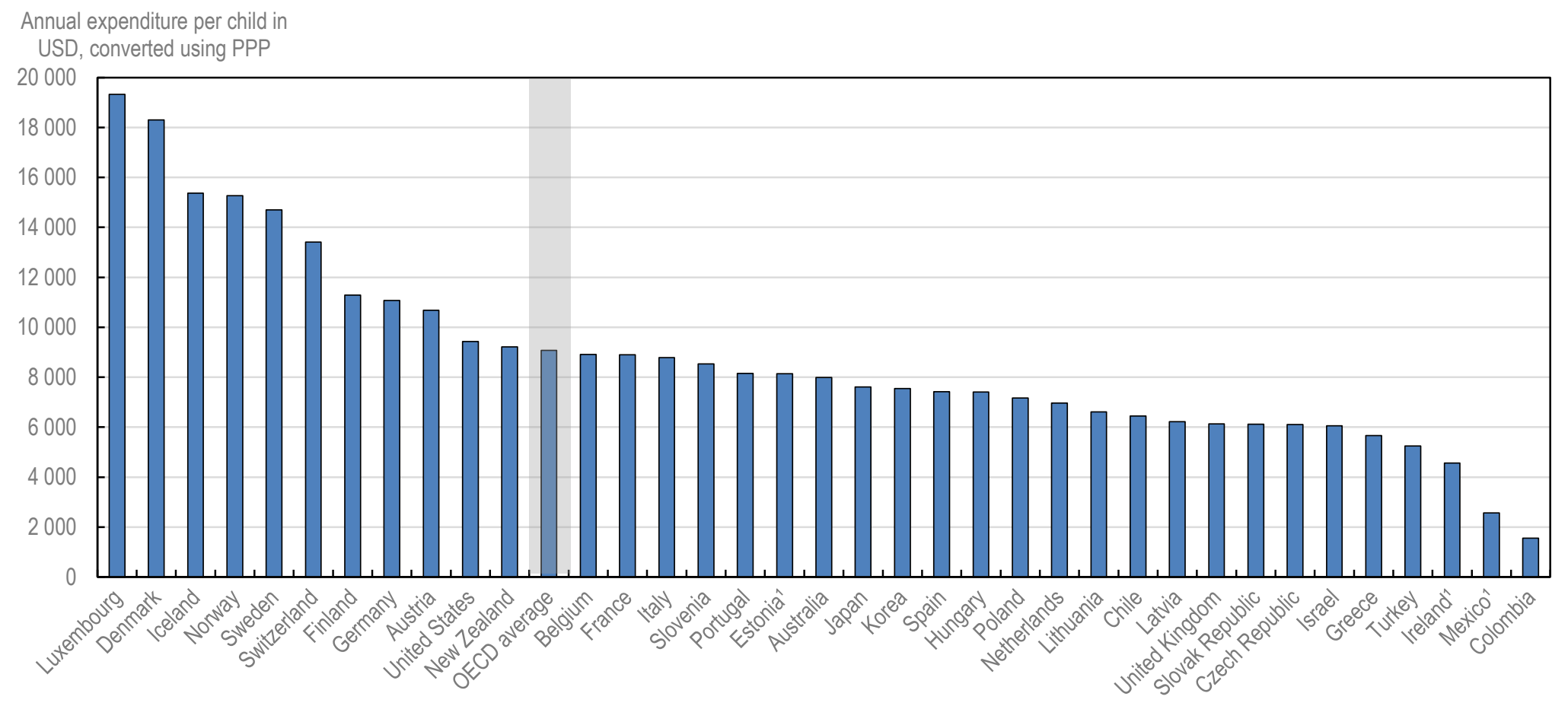

1. Data include expenditures on both early childhood educational development (ISCED Level 01) and pre-primary education (ISCED Level 02) for children aged 3 to 5 years. Note: Public and private institutions are included.

Countries are ranked in descending order of annual expenditure per child in USD, converted using purchasing power parity (PPP).

Source: OECD (2020[2]), Education at a Glance 2020: OECD Indicators, https://dx.doi.org/10.1787/69096873-en. 


\section{Interactions define high-quality early childhood education and care}

Policy makers want to better understand the successes of public investments in the early years and also identify areas for improvement. Research consistently underscores the importance of ensuring ECEC is of high quality to support children's well-being and to realise the numerous benefits of focusing on this period of the life course. Although the concept of quality in ECEC is multidimensional, convergence in research findings from multiple countries suggests some core aspects of quality (Edwards, 2021 [21]; OECD, 2018[22]; Melhuish et al., 2015[23]). Specifically, children's daily interactions through their ECEC settings, including with other children, staff and teachers, space and materials, their families and the wider community, reflect the quality of ECEC they experience. Together, these interactions are known as process quality.

Process quality in ECEC settings is directly linked to children's development, learning and well-being (OECD, 2018[22]). However, process quality depends on multiple factors, presenting challenges for regulation and policy solutions. Aspects of ECEC quality that are traditional targets of policy, such as child-staff ratios, group sizes, the physical size of settings, curriculum frameworks and minimum staff qualifications, create conditions to support good process quality (Burchinal, 2018[24]; OECD, 2018[22]; Pianta, Downer and Hamre, 2016[25]). These aspects of ECEC quality, often known as structural quality, are not, on their own, sufficient to ensure high process quality and promote children's development, learning and well-being. In addition to structural aspects of ECEC quality, factors that shape children's interactions in their ECEC settings include staff's capacity to adapt to individual children's needs and interests, engagement in different types of activities throughout the day, continuity of staff members throughout the day and year, and characteristics of children themselves, such as temperament, that matter for how individual children experience the same classroom or playgroup. With all of these factors contributing to children's daily experiences, process quality can be hard to assess and quantify, especially on a large-scale basis, making it difficult to identify policy levers that best support process quality.

The complex nature of quality in ECEC requires multifaceted policy solutions. This report builds on a conceptual framework to analyse the main drivers of process quality summarised in Figure 1.4. Policies instrumental for building ECEC systems that can foster process quality are grouped into five broad areas: governance, standards and funding; curriculum and pedagogy; workforce development; data and monitoring; and family and community engagement (OECD, 2012[26]). The Quality beyond Regulations project focuses on key aspects of curriculum and pedagogy (curriculum frameworks and goals; curriculum design and implementation; pedagogical approaches) and workforce development (delivery of staff training; working conditions; content of staff training) that closely support high-quality interactions in ECEC settings. The cross-cutting importance of family and community engagement, and of monitoring and data is noted in many of the specific policies investigated through the project.

Although governance, standards and funding are not an explicit focus of the Quality beyond Regulations project, they are considered the foundation for all other policies to support quality in ECEC. Without a strong foundation, the broad scope of policies necessary to enhance process quality and foster children's well-being are unlikely to be sustainable and successful. For example, ensuring consistent funding for ECEC services allows growth in other policy areas, such as around delivering staff training. Understanding the basis for ECEC policy through governance, standards and funding is essential for ensuring that other policy levers successfully support process quality. This aspect of ECEC policy is also critical for comparing other policy approaches across jurisdictions and countries, given the wide variation in ECEC systems. 
Figure 1.4. Five policy areas to support high-quality early childhood education and care Quality beyond Regulations policy review framework

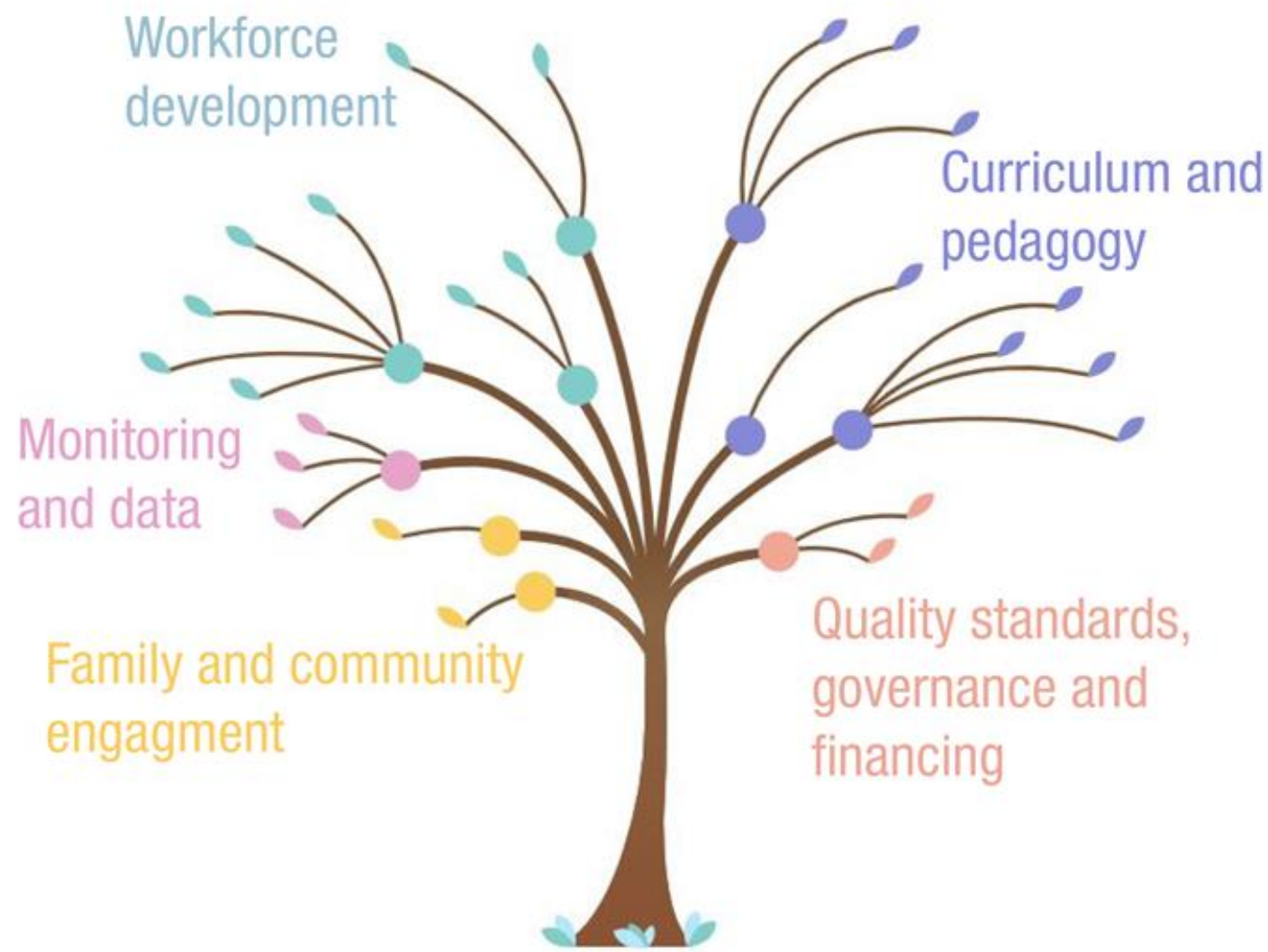

Source: Starting Strong: Mapping Quality in Early Childhood Education and Care, https://quality-ecec.oecd.org. 


\section{Box 1.2. The Quality beyond Regulations project}

The Quality beyond Regulations policy review was initiated to support countries and jurisdictions to better understand the different dimensions of quality in early childhood education and care (ECEC), focusing on process quality in particular. The first phase of the project culminated in a literature review and meta-analysis of the links between different dimensions of quality and children's learning, development and well-being, published under the title Engaging Young Children (OECD, 2018[22]).

The second phase of the project builds from this research base to address the overarching question: How can policies enhance process quality and child development and what are good examples of these policies? To address this question, countries in the OECD's Early Childhood Education and Care Network were invited to share information on relevant policies by completing a questionnaire. Twenty-six countries responded to this invitation, resulting in a rich database of information on ECEC systems around the world and their efforts to promote high-quality ECEC as of the year 2019 .

In addition, six countries (Australia, Canada, Ireland, Japan, Luxembourg and Switzerland) participated in the Quality beyond Regulations project by completing in-depth country background reports. These reports were undertaken by national governments, as well as provincial governments in Canada. The reports were based on a common framework developed by the OECD to facilitate comparative analysis and maximise the opportunities for countries and jurisdictions to learn from each other. The country background reports are complementary to the information collected in the policy questionnaire. Together, these two sources provide the data for the main analyses presented in this publication.

\section{Meeting the growing demand for early childhood education and care and the needs of an increasingly diverse population}

Ensuring that ECEC systems provide high quality to meet growing demand and address the needs of different segments of the population is a challenge for governments. The needs of diverse families, including those with very young children, children with special education or additional needs, immigrant, refugee and language-minority families, and families of different socio-economic backgrounds, span multiple policy areas. Innovative strategies are required to promote coherence and co-ordination across policies and services. Beyond providing a sufficient supply of ECEC to meet demand, the sector must also deliver these services in a holistic way that is responsive to the diversity of children and families.

Partnering with families and communities to identify needs and barriers to participation in ECEC is key to successfully meeting the challenges of serving increasingly diverse children. Parents are children's first teachers, and strong partnerships between families and ECEC promote children's social and cognitive development (Cadima et al., 2020[27]). The capacity of educational settings to support family engagement is also closely linked with children's learning and well-being (Ma et al., 2016[28]). Although essential throughout children's educational trajectories, co-operation between families and ECEC is especially important in the early years.

The ECEC sector for children under age 3 years highlights, in particular, the intersection of policies around parental labour market participation and the benefits of education and care beyond the family for very young children. Enrolment of children under age 3 in ECEC is increasing across OECD countries (Figure 1.5). Although still more variable than participation of children ages 4 or 5 years, the growth in ECEC enrolment among children under age 3 can place strain on systems that are funded and designed 
to engage mainly with pre-primary age children. Children under age 3 are growing and learning at a faster rate than at any other time in their lives, including acquiring early language skills and developing independent mobility. The rapid changes characteristic among this age group require that ECEC settings be specifically adapted to the evolving needs of these children. At this age, the integration of care and education is paramount, as routine caregiving activities (e.g. meals, diaper changes) require significant time but are meaningful occasions to support children's well-being, positive development and early learning (Cadima et al., 2020[27] ). Well-trained ECEC staff with appropriate space and adequate resources can provide rich environments and interactions through which very young children have opportunities to develop across sensorimotor, language and social domains.

\section{Figure 1.5. Change in enrolment rates of children under 3 years of age in early childhood education and care settings meeting ISCED Level 0 criteria}

Percentage of children under age 3 enrolled in early childhood education and care (ISCED Level 0), 2005-18

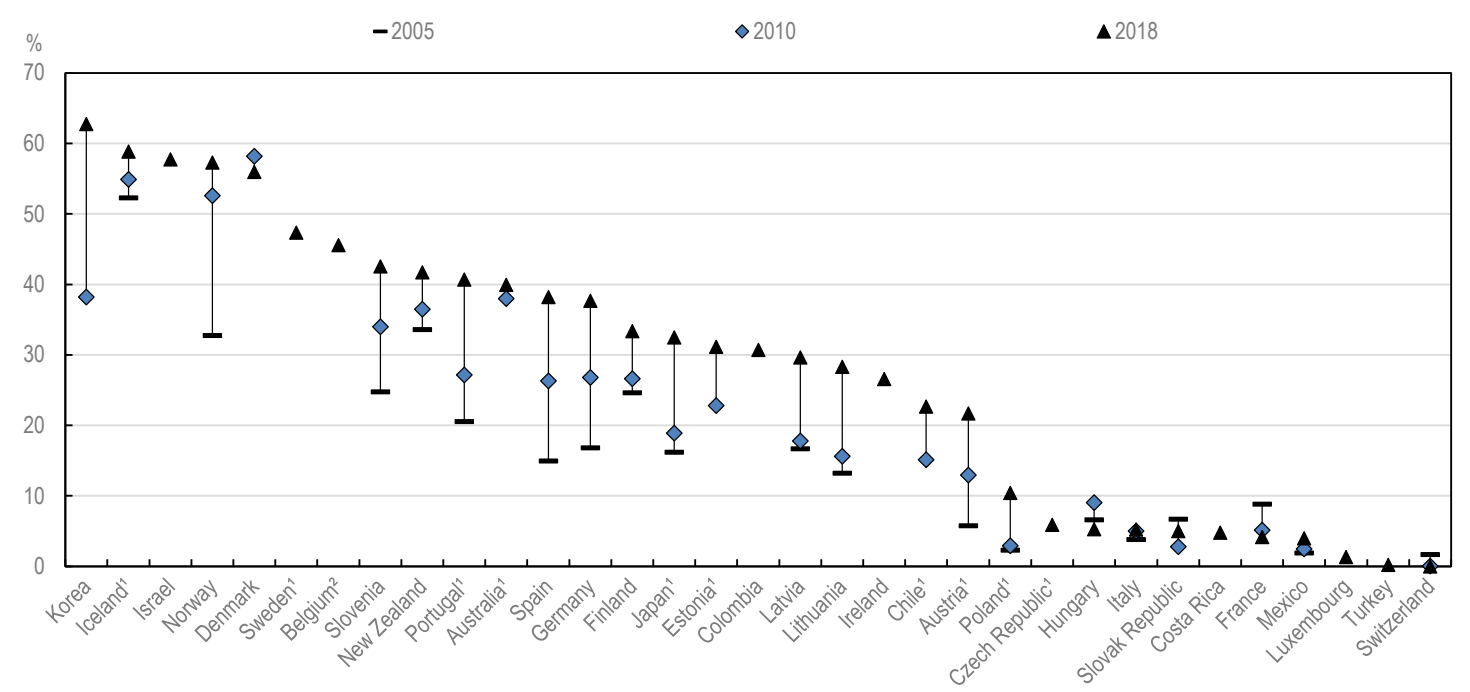

1. Enrolment rates include participation in both ISCED Level 0 and ECEC services outside the scope of ISCED Level 0 because they are not in adherence with all ISCED criteria.

2. ISCED Level 0 enrolment rates are underestimated since only the Flemish Community of Belgium has reported data on ISCED Level 1.

Notes: To be classified in ISCED Level 0, ECEC services should: 1) have adequate intentional educational properties; 2) be institutionalised (usually school-based or otherwise institutionalised for a group of children); 3) have an intensity of at least 2 hours per day of educational activities and a duration of at least 100 days a year; 4) have a regulatory framework recognised by the relevant national authorities (e.g. curriculum); and 5) have trained or accredited staff (e.g. requirement of pedagogical qualifications for educators). In several countries, ECEC settings for children under age 3 are not classified according to the ISCED Level 0 designation (e.g. France, Luxembourg, Switzerland). In these countries, the reported enrolment rates for children under age 3 may under-represent the number of children in this age group in ECEC settings when data are not also available on enrolment in settings outside the scope of ISCED Level 0.

Countries are ranked in descending order of the enrolment rate in early childhood education and care settings in 2018.

Source: OECD (2020[2]), Education at a Glance 2020: OECD Indicators, https://dx.doi.org/10.1787/69096873-en. 
Even with increasing enrolment, demand for ECEC for this young age group can outpace supply, resulting in waiting lists for services (OECD, 2020[29]). As a result, families often must choose between forgoing labour force participation or placing children in settings of uncertain quality, including informal or unregulated settings (OECD, 2020[20]). Yet, public investments are disproportionately made for pre-primary education compared with education and care for children under age 3 (OECD, 2020[2]). To ensure all children under age 3 have equitable access to high-quality ECEC, governments increasingly need strategies and investments that are adapted to developing a robust sector of services for the full age range of children prior to primary school. The ECEC sector is comprised of many different types of services, such as centre-based programmes, services provided in the home of a caregiver/educator, paid services in the home of a child, as well as informal arrangements with family, friends or neighbours. This range of services can enable families to find options that fit best with their preferences and needs; however, these services come with a range of public funding and regulations, meaning that quality is also variable. Countries and jurisdictions must work within existing structures and strengths of this mixed delivery system to enhance quality while further developing the supply of ECEC for children under age 3 years.

High-quality ECEC is well-positioned to identify children with, or at risk for, physical, mental, emotional, social, or learning impairments and assist families in accessing early intervention services. Intervening early can eliminate or mitigate the challenges children with special education or additional needs face as they progress through education systems and find their roles in society. At the same time, ensuring children with special education or additional needs have a place in ECEC has not always been at the forefront of ECEC policy. However, the importance of inclusive education systems more generally is gaining visibility (Brussino, 2020[30]). With this growing attention, it is not surprising that in many countries, working with children with special education and additional needs is the area reported by the largest share of staff as being of high need for ongoing professional development (OECD, 2019[31]).

ECEC is also a powerful way to support immigrant, refugee and language-minority families, in terms of parents' transition into the labour force, familiarisation with systems and culture in the receiving country and support for children's learning, development and well-being. Migration into OECD countries is increasing and reflects a heterogeneous population from all over the world with varying levels of human capital (OECD, 2019[32]; 2019[33]). On average, between 2003 and 2015, the population of 15-year-old students with an immigrant background grew by more than 6\% in OECD countries (OECD, 2019[32]). In addition, the number of children in the world who are refugees more than doubled between 2005 and 2015 (UNICEF, 2016[34]).

Data from the Programme for International Student Assessment (PISA) show that participation in at least one year of ECEC is associated with stronger performance in science at age 15 among students from immigrant families, and the benefits of earlier participation in ECEC is particularly strong for immigrant, compared to native, students (OECD, 2017[35]; Shuey and Kankaras, 2018[36]). Similarly, multilingualism can be a valuable asset, but for young children, a home language that is different from that of the schooling sector and ECEC also has important implications for their ability to interact with their peers and teachers and demonstrate mastery of emerging skills. The OECD's International Early Learning and Child Well-being Study, which collected data in Estonia, the United Kingdom (England) and the United States, found that children who are learning a different language at home compared with school or ECEC had lower scores on early literacy, numeracy and self-regulation tasks at age 5 compared to their peers whose home language matched that of their ECEC or school setting (OECD, 2020[3]). The growing numbers of children from diverse migration and language backgrounds, coupled with the importance of ECEC for these children in particular, underscores the critical role of ECEC systems that are prepared to work effectively with language and cultural diversity.

Families of different socio-economic backgrounds represent yet another type of diversity in ECEC settings. On average, in OECD countries, one in seven children lives in poverty, increasing their risk of material deprivation, including poor nutrition and unstable housing (OECD, 2019[37]). In addition, children from socio-economically disadvantaged backgrounds hear, on average, fewer words in their home 
environments compared to their more advantaged peers (Rowe, 2017 ${ }_{[38]}$ ). These early differences matter for how children adapt to and engage in their ECEC settings. ECEC staff must be attuned to the different early experiences of children in their classroom or playgroup and recognise how these differences may shape individual children's needs, behaviours and well-being. To this point, evidence from France demonstrates that within an ECEC system with strong regulations, children who participate in centre-based ECEC have an early advantage in language skills compared to their peers who do not participate in this type of ECEC. Importantly, the positive impact of centre-based ECEC on language skills is particularly concentrated among children from disadvantaged backgrounds (Berger, Panico and Solaz, 2020[39]).

Many children and families represent multiple domains of diversity and may fall into several of the categories described in this section, as well as others (e.g. family gender composition, ethnic group membership). The intersectionality across different domains of diversity requires ECEC staff and leaders to engage in continuous learning to work with families that may differ from their own or who may be minorities in the local or national context.

\section{Reducing inequalities remains a key goal of high-quality early childhood education and care}

ECEC is a powerful policy tool to reduce inequalities and help all children have strong foundations for learning and well-being. Much of the policy attention on ECEC in recent years stems from an interest in breaking intergenerational cycles of poverty by engaging more parents in the labour force and helping all young children develop a sense of connection and belonging, a love of learning and abilities that will support them to engage in their own education. With the increasing diversity of children and families, countries and jurisdictions are aware of the need to continue focusing on equitable access to the benefits of high-quality ECEC.

In general, children from socio-economically disadvantaged families are less likely than their more advantaged peers to participate in ECEC (OECD, 2017 $\left.{ }_{[35]}\right)$. This difference in ECEC access compounds with other sources of family, neighbourhood and societal disadvantage, creating gaps between children of different backgrounds that widen as they advance through school (OECD, 2017 $[40]$ ). Among students who participated in PISA in 2018, the vast majority reported having attended ECEC, and the typical number of years of participation increased in most countries between PISA 2015 and PISA 2018 (OECD, 2020[41]). However, gaps in ECEC participation persist based on students' socio-economic background. The PISA 2018 data show that, on average across OECD countries, 86\% of students from socio-economically advantaged backgrounds attended ECEC for at least two years, whereas this was the case for $74 \%$ of their less advantaged peers. There is substantial variation in this gap across countries, although this problem of equitable enrolment in ECEC is common (Figure 1.6). Importantly, the gap in ECEC participation between students of different socio-economic backgrounds did not change much on average across OECD countries between PISA 2015 and PISA 2018, suggesting that despite overall trends of growing participation in ECEC, equity remains an issue.

Findings from PISA provide valuable insight into the links between students' socio-economic background and participation in ECEC in a comparable manner across countries. However, students participating in PISA in 2018 attended ECEC settings more than a decade ago. The landscape of ECEC services has shifted to varying degrees across participating countries in the intervening time. In addition, PISA findings rely on students' memories of their ECEC participation. Thus, although the PISA data are an important indicator of how ECEC is associated with later stages of education systems internationally, findings must be interpreted with these caveats in mind.

More recent European data confirm that in many countries, young children from socio-economically disadvantaged families and those with less-educated mothers are less likely to participate in formal 
ECEC than their peers from more advantaged or educated families (Adema, Clarke and Thévenon, 2016[42]). These disparities in access to ECEC based on family background create a situation whereby families lose opportunities to raise their socio-economic profiles through parental participation in ongoing education or the labour market, and children simultaneously are not afforded the benefits of participating in high-quality ECEC.

Figure 1.6. Gaps in pre-primary education participation by students' socio-economic background

Difference in the percentage of 15-year-old students who had attended pre-primary education for at least two years between the top and bottom quarters of socio-economic background, 2015-18

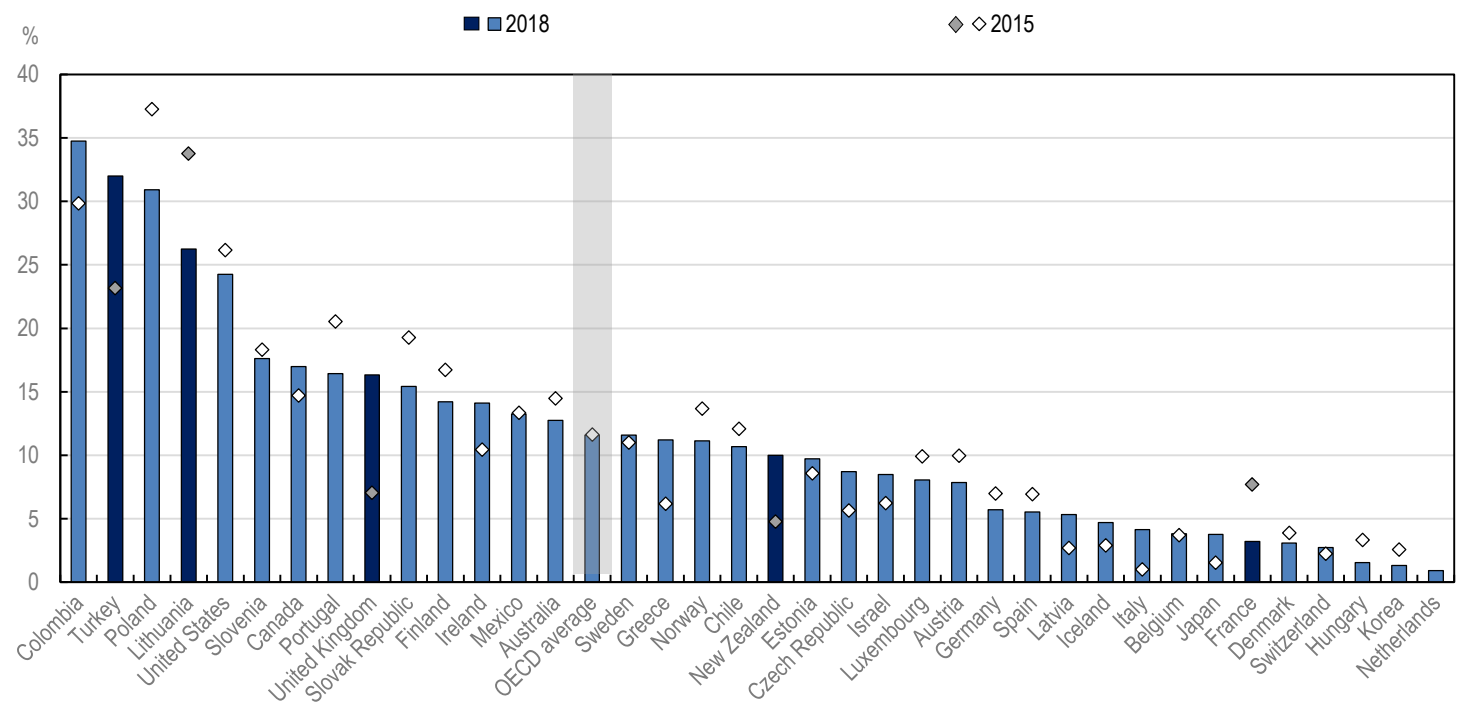

Notes: Statistically significant differences between 2015 and 2018 are marked in a darker tone. The socio-economic profile is measured by the PISA index of economic, social and cultural status (ESCS). A socio-economically disadvantaged (advantaged) student is a student in the bottom (top) quarter of the index of ESCS in the relevant country.

Countries are ranked in descending order of the percentage point difference of students who had attended pre-primary education for at least two years between the top quarter of socio-economically advantaged and disadvantaged students.

Source: (OECD, 2020[41]) (OECD, 2016[43]) 
One reason children from socio-economically disadvantaged families are less likely to participate is the costs associated with ECEC. Although parents have access to help with childcare costs in all OECD countries, the extent and type of support are highly variable. As a result, for many lower-wage workers, forgoing labour market participation and keeping young children at home can make financial sense (OECD, 2020[20]). The quality of ECEC opportunities may be a contributing factor in whether families access these programmes. Quality can be lower in areas where socio-economically disadvantaged families live, especially when private versus public provision dominates, but socio-economic segregation can occur even in contexts with substantial public investments (Drange and Telle, 2021 [44]; Hatfield et al.,

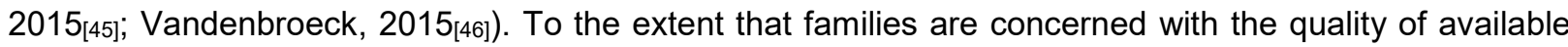
ECEC, they may choose, or feel compelled, to keep their children at home or seek informal childcare arrangements.

Strategies to equitably increase participation in ECEC include increasing the provision of free ECEC, for at least some hours, ages or targeted population groups. Universal free access to at least one year of ECEC is now common across OECD countries, and having readily available, high-quality ECEC can encourage broad participation from diverse families. However, universal free access to ECEC is typically targeted to pre-primary education, potentially limiting the available public resources to support the learning, development and well-being of children under age 3 years (OECD, 2017[35]). Countries and jurisdictions must carefully balance their investments to increase access to high-quality ECEC for children throughout the full age range of early childhood. Universal free access helps ensure ECEC can meet its goal of reducing inequalities by improving both affordability and accessibility for the most disadvantaged families. It is one tool governments can use along with others, such as regulatory frameworks, to foster high-quality ECEC across settings that are both publicly and privately managed, or mechanisms to adapt ECEC settings to the needs and preferences of more disadvantaged families to encourage their participation in particular (OECD, 2020[20]; Blanden et al., 2016[47]).

\section{The COVID-19 pandemic compounds pressures to provide equitable access to early childhood education and care}

The COVID-19 pandemic may exacerbate inequitable enrolment in ECEC and mean that more children miss opportunities to participate in ECEC. Not only is the pandemic deepening existing economic inequalities, but providing continuity of opportunities to support the education and development of this age group is even more challenging than at later stages of education. Young children require close contact with others to meet their basic needs, ensure their safety and promote their learning and well-being: these functions of ECEC cannot be replaced by even the best distance learning platforms.

Unequal participation in ECEC according to children's socio-economic backgrounds is likely to be intensified by rising unemployment due to the pandemic, with women experiencing some of the steepest job losses (OECD, 2020[48]). Between unemployment, reduced availability of ECEC and health risks of engaging in low-wage work outside the home, more disadvantaged families are likely to decide that caring for children at home makes health and economic sense.

Before the pandemic, mothers' labour market participation and enrolment rates in ECEC were closely linked (Figure 1.7). Government support is needed to ensure that children can continue to engage in ECEC despite the current growth in unemployment, for example, by expanding the provision of free or subsidised ECEC to more children, including targeting families who have income losses due to furloughs or unemployment. Financial supports that are provided to families to access ECEC also need to meet families' needs in a timely fashion, at the time they are required to pay for ECEC, rather than relying exclusively on tax-based measures that may provide support only on an annual basis (OECD, 2020[20]).

Women who are more educated and those who are employed before the birth of their children already enrol their children in ECEC at higher rates than those who are less-educated or unemployed (Adema, 
Clarke and Thévenon, 2016 $\left.{ }_{[42]}\right)$. These are also critical determinants of household economic resources. Higher-income families tend to provide more stimulating and responsive interactions in the home-learning environment (Burchinal et al., 2015[49]). These interactions foster children's early cognitive skills as well as their socio-emotional skills (OECD, 2020 $\left.0_{[3]}\right)$. Emerging evidence suggests job and income losses during the pandemic are associated with negative parent-child interactions among socio-economically disadvantaged families; however, for parents who lost jobs without losing income, parent-child interactions were more positive (Kalil, Mayer and Shah, 2020[50]). Finding ways to support less affluent parents as early teachers is an important policy direction that is amplified in the context of job losses and ECEC closures due to the COVID-19 pandemic.

Furthermore, parents' time and capacity to engage in home-learning activities are likely strained through the pandemic. Estimates based on the OECD Survey of Adult Skills, a product of the Programme for the International Assessment of Adult Competencies (PIAAC), suggest that approximately $31 \%$ of workers on average in OECD countries could feasibly work from home, with large disparities based on education and skills (Espinoza and Reznikova, 2020[51]). For workers with lower education and skills, this difference means an increased likelihood of unemployment in sectors where in-person work is limited during the pandemic (e.g. hospitality) or an ongoing need for high-quality ECEC to ensure children's development, learning and well-being when parents must continue going to work outside the home. Continuing employment outside the home throughout the pandemic may be detrimental to children's well-being to the extent parents are risking exposure to COVID-19, reinforcing the need for high-quality ECEC services to support both children and their parents (Kalil, Mayer and Shah, 2020[50]). For parents who are able to telework, balancing children's care and education at home is creating a new set of demands and ways of managing work and family responsibilities. For families in all of these situations, access to high-quality ECEC continues to be a necessity.

\section{Figure 1.7. Association between mothers' labour market participation and early childhood education and care enrolment rates}

Labour market participation of women whose youngest children are under age 3 years and enrolment rates in formal childcare of children under age 3 years, 2017

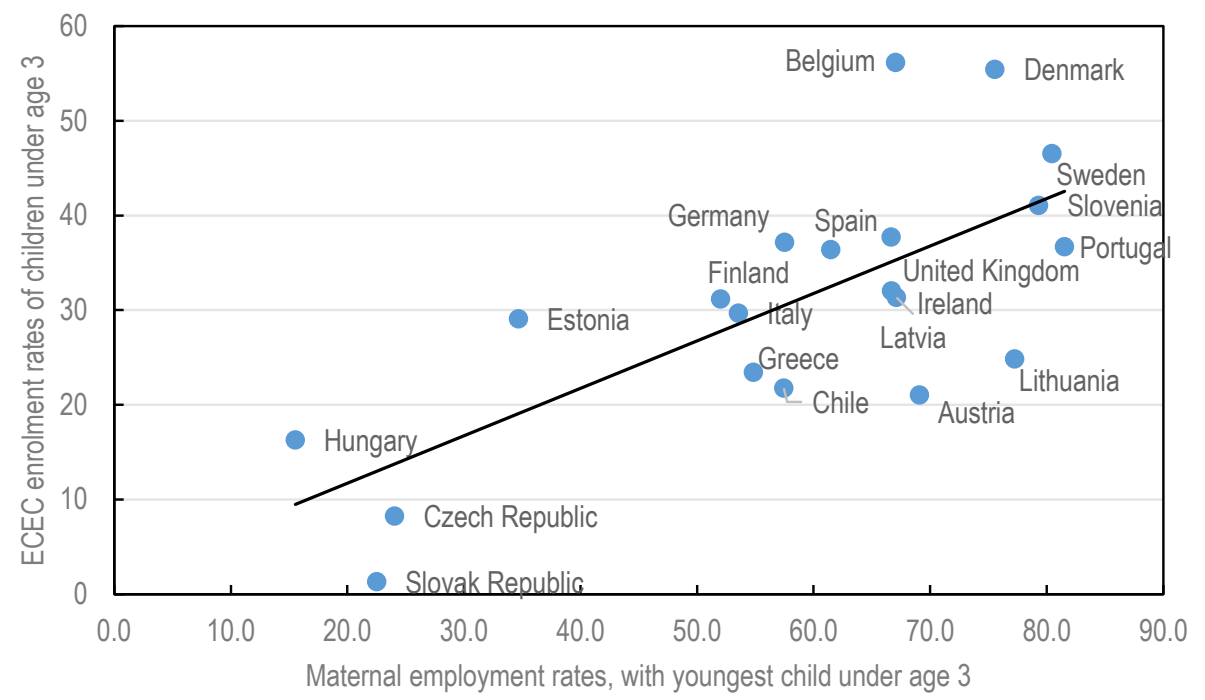

Notes: Data generally include children enrolled in ECEC (ISCED Level 0) and other registered ECEC services (ECEC services outside the scope of ISCED Level 0 because they are not in adherence with all ISCED criteria). Data for Denmark, Finland and Spain include only ISCED Level 0. Employment rates refer to women aged 25-54 years whose youngest children are aged 0 to 2 years.

Source: OECD (2021[52]), OECD Family Database, OECD, Paris, http://www.oecd.org/els/family/database.htm. 


\section{Curriculum and pedagogy shape ECEC staff's interactions with children and families}

Curriculum frameworks support process quality through several mechanisms, including their content, routines, activities, resources and encouragement of interactions (Edwards, 2021 ${ }_{\text {[21] }}$ ). Curriculum frameworks can vary greatly, particularly in ECEC compared with other levels of education, where the need for a structured approach to learning and to teaching is well accepted (Nesbitt and Farran, $2021_{[53]}$ ). Yet, curriculum frameworks adapted to the settings in which they are employed, including to the ages of children, are a key support to orient staff in their practices and a way to build shared goals across different types of provision within the ECEC system.

Pedagogy can be a set of foundational beliefs that underpin a curriculum or specific practices that emerge through the implementation of the curriculum (Edwards, 2021[21]). Articulating a curriculum framework and its links to pedagogy are important policy strategies for enhancing process quality in ECEC as this process makes explicit the values and beliefs embedded in the system, for instance, related to children's rights, to enriching experiences, or to expectations for short- or longer-term learning outcomes. As such, a curriculum framework is an important tool to support quality across the full age range covered by ECEC, including children under age 3 years (Chazan-Cohen et al., 2017[54]). However, the Quality beyond Regulations data show that several countries do not have curriculum frameworks that cover this early period of the life course. In other countries, the curriculum frameworks for this age group are not mandatory (Chapter 2). These findings underscore the need for a better understanding among policy makers of the meaning and importance of curriculum and pedagogy for this age group.

At the other end of the spectrum in terms of the availability of curriculum frameworks, many countries and jurisdictions participating in Quality beyond Regulations have multiple different curriculum frameworks in place for the same or overlapping age groups. This situation reflects the complexity of services and settings within the ECEC sector but also creates challenges for staff to navigate and align resources in practice. Furthermore, different curriculum frameworks for different ECEC settings can contribute to uneven quality throughout the sector, potentially reinforcing inequitable access to high-quality ECEC for some children.

In addition to supporting ECEC staff in their work with children, curriculum frameworks can support staff to engage with families, as well as support families to create home environments conducive to children's learning, development and well-being. Participation in high-quality ECEC is associated with greater parental warmth, provision of developmental stimulation, school involvement, and less use of physical discipline, highlighting the potential for ECEC staff to support interactions between children and

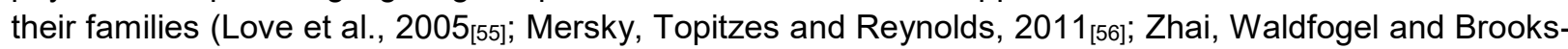
Gunn, 2013[57]). Curriculum frameworks can help ECEC staff foster interactions with families by setting expectations around this engagement and providing examples of strategies to foster such engagement. Importantly, curriculum frameworks can also be targeted to families, and in this way, encourage connections and continuity between the home and ECEC environments, contributing to children's social-emotional skills and early learning outcomes (OECD, 2020[3]).

\section{Curriculum frameworks situate early childhood education and care as the first stage of an educational continuum}

ECEC does not operate in isolation for children and families, nor should it be viewed as entirely separate from later stages of education. Curriculum is a powerful tool to create alignment and encourage co-ordination across stages of education, whether within ECEC (i.e. between settings for children under age 3 years and pre-primary education) or across levels of education. These transition points offer opportunities to ensure the benefits of high-quality ECEC endure beyond early childhood and to improve equity in educational outcomes (OECD, 2017[58]). 
The fact that young children are developing rapidly and learning new things through all of their daily experiences creates specific challenges for defining goals in curriculum frameworks for this age group, as well as for alignment with later stages of education. Yet, curriculum frameworks provide an opportunity to identify cultural and ideological values around learning and teaching that are relevant across multiple phases of the educational continuum (Edwards, 2021 [21]). This process of identifying key values can situate ECEC as a fundamental component of education systems, for example, by defining overarching goals relevant throughout the system, such as respect for diversity or promoting well-being and belonging.

Broad goals and principles are useful for developing curriculum frameworks that are relevant and adaptable to the wide age and developmental ranges covered by ECEC. However, the impact of such high-level frameworks can be difficult to assess, particularly compared to more skills-specific curricula that have clear links to discrete child outcomes (Jenkins and Duncan, 2017[59]). The pressures of "school readiness" rhetoric can push responsible authorities to adopt curriculum frameworks for ECEC that emphasise learning areas similar to those in later stages of education. This, in turn, raises concerns about the "schoolification" of ECEC if children's holistic development and well-being, including the fundamental role of play, are not also clearly supported through the curriculum framework (Needham and Ülküer, $2020_{[60]}$ ). Nevertheless, providing content-specific material and goals in curriculum frameworks can help ensure that staff have ample opportunities for rich interactions with children, creating higher quality environments (Denny, Hallam and Homer, 2012[61]; Wysłowska and Slot, 2020[62]). As such, countries and jurisdictions must strike a balance in their curriculum frameworks to support specific areas of learning and engagement between children and staff while keeping a holistic approach to children's development and being adaptable to the ages and stages of young children.

Among countries and jurisdictions participating in Quality beyond Regulations, the alignment of ECEC curricula with traditional learning areas is most evident in curricula for pre-primary education, compared with curricula that span a wider age range or those for children aged 0 to 2 years. The developmental or learning goals of curriculum frameworks for pre-primary education more often focus on traditional learning areas, whereas the goals of frameworks for younger children or a broader age group are more often framed around broad strands of concepts and competencies and principles and values (Chapter 2). Strengthening the use of shared goals across levels of ECEC and into later stages of education can facilitate continuity and support transitions for children as they grow. This does not depend on ECEC curriculum frameworks replicating or becoming a downward extension of primary education. Rather, a focus on transitions underscores the place of ECEC as part of the continuum of education with shared goals across levels while recognising important and unique features of the early childhood period.

A majority of the curricula covered in Quality beyond Regulations includes facilitation of continuity and transitions among their stated goals (see Table C.2.2). Nonetheless, the specific strategies that are required or are common practice in countries and jurisdictions to support children's transitions are somewhat limited (Figure 1.8). With the exception of providing information materials for parents on transitions, fewer than half of settings covered by the data systematically employ strategies to support transitions. This is an area where countries and jurisdictions can implement policies to improve quality, such as by building systems for ECEC settings to share child records with one another, with families and with primary schools. 


\section{Figure 1.8. Strategies to support children's transitions}

Percentage of early childhood education and care settings with the following strategies required or common practices, 2019

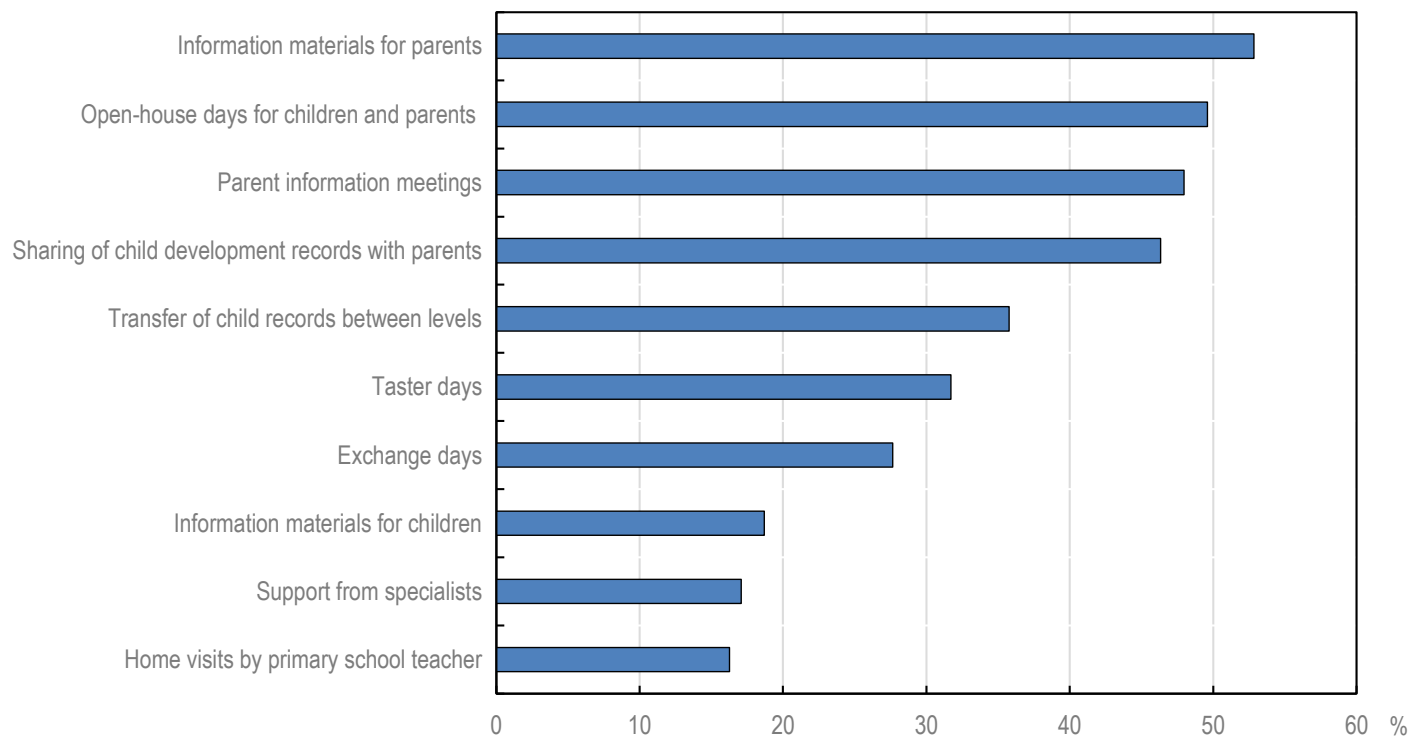

Source: OECD "Quality beyond Regulations" database.

Continuity across curriculum frameworks from ECEC to primary school and beyond not only supports smooth transitions. It can also ensure the focus of learning approaches is well-suited to children's level of development and that content builds, rather than repeats, from one stage to another. Creating this type of progression from ECEC to primary school may address the criticism that learning gains from ECEC "fade out" as children grow, by avoiding overlaps in material presented to children at these two levels of education (Jenkins and Duncan, 2017 $[59]$ ). Whereas in the past, compulsory education typically coincided with the start of primary school, a growing number of countries mandate participation in at least some pre-primary education (OECD, 2020[2]). These changes are often an effort to improve equity by ensuring access to ECEC for children from socio-economically disadvantaged backgrounds. However, they may fail to support longer-term learning goals if progression and alignment in curriculum frameworks are insufficient.

Approaches to children's learning, development and well-being in primary schools also need to adapt to reflect the needs of cohorts of children who have increasingly had access to ECEC. The Heckman Curve (Heckman, 2006[63]) is often cited to advocate for increased government expenditures in early childhood: it argues that the rates of return to human capital investment diminish throughout the life course, meaning that ECEC investments will yield better societal and economic returns than investments in later stages of education. However, critiques of the Heckman Curve caution that more research is needed on the specific types of investments needed to ensure ECEC delivers high rates of return and demonstrate that investment in high-quality education at later stages can also be cost-effective (Rea and Burton, 2020[64]; Whitehurst, 2017[65]). With this perspective, governments must continue to examine how best to integrate ECEC into their educational systems, with attention to investments in primary school and beyond as well. ECEC systems have many strengths that can inform improvements to other stages of education, such as tailoring activities to the needs and interests of different children, engaging with families, 
and addressing children's learning from a holistic perspective that includes well-being and socio-emotional development, alongside traditional academic learning areas.

\section{Early childhood education and care staff are gaining recognition as professionals}

The ECEC workforce is central to ensuring high-quality ECEC for all children. However, in part due to historical views of childcare as unpaid women's work, this essential workforce is not always regarded in light of the professionalism required for the sector. With research demonstrating the importance of well-educated ECEC staff for providing high-quality ECEC, policy makers are giving greater attention to the minimum qualifications of this workforce (Manning et al., 2017[66]; OECD, 2018[22]). ECEC staff need strong preparation to engage in high-quality interactions with multiple young children simultaneously, as well as to support children's interactions among each other and with materials in the ECEC setting. In addition, building strong relationships with families to promote continuity across ECEC and home environments can be supported through initial and ongoing staff training.

Across countries, the most prevalent qualification for ECEC teaching staff is a tertiary qualification (OECD, $\left.2020_{[2]}\right)$. However, educational requirements for ECEC staff vary substantially within countries. For example, within countries, staff credentialing in different types of ECEC settings can be subject to different regulatory requirements. This situation can create sharp divides within the sector, with some ECEC staff having educational background similar to that of primary school teachers and others having markedly less formal education. These gaps can correspond to differences in the pre-primary sector versus settings for children under age 3 years, with lower educational requirements for staff in the latter group in particular. The differences in staff educational attainment at these two levels of ECEC reflect the different value placed on education versus care, despite their interwoven nature in ECEC settings. This distinction also comes into play in different training profiles among teachers and assistants, even within the preprimary sector (Van Laere, Peeters and Vandenbroeck, 2012[67]).

In addition, many countries face shortages of ECEC staff, which creates challenges for raising educational requirements or enforcing existing standards. For example, in Iceland, pre-primary teachers are required to have training at a master's level, but a shortage of qualified staff means that in practice, nearly half of staff have secondary schooling as their highest level of education (OECD, 2019 [31] $)$. Data from the Starting Strong Teaching and Learning International Survey (TALIS Starting Strong) show that novice (i.e. those who have been in the field for three years or less) and more experienced ECEC staff have similar profiles of initial education (OECD, 2020[68]). This finding suggests that enhancing initial education may be an area where changes in policy or greater attention to implementation can impact ECEC quality through the workforce of the future. The breadth of training of ECEC staff is particularly important to consider, as staff whose training included a greater number of thematic areas reported a stronger sense of self-efficacy; when coupled with breadth in ongoing professional development as well, staff reported using more practices that engage children according to their individual backgrounds, interests and needs (OECD, 2020[68]).

Professional development opportunities help staff with different levels of education and experience adapt to changing needs of children and families, keep abreast of best practices in the field and generally engage in the rich interactions that constitute process quality. Research demonstrates that professional development can improve process quality and support children's learning, development and well-being (Egert, Fukkink and Eckhardt, 2018[69]; OECD, 2018[22]). However, more than half of staff participating in TALIS Starting Strong reported that a barrier to participating in professional development was not having enough staff to compensate for their absence (OECD, 2019 ${ }_{[31]}$ ). With tight budget constraints in addition to staff shortages, ECEC settings may be ill-equipped to help their staff members access ongoing professional development. Moreover, on average across OECD countries, pre-primary staff spend more 
time in direct contact with children than teachers at other levels of education, leaving less time for professional development (OECD, 2020[2] ). For these reasons, professional development strategies for ECEC staff must include opportunities for on-site learning and informal collaboration, in addition to building capacity for staff to engage in more traditional professional development activities.

Despite relatively high educational requirements for staff in some segments of the ECEC sector and expectations of participation in ongoing professional development, salaries have not necessarily kept pace. Per net hour of contact time with children, salaries of pre-primary teachers are below those of their colleagues teaching in primary schools in many OECD countries (OECD, 2020[2]). Improving salaries and opportunities for career progression can be a long-term objective for the ECEC sector as governments continue to focus on strategies to ensure high-quality ECEC for all children. This objective is a way to improve staff retention and the capacity of the ECEC sector to attract good candidates, as well as a strategy to support process quality. TALIS Starting Strong data show that staff have generally high satisfaction with their jobs, but low satisfaction with their salaries, and that staff who feel more valued by society also report adapting their practices more often to meet the needs and interest of individual children (OECD, 2019[31]). Striking the right balance between initial education requirements, participation in continuous professional development and elevating the professional status of ECEC staff with salaries commensurate to their education and training is a central policy challenge moving forward.

\section{Strong leadership in early childhood education and care settings contributes to high quality for children}

ECEC leaders can create organisational conditions that support process quality and thereby children's learning, development and well-being (Douglass, 2019[70]). Leaders' responsibilities, and their training and support to successfully engage in all aspects of their jobs, vary within countries, particularly related to the size of the ECEC settings in which they work (OECD, 2020[68]). Both within and across countries, leaders' authority and locus of control to manage their administrative and pedagogical work have important implications for the scope of influence they have in working with staff and with children and families.

Findings from TALIS Starting Strong highlight the importance of the content of leaders' initial education: in general, leaders whose education and training included a course on early childhood reported spending more time on pedagogical leadership (OECD, 2020[68]). This aspect of leadership includes observation of staff practices with children, providing effective feedback to staff based on these observations, establishing a collaborative culture among staff, as well as building positive relationships with families and community organisations. These practices are important for supporting process quality and for enabling staff to continue developing their skills and knowledge as part of their regular work duties.

Leadership can be exercised in more formal, hierarchical ways or in a more distributive, shared manner. Distributed leadership structures can help ECEC leaders fulfil their many job functions as well as motivate and retain staff by giving them a sense of ownership over their work. Data from TALIS Starting Strong suggest that staff who perceive more opportunities for participating in centre decisions tend to engage more frequently in professional collaborative practices and to report higher levels of job satisfaction. However, from the perspective of staff, distributed leadership structures are not always well established in different countries and could be further developed. Policy makers can support distributed leadership in ECEC by encouraging the development of specific middle leadership positions with differentiated pedagogical or administrative roles, which, combined with related preparation and training, can establish an effective leadership pipeline (OECD, 2020[68]). 


\section{COVID-19 places additional demands on the early childhood education and care workforce and requires innovative approaches to curriculum and pedagogy}

Countries and jurisdictions have taken very different approaches to the continuity of ECEC during the COVID-19 pandemic. These approaches range from closing the ECEC sector completely, to restricting in-person programming to children of essential workers, to requiring ECEC staff to provide pedagogical continuity through distance learning (OECD, 2020[68]). The policy responses for pre-primary education are less consistent than those for primary education: whereas a majority of primary school teachers in 34 countries were required to continue teaching (remotely/online) during school closures, only $42 \%$ of these countries required pre-primary staff to continue teaching (OECD, 2021 [1]). Similarly, remote learning tools to support teachers during this pandemic, including online, TV, radio and paper-based take-home materials, are less available at the level of pre-primary education compared to primary and higher levels of education, according to data from 118 countries (Alban Conto et al., 2020[71]).

Policy responses also vary in terms of whether they support ECEC settings and staff or whether they are directed to families (NCEE, 2020[72]). Regardless of the specific measures, COVID-19 is placing steep demands on the ECEC workforce, with yet unknown implications for the lasting impacts on this sector. Particularly in countries that rely heavily on private providers of ECEC, many ECEC settings are at risk of permanent closure due to forced closures in the short term and fears among families about the safety of continuing to access these settings during the health crisis (Friendly et al., 2020[73]; National Day Nurseries Association and Education Policy Institute, 2020[74]; OECD, 2020[68]; Zhang, Sauval and Jenkins, 2021[75]).

Before the COVID-19 pandemic, ECEC leaders already reported a shortage of staff, which aligns with a shortage of ECEC settings to meet the demand from families in many places. In turn, ECEC staff reported that extra duties due to absent colleagues or having too many children in their classroom/playroom are top sources of stress in their work. Along these same lines, staff indicated that reducing group sizes by recruiting more staff was a top priority if the budget for the ECEC setting was to be increased (OECD, $\left.2019_{[31]}\right)($ OECD, 2020[29]). With these existing pressures on the ECEC sector, any loss of staff related to the economic or health consequences of the pandemic could be deleterious for the availability and quality of ECEC in the coming years.

ECEC staff are meeting the challenges of working in new ways, adapting to changing requirements around health precautions when working in person and finding innovative ways to connect with young children and their families when working remotely (Franchino, 2020[76]; Pramling Samuelsson, Wagner and Eriksen $\varnothing$ degaard, $\left.2020_{[77]}\right)$. However, the myriad challenges of shifting work with young children to the COVID-19 context takes a toll on the well-being of the ECEC workforce, including among staff who are working remotely and navigating the limits of technology for this field (Friendly et al., 2020[73]; Nagasawa and Tarrant, 2020[78]; Pramling Samuelsson, Wagner and Eriksen Ødegaard, 2020[77]). The ECEC workforce can address these challenges through identifying and implementing best practices given the evolving contexts of their work, participating in professional development and training opportunities, and developing communities of practice to support one another both within and across ECEC settings. Countries and jurisdictions can support ECEC staff to engage in these professional activities by ensuring that relevant materials and opportunities are available and that infrastructure is in place for such activities (e.g. adequate Internet access). More investment in the sector might be needed in countries where ECEC staff's working conditions were already low before the COVID-19 pandemic.

Innovations in curriculum frameworks can help address the ongoing demands of the COVID-19 crisis, as well as prepare ECEC systems to flexibly adapt to new demands of the post-pandemic world and potential future shocks to the system. Related to ECEC closures in Hong Kong (China) in 2003 due to the Severe Acute Respiratory Syndrome (SARS) epidemic, the government responded quickly to release a special curriculum for children ages 3 to 6 years (Rao, 2006[79]). This curriculum included lessons on various aspects of SARS and personal hygiene, supporting ECEC staff to share information with children related 
to the changing circumstances and routines in their centres (e.g. increased hand-washing, more limited opportunities for children's social interactions). Although more supports or guidance for simultaneously adhering to health protocols and facilitating children's social interactions may have proven useful in the context of this epidemic, the availability of curriculum documents tailored to this epidemic was an important strategy to help staff.

The role of digital technologies in ECEC is an emerging area for both research and policy. Whether or not curriculum frameworks explicitly address strategies to foster interactions between staff and children using digital technologies, staff need dedicated training on best practices around engaging with technology. Such training can help staff further their own professional learning and identify best practices around the use of technologies to support children and families, even in the context of in-person ECEC.

Countries and jurisdictions acknowledge the importance of engaging families as a tool for enhancing quality in ECEC and supporting children; however, only about one-half of the curricula included in responses to the Quality beyond Regulations policy questionnaire included families in their development process (Chapter 2). Given the importance of the home-learning environment, ECEC curriculum frameworks must strive to build links between these two settings where young children spend most of their time, identifying ways to support families as a key mechanism to support children's learning, development and well-being. During the SARS epidemic in Hong Kong (China), centre leaders reported better communication with families as they worked to provide ongoing learning opportunities and then adapt to new ways of working in person when centres re-opened (Rao, 2006 $\left.6_{[79]}\right)$. As ECEC staff around the world are now also expanding their approach to working with families, taking lessons from these experiences in order to continue strong partnerships following the pandemic is important (Box 1.3).

\section{Box 1.3. Learning from countries: Early childhood education and care responses to the COVID-19 pandemic and lessons for the future}

Researchers in Norway, Sweden and the United States conducted interviews in early childhood education and care (ECEC) settings during the beginning of the COVID-19 pandemic, offering a snapshot into the day-to-day strategies, opportunities and concerns across the three countries (Pramling Samuelsson, Wagner and Eriksen Ødegaard, 2020[77]). Differences in the experiences of staff, children and parents in these countries are interpreted with respect to the social and political contexts. In Norway and Sweden, ECEC is considered a right for children and parents, while in the United States, ECEC closures and re-openings were viewed primarily from an economic (i.e. parental labour force participation) perspective. The Nordic perspective meant ECEC settings were expected to remain open to the greatest extent possible, with ministry directives emphasising the importance of children's attendance, unless ill. For staff, this became a matter of professional ethics, balancing their obligation and commitment to society with the stress from associated health risks of continuing in-person instruction.

Despite these different contexts, ECEC staff reported similar experiences across the three countries. Staff quickly adopted strategies to engage with children remotely, for example, creating private YouTube channels with personalised videos or daily online lesson plans consistent with children's usual routines, including music and storytime. Yet, staff consistently reported that they felt ill-prepared for the technological demands and found remote teaching draining. Additionally, as these virtual interactions relied heavily on parents having enough time to assist with the implementation, consistent attendance was complicated, particularly for children of working parents.

In ECEC settings that remained open in Norway and Sweden, staff also experienced high-stress levels when continuing their work in person, due to the health risks. However, new health protocols also meant smaller group sizes were required. Staff noted that they could interact more frequently with each child 
and follow up with their interests in tailored lessons, a change they hope to continue post-pandemic. A strategy for staff to mitigate stress involved regular staff meetings, which were an opportunity for reflection, to talk openly about their experiences and feelings, participate in further in-service trainings, discuss strategies to meet children's needs and support one another. These types of peer support and learning opportunities can be facilitated outside the context of the pandemic to promote staff well-being. Similarly, stronger communication with parents was noted in all three countries, which is another practice that can be supported following the pandemic to enhance ECEC quality.

Source: Pramling Samuelsson, I., J. Wagner and E. Eriksen Ødegaard (2020 77$]$ ), "The coronavirus pandemic and lessons learned in preschools in Norway, Sweden and the United States: OMEP Policy Forum", http://dx.doi.org/10.1007/s13158-020-00267-3.

\section{Countries take a diversity of approaches to governance and oversight of early childhood education and care}

There is more variability in approaches to ECEC governance, oversight and funding than at most other levels of education. The 26 countries and 41 jurisdictions that participated in the Quality beyond Regulations policy questionnaire reported on 56 different curriculum frameworks. They provided information on staff training requirements and working conditions across more than 120 different types of ECEC settings. This vast array of dimensions of ECEC represent networks that address different developmental stages of young children and various needs of families, adapted to local policy contexts. Yet, there are many parallels and areas of similarity across systems. Nonetheless, the complexity of ECEC systems creates challenges, from families attempting to navigate these systems on behalf of their children, to policy makers trying to develop and implement effective policies to support equitable access to high-quality ECEC for all children.

Making international comparisons on policies beyond regulations, those to support process quality, requires situating these policies in the context of the ECEC systems in which they operate. This publication highlights examples of country and jurisdiction efforts to enhance process quality through curriculum and pedagogy (Chapter 2) and through workforce development (Chapter 3). In addition, a multidimensional map of policy levers for quality in ECEC is available on line, making available the breadth and depth of policy information that underpins the findings described in this publication. This multidimensional map uses the project's conceptual framework (Figure 1.4) to organise data around the five policy levers: governance, standards and funding; curriculum and pedagogy; workforce development; data and monitoring; and family and community engagement.

Although not an explicit focus of this publication, data and monitoring strategies are tightly linked with the policy levers of curriculum and pedagogy and workforce development. Monitoring systems often focus on compliance with regulations, as opposed to focusing on interactions in ECEC settings and emphasising quality improvement. Countries and jurisdictions need to examine the extent to which their monitoring systems are able to collect and track information on process quality in order to inform policies for ongoing quality improvement.

The benefits of international comparisons of policies to support process quality are strong, despite the challenges of understanding the complexities and specific contexts of ECEC systems. As governments work to expand access to ECEC and simultaneously ensure high quality across all settings, the pace of changes means there are many opportunities to use examples from other countries/jurisdictions and adapt them for use in a particular policy context. The information and examples provided in this publication and the accompanying website offer policy makers opportunities to examine the place and priority of ECEC in their local contexts, to re-examine definitions of quality and move towards comprehensive approaches for building quality in ECEC settings through policy. 


\section{References}

Adema, W., C. Clarke and O. Thévenon (2016), "Who uses childcare? Background brief on inequalities in the use of formal early childhood education and care (ECEC) among very young children", Directorate for Employment, Labour and Social Affairs, OECD Publishing, Paris, https://www.oecd.org/els/family/Who uses childcareBackgrounder inequalities formal ECEC.pdf.

Alban Conto, C. et al. (2020), "COVID-19: Effects of school closures on foundational skills and promising practices for monitoring and mitigating learning loss", Innocenti Working Paper, No. 2020-13, UNICEF Office of Research - Innocenti, Florence.

Bauchmüller, R., M. Gørtz and A. Rasmussen (2014), "Long-run benefits from universal highquality preschooling", Early Childhood Research Quarterly, Vol. 29/4, pp. 457-470, http://dx.doi.org/10.1016/j.ecresq.2014.05.009.

Belfield, C. et al. (2006), "The High/Scope Perry Preschool Program”, Journal of Human Resources, Vol. XLI/1, http://dx.doi.org/10.3368/jhr.XLI.1.162.

Berger, L., L. Panico and A. Solaz (2020), "The impact of center-based childcare attendance on early child development: Evidence from the French Elfe Cohort", No. 254, INED, https://www.ined.fr/fichier/s rubrique/30325/working paper 2020254 childcare collective.c hildcare.fr.pdf (accessed on 11 April 2021).

Blanden, J. et al. (2016), "Universal pre-school education: The case of public funding with private provision", The Economic Journal, Vol. 126/592, http://dx.doi.org/10.1111/ecoj.12374.

Bowne, J. et al. (2017), "A meta-analysis of class sizes and ratios in early childhood education programs: Are thresholds of quality associated with greater impacts on cognitive, achievement, and socioemotional outcomes?", Educational Evaluation and Policy Analysis, Vol. 39/3, http://dx.doi.org/10.3102/0162373716689489.

Brussino, O. (2020), "Mapping policy approaches and practices for the inclusion of students with special education needs", OECD Education Working Papers, No. 227, OECD Publishing, Paris, https://dx.doi.org/10.1787/600fbad5-en.

Burchinal, M. (2018), "Measuring early care and education quality", Child Development Perspectives, Vol. 12/1, pp. 3-9, http://dx.doi.org/10.1111/cdep.12260.

Burchinal, M. et al. (2015), "Early child care and education", in Lerner, R., M. Bornstein and T. Leventhal (eds.), Handbook of Child Psychology and Developmental Science: Ecological Settings and Processes in Developmental Systems, John Wiley \& Sons, Inc.

Cadima, J. et al. (2020), "Literature review on early childhood education and care for children under the age of 3", OECD Education Working Papers, No. 243, OECD Publishing, Paris, http://dx.doi.org/10.1787/a9cef727-en.

Campbell, F. et al. (2012), "Adult outcomes as a function of an early childhood educational program: An Abecedarian Project follow-up.", Developmental Psychology, Vol. 48/4, http://dx.doi.org/10.1037/a0026644. 
Cattan, S., C. Crawford and L. Dearden (2014), "The economic effects of pre-school education and quality", IFS Reports, No. R99, Institute for Fiscal Studies, http://dx.doi.org/10.1920/re.ifs.2014.0099.

Chazan-Cohen, R. et al. (2017), Working Toward a Definition of Infant/Toddler Curricula: Intentionally Furthering the Development of Individual Children within Responsive Relationships, https://www.acf.hhs.gov/opre/report/working-toward-definition-infant/toddlercurricula-intentionally-furthering-development.

Denny, J., R. Hallam and K. Homer (2012), "A multi-instrument examination of preschool classroom quality and the relationship between program, classroom, and teacher characteristics", Early Education and Development, Vol. 23/5, http://dx.doi.org/10.1080/10409289.2011.588041.

Douglass, A. (2019), "Leadership for quality early childhood education and care", OECD Education Working Papers, No. 211, OECD Publishing, Paris, http://dx.doi.org/10.1787/6e563bae-en.

Drange, N. and K. Telle (2021), "Segregation in a universal child care system: Descriptive findings from Norway", European Sociological Review, Vol. 36/6, http://dx.doi.org/10.1093/esr/jcaa026.

Edwards, S. (2021), "Process quality, curriculum and pedagogy in early childhood education and care", OECD Education Working Papers, OECD Publishing, Paris.

Egert, F., R. Fukkink and A. Eckhardt (2018), "Impact of in-service professional development programs for early childhood teachers on quality ratings and child outcomes: A metaanalysis", Review of Educational Research, p. 003465431775191 , http://dx.doi.org/10.3102/0034654317751918.

Espinoza, R. and L. Reznikova (2020), "Who can log in? The importance of skills for the feasibility of teleworking arrangements across OECD countries", OECD Social, Employment and Migration Working Papers, No. 242, OECD, Paris.

Franchino, E. (2020), Traveling Turtles, Cardboard Playgrounds, and Bear Puppets: How Early Childhood Educators are Ensuring Joyful, Engaged Learning at a Distance, New American Education Policy Blog, https://www.newamerica.org/education-policy/edcentral/travelingturtles-cardboard-playgrounds-and-bear-puppets-how-early-childhood-educators-areensuring-joyful-engaged-learning-distance/ (accessed on 13 April 2021).

Friendly, M. et al. (2020), Canadian Child Care: Preliminary Results from a National Survey during the COVID-19 Pandemic, Childcare Resource and Research Unit, Toronto; Child Care Now, Ottawa; Canadian Child Care Federation, Ottawa.

García, J. et al. (2020), "Quantifying the life-cycle benefits of an influential early-childhood program", Journal of Political Economy, Vol. 128/7, pp. 2502-2541, https://doi.org/10.1086/705718.

Hatfield, B. et al. (2015), "Inequities in access to quality early care and education: Associations with funding and community context", Early Childhood Research Quarterly, Vol. 30, pp. 316326, http://dx.doi.org/10.1016/j.ecresq.2014.01.001.

Heckman, J. (2006), "Skill formation and the economics of investing in disadvantaged children", Science, Vol. 312/5782, http://dx.doi.org/10.1126/science.1128898. 
Heckman, J. and G. Karapakula (2019), "Intergenerational and intragenerational externalities of the Perry Preschool Project", HCEO Working Paper Series, No. 2019-033, Human Capital and Economic Opportunity Global Working Group, Chicago, IL, http://hceconomics.org.

Heckman, J. and G. Karapakula (2019), "The Perry preschoolers at late midlife: A study in design-specific inference", HCEO Working Paper Series, No. 2019-034, Human Capital and Economic Opportunity Global Working Group, Chicago, IL.

Heckman, J. et al. (2010), "The rate of return to the HighScope Perry Preschool Program", Journal of Public Economics, http://dx.doi.org/10.1016/j.jpubeco.2009.11.001.

Jenkins, J. and G. Duncan (2017), “Do pre-kindergarten curricula matter?", in The Current State of Scientific Knowledge on Pre-Kindergarten Effects, Brookings and Duke Center for Child and Family Policy, Washington, DC and Durham, NC.

Kalil, A., S. Mayer and R. Shah (2020), "Impact of the COVID-19 crisis on family dynamics in economically vulnerable households", No. 2020-143, Becker Friedman Institute for Economics at the University of Chicago, Chicago.

Karoly, L. (2016), "The Economic Returns to Early Childhood Education”, The Future of Children, Vol. 26/2, pp. 37-56.

Love, J. et al. (2005), "The effectiveness of early head start for 3-year-old children and their parents: Lessons for policy and programs", Developmental Psychology, http://dx.doi.org/10.1037/0012-1649.41.6.885.

Manning, M. et al. (2017), The Relationship between Teacher Qualification and the Quality of the Early Childhood Care and Learning Environment, Campbell Collaboration, Education Coordinating Group, http://dx.doi.org/10.4073/csr.2017.1.

Ma, X. et al. (2016), "A meta-analysis of the relationship between learning outcomes and parental involvement during early childhood education and early elementary education", Educational Psychology Review, Vol. 28, pp. 771-801, http://dx.doi.org/10.1007/s10648-015$\underline{9351-1 .}$.

Melhuish, E. et al. (2015), A Review of Research on the Effects of Early Childhood Education and Care (ECEC) on Child Development, http://ececcare.org/fileadmin/careproject/Publications/reports/CARE WP4 D4 1 review of effects of ecec.pdf.

Mersky, J., J. Topitzes and A. Reynolds (2011), "Maltreatment prevention through early childhood intervention: A confirmatory evaluation of the Chicago Child-Parent Center preschool program", Children and Youth Services Review, Vol. 33, pp. 1454-1463.

Nagasawa, M. and K. Tarrant (2020), Who Will Care for the Early Care and Education Workforce? COVID-19 and the Need to Support Early Childhood Educators' Emotional Wellbeing, New York Early Childhood Development Institute, City University of New York and Bank Street College of Education.

National Day Nurseries Association and Education Policy Institute (2020), The COVID-19 Pandemic and the Early Years Workforce August. 
NCEE (2020), Supporting Child Care During the Pandemic, Mini-stats, Top of the Class

Newsletter, https://ncee.org/2020/10/supporting-child-care-during-the-pandemic/ (accessed on 13 April 2021).

Needham, M. and N. Ülküer (2020), "A growing interest in early childhood's contribution to school readiness", International Journal of Early Years Education, Vol. 28/3, http://dx.doi.org/10.1080/09669760.2020.1796416.

Nesbitt, K. and D. Farran (2021), "Effects of Prekindergarten Curricula: $<\mathrm{i}>$ Tools of the Mind $</ \mathrm{i}>$ as a Case Study", Monographs of the Society for Research in Child Development, Vol. 86/1, http://dx.doi.org/10.1111/mono.12425.

OECD (2021), OECD Family Database, http://www.oecd.org/els/family/database.htm.

OECD (2021), The State of School Education, OECD Publishing, Paris, http://dx.doi.org/10.1787/201dde84-en.

OECD (2020), "Is Childcare Affordable?" Policy Brief on Employment, Labour and Social Affairs, OECD Publishing, Paris, https://www.oecd.org/els/family/OECD-Is-Childcare-Affordable.pdf.

OECD (2020), Building a High-Quality Early Childhood Education and Care Workforce: Further Results from the Starting Strong Survey 2018, TALIS, OECD Publishing, Paris, https://dx.doi.org/10.1787/b90bba3d-en.

OECD (2020), Early Learning and Child Well-being: A Study of Five-year-Olds in England, Estonia, and the United States, OECD Publishing, Paris, https://dx.doi.org/10.1787/3990407fen.

OECD (2020), Education at a Glance 2020: OECD Indicators, OECD Publishing, Paris, https://dx.doi.org/10.1787/69096873-en.

OECD (2020), OECD Employment Outlook 2020: Worker Security and the COVID-19 Crisis, OECD Publishing, Paris, https://dx.doi.org/10.1787/1686c758-en.

OECD (2020), PISA 2018 Results (Volume V): Effective Policies, Successful Schools, PISA, OECD Publishing, Paris, https://dx.doi.org/10.1787/ca768d40-en.

OECD (2020), Quality Early Childhood Education and Care for Children Under Age 3: Results from the Starting Strong Survey 2018, TALIS, OECD Publishing, Paris, https://dx.doi.org/10.1787/99f8bc95-en.

OECD (2019), Changing the Odds for Vulnerable Children: Building Opportunities and Resilience, OECD Publishing, Paris, https://dx.doi.org/10.1787/a2e8796c-en.

OECD (2019), International Migration Outlook 2019, OECD Publishing, Paris, https://dx.doi.org/10.1787/c3e35eec-en.

OECD (2019), Providing Quality Early Childhood Education and Care: Results from the Starting Strong Survey 2018, TALIS, OECD Publishing, Paris, https://dx.doi.org/10.1787/301005d1en.

OECD (2019), The Road to Integration: Education and Migration, OECD Reviews of Migrant Education, OECD Publishing, Paris, https://dx.doi.org/10.1787/d8ceec5d-en. 
OECD (2018), Engaging Young Children: Lessons from Research about Quality in Early

Childhood Education and Care, Starting Strong, OECD Publishing, Paris,

https://dx.doi.org/10.1787/9789264085145-en.

OECD (2017), Educational Opportunity for All: Overcoming Inequality throughout the Life

Course, Educational Research and Innovation, OECD Publishing, Paris, https://dx.doi.org/10.1787/9789264287457-en.

OECD (2017), Starting Strong 2017: Key OECD Indicators on Early Childhood Education and Care, Starting Strong, OECD Publishing, Paris, https://dx.doi.org/10.1787/9789264276116en.

OECD (2017), Starting Strong V: Transitions from Early Childhood Education and Care to Primary Education, Starting Strong, OECD Publishing, Paris, https://dx.doi.org/10.1787/9789264276253-en.

OECD (2016), PISA 2015 Results (Volume II): Policies and Practices for Successful Schools, PISA, OECD Publishing, Paris, https://dx.doi.org/10.1787/9789264267510-en.

OECD (2012), Starting Strong III: A Quality Toolbox for Early Childhood Education and Care, Starting Strong, OECD Publishing, Paris, http://dx.doi.org/10.1787/9789264123564-en.

OECD (2006), Starting Strong II: Early Childhood Education and Care, Starting Strong, OECD Publishing, Paris, http://dx.doi.org/10.1787/9789264035461-en.

Pianta, R., J. Downer and B. Hamre (2016), "Quality in early education classrooms: Definitions, gaps, and systems", The Future of Children, Vol. 26/2, pp. 119-138.

Pramling Samuelsson, I., J. Wagner and E. Eriksen Ødegaard (2020), "The coronavirus pandemic and lessons learned in preschools in Norway, Sweden and the United States: OMEP Policy Forum", International Journal of Early Childhood, Vol. 52/2, http://dx.doi.org/10.1007/s13158-020-00267-3.

Rao, N. (2006), "Sars, preschool routines and children's behaviour: Observations from preschools in Hong Kong", International Journal of Early Childhood, Vol. 38/2, http://dx.doi.org/10.1007/BF03168205.

Rea, D. and T. Burton (2020), "New evidence on the Heckman Curve", Journal of Economic Surveys, Vol. 34/2, http://dx.doi.org/10.1111/joes.12353.

Reynolds, A. and S. Ou (2011), "Paths of effects from preschool to adult well-being: A confirmatory analysis of the Child-Parent Center Program", Child Development, Vol. 82/2, http://dx.doi.org/10.1111/j.1467-8624.2010.01562.x.

Rowe, M. (2017), “Understanding socioeconomic differences in parents' speech to children”, Child Development Perspectives, http://dx.doi.org/10.1111/cdep.12271.

Shuey, E. and M. Kankaras (2018), "The power and promise of early learning", OECD Education Working Papers, No. 186, OECD Publishing, Paris, http://dx.doi.org/10.1787/f9b2e53f-en.

Sylva, K. et al. (2004), "The Effective Provision of Pre-school Education (EPPE) Project: Findings from Pre-school to end of Key Stage 1", https://dera.ioe.ac.uk/18189/2/SSU-SF2004-01.pdf. 
Taggart, B. et al. (2015), Effective Pre-school, Primary and Secondary Education Project (EPPSE 3-16+): How Pre-school Influences Children and Young People's Attainment and Developmental Outcomes Over Time, Department for Education, London, UK, https://assets.publishing.service.gov.uk/government/uploads/system/uploads/attachment dat a/file/455670/RB455 Effective preschool primary and secondary education project.pdf.pdf (accessed on 24 December 2020).

UNICEF (2016), Uprooted: The Growing Crisis for Refugee and Migrant Children, UNICEF, New York.

Van Huizen, T. and J. Plantenga (2018), "Do children benefit from universal early childhood education and care? A meta-analysis of evidence from natural experiments", Economics of Education Review, Vol. 66, pp. 206-222, http://dx.doi.org/10.1016/i.econedurev.2018.08.001.

Van Laere, K., J. Peeters and M. Vandenbroeck (2012), "The education and care divide: The role of the early childhood workforce in 15 European countries", European Journal of Education, Vol. 47/4.

Vandell, D. et al. (2010), "Do effects of early child care extend to age 15 years? Results from the NICHD study of early child care and youth development", Child Dev, Vol. 81/3, pp. 737-756, http://dx.doi.org/10.1111/j.1467-8624.2010.01431.x.Do.

Vandenbroeck, M. (2015), Quality ECEC for all: Why we can't afford not to invest in it, https://www.researchgate.net/publication/281579157 Quality ECEC for all Why we can\% $27 \mathrm{t}$ afford not to invest in it.

Whitehurst, G. (2017), Rigorous preschool research illuminates policy (and why the Heckman Equation may not compute), Brookings, Washington, DC, https://www.brookings.edu/research/rigorous-preschool-research-illuminates-policy-and-whythe-heckman-equation-may-not-compute/ (accessed on 13 April 2021).

Wysłowska, O. and P. Slot (2020), "Structural and process quality in early childhood education and care provisions in Poland and the Netherlands: A cross-national study using cluster analysis", Early Education and Development, Vol. 31/4, pp. 524-540, http://dx.doi.org/10.1080/10409289.2020.1734908.

Zhai, F., J. Waldfogel and J. Brooks-Gunn (2013), "Estimating the effects of Head Start on parenting and child maltreatment", Children and Youth Services Review, Vol. 35, pp. 11191129.

Zhang, Q., M. Sauval and J. Jenkins (2021), "Impacts of COVID-19 on the child care sector: Evidence from North Carolina", EdWorkingPaper, No. 21-371, Annenberg Institute at Brown University, Providence, https://www.edworkingpapers.com/sites/default/files/ai21-371.pdf (accessed on 13 April 2021). 


\section{Curriculum frameworks, pedagogy and process quality in early childhood education and care}

This chapter discusses the relationship between curriculum frameworks, pedagogy and process quality in early childhood education and care.

By articulating policy-relevant questions and key indicators, this chapter links research findings and conceptual work with the policy levers needed to enhance process quality and support children's learning, development and well-being. This chapter provides an overview of policies concerning these indicators across OECD countries and jurisdictions. It also provides concrete examples of good practices that can enhance process quality and child development through these policy levers. 


\section{Key messages}

- In participating countries and jurisdictions, the share of mandatory curricula is higher for curriculum frameworks covering children aged 3 to 5 than for those covering children aged 0 to 2 or those covering a broad age range ( 0 to 5 ). Some $14 \%$ of participating countries and jurisdictions do not have a curriculum framework for children aged 0 to 2 . The absence of curricula for the youngest children can result in differences in the quality of early childhood education and care (ECEC) across ages. It can also make transitions to pre-primary education more difficult than when there is curricular continuity for children from birth to entry into primary education. There is no common curriculum framework for all children aged 0 to 5 in $40 \%$ of participating countries and jurisdictions. In almost $25 \%$ of participating countries and jurisdictions, there is more than one curriculum in place per age group, which may create equity issues as well as challenges for monitoring. A few countries also have multiple curricula per setting, which may lead to additional complexity for ECEC staff.

- The majority of curricula covering children aged 0 to 2 and 0 to 5 y design their developmental and learning goals for children around principles and values and broad competences, whereas the goals of the majority of curricula targeting children aged 3 to 5 reflect traditional learning areas. The learning areas covered are broad, including socio-emotional, physical and cognitive skills. Information and communication technologies (ICTs) are less frequent than other learning areas.

- Most curricula across age groups suggest the use of multiple pedagogical approaches. Whereas curricula for ages 0 to 2 and 0 to 5 typically build on pedagogical approaches that view learning as an active exchange, approaches on readiness for school, outcome/performance-based education, and didactic/direct instruction are more frequent among curricula for children aged 3 to 5 . This difference may correspond to a stronger alignment of curricula for children aged 3 to 5 with primary school pedagogical practices.

- A majority of curricula are child-centred and based on a holistic vision of the child, despite differences in the ways this is portrayed. Most participating countries and jurisdictions also recognise the importance of play in ECEC in the principles and goals of their curriculum frameworks.

- Most curricula include or are accompanied by guidelines for implementation that provide examples of pedagogical practices to support the use of curricula in practice. Guidelines are mostly directed at ECEC settings despite the fact that the majority of curricula for all age groups explicitly sets goals to highlight the importance of co-operation with families and community as part of children's broader learning, development and well-being. Only $40 \%$ of guidelines address parents, $30 \%$ address local governments, and less than $12 \%$ are directed to community groups and agencies.

- Monitoring of curriculum implementation is mandatory in most participating countries and jurisdictions. More than one-third of them conduct external monitoring of curriculum implementation at least once a year in all age groups, and $23 \%$ of them conducts it depending on the last monitoring results. The most common method for external monitoring of curriculum implementation is inspections. Staff self-assessment as part of external monitoring is also common. Only a few curricula are monitored through child assessments and peer reviews.

- Countries and jurisdictions monitor process quality, but they focus on some types of interactions more than others. Less than a half of participating countries and jurisdictions monitors interactions among children and between children and materials, and only $37 \%$ monitor interactions between ECEC staff and parents.

- While a majority of participating countries and jurisdictions engaged central government agencies and ECEC staff in the development of their curriculum frameworks, fewer included parents and communities in the process. Very few countries and jurisdictions include children in curriculum design processes. 


\section{Introduction}

Curriculum frameworks define early childhood education and care goals, learning and development content, and types of activities that can be used by staff to foster children's development, learning and well-being. They can be regulated, changed and adapted to evolving goals and quality standards, and thereby constitute a core lever for policies. Pedagogy, on the other hand, refers to the practices and methods employed by staff to support children's development, learning and well-being. The ways in which curricula are implemented through pedagogy have direct effects on children's experiences in ECEC (OECD, 2018[1]; Shuey et al., 2019 $\left.{ }_{[2]}\right)$. Curriculum frameworks and pedagogy are, therefore, important drivers of the quality of interactions in ECEC and home-learning environments, including how ECEC staff engage with children and parents and how children interact with one another. These interactions are the basis of process quality in ECEC.

The Quality beyond Regulations policy review collected information on different characteristics of curriculum frameworks and pedagogical approaches and built key indicators to better understand how countries differ in their approaches to supporting process quality (see Box 2.1 in the next section). Countries and jurisdictions have reported information on 56 curriculum frameworks. Drawing on research literature, this chapter explains different dimensions of curriculum frameworks and pedagogy that matter for process quality. It presents a selection of indicators of the key parameters of curriculum frameworks and pedagogy in countries and jurisdictions that participated in the Quality beyond Regulations data collection. The chapter also discusses features of curriculum frameworks and pedagogy in specific countries and jurisdictions. More indicators and figures on policies targeting curriculum frameworks and pedagogy can be found on the platform Starting Strong: Mapping quality in early childhood education and care, available at https://quality-ecec.oecd.org.

\section{Defining the concepts}

Curriculum frameworks are documents that set out principles, goals, guidelines, values and approaches to children's development, learning and well-being in a country or jurisdiction (European Commission Working Group, 2014[3]; OECD, 2011[4]). For early childhood education and care, they generally cover knowledge, competencies and skills areas, the characteristics of children's interactions with staff and other children, and the experiences and resources that children are offered within the ECEC setting and sometimes in the home-learning environment (Wood and Hedges, 2016 $\left.{ }_{[5]}\right)$.

These documents provide policy directions as well as technical specifications to ensure that children's experiences in ECEC settings support their learning and development. They often provide guidance to help staff organise their practices to address developmental goals and may also include guidelines on pedagogies (OECD, 2018[6]). Curriculum frameworks aim to constitute overarching agreements among various institutions and stakeholders at the national or sub-national level and to articulate a broad vision of curricula within the context of ECEC and education systems (OECD, 2011 [4]). The design, revision, implementation and evaluation of curriculum frameworks are important levers to support process quality and children's development, learning and well-being (OECD, 2015 $\left.{ }_{[7]}\right)$.

Pedagogy can be defined in multiple ways. In a narrow sense, pedagogy refers to the practices and methods employed by staff to support children's development, learning and well-being. It refers to the set of strategies and techniques implemented by staff to provide opportunities for young children's development in skills, attitudes and dispositions within a particular social and material context (Siraj-Blatchford et al., 2002[8]). Research emphasises the need to understand pedagogy as an interactive process between staff, children and the environment, rather than as a top-down process (Edwards, forthcoming $\left.{ }_{[9]}\right)$. With this definition, pedagogy can be considered as subsidiary to curriculum, and a variety of pedagogical practices may be employed within a given curriculum framework. 
In the broader sense, pedagogy can denote the theoretical foundation of a curricular approach, setting principles and values for specific methods of teaching or interacting. In this perspective, pedagogy reflects the meaning and purpose of education as well as informs the specific modes of learning across activities. Thus, taken in this sense, pedagogy can both inspire and support curriculum (Edwards, forthcoming[9]; Sylva et al., 2016[10]).

A shared understanding of the relationship between curriculum and pedagogy can help ensure both that curriculum makes sense for the cultural values and expectations in a community, and that pedagogy will work in synergy with curriculum towards the same established goals. Without a clear definition of the relationship between curriculum and pedagogy, the capacity of these policy levers to support process quality may be hindered because the nature of learning and teaching intended within the ECEC setting is not clearly established (Edwards, forthcoming $\left.{ }_{[9]}\right)$. It is also important to rely on initial education and professional development to provide opportunities and guidance for all ECEC staff to understand and interpret the relationship between curriculum and pedagogy in ECEC, including the specific pedagogical approaches used in their own context (see Chapter 3).

\section{Box 2.1. Quality beyond Regulations policy review: Coverage and methodology}

This chapter is based on findings on curriculum frameworks and pedagogy from the Quality beyond Regulations policy questionnaire for the reference year 2019 and country background reports (see the Reader's Guide for more information). Twenty-six countries, covering 41 jurisdictions, completed the policy questionnaire, and six countries (Australia, Canada, Ireland, Japan, Luxembourg and Switzerland) provided background reports. Given the complex architecture of ECEC systems, the Quality beyond Regulations policy review collected information for each of the different curriculum frameworks (56 in total) and ECEC settings (121 in total) that exist within the participating countries and jurisdictions.

Regarding curriculum and pedagogy, the questionnaire included questions on:

- each curriculum framework's developmental goals and areas

- pedagogical approaches in place

- the process of designing and implementing each curriculum framework

- the engagement of families and communities through curriculum frameworks

- monitoring the implementation of each curriculum framework.

Standardised age groups were assigned to the different curricula and settings to facilitate analysis and comparisons. The age groups were assigned as follows:

- Age 0 to 2: If the majority of years of a setting or curriculum targets or covers children aged 0 to 2 . This includes settings or curricula that start for children from birth (e.g. 12 weeks, 3 months, etc.) and end at age 3.

- Age 3 to 5/primary school entry: If the majority of years of a setting or curriculum targets or covers children aged 3 to 5 . This includes settings or curricula that start earlier than age 3 (e.g. 2.5 years) or later than age 3 (e.g. 4 years).

- Integrated for age 0 to 5/primary school entry: If a setting or curriculum targets or covers children aged below and above the cut-off point of 3 years to a similar extent (e.g. 0 to 8 years).

Information was then aggregated across curricula for indicators where information was the same or very similar within these standardised age groups (e.g. for a country with two curriculum frameworks in place for the same age group). No information for different curricula or settings was aggregated across different age groups.

Table A.A.1 in Annex A shows the list of curriculum frameworks for participating countries and jurisdictions included in this report. 


\section{Features of curriculum frameworks that support process quality}

Several features of curriculum frameworks can have effects on the quality of interactions that take place in ECEC settings, i.e. process quality. These features include curriculum frameworks' characteristics such as their coverage, principles, goals, learning areas and material resources, which can affect process quality by promoting conditions that allow all children to develop relationships with peers, ECEC staff, space and materials, parents and family, and the community in a consistent way throughout their ECEC experience (Edwards, forthcoming[9]).

\section{Coverage across age groups and settings}

Age range and settings covered by curriculum frameworks are important factors for ensuring continuity and progression in ECEC and from ECEC to primary education. When curriculum frameworks target specific age groups or settings, the alignment of their goals and standards within ECEC and with primary school curricula can have positive effects on children's early experiences with education systems (OECD, $\left.2017_{[11]}\right)$. At the same time, curriculum frameworks that cover broad age ranges need to be adapted to children's developmental needs at various ages.

High-quality ECEC aims for a comprehensive approach to children's development that includes cognitive, social and emotional development, while primary school tends to be more academically oriented. Efforts to promote continuity across these levels creates a risk of "schoolification" in ECEC, which is when curricula and pedagogy become increasingly like those used in later stages of schooling (Slot et al., 2018[12]; Shuey et al., 2019 $\left.9_{[2]}\right)$. However, curricular alignment across ECEC and primary school can be done in ways that maintain the holistic and child-centred approaches that are typical in ECEC.

Ensuring that curricula cover children aged 0 to 2 in all settings is also fundamental to avoid differences in the quality of ECEC provision across age groups and ensure continuity in transitions to pre-primary education. In some ECEC settings, especially those for the youngest children and those in home-based settings ${ }^{1}$, curriculum frameworks may not be implemented either because the setting is not officially covered by the curriculum or because the ECEC workforce in these settings lacks preparation to use the curriculum.

The results from the Quality beyond Regulations policy review show that there is no common curriculum framework for all children aged 0 to 5 in $40 \%$ (14 out of 35) of participating countries and jurisdictions (Table 2.1). Some countries have a curriculum for children aged 0 to 5 in specific settings, but a different curriculum for children aged 3 to 5 in other settings, with no overlap between them. For example, this is the case in Japan. In other countries, there are separate curricula in place for children aged 0 to 2 and 3 to 5 .

There is no curriculum framework in place for children aged 0 to 2 in 14\% (5 out of 35) of participating countries and jurisdictions. This is the case in the Czech Republic, France, Israel, Portugal and the Slovak Republic. The share of mandatory curricula is significantly higher in the 3 to 5 age group $(94 \%, 17$ over 18$)$ than in ages 0 to $2(50 \%, 3$ out of 6$)$ and 0 to $5(62 \%, 20$ out of 32$)$, which reflects stronger importance placed on curricula as the level of education increases (see Table C.2.1).

There is a single curriculum framework per specific age group in most participating countries and jurisdictions (80\%, 28 out of 35), but in some countries, two or more curricula are in place (Table 2.1). This is the case in Canada (New Brunswick), Chile, Japan, New Zealand, Switzerland and Turkey. In these countries, children in the same age groups may have a different experience of ECEC according to the curriculum framework applied in the setting they attend. Furthermore, in some cases, in some of these countries or jurisdictions, ECEC settings may be required to follow the guidance of two or more frameworks simultaneously. While co-existing frameworks may provide additional resources on how to best support quality in ECEC, it may also create challenges for monitoring curriculum implementation, as well as complexity for ECEC leaders and staff. In these cases, aligning the frameworks and providing support for curriculum implementation can help overcome these complexities. 
Table 2.1. ECEC curriculum framework coverage

Curriculum frameworks' coverage across age groups and settings, 2019

Broad coverage across age groups and settings Specific coverage across age groups and settings

\begin{tabular}{|c|c|c|c|}
\hline Country/jurisdiction & $\begin{array}{l}\text { Ages covered by ECEC } \\
\text { curriculum framework(s) }\end{array}$ & $\begin{array}{l}\text { Common curriculum framework(s) } \\
\text { across age groups and settings }{ }^{2}\end{array}$ & $\begin{array}{l}\text { Single curricula per age } \\
\text { group }^{3}\end{array}$ \\
\hline Australia & All ECEC ages & Yes & Yes \\
\hline Belgium - Flanders & All ECEC ages & No & Yes \\
\hline Canada - Alberta & All ECEC ages & Yes & Yes \\
\hline Canada - British Columbia & All ECEC ages & Yes & Yes \\
\hline Canada - Manitoba & All ECEC ages & No & Yes \\
\hline Canada - New Brunswick & All ECEC ages & No & No \\
\hline Canada - Nova Scotia & All ECEC ages & Yes & Yes \\
\hline Canada - Ontario & All ECEC ages & Yes & Yes \\
\hline Canada - Quebec & All ECEC ages & Yes & Yes \\
\hline Canada - Saskatchewan 4 & All ECEC ages & Yes & Yes \\
\hline Chile & All ECEC ages & Yes & No \\
\hline Czech Republic & Only ages 3 to 5 & No & Yes \\
\hline Denmark & All ECEC ages & Yes & Yes \\
\hline Estonia & All ECEC ages & Yes & Yes \\
\hline Finland & All ECEC ages & No & No \\
\hline France & Only ages 3 to 5 & No & Yes \\
\hline Germany - Bavaria & All ECEC ages & Yes & Yes \\
\hline Germany - Berlin & All ECEC ages & Yes & Yes \\
\hline Germany - Brandenburg & All ECEC ages & Yes & Yes \\
\hline $\begin{array}{l}\text { Germany - North Rhine- } \\
\text { Westphalia }\end{array}$ & All ECEC ages & Yes & Yes \\
\hline Iceland & All ECEC ages & Yes & Yes \\
\hline Ireland & All ECEC ages & Yes & Yes \\
\hline Israel $^{5}$ & Only ages 3 to 5 & No & Yes \\
\hline Japan & All ECEC ages & No & No \\
\hline Luxembourg & All ECEC ages & No & Yes \\
\hline Mexico & Only ages 3 to 5 & No & Yes \\
\hline New Zealand & All ECEC ages & Yes & No \\
\hline Norway & All ECEC ages & Yes & Yes \\
\hline Portugal & Only ages 3 to 5 & No & Yes \\
\hline Slovak Republic & Only ages 3 to 5 & No & Yes \\
\hline Slovenia & All ECEC ages & Yes & Yes \\
\hline South Africa & All ECEC ages & Yes & Yes \\
\hline
\end{tabular}




\begin{tabular}{l|c|c|c}
\hline \multicolumn{1}{c|}{ Country/jurisdiction } & $\begin{array}{c}\text { Ages covered by ECEC } \\
\text { curriculum framework(s) }\end{array}$ & $\begin{array}{c}\text { Common curriculum framework(s) } \\
\text { across age groups and settings }\end{array}$ & $\begin{array}{c}\text { Single curricula per age } \\
\text { group }^{3}\end{array}$ \\
\hline Switzerland & All ECEC ages & No & No \\
\hline Turkey & All ECEC ages & No & No \\
\hline United Kingdom - England & All ECEC ages & Yes & Yes \\
\hline
\end{tabular}

1. In some countries and jurisdictions, some children aged 3 to 5 might be under the coverage of primary school's curriculum frameworks, which are beyond the scope of this review.

2. Common curriculum framework across age groups and settings: "Yes" refers to countries or jurisdictions where at least one curriculum framework covers children aged 0 to 5 in all settings; "No" refers to countries and jurisdictions where there is no curriculum framework covering children aged 0 to 5 in all settings.

3. Single curriculum per age group: "Yes" refers to countries and jurisdictions where there are no overlapping curricula for the same age group; "No" refers to countries or jurisdictions where an age group is covered by more than one curriculum framework simultaneously.

4. In Canada (Saskatchewan) an overarching framework, Play and Exploration: Early Learning Program Guide, covers children aged 0 to 5. However, in this report, the curriculum frameworks analysed are the following age-specific documents: Play and Exploration for Infants and Toddlers (covering children aged 0 to 2), and Essential Learning Experiences (covering children aged 3 to 5). See Table A.A.1 for reference. 5. In Israel, a curriculum framework for children aged 0 to 2 is currently under development.

Note: Information on curriculum frameworks included for each country and jurisdiction and classification according to standardised age groups is provided in Annex $A$.

Source: OECD "Quality beyond Regulations" database.

StatLink 제내 https://doi.org/10.1787/888934249148

\section{Goals and principles}

The goals of curriculum frameworks, including their breadth or specificity, as well as their target (children and/or staff), may influence process quality in ECEC. For curriculum goals that target children, broad approaches focused on well-being can be more appropriate in ECEC (OECD, 2011 ${ }_{[4]}$ ). Research shows that while it is important that curriculum frameworks set broad goals for children's development, skill-specific targets even for the youngest children support children to develop competencies in specific domains. For example, skill-specific curricula targeting pre-academic (e.g. literacy, mathematics) and social-emotional skills (e.g. self-regulation, problem solving) show positive effects in these domains (Jenkins and Duncan, 2017 $[13]$ ).

The Quality beyond Regulations policy questionnaire asked whether developmental and learning goals were expressed in terms of broad strands of concepts or competencies (e.g. communicating, developing curiosity), values or principles for ECEC (e.g. respect, equality, opportunities for play), and traditional learning areas (e.g. arts, sciences).

Most participating countries and jurisdictions specify the goals in their curricula using combinations of broad concepts or competencies, values or principles and traditional learning areas. Goals around broad strands of concepts or competencies and around principles and values are found in all curriculum frameworks covering ages 0 to 2, as well as in most of those for ages 0 to 5 , but they are less frequent in curricula for ages 3 to 5 . Instead, goals reflecting traditional learning areas are more common in curricula for ages 3 to $5(72 \%, 13$ out of 18$)$, compared to curricula for 0 to $2(33 \%, 2$ out of 6$)$ and for 0 to $5(37 \%, 12$ out of 32$)$ (see Figure C.2.1).

The prevalence of traditional learning areas in pre-primary curricula may aim to align with primary school curricula. In Switzerland, for example, the curricular goals for children age 3 to 5 are expressed as both traditional learning areas and broad concepts or competences. The subject areas are aligned with teaching and learning areas included in primary and secondary school curricula, such as mathematics and sciences. However, in ECEC settings, these subject areas are more oriented towards child development and are approached with an interdisciplinary perspective. 
Figure 2.1 illustrates the different combinations that countries and jurisdictions use in curricula covering children aged 0 to 5 . More than half of these curricula set goals both around principles and values and broad strands of concepts or competencies. In one-third of them, goals are expressed using the three categories.

\section{Figure 2.1. Specification of developmental and learning goals in curriculum frameworks covering children aged 0 to 5}

Percentage of curriculum frameworks covering children aged 0 to 5/primary school entry with goals expressed in the following ways, 2019
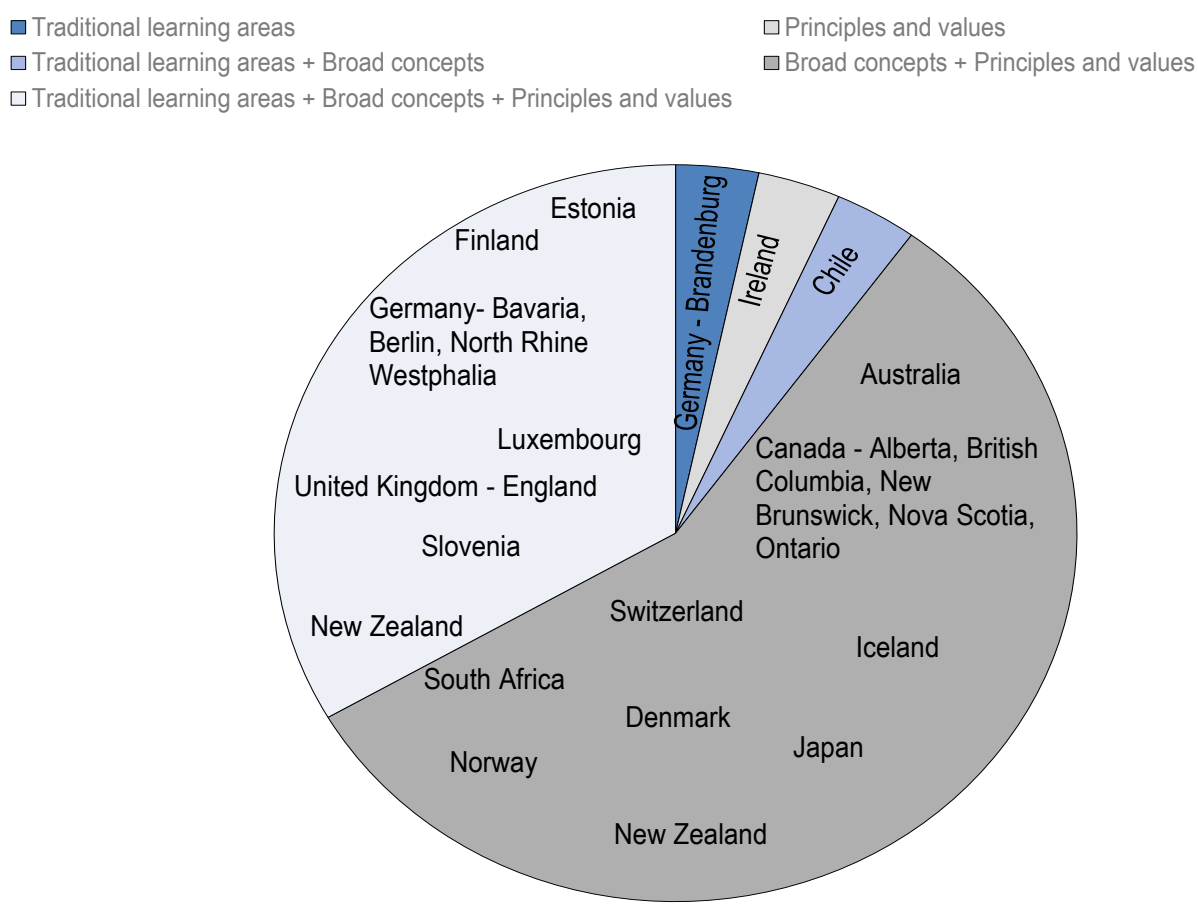

Notes: In countries with multiple curriculum frameworks reported at the sub-national level, when goals are expressed in the same way across sub-national jurisdictions, only the name of the country is shown. When pedagogical approaches are specified in different ways, the name of the jurisdiction is also indicated. Information on curriculum frameworks included for each country and jurisdiction and classification according to standardised age groups is provided in Annex $A$.

Source: OECD "Quality beyond Regulations" database.

StatLink 젶ㄴ https://doi.org/10.1787/888934248825

In one of the curricula in Chile, for example, goals are expressed in the form of traditional learning areas and broad concepts or competencies. In Germany (Brandenburg) and Ireland, goals are expressed respectively as traditional learning areas and as principles and values. In Ireland, the curriculum includes 12 principles presenting the core values of the framework, such as "equality and diversity", a "child's uniqueness", and "holistic learning and development" (NCCA, 2009 [14]). It is also organised in four interconnected themes, which structure the aims and goals for child learning and development. In Australia, five principles underpin the curriculum (e.g. "high expectations and equity", "secure, respectful and reciprocal relationships", "respect for diversity"), which are accompanied by five learning outcomes to foster child development, building on broad competencies and concepts. In Canada, curriculum frameworks across provinces typically describe broad learning goals or pathways (e.g. well-being and belonging, play, discovery and experimentation) rather than normative developmental or academic goals. 
Among curriculum frameworks covering children aged 3 to 5 , some build exclusively on goals reflecting traditional learning areas, which is less common in curricula for children aged 0 to 5 and 0 to 2 , respectively (Figure 2.2). This is the case of Belgium (Flanders), for example, where the curriculum for children aged 3 to 5 sets goals for Dutch, introduction to mathematics, sciences and technologies, physical education, and artistic education, among others. All curriculum frameworks targeting children aged 0 to 2 structure their goals around principles and values and broad concepts or competencies. Among them, two also have goals reflecting traditional learning areas (see Figure C.2.1). For example, in Belgium (Flanders), the curriculum targeting children aged 0 to 2 emphasises the interactive process between childcare practitioners and children and on the learning environment, instead of referring to learning areas. It aims to provide opportunities for child development in skills, attitudes and dispositions within a particular social and material context.

\section{Figure 2.2. Specification of developmental and learning goals in curriculum frameworks covering children aged 3 to 5}

Percentage of curriculum frameworks covering children aged 3 to 5/primary school entry with goals expressed in the following ways, 2019
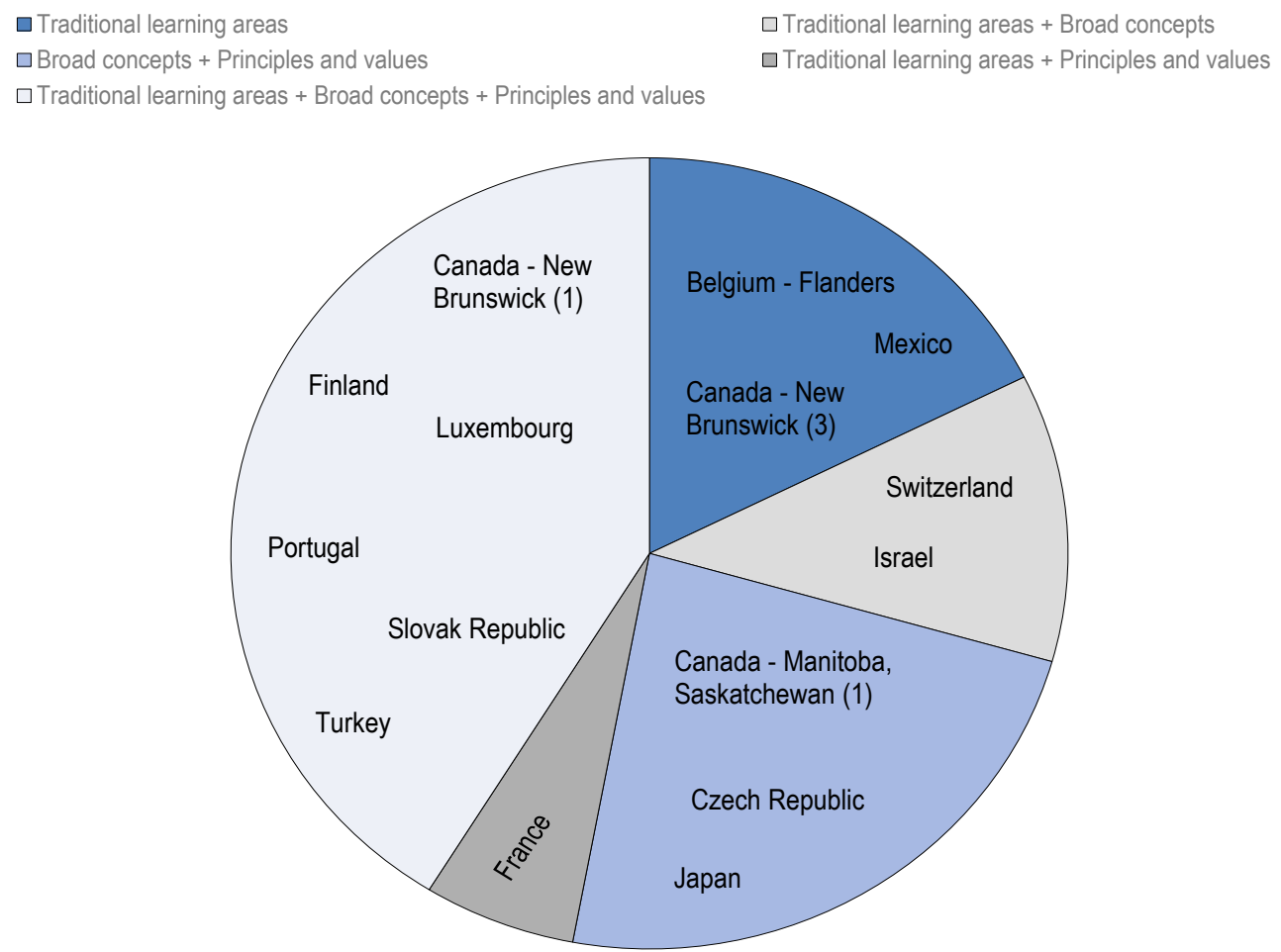

Notes: In countries with multiple curriculum frameworks reported at the sub-national level, when goals are expressed in the same way across sub-national jurisdictions, only the name of the country is shown. When pedagogical approaches are specified in different ways, the name of the jurisdiction is also indicated. Countries and sub-national jurisdictions that have multiple curricula can appear more than once. In these cases, the curriculum is identified by a reference number in parentheses (see Table A.A.1). Information on curriculum frameworks included for each country and jurisdiction and classification according to standardised age groups is provided in Annex $A$.

Source: OECD "Quality beyond Regulations" database. 
In addition to asking about the framing of developmental or learning goals, the Quality beyond Regulations policy questionnaire also asked more broadly about the stated goals of the curriculum framework around supporting goals for children. The majority of curricula for all age groups explicitly provide guidance on the holistic development, learning and well-being of children (Figure 2.3). This is not the case, however, of curriculum frameworks in France (ages 3 to 5), Iceland (ages 0 to 5 ) and Mexico ( 3 to 5 ). More than $80 \%$ of curricula in all age groups also provide guidance on goals for children, such as the skills, knowledge, competencies, or attitudes to be fostered. The percentage of curricula that includes the facilitation of continuity and transitions among their goals is slightly higher in the 0 to 2 and 0 to 5 age groups, as compared to the 3 to 5 age group.

\section{Figure 2.3. Stated goals in curriculum frameworks}

Percentage of curriculum frameworks that includes the following as stated goals, by age group, 2019

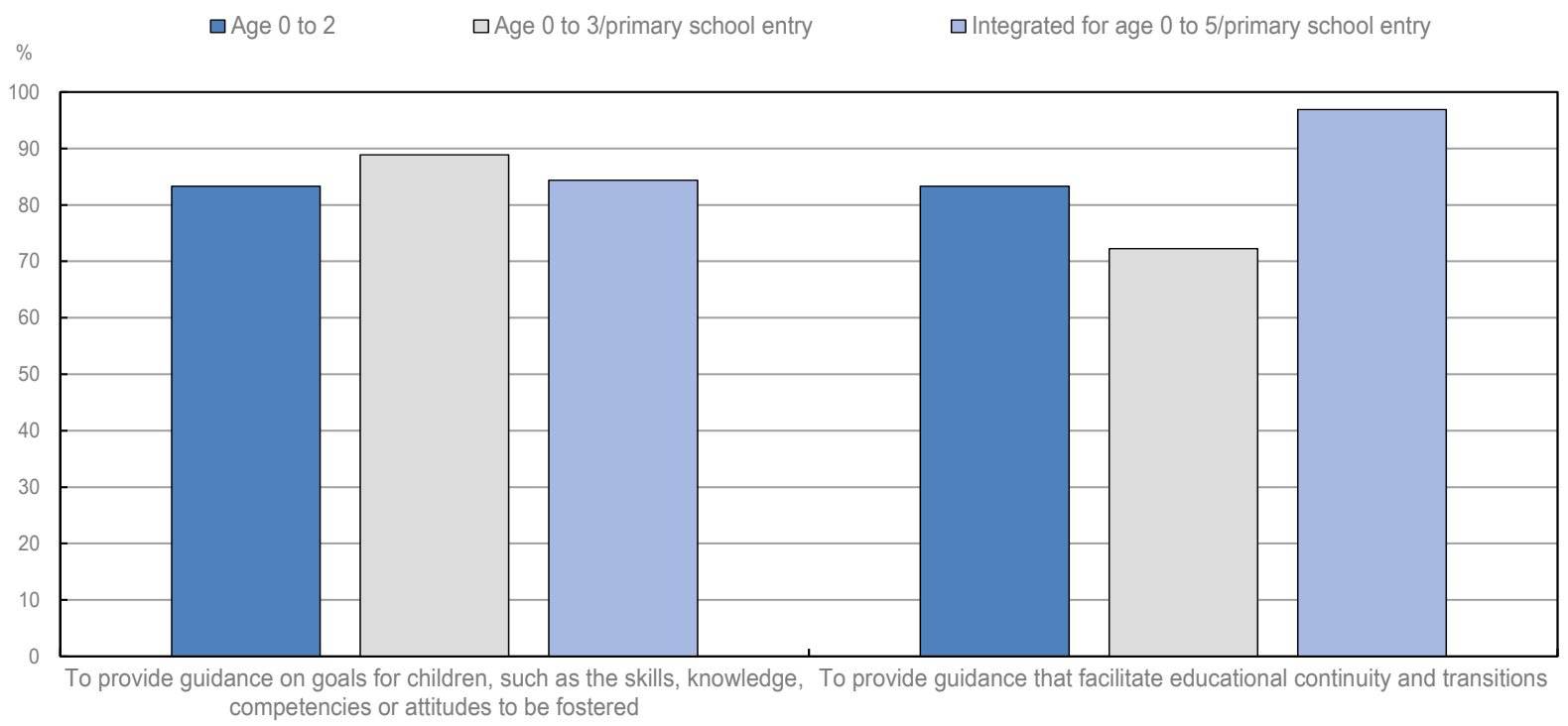

Note: The percentages are calculated within each age group. Information on curriculum frameworks included for each country and jurisdiction and classification according to standardised age groups is provided in Annex A.

Source: OECD "Quality beyond Regulations" database.

StatLink त्राज https://doi.org/10.1787/888934248863

Countries and jurisdictions might not explicitly state these goals for children in their curricula, but they can be implicit or provide guidance to achieve similar outcomes through policy levers other than curriculum frameworks. For instance, in Denmark, the curriculum framework aims to set goals for the pedagogical learning environment. In Iceland, guidance is provided to teachers to support children's holistic development, learning and well-being. Some countries highlight specifically that they set developmental goals for children, not for teachers, and that they provide guidelines and resources directed at teachers to help them support children in achieving those goals. For example, Japan's curriculum framework states goals for children, and it requires teachers to develop the appropriate environment to support them, taking into account their individual characteristics. In Switzerland, curricula for children aged 3 to 5 mostly focus on describing what children should be able to know and to do at the end of the cycle, and how teachers can support them, instead of describing the content that teachers should teach. 
The ECEC literature recognises that taking into account children's perspectives is fundamental for process quality. Children's perspectives are not just about their participation in the classroom, but how they should inform, inspire and structure ECEC policies (Broström, 2017 ${ }_{[15]}$; Clark, Mcquail and Moss, 2003[16]; Sommer, Pramling Samuelsson and Hundeide, 2010 ${ }_{[17]}$; Samuelsson and Carlsson, 2008[18]). Curriculum frameworks that are built taking into consideration children's perspectives, priorities and experiences can facilitate a child-centred approach to ECEC (OECD, 2015 [7]). Child-centred curriculum frameworks are informed by evidence on children's learning and development and set principles to support it through play, enjoyment, active participation, experimentation and interaction (OECD, 2015 $\left.{ }_{[7]}\right)$.

The recognition of the active role of the child matters as it has been shown that the quality of interactions in the classroom is influenced by whether activities are exclusively teacher-directed or also child-initiated (Edwards, forthcoming[9]). Research also shows the importance of balancing play with adult-directed interactions and with interactions with peers (Bowman, Donovan and Burns, $2000_{[19]}$; Siraj-Blatchford and Sylva, $2004_{[20]}$. For example, a study found that play aligned with adult-led interactions can effectively support young children's development (Stephen, 2010[21]). In this conceptualisation of "playful learning", the direction of the interactions between children and staff goes both ways, although the teacher has the role of establishing the conditions for the activities in the first instance. In the same way, research on child development has shown the importance of both active engagement of children and receiving feedback for learning (Edwards, forthcoming[9]).

Awareness has grown across OECD countries on the importance of developing curriculum frameworks that are child-centred in recent decades (OECD, 2015[7]) (Box 2.2). Curriculum frameworks need to be informed by understanding children's experiences, which are rooted in their individual needs, strengths, interests, language and culture (OECD, 2015[7]).

\section{Learning from countries: A child-centred approach to curriculum frameworks}

In Luxembourg, both curriculum frameworks for formal and non-formal education sectors ${ }^{2}$ give children agency and consider them co-constructors of knowledge, identity, culture and values. They also propose ways of making children's views visible by creating enabling free spaces and recommending that staff regularly consult with children about their interests and wishes.

Similarly, Ireland's curriculum framework promotes a holistic vision of learning and development, recognising the child's uniqueness and incorporating children's views (see Box 2.5 later in this chapter). The curriculum promotes a balance of child-led and adult-led learning, for which it provides sample interaction practices.

In Australia, curricula state that ECEC staff and children contribute to knowledge development and acknowledges the importance of recognising children's views. They promote practices of collaborative learning between children and staff, with a balance between child-initiated and staffsupported learning.

In Japan, curriculum frameworks set expectations that ECEC should be provided from the standpoint of children. The staff's role is to provide an enabling environment that encourages children to initiate and develop the activities of their choice.

In Slovenia, the curriculum emphasises the principle of active learning. It encourages providing a learning environment that provides opportunities for the child's own initiatives, together with activities with planned and unplanned guidance from ECEC staff. 


\section{Box 2.2. Supporting inclusion, diversity and multilingualism through curriculum frameworks and guidelines}

Curriculum frameworks can be an important tool to foster inclusion, equity, diversity and multilingualism in ECEC.

In Australia, curricula view children as intrinsically connected to their family, community and place. ECEC staff are expected to promote all children's participation, with an informed understanding of their different circumstances and abilities, and to encourage children to use their home languages in the ECEC setting, in addition to English. The curricula also encourage staff to provide resources that reflect each child's social world and expressly embraces the cultural and linguistic diversity of the community. For example, they recognises the unique place of Indigenous Australian cultures and the wealth of learning and experience available within local communities. States and territory governments also provide support to adapt ECEC curriculum design and implementation to the different cultural and socio-economic profiles and backgrounds of their communities.

In Canada, curriculum frameworks across the country stress that ECEC should recognise each child's strengths, capabilities and interests, and celebrate diversity in their family, community and culture. This is illustrated by British Columbia and New Brunswick, where the curriculum frameworks include supporting diversity and social responsibility as a goal to guide educators in their practice. In Quebec, ECEC settings are encouraged to consider each child's context, environment and resources when applying the curriculum framework. In all provinces, there are also examples of approaches that foster cultural diversity and multilingualism. For example, Nova Scotia's curriculum framework recognises four founding cultures in the province, including Indigenous people, the Acadian/Francophone population, African Nova Scotians and the Gaels. The curriculum also calls for a deep understanding of all cultures' values and ways of learning.

In Luxembourg, the concepts of inclusion and respect of linguistic and cultural diversity are also embedded in curriculum frameworks. In non-formal education, the curriculum fosters interactions that support the language development of children. The aim is to offer an early playful introduction to the Luxembourgish and French languages and create an ECEC environment that encourages openness towards other languages and cultural contexts. Children in all settings are encouraged to express themselves in their home language, with the aim of supporting process quality for cultural minorities or migrant children. In formal education, too, the curriculum takes a multilingual approach, acknowledging and recognising all children's multilingual potential. The conceptual framework for language education in this sector focuses on Luxembourgish as the main language but also promotes playful initiation to French and the home languages of the children.

Play has a strong and historical presence in Western European approaches to ECEC, informed by philosophical thinking about childhood as a period of natural learning that is aided through opportunities for children to participate in exploratory, hands-on activities (Wood, 2010[22]). There is an established understanding across OECD countries of the importance of play and exploration to capitalise on children's natural curiosity (OECD, $\left.2015_{[7]}\right)$. Through experimentation of the material world around them and playful interaction with one another, children are able to develop cognitive and non-cognitive competencies (OECD, 2015 $[7]$ ). Research has shown the advantages of play for young children in terms of their social development, emotional regulation and language learning. It is thus recommended as a primary approach for teaching and learning in the early years (Wisneki and Reifel, 2012[23]). 
How to best integrate play in interactions with and among children is still debated. Some authors argue that play is a culturally determined activity and that its value in ECEC may not be intrinsic but conditional on whether it is adequate in supporting children according to the socio-cultural context where they live, and in preparing them for participation in that context (Edwards, forthcoming $\left.{ }_{[9]}\right)$. Some authors argue that only play initiated by the child may have this value since it consists of an activity that is freely chosen and pleasurable for children, as compared to "pretend-play" activities guided by teachers (Pyle and Alaca, 2018[24]). Other researchers, however, argue that play and exploration alone are not sufficient to develop conceptual knowledge and that staff support in understanding structured content is needed (Hedges and Cullen, 2005 $\left.{ }_{[25]}\right)$. In the middle, notions of guided play, incorporating both child-initiated and adult-oriented activities, have been proposed as a lever to support children's development (Broadhead, 2018[26]). In this sense, curriculum framework guidance is fundamental to support teachers in applying a child-centred approach to play that takes into account children's socio-cultural diversity.

Most participating countries and jurisdictions recognise the importance of play in ECEC in their curriculum frameworks, either in the principles and goals or as a thematic area. Also, all curriculum frameworks for all age groups include "play" as a learning area (see Figure 2.4 further below).

\section{Learning from countries: Integrating play in curriculum frameworks}

In France, the principle of learning by playing is affirmed in the curriculum's preamble.

In the Slovak Republic, one of the general aims of ECEC in pre-primary education is to support children in engaging in life and learning through play, experience and exploration.

Australia's curricula reflect children's right to play in its learning outcomes and practices and provides staff with guidance for play-based learning.

In Ireland, the curriculum includes as a principle the importance of play and hands-on experiences for children. It also provides resources and guidelines for teachers to support learning and developing through play.

In Japan, the curriculum framework is based on the belief that educational aims are comprehensively achieved through play-centred instruction and promotes learning through play as a spontaneous activity of children.

In Luxembourg, curriculum frameworks stress the importance of play and provide guidance for an "education based on games" with different ways of playing proposed: free play, structured play, exploration games, building games, symbolic games and games with specific rules.

In Slovenia, play occupies a central role in the curriculum and is considered an important means to children's development and learning.

In Switzerland, the curricula emphasise the need to support children's learning through play and provides guidance on guided play and activities as well as on free play.

In Canada, all provinces' curriculum frameworks recognise play as crucial for children with different developmental stages of play (solitary, parallel, social) and types of play. For example, curricula in New Brunswick and Alberta incorporate "dizzy play", understood as an activity where children take pleasure in engaging in rough and tumble play and experiencing exhilarating physical release and laughter. 


\section{Substantive content and learning areas}

Substantive content is a key aspect of curriculum frameworks that can support process quality. There is a consensus among researchers that children should be supported in their development along multiple areas, including both cognitive and socio-emotional dimensions as well as their well-being. Hence, curriculum frameworks need to have broad coverage in terms of substantive content. Research suggests that curricula where content is based on research and policy evidence can improve children's development, learning and well-being (Burchinal, 2018[27]).

In addition, curriculum frameworks should be relatively specific in terms of content while providing flexibility to staff. For example, New Zealand's ECEC curriculum is based on a social pedagogical approach that does not specify content in terms of subject matter so that this content can be developed locally by teachers. A critique of this approach is that it can lead to a reduction in subject-specific content and learning experiences that provide opportunities for rich interactions between ECEC staff and children, as well as among children (Blaiklock, 2010 ${ }_{[28]}$; Edwards, forthcoming[9]; Denny, Hallam and Homer, 2012[29]). At the same time, the alignment of a curriculum's content with children's cultural background and real life has been found to help support children's development, learning and well-being (Edwards, forthcoming[9]). New Zealand's curriculum intends to make these linkages to children's everyday experiences and to special events celebrated by local and cultural communities.

Some studies have focused on the cultural appropriateness of curriculum frameworks' content and how this affects process quality. For example, a study on Indian pre-primary settings that adopted a curriculum framework inspired by British ECEC showed that content (focused on mathematics and English) did not provide sufficient opportunities for staff to develop the skills required for children to participate in their communities and was considered disconnected from their real lives (Admas, 2019 [30]). These findings highlight the need for curriculum frameworks to account for the diversity of children in terms of socio-economic background, native language and cultural background.

Across participating countries and jurisdictions, curriculum frameworks strike a balance between learning areas based on subjects, attitudes and values, as well as on skills (cognitive and meta-cognitive; physical and practical and socio-emotional). Most of the areas considered in the Quality beyond Regulations policy questionnaire are included in all curriculum frameworks across participating countries and jurisdictions and age groups (Figure 2.4). 
Figure 2.4. Developmental and learning areas specified in curriculum frameworks

Percentage of curriculum frameworks specifying the following developmental and learning areas, 2019

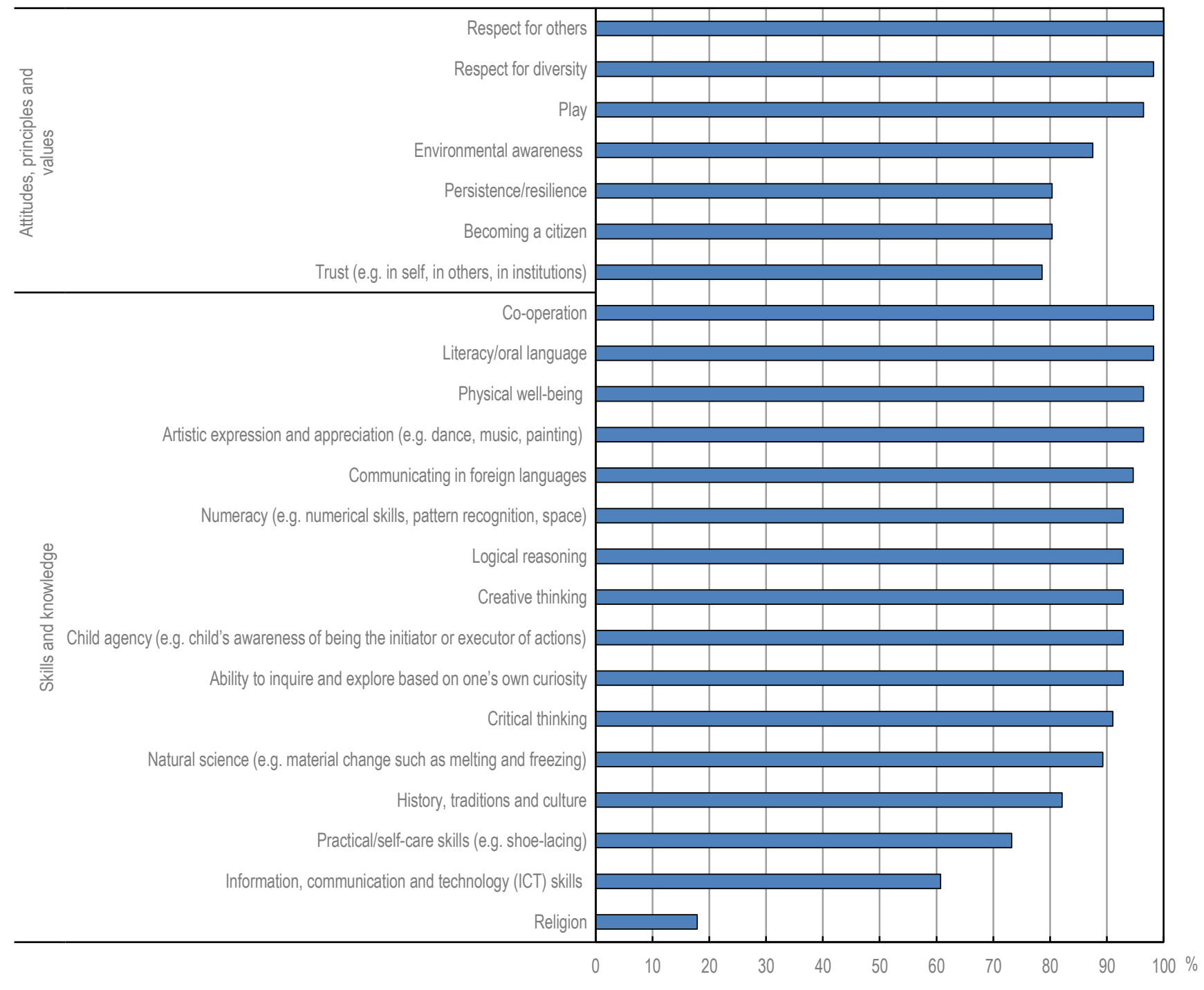

Note: Information on curriculum frameworks included for each country and jurisdiction and classification according to standardised age groups is provided in Annex $A$.

Source: OECD "Quality beyond Regulations" database.

StatLink ज्ञाज् https://doi.org/10.1787/888934248882

All curricula include respect for others as an area, and most of them include literacy/oral language, co-operation, respect for diversity, play, artistic expression and appreciation, and physical well-being. Another area present in almost all curricula is communicating in foreign languages. In some participating countries and jurisdictions, this area may take the form of an introduction or openness to multilingualism, for example, in Canada (New Brunswick) and Germany (North Rhine-Westphalia). The inclusion of foreign languages in curricula has increased over time, reflecting a growing commitment to supporting diversity in ECEC settings. In a similar policy questionnaire administered to countries and jurisdictions in 2016 , only $37 \%$ (20 out of 54 countries and jurisdictions) included foreign languages (OECD, 2017[11]). 
Areas that are least frequently included across curricula are practical self-care skills $(73 \%, 40$ out of 56$)$, ICT skills $(61 \%, 34$ out of 56$)$ and religion (18\%, 10 out of 56). Compared to 2016 , the inclusion of religion is less frequent $(41 \%$ of the considered curricula in 2016). In contrast, the percentage of curricula that includes ICT skills has increased in four years (compared to 43\% in 2016) (OECD, 2017[11]).

\section{Interactions and resources}

Interactions between children and ECEC staff are at the core of process quality (Arnett, 1989 [31]; Melhuish et al., 2016[32]; Pianta, 2001[33]; Pianta, LaParo and Hamre, 2007[34]). Interactions with material and spaces have also been emphasised as important for young children's development (Bronfenbrenner and Morris, 2006[35]; Escayg and Kinkead-Clark, 2018[36]; Tiko, 2017[37]; Ukala and Agabi, 2017[38]; Edwards, forthcoming $\left.{ }_{[9]}\right)$. The literature also suggests that activities and resources are important features of curriculum that can enable high-quality interactions (Edwards, forthcoming $\left.{ }_{[9]}\right)$. Participation in routines and activities depends, in practice, on the possibilities for children to engage with the materials and space available around them. For example, a wider range of material resources available was found to be associated with more opportunities for free play, which in turn is linked to children's dispositions, such as curiosity and problem solving (Admas, 2019[30]).

OECD countries increasingly recognise the importance of including a range of interactions in their curriculum frameworks (OECD, 2015[7]). Countries and jurisdictions that highlight interactions in their frameworks are Australia, Belgium (Flanders, ages 0 to 2), Canada, Germany (Bavaria), Ireland, Japan, Luxembourg, New Zealand, Slovenia and Switzerland.

\section{Learning from countries: Reflecting the importance of multiple interactions in curriculum} frameworks

Curriculum frameworks in some countries provide guidance to foster process quality and highlight that space and materials in the ECEC environment matter for the quality of interactions.

In Australia, the curriculum promotes interactions among children and between children and adults, places, technologies and natural and processed materials. It also stresses that the use of outdoor space can promote children's appreciation of nature, opportunities for individual exploration and play-based learning, as well as discussions and collaborative learning among children.

Across Canada, curriculum frameworks provide guidance for supporting children's development and learning through relationships with others, including children, adults, families and communities.

In Ireland, the curriculum provides guidance to inform interactions within and beyond ECEC settings, including child-child, child-staff, staff-staff, staff-parents, child-parents and child-community.

In Japan, curricula recommend that space and materials available in ECEC promote relationships among children and enrich children's play. It also highlights that staff's choice of the type, quantity and quality of materials should be informed by a good understanding of children and their interests and should create an enabling space for them to engage with the surrounding environment.

In Luxembourg, the curriculum framework for non-formal education emphasises interactions between adults and children, but particularly interactions within the peer group and with the environment. Both curriculum frameworks provide guidelines on the design of indoor and outdoor spaces and the materials that can support quality interactions.

In Switzerland, curriculum frameworks refer to interactions between children with adults, with the peer group and with their spatial-material environment. The relationships with parents, families and communities are also mentioned. 


\section{Pedagogical approaches to support process quality}

ECEC curriculum frameworks can be based on a specific pedagogy, prescribing certain practices, values and beliefs to ECEC staff. Conversely, pedagogy can be considered as a vehicle for curriculum frameworks, allowing multiple pedagogies to emerge according to a local context's specific needs.

Different traditions of pedagogy exist in ECEC among OECD countries and are considered in the Quality beyond Regulations policy questionnaire (Box 2.3). The pedagogical model that is followed can influence ECEC staff practices and thus affect process quality. However, while neuroscience has advanced understanding over the last decades of children's development and principles that can support it, there is no consensus on a pedagogy that should prevail, as various factors affect how pedagogical practices influence process quality in practice, such as cultural factors. The goals that countries and jurisdictions have for children's cognitive and socio-emotional outcomes can be attained through different pedagogical approaches.

\section{Box 2.3. Pedagogical approaches in early childhood education and care}

Different pedagogical approaches exist in ECEC, inspired by different traditions and ideologies. The main approaches to pedagogy in ECEC that are considered in the Quality beyond Regulations policy questionnaire are:

Constructivist/interactive: Approaches that view learning as an active exchange between the child and environment that progresses in "stages", with adults and peers providing important stimuli in learning. Based on the idea that learners construct new ideas and concepts based on their existing knowledge.

Developmentally appropriate practices: A balance of child-initiated learning and guidance from staff members. The approach provides a wide range of different activities, which are carried out in groups or independently. The approach focuses on socio-emotional, physical and cognitive development. All practices are based on: 1) theories of child development; 2) individual needs; and 3) the child's cultural background.

Didactic/direct instruction: Classic method of learning with mainly teacher-initiated activities, including repetition. This approach normally follows highly academic programmes that emphasise literacy and numeracy skills.

Experiential education: This approach focuses on the emotional well-being and the level of involvement of children. It emphasises satisfying children's basic needs so that they feel at ease and self-confident, allowing them to act spontaneously and to be concentrated, interested and fascinated.

Readiness for school: This approach emphasises preparing children for primary school, e.g. by developing children's early literacy and mathematics development. The pedagogy is aligned with primary schooling.

Social pedagogy: This approach stresses content and quality of practice rather than assessing children's achievement levels. It highlights the importance of dialogue between adults and children, as well as creative activities with discussions and reflections.

Outcome-based education/performance-based education: This approach sets specific aims and strategies for teachers to achieve outcomes for children, e.g. literacy and numeracy skills, specific subject knowledge, intelligence quotient (IQ) scores as well as children's socio-emotional and soft skills, such as motivation to learn, creativity, independence, self-confidence, general knowledge and initiative.

Source: Wall, S., I. Litjens and M. Taguma (2015[39]), Early Childhood Pedagogy Review: England, https://www.oecd.org/education/earlychildhood-education-and-care-pedagogy-review-england.pdf. 
Pedagogy informed by children's views also fosters process quality (Edwards, forthcoming[9]). Children's spontaneous interests derive from their social and cultural experiences. Therefore, incorporating their views helps ensure that the ECEC experience is appropriately connected to their lives. Cultures hold particular values about children, and the values and traditions of a community influence the ultimate form in which pedagogy is enacted, beyond what is stated in countries' formal curriculum frameworks.

Therefore, adapting pedagogical approaches to the local context is of great importance. The ability of countries to provide flexibility in curriculum frameworks in order to allow the right pedagogical approaches to emerge can make a difference for process quality. At the same time, countries need to find the balance between flexibility and richness in an evidence-based curriculum framework content so that opportunities can be maximised by pedagogy. In addition, while local flexibility can enhance process quality when it is responsive to the needs and values of the community, variability in the implementation of curriculum frameworks can also create uneven access to high-quality ECEC and contribute to concerns around equity. Some curricula allow ECEC staff, centres or jurisdictions to choose their preferred pedagogy but recommend and favour certain approaches.

Depending on guidance included in curriculum frameworks, ECEC staff might propose different activities that will impact the quality of interactions in the setting. ECEC staff autonomy to decide how to implement curriculum frameworks can help them tailor activities to local contexts and specific needs, which can be beneficial for children's engagement in positive interactions. Depending on the curriculum framework, ECEC staff may have more flexibility to design activities within the curriculum, or a curriculum may be more prescriptive, specifying the activities to follow as well as the teaching and learning materials.

Most curriculum frameworks in participating countries and jurisdictions encourage the use of multiple pedagogical approaches in all age groups. This is the case for all curriculum frameworks for children aged 0 to 5 and $83 \%$ ( 15 out of 18) of those for children aged 3 to 5 (Figure 2.5). Among countries with curriculum frameworks in place covering children aged 0 to 2, Canada (Manitoba), Mexico and Turkey foster multiple approaches. In Belgium (Flanders), for children aged 0 to 2, only one pedagogical approach is specified in the curriculum framework. ECEC staff are, however, given flexibility in applying this pedagogical approach, and they use it building on the environment, the vision of the setting, and parents' preferences, among other factors. 
Figure 2.5. Specification of pedagogical approaches in curriculum frameworks

Percentage of curriculum frameworks specifying multiple and specific pedagogical approaches, by age group, 2019

\section{Age 0 to 2}

$\square$ Multiple pedagogical approaches $\square$ Specific pedagogical approach

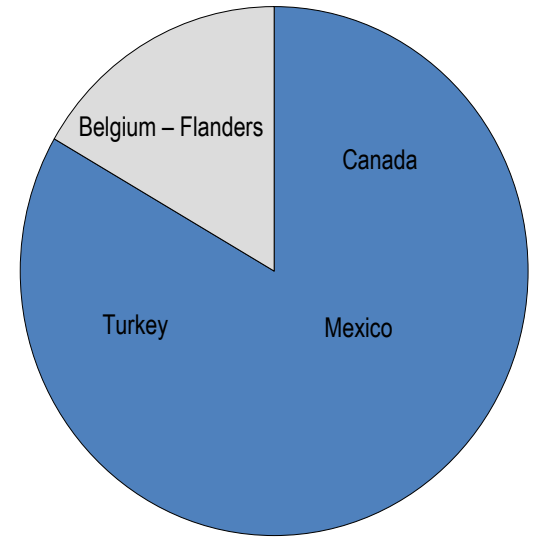

Age 3 to 5/primary school entry

口Multiple pedagogical approaches $\quad$ 口Specific pedagogical approach

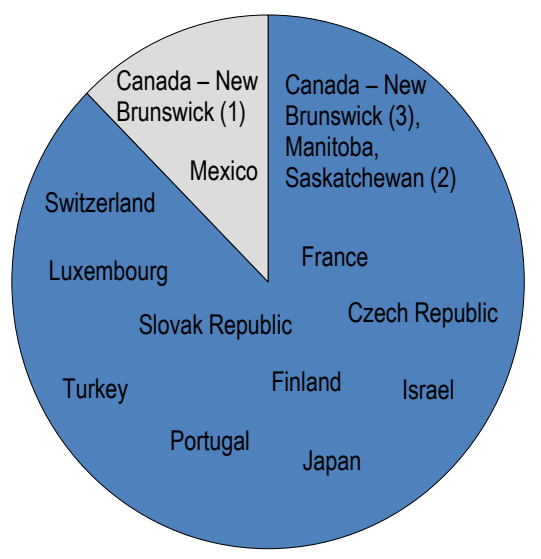

Integrated for age 0 to 5/primary school entry

$\square$ Multiple pedagogical approaches $\quad$ ¿Specific pedagogical approach

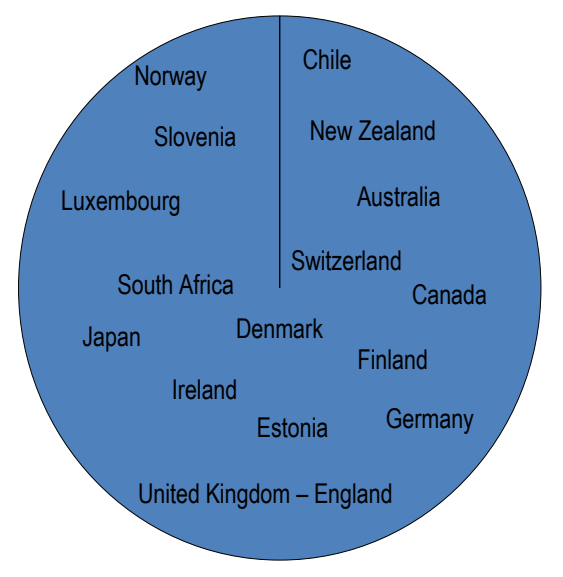

Notes: In countries with multiple curriculum frameworks reported at the sub-national level, when curriculum frameworks specify pedagogical approaches in the same way (multiple or specific) across subnational jurisdictions, only the name of the country is shown. When pedagogical approaches are specified in different ways, the name of the jurisdiction is also indicated. Countries and sub-national jurisdictions that have multiple curricula can appear more than once. In these cases, the curriculum is identified by a reference number in parentheses (see Table A.A.1). Information on curriculum frameworks included for each country and jurisdiction and classification according to standardised age groups is provided in Annex A.

Source: OECD "Quality beyond Regulations" database. 
Among the various pedagogical approaches considered in the Quality beyond Regulations policy questionnaire, countries and jurisdictions could specify all the approaches included in their curricula. When curriculum frameworks for all age groups are considered, more than three-quarters of them include the "constructivist/interactive" and "social pedagogy" approaches (Figure 2.6). The "developmentally appropriate practices" approach is present in more than half of curricula, and the "experiential education" approach in 44\% (25 out of 56) of curricula. For instance, in Canada, provinces' curriculum frameworks primarily adopt social pedagogical approaches, although some provinces also include other approaches. In Ireland, the curriculum reflects a socio-cultural view of children's development and promotes an integrated approach to practice that combines care and education (academic and play-based approaches).

One-third of curriculum frameworks specifies a "readiness for school" approach, and 23\% (13 out of 56) includes an "outcome/performance-based education" approach. This is the case of curricula in Australia, Canada (New Brunswick), the Czech Republic, Estonia, Japan, Luxembourg, New Zealand, the Slovak Republic, South Africa and Switzerland.

Another $21 \%$ (12 out of 56 ) of curricula specifies a "didactic/direct instruction" approach. This is the case in Canada (New Brunswick), Chile, Estonia, Finland, France, Israel, the Slovak Republic, South Africa and Switzerland.

\section{Figure 2.6. Pedagogical approaches specified in curriculum frameworks}

Percentage of curriculum frameworks specifying the following pedagogical approaches, by age group, 2019

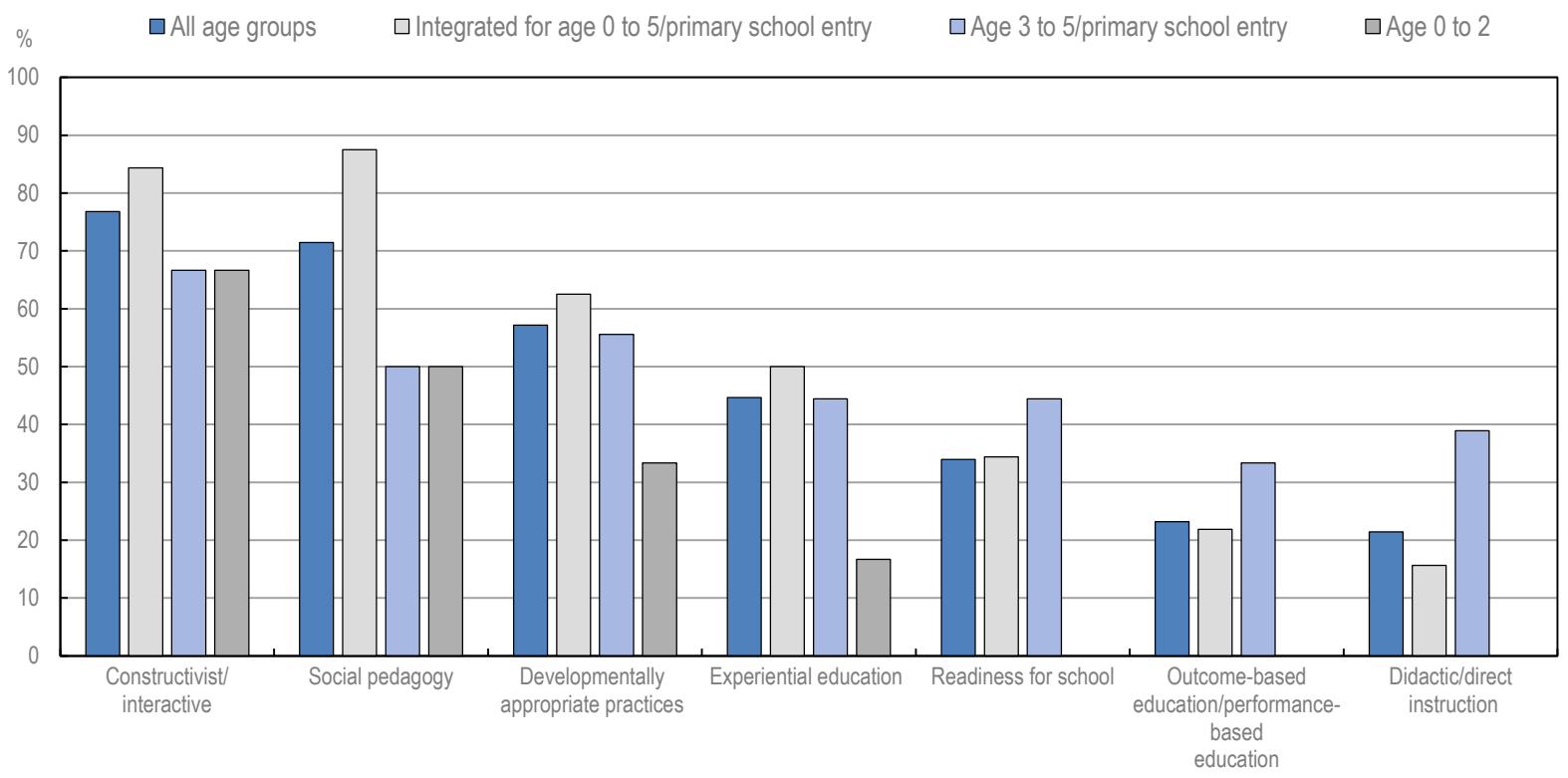

Note: Information on curriculum frameworks included for each country and jurisdiction and classification according to standardised age groups is provided in Annex $A$.

Source: OECD "Quality beyond Regulations" database. 
Pedagogical approaches of curricula for children aged 3 to 5 tend to be more aligned with those of primary education, while those of curricula for children aged 0 to 5 or 0 to 2 specify more holistic approaches. The "social pedagogy" and "constructivist/interactive" approaches are more often specified in curricula for children aged 0 to 5 and 0 to 2 . None of the curricula for children aged 0 to 2 includes "readiness for school", "outcome/performance-based education", or "didactic/direct instruction". These approaches are more frequent among curricula for ages 3 to 5 than for ages 0 to 5 .

In practice, a curriculum is implemented through discussions among ECEC staff as well as with children (Sylva et al., 2016[10]). There is an inevitable gap between curriculum frameworks as they are conceived and implemented, making it important to promote balanced, dynamic and flexible pedagogical approaches that respond to children's needs and the specific characteristics of the group of children staff are working with.

Curriculum frameworks can give more or less autonomy to ECEC staff in their use of pedagogical practices. Some curricula are more specific and prescriptive regarding the pedagogical practices to be implemented and how to apply pedagogical approaches, while others are less specific. Across participating countries and jurisdictions, curriculum frameworks vary in the degree of detail in which they provide pedagogical guidance and support. The majority of reported curricula covering all age groups provides some examples of specific pedagogical practices and/or curriculum implementation suggestions but give staff flexibility to use other approaches as well (Figure 2.7). 
Figure 2.7. Pedagogical guidance and support for staff as provided in curriculum frameworks

Percentage of curriculum frameworks providing examples of specific practices and/or implementation suggestions to guide teachers in using the specified pedagogical approach(es) by age group, 2019
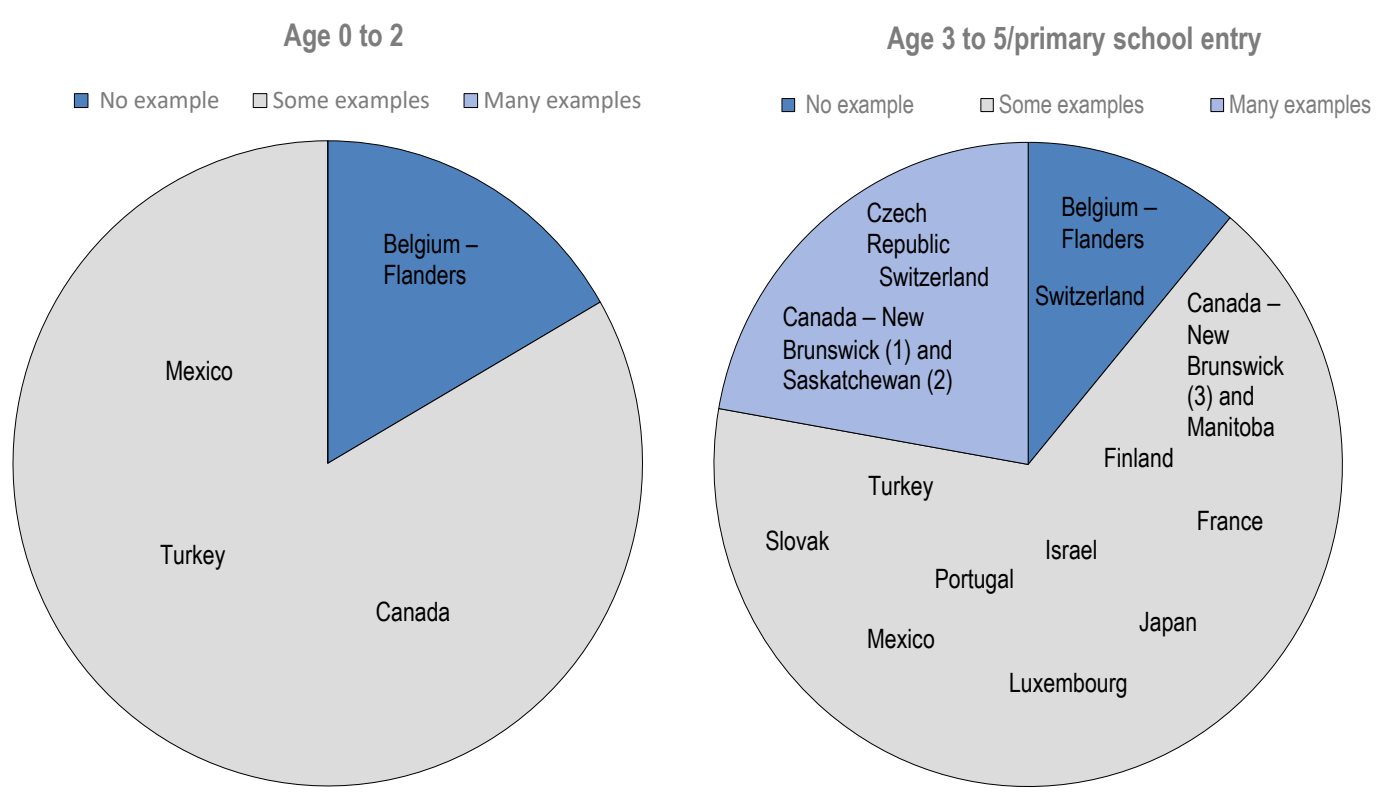

Integrated for age 0 to $5 /$ primary school entry

$\square$ No example $\square$ Some examples $\square$ Many examples

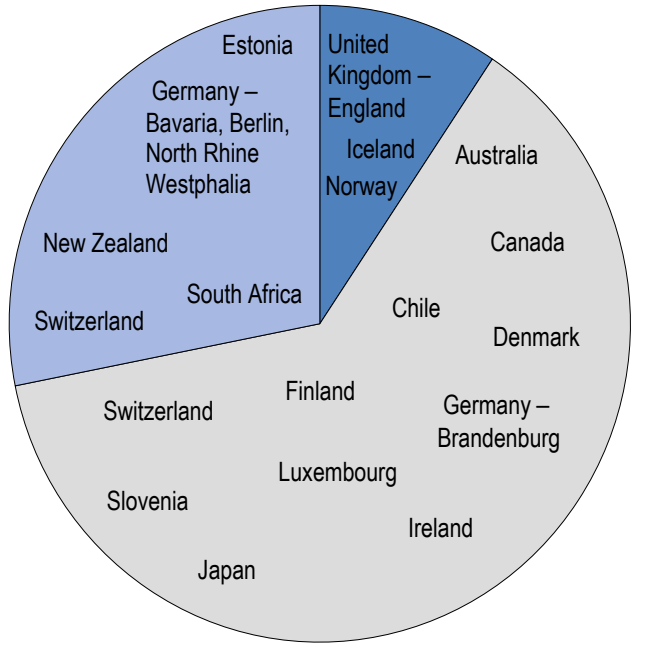

Notes: Countries and jurisdictions that have more than one curriculum framework providing different examples of practices (many, some, or no examples) can appear multiple times. In countries with multiple curriculum frameworks reported at the sub-national level, when curriculum frameworks provide different examples of practices (many, some, or no examples) across sub-national jurisdictions, only the name of the country is shown. When specified in different ways, the name of the jurisdiction is also indicated. Countries and sub-national jurisdictions that have multiple curricula can appear more than once. In these cases, the curriculum is identified by a reference number in parentheses (see Table A.A.1). Information on curriculum frameworks included for each country and jurisdiction and classification according to standardised age groups is provided in Annex A.

Source: OECD "Quality beyond Regulations" database.

StatLink त्राजी https://doi.org/10.1787/888934248939 
Providing many examples of pedagogical practices in curriculum frameworks does not necessarily translate into less autonomy for teachers. For example, in New Zealand, where the curriculum provides many examples of practices, the framework highlights that its role is to set the direction, but that it is up to teachers, along with families and communities, to implement the curriculum in a way that is appropriate for their setting and for children's learning needs.

\section{Learning from countries: Providing flexibility to ECEC staff through curriculum frameworks}

Curriculum frameworks can encourage staff to be flexible in adapting a curriculum's principles to their ECEC setting context and children's individual needs through relevant pedagogical practice.

For example, in Australia, ECEC staff are encouraged to use their expertise, knowledge and understanding of each child to propose activities and interactions that support them in achieving outcomes. Additionally, guidelines encourage ECEC staff to explore new ideas and approaches and to meet the needs of every child. The curriculum also provides examples of pedagogical practices, including responsiveness to children, learning through play, intentional teaching and cultural competence.

Likewise, the curriculum framework in Ireland provides information to support staff and leaders in adapting all curricular principles and themes to their settings' needs. It also promotes pedagogical practices that are emergent, play-based, a balance between group and individual learning, and a balance between being adult-initiated and child-initiated.

In Luxembourg, the objectives in curriculum frameworks are deliberately general, allowing ECEC settings to decide on the most relevant ways to implement them. Settings are free to develop their own activities and practices to implement the curricula in the way they consider appropriate to the local context and children's individual needs.

In Canada, too, across provinces, curriculum frameworks encourage staff to be responsive to children's contexts, interests and capabilities when implementing its principles. Curricula promote pedagogical practices such as intentional teaching, reflective practice, and observation and documentation.

In Finland, whereas the curriculum framework goals remain an orientation for ECEC pedagogy, ECEC staff are encouraged to apply pedagogical practices based on observation, documentation and ongoing development of the culture of the ECEC setting and every child's needs.

In Japan, curricula provide general standards, but it is up to each setting to formulate their pedagogical practices with a deep understanding of each child's needs and feelings. The curriculum promotes basic approaches, including comprehensive, play-centred instruction and instruction based on the individual characteristics of each child.

In Slovenia, the curriculum suggests possible content, activities and methods to achieve its goals. However, it allows ECEC staff autonomy to decide which, when and how to apply them according to their professional judgment, considering the characteristics of the children, their parents and the environment.

In Switzerland, ECEC staff can decide how to apply curriculum and teaching content, topics, tasks and materials to support children's different needs. However, the implementation of pre-primary settings' curriculum is the responsibility of cantons, which may require ECEC staff to use certain teaching materials and subjects. 


\section{The design and implementation of curriculum frameworks}

Curriculum frameworks go through several processes: design, implementation, and, over time, revisions. The design and reform processes include the definition of curriculum frameworks' goals and content, as well as planning and directions for the implementation stage, including training for ECEC leaders and staff on the new curriculum, materials for parents, availability of resources, etc. Curriculum frameworks design and reform processes vary in their characteristics; for example, they can involve different types and numbers of stakeholders, have more or fewer mechanisms for consultation at the design and reform stages and prescribe different strategies to ensure stakeholders' support at the implementation stage.

Designing a curriculum framework's goals and content can be a challenge due to the multiplicity of visions on curriculum among a variety of stakeholders, including policy makers, researchers, ECEC professionals, and parents and communities, in addition to including children's views. Furthermore, aligning curriculum goals and content with the future needs of society at large can be challenging, especially with rapid changes, such as increasing migration and advances in information and knowledge economies. In order to foster process quality in ECEC settings and support children's development, learning, and well-being, curriculum frameworks need to adapt to multiple stakeholder's needs as well as to global trends, local contexts and children's needs.

Another factor that may ensure that curriculum frameworks support process quality effectively is stakeholders' support for implementation, which can be achieved by involving them early in the design process. Curriculum implementation and reform need support from stakeholders, which can be built via sufficient and strategic consultation from the early design stage. Increased empirical investigation via comparative research establishing the definition of curriculum and pedagogy held by various ECEC stakeholders may also be helpful in the design and implementation of ECEC internationally (Edwards, forthcoming[9]).

Implementing a complex and rich curriculum successfully is linked to the quality of support for ECEC staff and to their training and qualifications, in particular their opportunities for professional development on relevant pedagogical practices (Sylva et al., 2016[10]). Preparing conditions for staff to implement a curriculum effectively is also important. Insufficient guidelines and resources are likely to enhance difficulties, especially for inexperienced, new staff or staff with lower qualifications. Other important factors include providing practical support materials to facilitate implementation in ECEC settings; setting out clear, informative guidelines for ECEC staff and parents; and providing expert assistance on curriculum frameworks to ECEC providers. Also, changes to curriculum may require ensuring alignment with ECEC staff initial education and training. Working environment factors, such as child-staff ratios and group size, as well as material conditions of ECEC centres, may also hinder or support practising the pedagogy suggested in the curriculum (Chapter 3 ).

\section{Stakeholder involvement in curriculum framework design}

Depending on the historical, political and cultural context, the design processes of a curriculum framework may have different characteristics and involve different actors.

The Quality beyond Regulations policy questionnaire asked participating countries and jurisdictions whether different categories of actors had been involved in the development of the most recent version of the curriculum framework, including the central government, ECEC staff, parents, children, community groups, representatives of ECEC training programmes and associations of ECEC professionals. 
Across age groups, central government ministries or agencies were unsurprisingly the most frequently included in the development of curriculum frameworks, followed by researchers, ECEC staff, associations of ECEC professionals, and representatives of ECEC pre-service training programmes (Figure 2.8). Parents and community groups were less frequently included $(52 \%, 30$ out of 56 curricula). The least commonly included category is children, with only $18 \%$ (10 out of 56 ) of curricula involving children in the design processes.

The countries and jurisdictions that involved children in developing their curriculum frameworks are: Belgium (Flanders, ages 0 to 2), Canada (Alberta and Saskatchewan, ages 0 to 2), Estonia, Finland, Ireland, New Zealand and Portugal. Ireland, for example, included children's views in the development process of their curriculum framework and is planning to do so again to inform the update process of the curriculum. In Belgium (Flanders), this was done through consultation with the children's rights commissioner, who represented children's views.

The percentage of the categories of stakeholders involved in the design of curriculum frameworks covering children aged 0 to 5 varies from 100\% (8 out of 8 ) in Estonia and Finland to $37 \%$ (3 out of 8 ) in Luxembourg and the United Kingdom (England) (Figure 2.9). Similar variations among countries are found for curriculum frameworks covering other age groups (see Figure C.2.2 and Figure C.2.3).

\section{Figure 2.8. Stakeholders involved in curriculum framework design}

Percentage of curricula that involved the following categories of stakeholders in the development of the most recent version, 2019

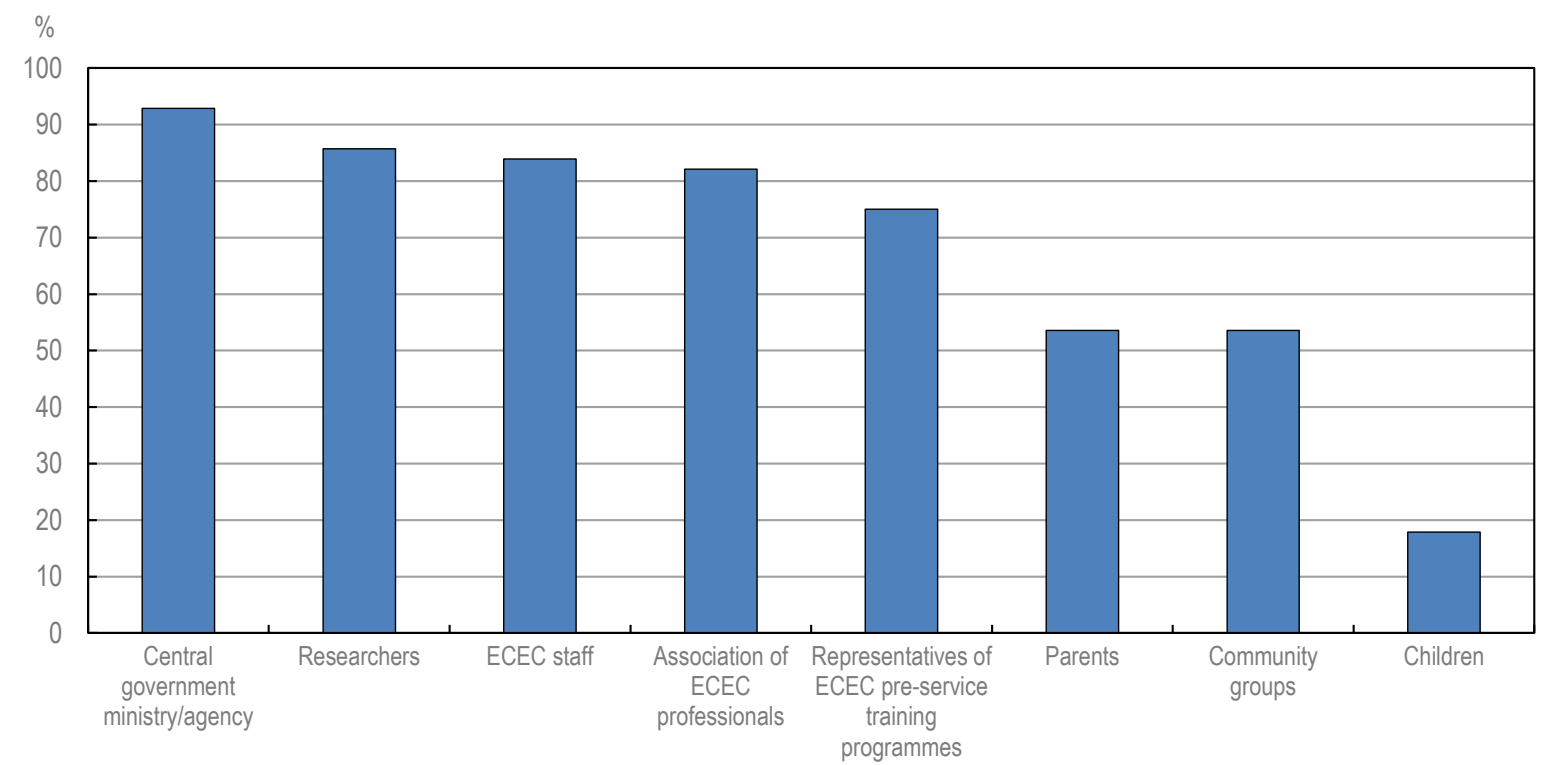

Note: Information on curriculum frameworks included for each country and jurisdiction and classification according to standardised age groups is provided in Annex A.

Source: OECD "Quality beyond Regulations" database. 
Figure 2.9. Scope of stakeholders' involvement in the design of curriculum frameworks covering ages 0 to 5

Percentage of categories of stakeholders (among the eight considered categories) involved in the most recent version of the curriculum framework, for curricula covering ages 0 to 5/entry to primary school, 2019

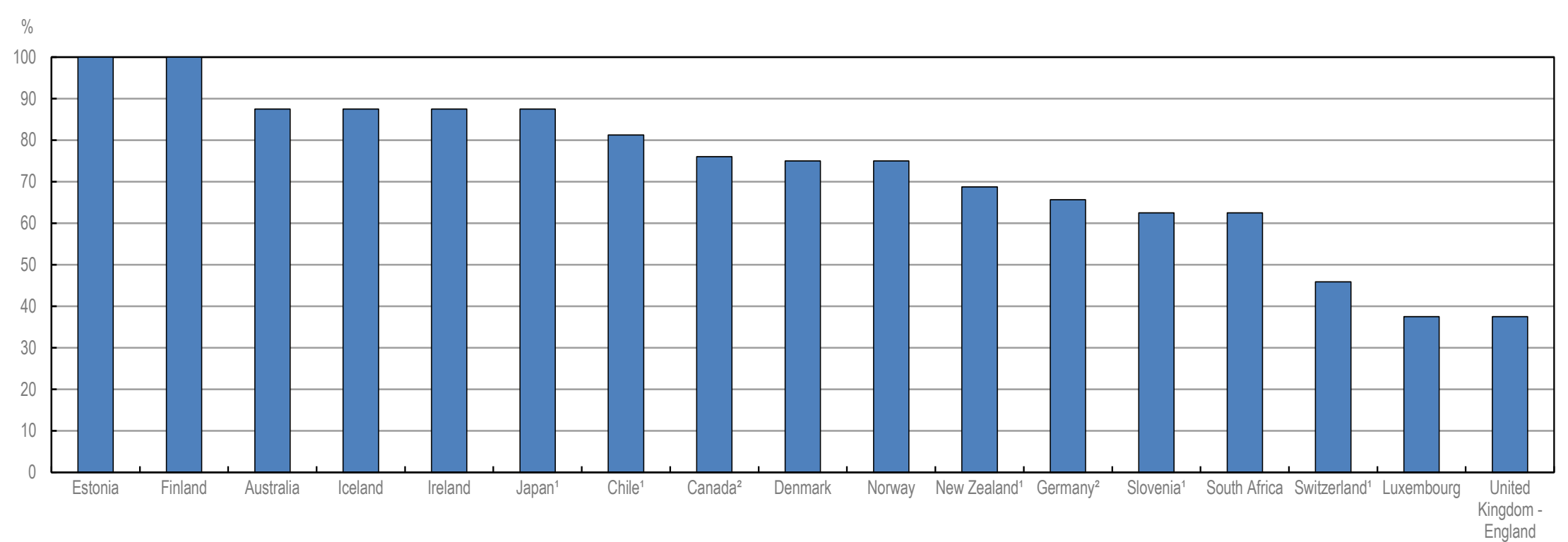

1. Chile, Japan, New Zealand, Slovenia and Switzerland have more than one curriculum covering the age group 0 to 5 . Thus, the values are the average of the percentages.

2. For Canada and Germany, the value is the average of all jurisdictions' values.

Note: Information on curriculum frameworks included for each country and jurisdiction and classification according to standardised age groups is provided in Annex A.

Source: OECD "Quality beyond Regulations" database. 


\section{Box 2.4. Consultation and collaborative approaches to the design and revision of curriculum frameworks}

In Australia, the curriculum frameworks were developed based on evidence of best practices for ECEC quality. This was done in collaboration between national, state and territory governments, with input from the ECEC sector. It was the result of a large consultation process that included national symposiums, national public consultation forums, consultation of focus groups, and an online forum and case-study trials.

Across Canada, all provinces have based the development of their curriculum framework on collaborative processes and broad consultations, particularly in Indigenous and multicultural communities. For example, in Yukon, consultation was held with First Nations communities across the territory. Governments, ECEC and curriculum experts, and advisory groups are some example of the actors that led the process of curriculum development in different provinces.

In Ireland, the development of the curriculum framework also took place on the basis of broad consultation, to ensure that the framework would be relevant to the everyday experiences of children and staff. In particular, a study was commissioned to collect information on children's interests and experience of ECEC, with the objective of incorporating their views in the design of the framework.

In Japan, the development process of the curriculum framework for pre-primary settings has involved discussions and reports by a council composed of experts. Besides the national government, several actors have been consulted, including ECEC staff associations, parents, community groups and representatives of ECEC pre-service training programmes.

In Luxembourg, a thematic conceptual framework for early language learning was developed under the oversight of a working group including experts and ECEC staff. A draft version of the framework had been discussed with hundreds of ECEC professionals. The design of the curriculum framework for the formal education sector in 2017 took place in a similar fashion.

In Switzerland, the curriculum that sets the main guidelines for ECEC resulted from a systematic consultation process with experts and ECEC practitioners. To design the framework, an ECEC training and research institute conducted a study with structured groups of experts, practitioners, researchers and policy makers.

\section{Supporting curriculum implementation}

Different policies and mechanisms exist to support and facilitate curriculum implementation. As mentioned in the sections above, providing practical support materials and setting out clear, informative guidelines for different audiences facilitates curriculum implementation in the ECEC context.

Among participating countries and jurisdictions, most curriculum frameworks include, or are accompanied by, guides for implementation. For most of the curriculum frameworks, the central government elaborates these guidelines (see Figure 2.10). 
Figure 2.10. Implementation guides or documents accompanying curriculum frameworks

Percentage of curriculum frameworks for which guidelines to support implementation are set by the central or local/regional government, by age group, 2019

Age 0 to 2

$\square$ Central $\square$ Local/regional $\square$ Not applicable

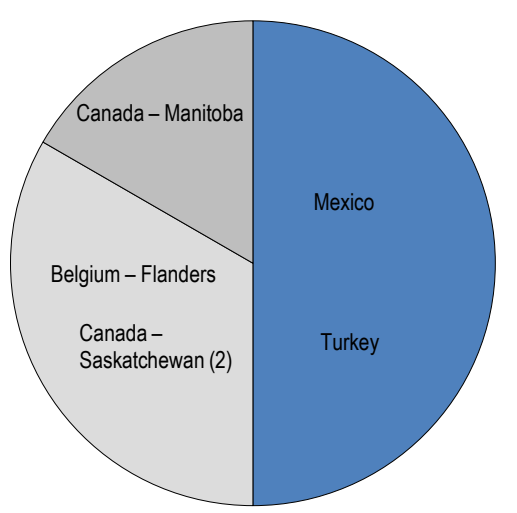

Age 3 to 5/primary school entry

$\square$ Central $\square$ Local/regional

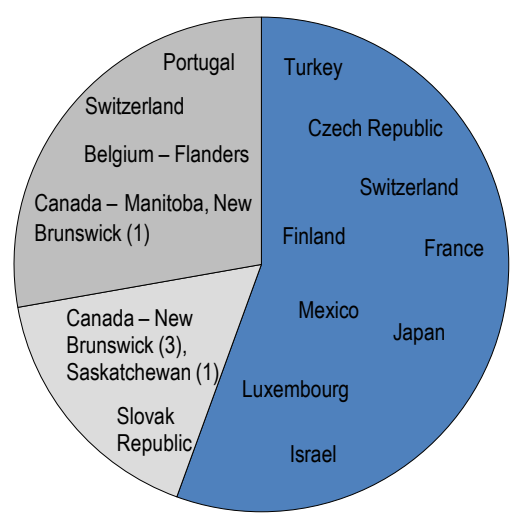

Integrated for age 0 to $5 /$ primary school entry

Notes: In countries with multiple curriculum frameworks reported at the sub-national level, when curriculum frameworks' guides for implementation are developed at the same level of government across sub-national jurisdictions, only the name of the country is shown. When specified in different ways, the name of the jurisdiction is also indicated. Countries and sub-national jurisdictions that have multiple curricula can appear more than once. In these cases, the curriculum is identified by a reference number in parentheses (see Table A.A.1). Information on curriculum frameworks included for each country and jurisdiction and classification according to standardised age groups is provided in Annex A.

"Not applicable" corresponds to countries/jurisdictions where there are no guidelines to support implementation in place.

Source: OECD "Quality beyond Regulations" database.

StatLink ज्ञाजम https://doi.org/10.1787/888934248996 


\section{Learning from countries: Supporting and facilitating curriculum implementation}

Luxembourg offers support to curriculum implementation by organising conferences on pedagogy and curriculum, as well as by distributing documentation, publications and posters on pedagogical topics free of charge. Support is also provided through Internet platforms that publish information on the ECEC system, as well as explanations, films and practical examples of different areas of the curricula.

Australia provides additional resources about curriculum decision making, the intended operation of the curriculum and expectations in terms of principles, practices and learning outcomes that ECEC services should meet. These resources are targeted to the ECEC sector, including ECEC staff, state and territory government, families and the community.

In Ireland, where the curriculum framework is accompanied by a quality framework for ECEC, several resources support ECEC staff and families in the understanding of the two frameworks. For example, a practice guide explains the two frameworks with supporting materials, which are available on line, including self-evaluation tools, examples of pedagogical strategies and ideas for planning, documenting, assessing and action planning.

ECEC settings are the audience most frequently targeted by curriculum framework guidelines provided by central governments, across all age groups in participating countries and jurisdictions, at almost $68 \%$ (Figure 2.11). Some $41 \%$ (23 out of 56 ) of curricula's guidelines are targeted at parents, and one-third of them are directed at supporting local governments in curriculum implementation. Only $12 \%$ (7 out of 56 ) of curricula includes guidelines directed at children; this is the case of Estonia, Germany (Berlin and North Rhine-Westphalia), Mexico, New Zealand, the Slovak Republic and Turkey. Another $11 \%$ ( 6 out of 56 ) of curricula is accompanied by material targeted to community groups and agencies, such as in Australia, Canada (New Brunswick), Estonia, Mexico and Turkey. 


\section{Figure 2.11. Audiences targeted by implementation guides or documents accompanying curriculum frameworks}

Percentage of curriculum frameworks where accompanying guidelines to support implementation provided by governments target the following audiences, 2019

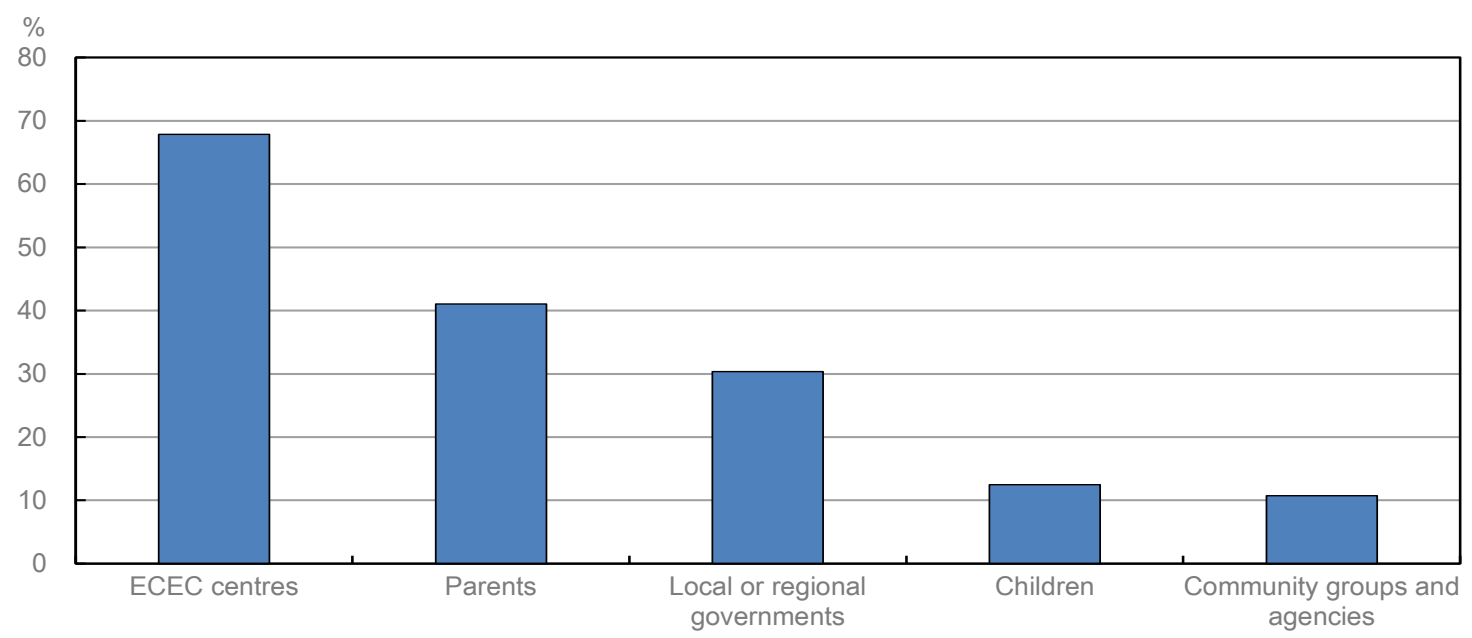

Note: Information on curriculum frameworks included for each country and jurisdiction and classification according to standardised age groups is provided in Annex $A$.

Source: OECD "Quality beyond Regulations" database.

StatLink 제 Sh https://doi.org/10.1787/888934249015

Designing resources that target community organisations can promote further involvement from these groups in supporting children's learning and well-being. For example, the United Kingdom (England) developed a campaign to support children's learning at home and through everyday activities in the community. The campaign aims at providing ideas to parents and community members to engage with children, e.g. while catching the bus or doing the shopping. Businesses are engaging in this initiative. For example, a bus company has included posters on the ceiling of some buses suggesting activities to do with young children, such as "chatting about what has happened so far in the day". In addition, frontline staff in shops are being trained to engage with children. The campaign also has a website with resources and organises book events, where free children's books are provided in places like bus stations or shops.

Apart from guidelines and documentation accompanying curricula, a highly qualified workforce is also a fundamental resource to ensure good curriculum implementation and appropriate pedagogical practices (Sylva et al., 2016[10]). For this, countries may implement different measures, including enhancing professional development and the role of ECEC leaders in fostering staff development and training (see Chapter 3). 
Learning from countries: Supporting ECEC staff in the implementation of curriculum frameworks

In Australia, pre-service training for ECEC staff includes the ECEC curriculum as a central element. Also, ECEC settings are required to designate an educational leader to develop and implement educational programmes. This includes building staff's educational capability through professional development. There are guidelines available to support leaders and providers in this mission.

In Ireland, different measures aimed at supporting alignment between curriculum and pedagogical practices have been put in place. These include plans to integrate the curriculum into staff initial education programmes, as well as on-site mentoring and training for staff and education-focused inspections.

In Luxembourg, in-service training for teachers is required to comply with the principles and pedagogical objectives of the national curriculum framework.

In Switzerland, too, the orientation framework and pre-primary school curricula offer guidance for leaders to create enabling conditions for high-quality pedagogical practices in their centres, taking into account teachers' needs.

\section{Engaging families and communities through curriculum frameworks}

Research shows that strong parental involvement in ECEC can improve children's reading and numeracy outcomes and have a positive impact on their behaviour and social and emotional skills, particularly for socio-economically disadvantaged children (Sim et al., 2019 $9_{[40]}$; OECD, 2020 ${ }_{[41]}$ ). In addition, supportive child-parent relationships generate healthy attachments and can positively affect children's understanding and regulation of emotions, as well as their feelings of security and taste for exploration and learning (OECD, 2015 ${ }_{[42]}$ ). The Programme for International Student Assessment (PISA) and many other studies show that children whose parents engage in activities such as reading, writing words, telling stories and singing songs not only tend to achieve better reading and numeracy skills as they age, but they are also more motivated to learn. There is also evidence that community engagement in ECEC can help ensure continuity in children's development beyond what is happening in ECEC settings and is therefore important for process quality (Weiss, Caspe and López, 2008[43]). In addition to promoting social cohesion, involving community actors and institutions in ECEC is important to create connections between families, ECEC settings and other services for children.

Curriculum frameworks can play a key role in recognising the importance of the engagement of parents and communities in ECEC and in specifying their role. The continuity between the ECEC centre and the home-learning environment is important for children's development, learning and well-being. Parents and families play a role in the implementation of curriculum frameworks by supporting children at home through practices and values that might be aligned (or not) with the goals of curriculum frameworks. Curricula written in a user-friendly format can facilitate the understanding of ECEC goals among the wider public and align practices in the ECEC and home-learning environments. Curriculum frameworks also provide guidance and strategies for the ECEC setting to communicate with parents, families and communities.

Across OECD countries, there is increasing recognition of the fundamental role of parents and communities in children's development and of the importance of integrating them in ECEC (OECD, 2015[7]; 2017[11]). To capture the extent to which parents are involved in ECEC, the Quality beyond Regulations policy questionnaire asked countries and jurisdictions whether curriculum frameworks support the involvement of families in different ways. 
Most curriculum frameworks in participating countries and jurisdictions include co-operation between ECEC settings and families and communities to support children's development as one of their goals (Figure 2.12). Most of them also suggest ways in which ECEC staff and leaders can engage with families, and around $80 \%$ of them discuss the role of families in children's development, learning and well-being. Some $80 \%$ of curricula also consider families as a core component of children's ECEC experience.

\section{Figure 2.12. Inclusion of families and communities in curriculum frameworks}

Percentage of curriculum frameworks that include families and communities in the following aspects of curriculum frameworks, 2019

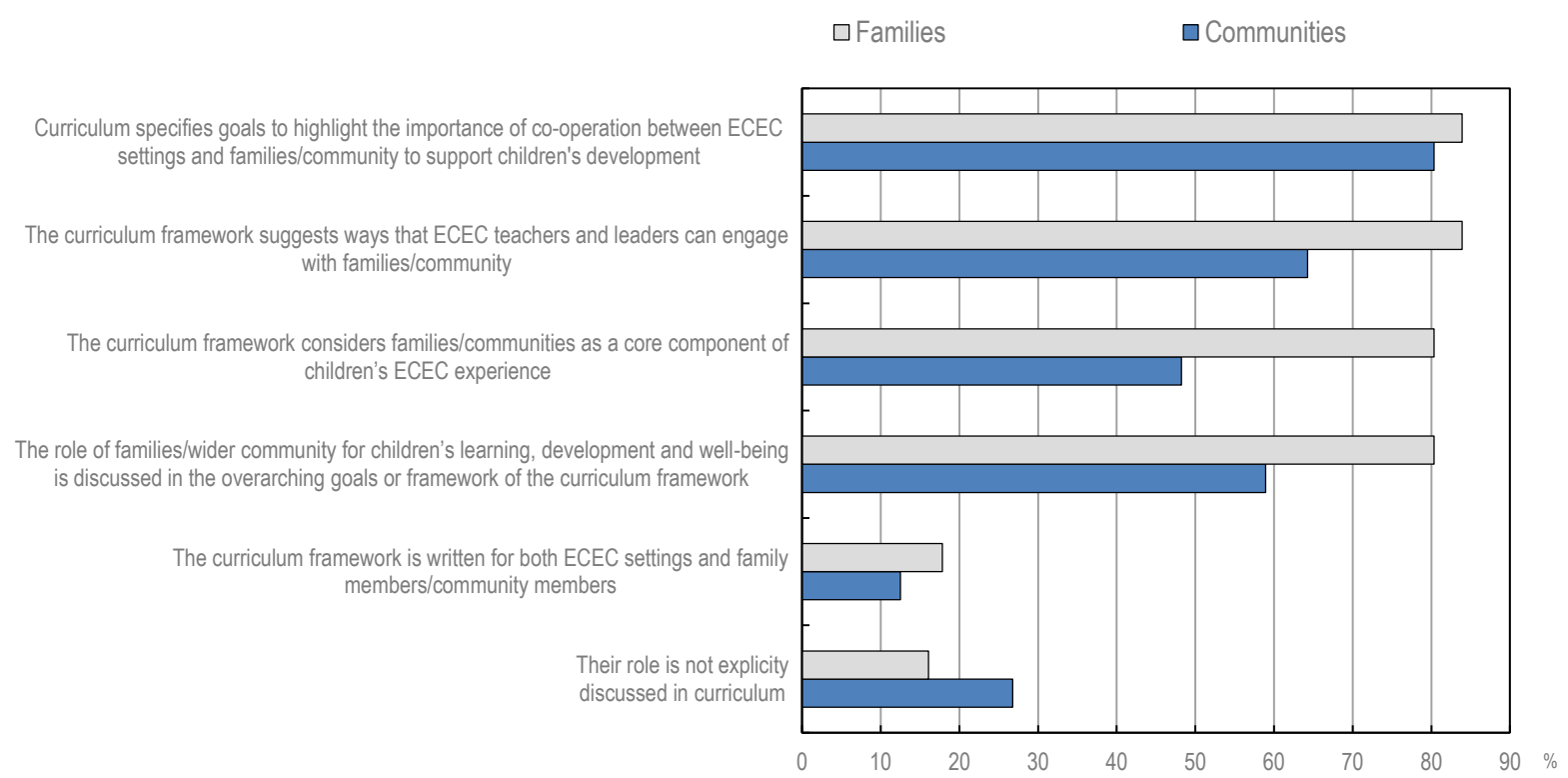

Note: Information on curriculum frameworks included for each country and jurisdiction and classification according to standardised age groups is provided in Annex $A$.

Source: OECD "Quality beyond Regulations" database.

StatLink त्ताIs https://doi.org/10.1787/888934249034

Findings from the OECD Starting Strong Teaching and Learning International Survey (TALIS Starting Strong) on nine participating countries found that the exchange of information between ECEC staff and parents was common, in line with the findings from this policy questionnaire (OECD, 2019[44]). However, they also pointed out that fewer ECEC staff encouraged parents to play and carry out learning activities at home with their children.

Still, $16 \%$ of curricula do not explicitly discuss the role of families. This is the case for curricula covering children aged 0 to 2 in Canada (Manitoba and Saskatchewan); children aged 3 to 5 in Belgium (Flanders), Canada (Manitoba and Saskatchewan), Israel, Luxembourg and Switzerland; and children aged 0 to 5 in the United Kingdom (England). Although the majority of curricula include families in different ways, only $19 \%$ are written for families.

Curriculum frameworks aim to engage communities in ECEC to a lesser extent than parents. Two-thirds of them suggest ways for ECEC staff and leaders to engage with the community. The role of communities in children's development, learning and well-being is discussed in less than two-thirds of curricula, and half of curricula consider communities as a core component of children's ECEC experience. Only 12\% of curricula are written for communities, and $27 \%$ of curricula do not explicitly discuss the role of communities. 
Learning from countries: Recognising the importance of guardians, parents and communities in curriculum frameworks

In Australia, the interconnectedness of children with family, community and culture is recognised throughout the curriculum frameworks, which encourage ECEC staff to support child-parent relationships and to provide opportunities for children to engage with their local community and environment.

In Luxembourg, too, the curricula encourage the collaboration of ECEC settings with parents and families, as well as networking with other formal institutions such as social, medical and therapeutic services, and emphasises that children's interactions with the cultural environment enrich their horizons.

In Canada, across provinces, all curriculum frameworks stress the need to establish co-operation between ECEC settings and parents. Some curricula emphasise the important role of the community (e.g. in Alberta and British Columbia, the frameworks encourages ECEC staff to foster interactions with elders and community leaders).

In Ireland, the curriculum framework highlights that parents are children's first educators and includes guidelines to support learning at home. These encourage staff to build partnerships with parents and foster continuity between the ECEC and home-learning environments.

In Japan, the curricula place great emphasis on the importance of children's interactions with the local community, and they encourage ECEC staff to foster their relationships with local nature spots, public facilities and also human resources, including the elderly, working people and local children of different ages.

In Switzerland, although curricula do not explicitly discuss the role of communities, they do encourage ECEC settings' co-operation with parents, and different initiatives are in place to foster such co-operation, including practical guidelines, traditional counselling services for parents and home visits, among others.

In addition to recognising the role of parents and communities, curriculum frameworks of several countries and jurisdictions include concrete guidance for ECEC staff to engage them in ECEC (Box 2.5). 


\section{Box 2.5. Guidance for ECEC staff to engage families and communities in ECEC}

In Australia, curricula encourage staff to plan their activities by working in partnership with families and involving them in decisions so as to better identify children's strengths and interests and choose appropriate teaching strategies. One strategy implemented as a result is to facilitate communication between staff and parents through several websites managed by national, state and territory governments. For example, one of these websites suggests to parents different practices that can be implemented at home to better support children's experiences, and provides resources that can be downloaded in six commonly used languages.

In Ireland, the guidelines accompanying the curriculum incites staff to organise information sessions for parents, including on curriculum content, and to invite parents to spend time in the setting and join in with activities. It also suggests ways in which ECEC staff can support continuity with the home-learning environment, for example, by informing parents about topics that interest their children; asking about their interests at home; and lending storybooks and tapes for children to take home. The curriculum also includes a set of guidelines for parents, with specific suggestions for them to spend time together with children at home, such as reading to children and enjoying books; having fun, playing, singing songs and telling stories; having conversations and encouraging children to ask questions.

In Japan, the curriculum framework for pre-primary education encourages ECEC staff to provide opportunities for information exchange and joint activities with children and their families in the ECEC setting. This is done by sharing with families details about children's experience and daily activities. The curriculum framework suggests that information exchanges can take place through regular parent-staff meetings but also on an informal basis during children's drop-off and pick-up. Other ways in which communication can take place is through correspondence notebooks or letters. The curriculum also encourages co-operation between ECEC and other community institutions.

\section{Monitoring and assessing the implementation of curriculum frameworks}

Monitoring and evaluating ECEC policies can be a powerful lever to ensure quality in ECEC. Monitoring helps determine whether curriculum frameworks are implemented as intended, fulfil their goals in practice and deliver expected outcomes. Continued assessment over time also helps determine a curriculum's effectiveness and relevance, as the objectives of ECEC may change and research may bring new findings to be taken into account in the design of curricula.

In most countries and jurisdictions, the existence of multiple settings and curricula may pose difficulties in the organisation of a system for monitoring curriculum implementation. At the same time, it makes the monitoring of curriculum implementation even more important to ensure high-quality ECEC uniformly across settings and age groups. When responsibilities for monitoring are shared across different agencies and/or levels of governance, good co-ordination is crucial to enhance an efficient monitoring system that does not overburden ECEC settings. Another important element in this sense is to design plans for inspections depending on the level of need of providers. This approach allows for better use of resources than regular monitoring cycles, but it requires that monitoring systems have access to information on the quality of ECEC settings from a variety of sources. Co-ordination is essential to build capacity at the policy level for conducting evaluations, collecting valid information and data, and developing assessment procedures that are both efficient and informative (OECD, 2011 $\left.{ }_{[4]}\right)$. 
Curriculum implementation is most commonly monitored as part of the monitoring of ECEC staff. This includes assessing staff's pedagogical practices, their approaches in interpreting curricula, and their capacity to adapt it to children's specific needs and the everyday reality of the local context. For monitoring to be effective in informing policy and practice, it is necessary to design and use the assessment with the objectives of reflection and improvement. In practice, this means providing ECEC settings and staff with feedback and support on how to use monitoring results for their development (OECD, 2018 $\left.{ }_{[1]}\right)$. Monitoring systems need to be closely linked to quality support systems to provide staff with professional development opportunities that train them in implementing the curriculum. Also, making monitoring results available to the public is particularly important to involve a multiplicity of stakeholders in the monitoring process, increase the objectivity and transparency of the assessment, stimulate parent and community engagement and increase parental satisfaction.

Curriculum implementation needs to be monitored for all age groups and types of settings, including children aged 0 to 2 and home-based settings. The scope of monitoring also needs to concern all aspects of process quality, including interactions between staff-child, child-child, child-materials, staff-parents and child-parents. Some studies have found that monitoring may inadvertently direct ECEC staff's attention towards only the dimensions of curricula being assessed (Denny, Hallam and Homer, 2012[29]). Adapting monitoring instruments to match curriculum framework goals and learning areas may ensure that all relevant aspects are monitored and that the results are useful to inform policy and practice.

Monitoring can be external when led by an external institution or internal when conducted by the ECEC setting or staff themselves. While these two types of monitoring might have different purposes and general methods, they can also share common tools, as internal monitoring tools are often used for external monitoring procedures. For instance, staff self-assessment practices can be part of a larger monitoring procedure conducted by an external institution (OECD, 2015[45]). Since the characteristics of internal monitoring are very diverse across participating countries and jurisdictions, and they often depend on the decisions of each ECEC setting, this chapter focuses only on external monitoring of curriculum implementation.

In participating countries and jurisdictions, external monitoring of curriculum implementation is mandatory for two-thirds of curriculum frameworks for ages 0 to 5 and for half of those for ages 0 to 3 , but it is less commonly mandatory for those for ages 0 to 2 (Figure 2.13). 
Figure 2.13. Mandatory external monitoring of curriculum framework implementation

Percentage of curriculum frameworks for which external monitoring of curriculum implementation is mandatory, by age group, 2019

Age 0 to 2

$\square$ Yes $\square$ No

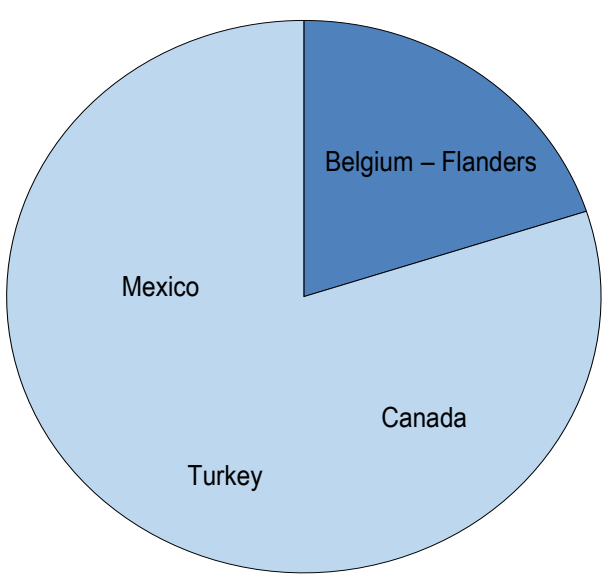

Age 3 to 5/primary school entry

$\square$ Yes $\square$ No

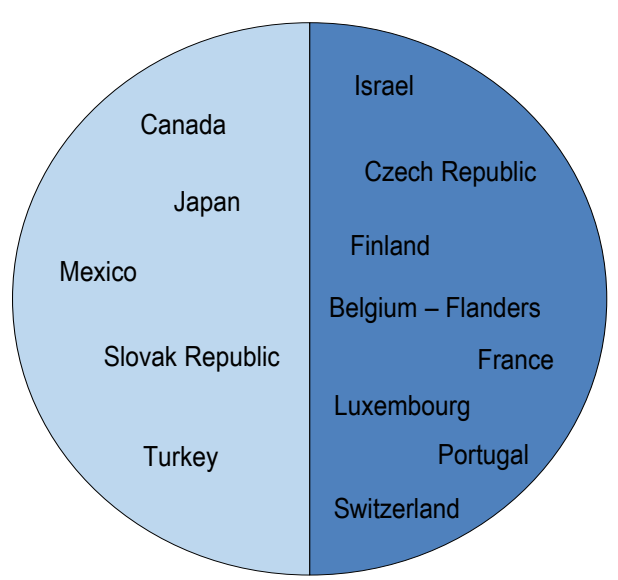

Integrated for age 0 to 5/primary school entry

$\square$ Yes $\square$ No

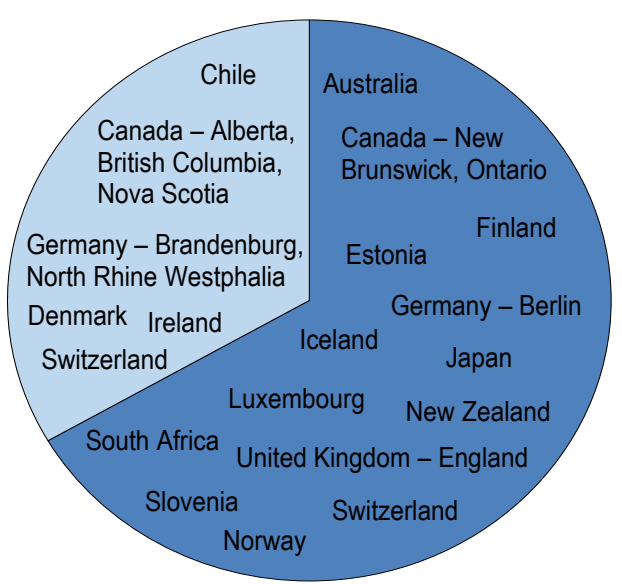

Notes: In countries with multiple curriculum frameworks reported at the sub-national level, when curriculum frameworks have the same legal status (mandatory or not) across sub-national jurisdictions, only the name of the country is shown. When the legal status is specified in different ways across jurisdictions, the name of the jurisdiction is also indicated. Information on curriculum frameworks included for each country and jurisdiction and classification according to standardised age groups is provided in Annex A.

For Germany (Bavaria), this indicator is not applicable.

Source: OECD "Quality beyond Regulations" database. 
The central level is more frequently responsible for monitoring in curricula for ages 0 to 5 and 3 to 5 (Figure 2.14). The regional/sub-regional and the local level are responsible for one-third of curricula for ages 0 to 5 and one-fifth of those for 3 to 5 .

In some cases, the responsibility for external monitoring is placed at the ECEC setting level. This is more common in curricula for ages 3 to 5 than in curricula for ages 0 to 5 . The responsibility for external monitoring of curriculum implementation is shared across multiple levels only in two countries: Chile and Luxembourg.

External monitoring of curriculum framework implementation is conducted at least once a year in $37 \%$ of curricula for ages 0 to $5,39 \%$ of those for ages 3 to 5 , and $33 \%$ of those for 0 to 2 (Figure 2.15). In $21 \%$ of curriculum frameworks for ages 0 to 3 and in $28 \%$ for ages 0 to 5 , external monitoring is conducted depending on the results of the last monitoring. For instance, this is the case in Australia, where the frequency of assessment is dependent on the results of the previous assessment and the risk profile of the setting, among other factors. A smaller percentage of curricula is monitored externally less than once a year; this is the case for all curricula in Belgium (Flanders), as well as in Denmark, Germany (Berlin), Ireland and Slovenia for curricula for ages 0 to 5 . In Slovenia, regular inspections take place every five years, but extraordinary inspections are also conducted in some settings based on the initiative of parents, ECEC leaders, staff and staff unions, as well as on anonymous requests.

\section{Figure 2.14. Responsibility for monitoring the implementation of curriculum frameworks}

Percentage of curriculum frameworks monitored by the following levels of authority, by age group, 2019

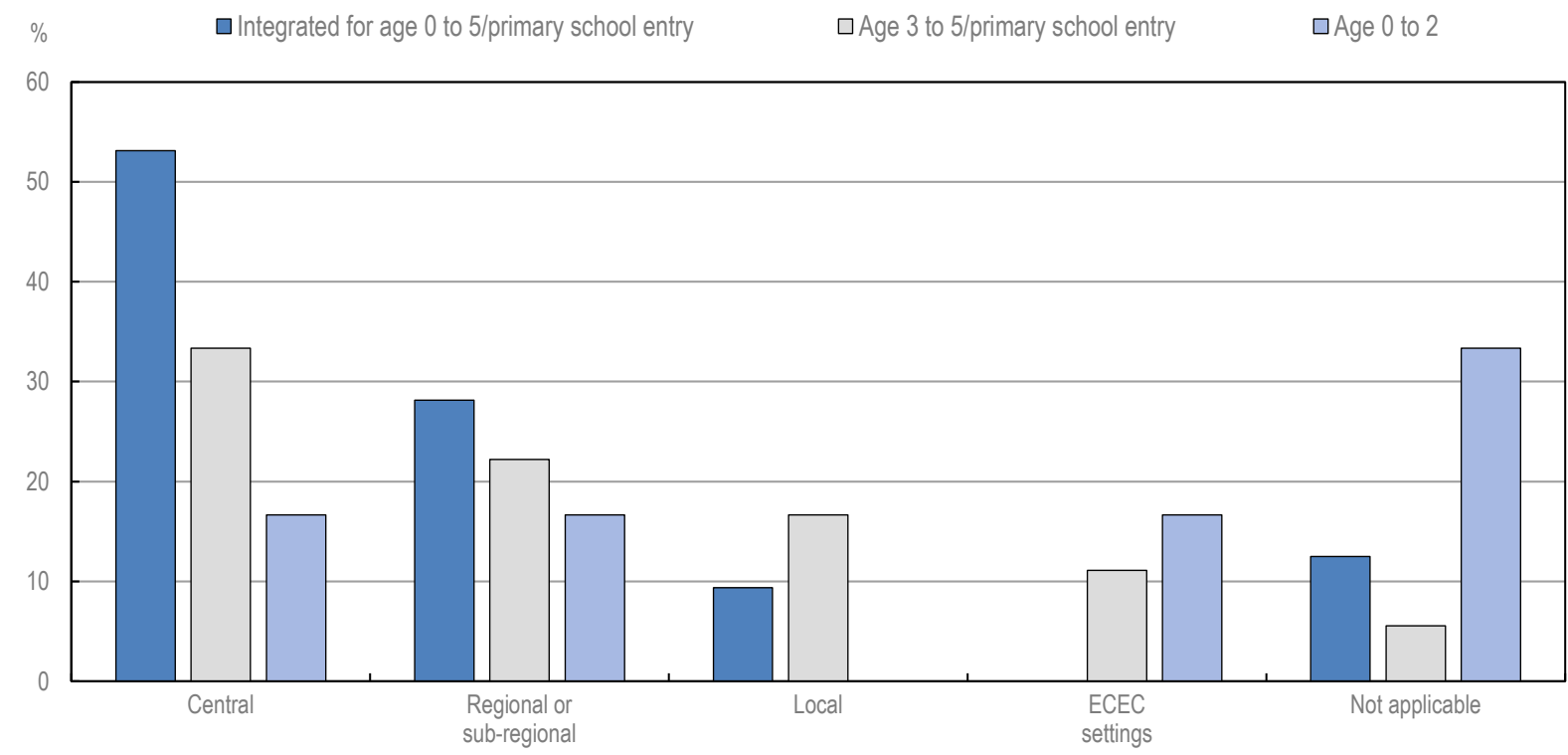

Note: "Not applicable" refers to countries and jurisdictions where there is no requirement for external monitoring of curriculum implementation. Information on curriculum frameworks included for each country and jurisdiction and classification according to standardised age groups is provided in Annex A.

Source: OECD "Quality beyond Regulations" database. 
Figure 2.15. Frequency of external monitoring of the curriculum framework implementation

Percentage of curriculum frameworks for which implementation is monitored in the following frequencies, by age group, 2019

$\square$ At least once a year $\square$ Less than once a year $\square$ Depends on last monitoring results $\square$ Not applicable
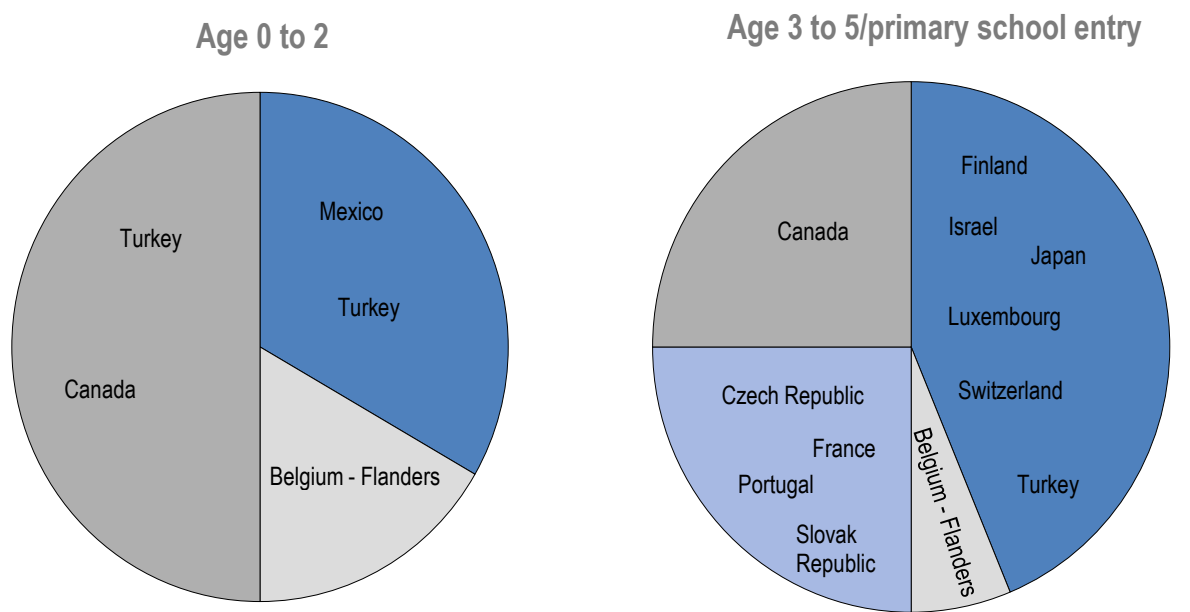

Integrated for age 0 to 5/primary school entry

Notes: "Not applicable" refers to countries and jurisdictions where there is no requirement for external monitoring of curriculum implementation. In countries with multiple curriculum frameworks reported at the sub-national level, when curriculum frameworks are monitored in the same frequency across sub-national jurisdictions, only the name of the country is shown. When specified in different ways, the name of the jurisdiction is also indicated. Information on curriculum frameworks included for each country and jurisdiction and classification according to standardised age groups is provided in Annex A.

Source: OECD "Quality beyond Regulations" database.

StatLink ज्ञाजम https://doi.org/10.1787/888934249091 
Inspections are the most common method for external monitoring of curriculum implementation in participating countries and jurisdictions $(65 \%, 37$ out of 56 curricula) (Figure 2.16). A smaller percentage of curricula is monitored externally through staff self-assessment/evaluation (44\%, 25 out of 56). For instance, in New Zealand, ECEC staff are asked to complete a self-report (self-evaluation) at the beginning of the external monitoring process. This instance is an opportunity for staff to share with the monitoring institution their perception of their own effectiveness in the key aspects being evaluated.

Other countries and jurisdictions use surveys and portfolios (collections of pieces of work that provide information on child or staff achievement in given areas) as a method. In Canada (New Brunswick), portfolios serve to document ECEC staff's reflections and pedagogical learning journeys. In France, too, portfolios are used during evaluation and inspections of ECEC settings. In Finland, surveys constitute the main source of data for the external evaluation of curriculum implementation. Only a small percentage of curricula are monitored through peer review and child assessments. In New Zealand, for instance, child assessments are conducted following the principles and strands of the curriculum framework. No participating countries or jurisdictions conduct staff tests to monitor curriculum implementation.

\section{Figure 2.16. Methods for external monitoring of curriculum frameworks' implementation}

Percentage of curriculum frameworks for which implementation is monitored using the following methods, 2019

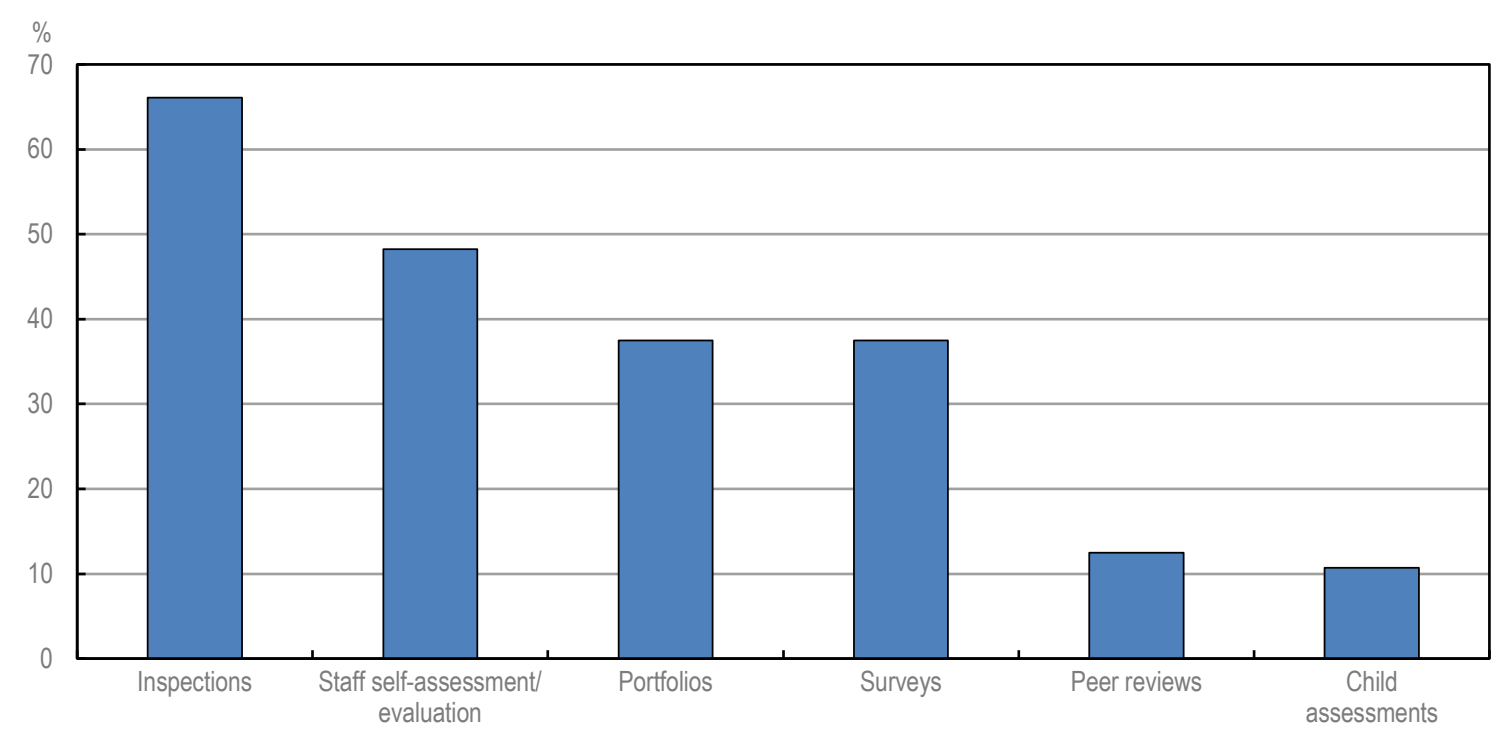

Note: Information on curriculum frameworks included for each country and jurisdiction and classification according to standardised age groups is provided in Annex $A$.

Source: OECD "Quality beyond Regulations" database.

Across OECD countries, initiatives exist to enhance monitoring systems to better assess curriculum implementation. In Belgium (Flanders), for example, three monitoring instruments were developed in alignment with the content of the curriculum framework for children aged 0 to 2: one to measure process quality in a representative sample of all home-based settings in Flanders; another for monitoring process quality in each home-based setting, used by inspectors; and a self-assessment tool to be used by ECEC staff in individual settings. These instruments are part of a wider initiative to measure and monitor quality in home-based settings, which was developed by a wide range of stakeholders, including experts from universities. Developing monitoring tools specially designed for monitoring curriculum implementation can enhance process quality in ECEC (see Box 2.6) 


\section{Box 2.6. Developing monitoring tools for curriculum frameworks' implementation and process quality}

In Australia, external monitoring and inspection occur through an assessment and rating of ECEC settings' quality against the standards of the quality framework accompanying the curriculum. Curriculum implementation is one of the areas of the quality framework. The evaluation visits determine whether and to what extent the settings meet the underpinning requirements. Following the evaluation, ECEC settings receive a report, after which the ratings are published and available to families. Areas of process quality that are evaluated include staff-child and child-child relationships, as well as staff pedagogical practices.

All provinces across Canada monitor the implementation of their curriculum frameworks. Some provinces developed monitoring tools that are aligned with concepts from their own curricula. Continuous quality improvement processes are also in place in some provinces. For example, Nova Scotia has an initiative in place that evaluates ECEC settings' compliance with regulations and the quality of the programme, including implementation of the curriculum framework and different areas of process quality. This process takes place through the completion of a self-assessment tool and the development of a quality improvement plan by the centre. In Quebec, the evaluation of process quality takes place through the CLASS assessment tool, along with interviews for setting leaders and staff as well as questionnaires for parents. Monitored areas include interactions between staff and children, as well as between staff, staff and parents; the nature and variety of the activities offered to children; and the physical structure and materials that surround them.

In the non-formal education sector in Luxembourg, process quality is monitored at least twice a year in ECEC settings that receive public funding. These providers are required to incorporate measures to support process quality in their programmes in line with the national curriculum framework. External monitoring checks that the pedagogical practices, in-service training for staff and the general quality of service align with the curriculum. The areas of process quality monitored in most settings include the implementation of the curriculum, the use of learning and play materials and the implementation of the educational principles of inclusion and multilingualism.

The Quality beyond Regulations policy questionnaire asked countries and jurisdictions to indicate the types of interactions included in the monitoring of the implementation of the curriculum framework. Although all types of interactions are stressed in curriculum frameworks across countries and jurisdictions, not all of these interactions, which all matter for children's experiences in ECEC, are monitored equally (Figure 2.17). Although interactions between staff and children are monitored in the majority of curricula $(60 \%, 34$ out of 56$)$, less than one-half targets interactions among children and between children and materials, which are of fundamental importance for children's development. Further, even though most curricula recognise the importance of engaging parents and families in ECEC, only $37 \%$ monitors interactions between ECEC staff and parents. The least monitored interactions across participating countries and jurisdictions are between children and parents, and children and communities. Although these relationships occur outside of ECEC settings, they are a core element for educational continuity across ECEC and the home-learning environment. These results may indicate that countries and jurisdictions' monitoring frameworks are not always aligned with curriculum frameworks regarding the importance given to quality in all types of interactions. Monitoring frameworks, through their evaluation standards, as well as methods and tools, may be promoting the evaluation of certain types of interactions more than others.

Related to these findings, TALIS Starting Strong 2018 asked ECEC centre leaders about the frequency and content of inspections and showed that monitoring activities tend to focus more on assessing the 
facilities and financial situation of centres than on process quality (OECD, 2019[44]). Overall, both sources of findings suggest that monitoring should place more focus on process quality and the full range of interactions included in curriculum frameworks. Monitoring these interactions can provide valuable knowledge to inform ECEC policies and practices to support children's experiences.

\section{Figure 2.17. Interactions monitored in external monitoring of curriculum frameworks' implementation}

Percentage of curriculum frameworks for which the following interactions are monitored, 2019

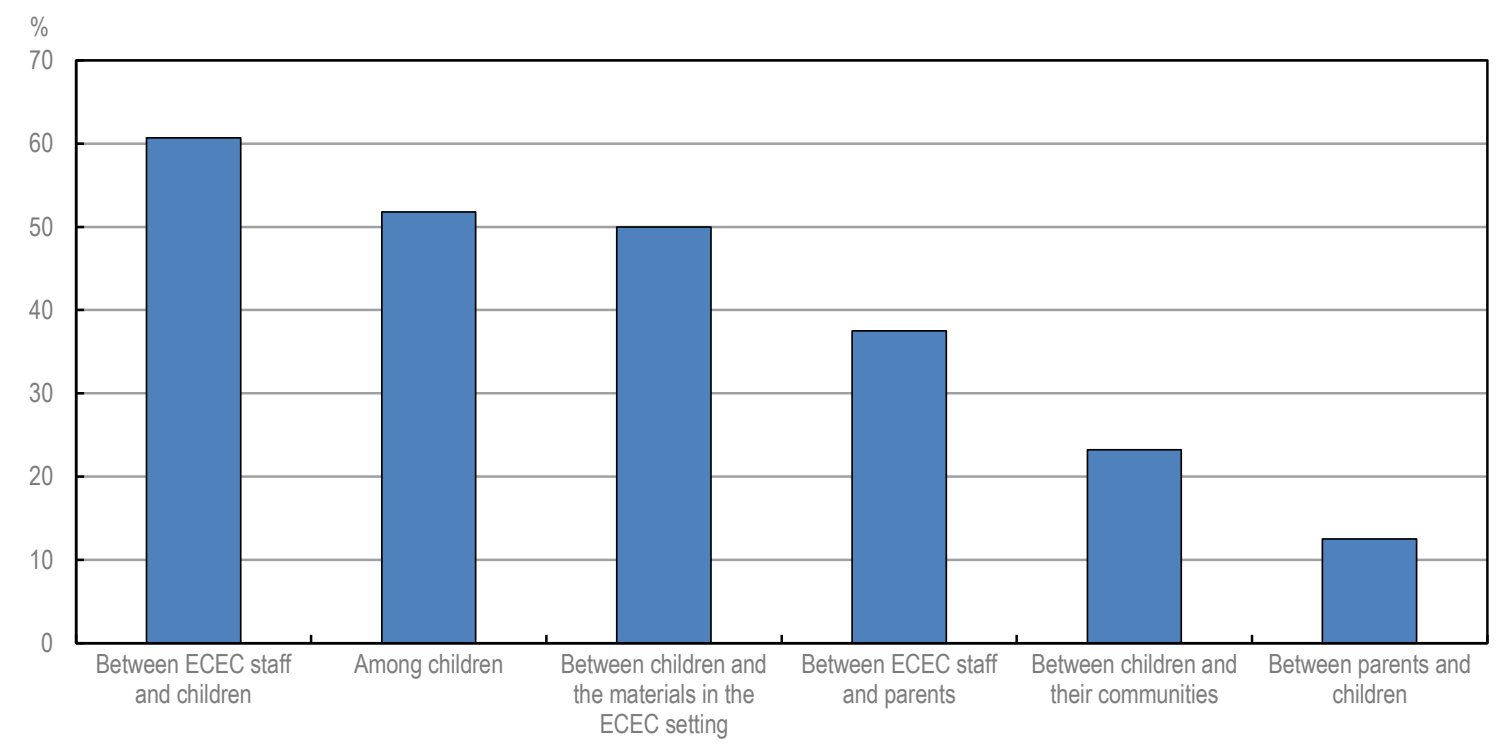

Note: Information on curriculum frameworks included for each country and jurisdiction and classification according to standardised age groups is provided in Annex $A$.

Source: OECD "Quality beyond Regulations" database.

StatLink 세피 https://doi.org/10.1787/888934249129

\section{Learning from countries: Actions following curriculum implementation monitoring}

In almost all participating countries and jurisdictions, the results of curriculum implementation monitoring are provided through reports, which are sent to the ECEC setting. In some cases, these reports are also made available to parents and the wider public. For example, in Turkey, the reports are shared with ECEC settings and the relevant province, district, and school administrations. In Iceland, the results are published on line for public access. In other countries, interviews or feedback sessions with the ECEC setting are common. This is the case, for example, of Germany (Berlin and Brandenburg) and Israel.

Following the monitoring process, some countries and jurisdictions provide recommendations for quality improvement that ECEC settings are expected to follow. In Australia, ECEC settings are required to have a quality improvement plan, which includes self-assessment against the monitoring framework standards and identifies areas for improvement. In the Czech Republic, monitoring reports provide an overview of the ECEC setting's strengths and weaknesses, as well as recommendations for improvement. In Iceland, ECEC settings are required to design a reform plan and to report to the ministry on the reform process. In New Zealand, a report provides recommendations to both the ECEC setting and the ministry, which are both expected to take into consideration. 
Some countries' and jurisdictions' monitoring systems track that the recommendations provided are taken into account by the ECEC settings, and that actions for quality improvement are put in place. This is usually done through follow-up visits to check the improvements made by ECEC settings, as happens in Belgium (Flanders, in settings for children aged 0 to 2 years); Estonia, Portugal and the Slovak Republic, among others. In some cases, ECEC settings are given a specific timeframe to address the issues identified during inspections. This is the case, for example, in Canada (Ontario) and Slovenia. ECEC setting leaders and staff are expected to design and implement adjustments to their pedagogical practices. The quality improvement of the setting is evaluated at a future inspection.

Some countries also provide quality support following the monitoring of curriculum frameworks. In South Africa, the type of support provided stems from the analysis of the monitoring results report. In France, this includes visits from pedagogical counsellors to the ECEC settings, the organisation of professional development activities for ECEC staff and the provision of guidance and support. In Switzerland, a national committee provides supplementary materials and organises conferences for ECEC staff.

\section{Policy pointers}

This section provides policy pointers for countries to support process quality through curriculum frameworks and identifies strategies that build on the information presented in this chapter.

\section{Ensure children's holistic development through curriculum frameworks that are adapted to children's stages of development}

A significant percentage of countries and jurisdictions do not have a common curriculum framework for all children aged 0 to 5 . Where split curricula for different age groups are in place, aligning curriculum framework's principles, goals and pedagogical approaches across them can help ensure that an integrated approach to ECEC is taken. In particular, curricula for children aged 3 to 5 rely more strongly on traditional learning areas, in preparation for children's entry to primary school. Also, while pedagogical approaches based on a social-pedagogical tradition are present more frequently in curricula for children aged 0 to 2 and 0 to 5 , curricula for children aged 3 to 5 seem to more commonly build on approaches based on readiness for school, outcome/performance-based education and didactic/direct instruction. The risk of "schoolification" in this age group could be avoided by setting broad developmental goals and by promoting balanced, dynamic and flexible pedagogical approaches that allow ECEC staff to support children in developing their cognitive skills, in addition to socio-emotional, physical, practical and meta-cognitive skills. This requires the articulation of strategies for facilitating play, exploration and opportunities for interactions. Curricula aimed at children aged 0 to 5 also need to consider children's specific developmental needs at every age to ensure quality ECEC for all children.

In countries where only curricula for children aged 3 to 5 are in place, expanding coverage to children aged 0 to 2 in all settings, including home-based, is crucial to ensure quality ECEC for the youngest. Curricula for this age group recognise the foundational learning that occurs in ECEC settings during this developmental period and provides strategies to guide staff in intentionally supporting children's exploration and engagement with others and with their environments. Providing guidance for transitions can also ensure continuity in children's experiences across levels and settings.

\section{Support ECEC staff in implementing curriculum frameworks through pedagogical practices}

ECEC staff play a crucial role in translating curriculum frameworks principles into practice. Some countries and jurisdictions face difficulties in ensuring that all staff apply some of these principles, such as adopting 
a holistic, child-centred vision of the child and incorporating play, in practice. This is the case, for example, in Ireland, Japan, and the Netherlands, among others. Additional complexities arise for ECEC staff and leaders in applying curricula when multiple frameworks exist for the same settings or age groups, as is the case in a quarter of countries and jurisdictions.

Initial education and continued professional development are crucial levers to ensure that ECEC staff are prepared to apply curriculum frameworks. Ireland, for example, has implemented measures in this sense. Also, providing guidelines and resources for staff, as well as including examples of pedagogical practices in curricula, can help staff understand the principles and aims of the curricula. These can illustrate how abstract ideas may look in practice and what types of behaviours to look for in children to successfully adapt activities to children's needs and emerging abilities. These examples should not be prescriptive but an orientation, giving ECEC staff the flexibility to adapt the curriculum responding to children's needs and the specific characteristics of the local context. This is the case, for example, in New Zealand.

\section{Make the most of curriculum frameworks to further engage families and communities in ECEC}

Most curricula across age groups discuss the importance of co-operation between ECEC settings and families and provide guidance for staff to engage with them, although the percentage is smaller regarding communities. In a small percentage of countries and jurisdictions, still, the role of families and communities are not explicitly discussed. Further developing curricula's guidance and resources, as well as enhancing professional preparedness, is fundamental to ensure that ECEC staff understand the importance of involving parents and communities in ECEC, and that they can effectively promote opportunities for interaction and communication with them.

Involving parents and communities in curriculum design and implementation can also help ensure that curriculum frameworks reflect children's social and cultural backgrounds. Including children themselves is also crucial to design curriculum frameworks that reflect children's experiences, interests and needs. However, only half of countries and jurisdictions involve families and communities in the design process of curriculum frameworks, and very few of them include children. Also, only $40 \%$ of guidelines to support curriculum implementation are addressed to parents, and very few to community groups and agencies. Developing materials to disseminate to community organisations can help build continuity between ECEC settings and children's experiences elsewhere.

\section{Enhance the monitoring of curriculum framework implementation, in particular regarding interactions in ECEC settings}

Countries and jurisdictions need a broad range of tools to monitor the implementation of the principles and goals of their curriculum frameworks across ages and settings, including in home-based settings. These tools can include inspection visits, the establishment of learning communities for ECEC settings to monitor and learn from one another, self-assessment, as well as collecting feedback from key stakeholders such as centre leaders, staff, families and children. To enhance the efficiency of monitoring, these various tools can be used at different time intervals to support continuous quality improvement even between major inspection visits. In countries and jurisdictions where external monitoring is conducted at least once a year, it would be informative to reflect on the potential gains in efficiency of approaches based on the level of risk of the settings, while maintaining clear commitments to ensuring process quality in all settings.

Special focus should be placed on the monitoring of the actual child's experience, which includes all interactions that take place in the ECEC setting. Although most participating jurisdictions recognise the importance of process quality in their frameworks, they monitor some types of interactions more than others. Less than half of countries and jurisdictions monitor interactions among children and between children and, and only $37 \%$ monitors interactions between ECEC staff and parents. The least monitored 
interactions are those between children and parents, and children and communities. Although these relationships occur outside of the ECEC settings, they are a core element for curricular and overall educational continuity across the ECEC and home-learning environments. In order to enhance the quality of interactions in practice, it can be helpful to design monitoring frameworks in alignment with curriculum frameworks, and to provide support to inspectors and ECEC staff in the use of diverse monitoring methods and tools, which can be adapted to the measurement of all types of interactions.

\section{References}

Admas, F. (2019), "Quality of early childhood education in private and government preschools of Addis Ababa, Ethiopia", International Journal of Early Childhood, Vol. 51/2, pp. 163-176, http://dx.doi.org/10.1007/s13158-019-00248-1.

Arnett, J. (1989), Caregiver Instruction Scale, Educational Testing Service, NJ.

Blaiklock, K. (2010), "Te Whāriki, the New Zealand early childhood curriculum: Is it effective?", International Journal of Early Years Education, Vol. 18/3, pp. 201-212.

Bowman, B., M. Donovan and M. Burns (2000), Eager to Learn: Educating our Preschoolers, National Academies Press, Washington, DC, https://doi.org/10.17226/9745.

Broadhead, P. (2018), Supporting the Application of Playful Learning and Playful Pedagogies in the Early Years Curriculum Through Observation, Interpretation, and Reflection, Springer, Dordrecht.

Bronfenbrenner, U. and P. Morris (2006), "The bioecological model of human development", in Lerner, R. and W. Damon (eds.), Handbook of Child Psychology: Theoretical models of human development, Hoboken NJ.

Broström, S. (2017), "A dynamic learning concept in early years' education: A possible way to prevent schoolification”, International Journal of Early Years Education, Vol. 25/1, pp. 3-15, https://doi.org/10.1080/09669760.2016.1270196.

Burchinal, M. (2018), "Measuring early care and education quality", Child Development Perspectives, Vol. 12/1, pp. 3-9, https://doi.org/10.1111/cdep.12260.

Clark, A., S. Mcquail and P. Moss (2003), Exploring the Field of Listening to and Consulting with Young Children RESEARCH, http://www.ness.bbk.ac.uk/support/GuidanceReports/documents/172.pdf (accessed on 18 May 2021).

Denny, J., R. Hallam and K. Homer (2012), "A multi-instrument examination of preschool classroom quality and the relationship between program, classroom, and teacher characteristics", Early Education and Development, Vol. 23/5, pp. 678-696, https://doi.org/10.1080/10409289.2011.588041.

Edwards, S. (forthcoming), "Process quality, curriculum and pedagogy in early childhood education and care”, OECD Education Working Papers, OECD Publishing, Paris.

Escayg, K. and Z. Kinkead-Clark (2018), "Mapping the Contours of Caribbean Early Childhood Education”, Global Education Review, Vol. 5/4, pp. 236-253. 
European Commission Working Group (2014), Proposal for key principles of a Quality Framework for Early Childhood Education and Care, Report of the Working Group on Early Childhood Education and Care under the auspices of the European Commission, https://ec.europa.eu/assets/eac/education/policy/strategicframework/archive/documents/ecec-quality-framework en.pdf.

Hedges, H. and J. Cullen (2005), "Subject knowledge in early childhood curriculum and pedagogy: Beliefs and practices", Contemporary Issues in Early Childhood, Vol. 6/1, pp. 6679, https://doi.org/10.2304\%2Fciec.2005.6.1.10.

Jenkins, J. and G. Duncan (2017), "Do pre-kindergarten curricula matter?", in Phillips, D., K. Dodge and Pre-Kindergarten Task Force (eds.), The Current State of Scientific Knowledge on Pre-kindergarten Effects, Brookings Institution and Duke University, Washington DC.

Melhuish, E. et al. (2016), "Fostering Effective Early Learning (FEEL) through a professional development program for early childhood educators to improve professional practice and child outcomes in the year before formal schooling: protocol for a cluster randomised controlled trial", Trials, Vol. 17/1, pp. 602-610, https://doi.org/10.1186/s13063-016-1742-1.

NCCA (2009), Aistear: The Early Childhood Curriculum Framework, https://curriculumonline.ie/Early-Childhood/ (accessed on June 2020).

OECD (2020), Early Learning and Child Well-being: A Study of Five-year-Olds in England, Estonia, and the United States, OECD Publishing, Paris, https://doi.org/10.1787/3990407f-en.

OECD (2019), Providing Quality Early Childhood Education and Care: Results from the Starting Strong Survey 2018, TALIS, OECD Publishing, Paris, https://dx.doi.org/10.1787/301005d1en.

OECD (2018), Engaging Young Children: Lessons from Research about Quality in Early Childhood Education and Care, Starting Strong, OECD Publishing, Paris, http://dx.doi.org/10.1787/9789264085145-en.

OECD (2018), The Future of Education and Skills - Education 2030: The Future We Want, OECD, Paris, http://www.oecd.org/education/2030/E2030\%20Position\%20Paper\%20(05.04.2018).pdf.

OECD (2017), Starting Strong V: Transitions from Early Childhood Education and Care to Primary Education, Starting Strong, OECD Publishing, Paris, https://dx.doi.org/10.1787/9789264276253-en.

OECD (2015), ECEC Network Common Understandings on Early Learning and Development, http://www.oecd.org/education/school/ECEC-Network-Common-Understandings-on-EarlyLearning-and-Development.pdf.

OECD (2015), Skills for Social Progress: The Power of Social and Emotional Skills, OECD Publishing, Paris, http://dx.doi.org/10.1787/9789264226159-en.

OECD (2015), Starting Strong IV: Monitoring Quality in Early Childhood Education and Care, Starting Strong, OECD Publishing, Paris, http://dx.doi.org/10.1787/9789264233515-en.

OECD (2011), Starting Strong III: A Quality Toolbox for Early Childhood Education and Care, Starting Strong, OECD Publishing, Paris, http://dx.doi.org/10.1787/9789264123564-en. 
Pianta, R. (2001), Student-teacher relationship scale: Professional manual, Psychological Assessment Resources, Lutz, FL.

Pianta, R., K. LaParo and B. Hamre (2007), Classroom Assessment Scoring System ${ }^{\mathrm{TM}}$ CLASS, Brookes, Baltimore.

Pyle, A. and B. Alaca (2018), "Kindergarten children's perspectives on play and learning”, Early Child Development and Care, Vol. 188/8, pp. 1063-1075, https://doi.org/10.1080/03004430.2016.1245190.

Samuelsson, I. and M. Carlsson (2008), "The playing learning child: Towards a pedagogy of early childhood", Scandinavian Journal of Educational Research, Vol. 52/6, pp. 623-641, http://dx.doi.org/10.1080/00313830802497265.

Shuey, E. et al. (2019), "Curriculum alignment and progression between early childhood education and care and primary school : A brief review and case studies", OECD Education Working Papers, No. 193, OECD Publishing, Paris, https://dx.doi.org/10.1787/d2821a65-en.

Sim, M. et al. (2019), "Starting Strong Teaching and Learning International Survey 2018 Conceptual Framework", OECD Education Working Papers, No. 197, OECD Publishing, Paris, https://dx.doi.org/10.1787/106b1c42-en.

Siraj-Blatchford, I. and K. Sylva (2004), "Researching pedagogy in English pre-schools", British Educational Research Journal, Vol. 30/5, pp. 713-730, https://doi.org/10.1080/0141192042000234665.

Siraj-Blatchford, I. et al. (2002), Researching Effective Pedagogy in the Early Years: Report $R R 356$, Department for Education and Skills, London.

Slot, P. et al. (2018), Kwaliteit van de Nederlandse kinderdagopvang, peuteropvang, buitenschoolse opvang en gastouderopvang.

Sommer, D., I. Pramling Samuelsson and K. Hundeide (2010), Child Perspectives and Children $\_$s Perspectives in Theory and Practice, Springer Netherlands, http://dx.doi.org/10.1007/978-90-481-3316-1.

Stephen, C. (2010), "Pedagogy: The silent partner in early years learning”, Early Years, Vol. 30/1, pp. 15-28, https://doi.org/10.1080/09575140903402881.

Sylva, K. et al. (2016), D2.4: Integrative Report on a Culture Sensitive Quality and Curriculum Framework.

Tiko, L. (2017), "Creating an early childhood curriculum pathway for sustaining indigenous Fijian cultural knowledges", New Zealand International Research in Early Childhood Education Journal, Vol. 20/1, pp. 17-33.

Ukala, C. and O. Agabi (2017), "Linking early childhood education with indigenous education using gamification: The case of maintaining cultural value and identity", Journal of International Education Research, Vol. 13/1, pp. 17-26, https://doi.org/10.19030/jier.v13i1.9960.

Wall, S., I. Litjens and M. Taguma (2015), Early Childhood Pedagogy Review: England, OECD Publishing, Paris, https://www.oecd.org/education/early-childhood-education-and-carepedagogy-review-england.pdf. 
Weiss, H., M. Caspe and M. López (2008), Family Involvement Promotes Success for Young Children: A Review of Recent Research, Information Age Publishing.

Wisneki, D. and S. Reifel (2012), "The place of play in early childhood curriculum", in File, N., J. Müeller and D. Wisneki (eds.), Curriculum in Early Childhood Education: Re-examined, rediscovered, renewed, Routledge, New York.

Wood, E. (2010), "Developing integrated pedagogical approaches to play and learning", in Braodhead, P., J. Howard and E. Wood (eds.), Play and Learning in the Early Years, Sage, London.

Wood, E. and H. Hedges (2016), "Curriculum in early childhood education: Critical questions about content, coherence, and control", The Curriculum Journal, Vol. 27/3, pp. 387-405, https://doi.org/10.1080/09585176.2015.1129981.

\section{Notes}

1. "Home-based settings" refers to early childhood education and care that is provided in a home setting rather than a centre. These settings may or may not have an educational function and be part of the regular ECEC system. The minimum requirements defined for home-based settings vary widely across countries. Registered home-based settings providers are accredited to take care of children in their own homes.

2. In Luxembourg, non-formal education is distinguished from formal ECEC offered by schools within the public school system. In the context of the non-formal ECEC provision, children can spend time in centres or in home-based settings. 
3 Workforce and process quality in
early childhood education and care

This chapter discusses the relationship between the early childhood education and care (ECEC) workforce and process quality. Building on research findings, this chapter discusses how ECEC staff's initial education, professional development, working conditions and leadership can enhance process quality and support children's learning, development and well-being. This chapter provides an overview of the policies that affect the ECEC workforce through a range of indicators across OECD countries and jurisdictions. It also provides concrete examples of good practices that can enhance process quality and child development through these policies. 


\section{Key messages}

- The most prevalent qualification required for teachers is a bachelor's degree or equivalent (ISCED Level 6), although qualification requirements vary considerably among participating countries and jurisdictions. Compared to teachers' qualifications, the qualifications of assistants are more homogeneous, the most prevalent qualification requirement being ISCED Level 3 (upper secondary education).

- For early childhood education and care (ECEC) teachers, work-based learning during initial education is required for most settings covering children aged 3 to 5/primary school entry, as well as in most settings covering children aged 0 to 5/primary school entry, but not all. In settings for children aged 0 to 2 , this is less frequent. For assistants, it is less common to require work-based learning in initial education.

- The breadth of initial education of ECEC staff in terms of content areas varies sharply across countries and jurisdictions. This is true both for teachers and assistants. For assistants, initial education requirements in terms of content areas are less broad than for teachers. Most settings require teachers to have been trained in child development, playful learning aspects, and curriculum and pedagogy in general, although the implementation of the curriculum framework is less common. Linking ECEC and home-learning activities is one of the least covered topics.

- While most participating countries and jurisdictions do not have accreditation of professional development activities and do not regulate the monitoring of quality, several countries have requirements for participation in professional development.

- The assessment of staff professional development needs, and barriers to participation, in professional development is not a common practice in several participating countries and jurisdictions.

- Allowing time for teachers to participate in professional development is a common or required practice in ECEC settings covering children aged 3 to 5/primary school entry, but is less frequent in settings for children aged 0 to 2 . For assistants, time incentives to participate in professional development activities are not regulated or are not required in most participating countries and jurisdictions.

- More generally, countries and jurisdictions differ in their regulations of time for activities to be performed without children, with some of them protecting time for a wide range of activities without children and others that do not. Regulations or practices that protect time are more common for teachers than for assistants across ECEC settings for all age groups. For teachers, protected time is higher in settings covering children aged 3 to 5/primary school entry.

- The most prevalent qualification required for ECEC centre leaders is tertiary education (ISCED Level 6). Several participating countries and jurisdictions have not reported information on the requirements for training programmes of leaders in terms of content, but for those who have, pedagogical leadership is widely covered.

\section{Introduction}

Early childhood education and care (ECEC) professionals are key agents for assuring the quality of an ECEC system. ECEC professionals can profoundly shape children's everyday interactions, which are likely to influence their learning, development and well-being. Among the vast array of features relevant for process quality - that is, the quality of interactions in ECEC settings - ECEC staff's initial education has been identified as one of the strongest predictors of high process quality (Manning et al., 2019 ${ }_{[1]}$ ). 
Similarly, professional development can help staff stay up to date on scientifically based strategies and knowledge, as well as feel supported and part of the team, which in turn contributes to high-quality practices. As such, preparing the ECEC workforce to work with children and ensuring that they can continuously engage in learning opportunities are at the very core of ECEC quality.

Working conditions, including salaries, contract status, and the organisational climate, are a second pillar for building and retaining a high-quality ECEC workforce (OECD, 2020[2]). Good working conditions can help sustain a positive working climate and support well-being, and thereby safeguard the capacity of the sector to retain highly motivated professionals. Relatedly, leaders in ECEC centres can play an important role in creating opportunities for improving working conditions and supporting professional development initiatives. Leaders can help build a respectful, trusting and safe environment necessary for skills improvement and teacher well-being (Ehrlich et al., 2019 $[3]$; Ratner et al., 2018[4]).

This chapter details different dimensions of the ECEC workforce that research has highlighted as important for process quality. In addition, utilising data from the Quality beyond Regulations policy review, it presents a selection of key indicators related to workforce development in countries and jurisdictions that participated in the project and related data collection (Box 3.1). More indicators and figures on policies targeting the ECEC workforce can be found on the platform Starting Strong: Mapping quality in early childhood education and care, available at https://quality-ecec.oecd.org.

\section{Box 3.1. Quality beyond Regulations policy review: Coverage and methodology concerning indicators related to the workforce}

This chapter is based on findings on policies and regulations concerning the ECEC workforce from the Quality beyond Regulations policy questionnaire for the reference year 2019, along with country background reports (see the Reader's Guide for more information). Twenty-six countries, covering 41 jurisdictions, completed the policy questionnaire, and six countries (Australia, Canada, Ireland, Japan, Luxembourg and Switzerland) provided background reports. Given the complex architecture of ECEC systems, the Quality beyond Regulations policy review collected information for each of the different curriculum frameworks (56 in total) and ECEC settings (121 in total) within the participating countries and jurisdictions.

Regarding workforce development, the questionnaire included questions on:

- initial education and training (e.g. requirements in terms of level of education and content, accreditation responsibilities)

- professional development (e.g. types of activities, content, incentives and assessment of needs)

- working conditions (e.g. regulations on contractual status and wages).

Standardised age groups were assigned to the different curricula and settings to facilitate analysis and comparisons. The age groups were assigned as follows:

- Age 0 to 2: If the majority of years of a setting or curriculum targets or covers children aged 0 to 2. This includes settings or curricula that start for children from birth (e.g. 12 weeks, 3 months, etc.) and end at age 2.

- Age 3 to 5/primary school entry: If the majority of years of a setting or curriculum targets or covers children aged 3 to 5 . This includes settings or curricula that start earlier than age 3 (e.g. 2.5 years) or later than age 3 (e.g. 4 years).

- Integrated for age 0 to 5/primary school entry: If a setting or curriculum targets or covers children aged below and above the cut-off point of 3 years to a similar extent (e.g. 0 to 8 years). 
Information was then aggregated across settings for indicators where information was the same or very similar within these standardised age groups (e.g. for a country with two settings in place for the same age group). No information for different settings was aggregated across different age groups.

Table A.A.2 in Annex A shows the list of settings for participating countries and jurisdictions included in this report.

The chapter focuses on staff who regularly work in a pedagogical way with children in ECEC settings. For comparability across countries and jurisdictions, staff have been classified as teachers or assistants, according to their overall roles in the ECEC centre.

The term "teachers" refers to the individuals with the most responsibility for a group of children at the class- or playroom-level. They may also be called pedagogues, educators, childcare practitioners or pedagogical staff.

The term "assistants" refers to ECEC staff whose role is to provide support to the teachers or lead staff member with a group of children.

The term "leader" refers to the person who has the most responsibility for administrative, managerial and/or pedagogical leadership at the ECEC centres.

Table A.A.3 in Annex C shows the categories of staff for participating countries and jurisdictions included in this report.

Within and across ECEC systems, there is a wide variety of settings. As mentioned above, 26 countries answered the Quality beyond Regulations policy questionnaire and reported information on 121 settings, reflecting the complexity of the sector's organisation. Settings are often differentiated by age, whether they are centre-based or home-based, or whether they are specifically designed to serve specific groups of children. In order to enable comparisons within and across countries or jurisdictions, for the analyses conducted in this chapter, settings were classified into three groups:

- settings serving mainly children aged 0 to 2

- settings serving mainly children aged 3 to 5 or until primary school entry

- settings serving children from birth or aged 1 until entry into primary school, also called "integrated settings".

Building on information from the Quality beyond Regulations policy questionnaire and the six country background reports, this chapter provides insights into the main strengths and challenges faced by countries in building and retaining an ECEC workforce that can best support quality.

\section{Features of initial education that contribute to process quality}

Initial education of ECEC staff is one of the most important determinants of quality in ECEC. It is also one of the main areas that can be regulated or changed through policies to improve the quality of ECEC provision. Initial education refers to the level and type of education required for ECEC staff to work in the sector. It includes the knowledge, skills and competencies recognised as important for working with young children (Manning et al., 2019[1]).

In addition to the qualification levels, specialised education in ECEC may be important for process quality in ECEC. Specialised training can help professionals build knowledge, skills and competencies, as well as provide pedagogical learning opportunities tailored to children's developmental and socio-emotional needs. Studies examining the specific links between specialised training and interaction quality have pointed to the added value of focusing on ECEC in initial education programmes (Hu et al., 2019 ${ }_{[5]}$; Schaack, Le and Setodji, 2017[6]; Wang, Hu and LoCasale-Crouch, 2020[7]; OECD, $2019_{[8]}$ ). 
Researchers have tried to understand how initial education can shape ECEC staff practices with children (Romo-Escudero, LoCasale-Crouch and Turnbull, 2021 ${ }_{[9]}$ ). Specifically, specialised training in ECEC can contribute to more complex and multifaceted knowledge about development, further supporting ECEC staff in more appropriately reading children's cues and responding accordingly (Barros et al., 2018[10]; Schaack, Le and Setodji, $\left.2017_{[6]}\right)$. To be attuned and prepared to respond to child behaviours in real contexts, ECEC staff's ability to notice behavioural markers of child development can be important, including noticing more salient markers, such as crying or vocalising, as well as more subtle ones, such as gestures and eye gaze (Romo-Escudero, LoCasale-Crouch and Turnbull, 2021 ${ }_{[9]}$ ).

\section{Initial education levels}

Staff qualifications, that is, their level of education (e.g. secondary diploma, post-secondary diploma, university degree), are the most researched indicator and have the largest evidence base, with several studies pointing to positive links between higher qualifications and process quality (Manning et al., 2019 [1]). Still, not all studies find a direct link between higher qualifications and higher process quality (von Suchodoletz et al., 2020[11] $)$, suggesting the need to look above and beyond education levels and examine the content and delivery of initial education levels.

Highly qualified ECEC staff are better able to sustain enriching and stimulating interactions with children than staff with lower initial qualifications. These positive associations have been documented across regions, such as Sub-Saharan Africa, and countries, namely, Australia, the People's Republic of China (hereafter "China"), Denmark, Germany, Norway, Portugal and the United States, for infant and toddler centre-based ECEC settings (Barros et al., 2018[10]; Bjørnestad et al., 2019 [12]; Castle et al., 2016[13]), home-based settings (Eckhardt and Egert, 2020[14]; Schaack, Le and Setodji, 2017[6]) and

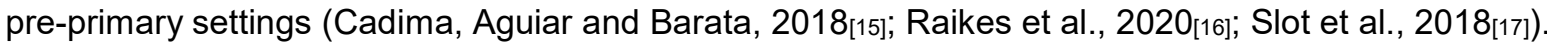

Although the literature has primarily focused on teachers, assistants can also play an important role in assuring high levels of process quality (Sosinsky and Gilliam, 2011 $\left.{ }_{[18]}\right)$. Studies examining the role of multiple staff members within a group have suggested that all staff, regardless of their roles, matter for process quality (Bjørnestad et al., 2019[12]; Barros et al., 2018[10]). Research also shows that the importance of assistants is recognised by teachers, who view them as extremely useful in supporting them in their multiple tasks and interacting with children (Sosinsky and Gilliam, 2011 [18]).

Data from the OECD Starting Strong Teaching and Learning International Survey (TALIS Starting Strong) show that across participating countries, a majority of staff report having at least some post-secondary education (International Standard Classification of Education [ISCED] Level 4 or above) (Figure 3.1). However, the educational profiles of staff vary substantially across countries. The overall educational attainment data hides differences between categories of staff, with teachers often having a bachelor's degree or equivalent or higher, and some of the assistants not having an ISCED Level 4. Whether staff are trained specifically to work with children, which is also important for ECEC quality, is somewhat separate from their level of educational attainment. For example, in Germany and Japan, where junior college or vocational education and training programmes are most common for ECEC staff, nearly all staff are trained specifically to work with children, while in Turkey, where education at the level of a bachelor's degree or equivalent or higher is most typical for ECEC staff, more than one-quarter of staff do not have training specifically to work with children.

Setting education requirements is a way to ensure that ECEC staff have at least a certain level of education, though it may take time for the whole workforce to reach this level. The most prevalent qualification requirement for teachers across countries and jurisdictions participating in the Quality beyond Regulations policy review varies between ISCED Level 5 and ISCED Level 7, with the exception of the Slovak Republic (ISCED Level 3) (Table 3.1). ${ }^{1}$ For the majority of countries with available data, a bachelor's degree or equivalent (ISCED Level 6) is the most prevalent qualification requirement. 
France, Poland and Portugal are the countries with the highest level of qualification requirements, which is a master's degree or equivalent (ISCED Level 7).

In comparison to teachers' education requirements, requirements for assistants are more homogeneous across countries. For most countries with available data, the most prevalent qualification required for assistants is ISCED Level 3 (upper secondary education), with one exception being Mexico, which requires ISCED Level 2 and further training. In half of these countries, Chile, France, Germany and Slovenia, the requirement for assistants is a vocational education programme.

Figure 3.1. Educational attainment of staff and content of initial training

Staff reports of their highest level of education and whether they received training specifically to work with children, 2018

口Below ISCED Level $4 \quad$ aISCED Level 4 or $5 \quad$ aISCED Level 6 or above $\quad \triangle$ Trained to work with children

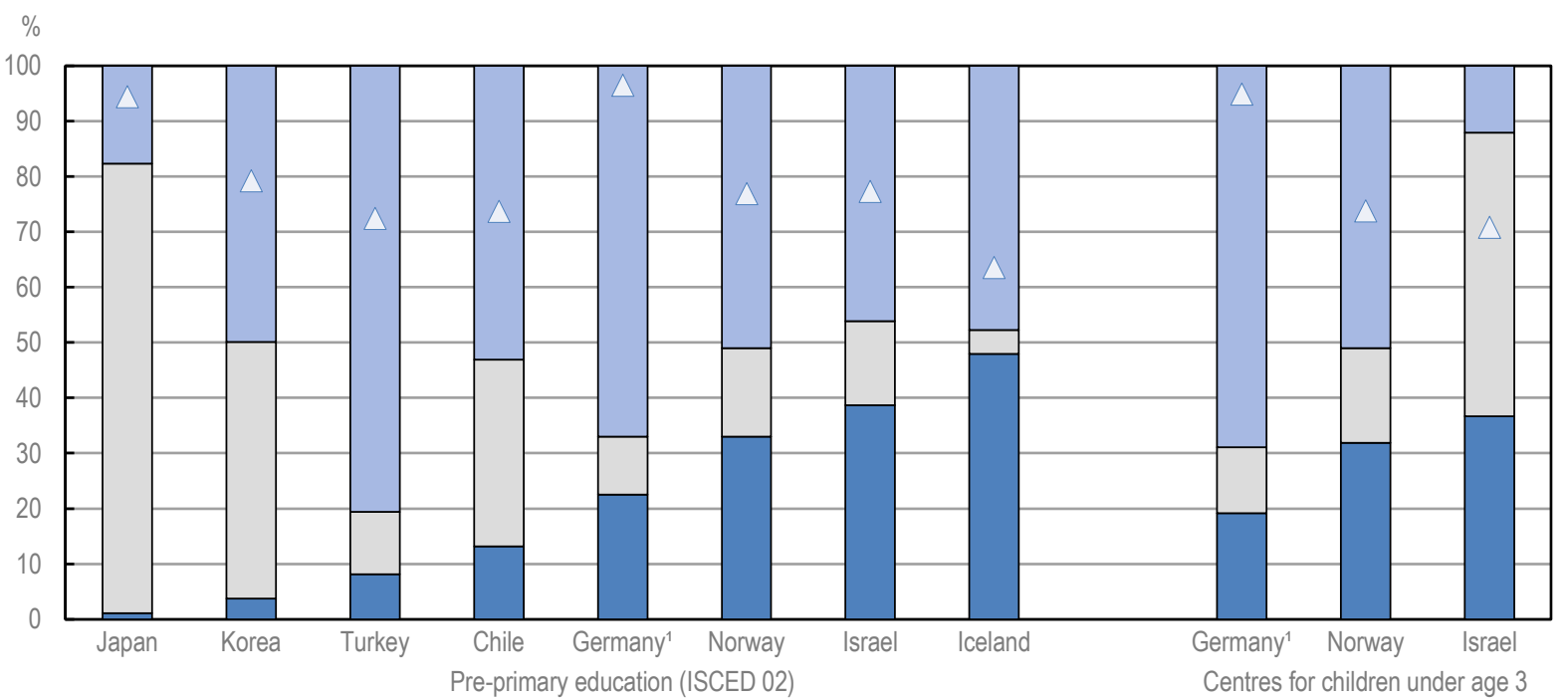

1. Estimates for sub-groups and estimated differences between sub-groups need to be interpreted with care.

Notes: Respondents in the "Below ISCED Level 4" group are those whose highest education is at a secondary level or below. Respondents in the "ISCED Level 4 or 5 " group are those whose highest education is beyond secondary schooling but less than a bachelor's degree (or equivalent), including post-secondary, non-tertiary education (generally vocationally oriented) and short-cycle tertiary education. Respondents in the "ISCED Level 6 or above" group are those whose highest education is at the level of a bachelor's degree or equivalent or higher.

Source: OECD (2019[8] $)$, Providing Quality Early Childhood Education and Care: Results from the Starting Strong Survey 2018, https://doi.org/10.1787/301005d1-en.

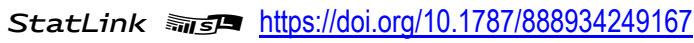

Table 3.1. Most prevalent qualification required of ECEC staff to enter the profession

\begin{tabular}{|c|c|c|}
\hline Country & Teachers & Assistants \\
\hline Belgium & ISCED Level 6 & ISCED Level 3 \\
\hline Chile & ISCED Level 6 & ISCED Level 3, vocational \\
\hline Czech Republic & ISCED Level 3 & \\
\hline Denmark & ISCED Level 6 & \\
\hline Estonia & ISCED Level 6 & \\
\hline Finland & ISCED Level 6 or 7 & \\
\hline France & ISCED Level 7 & ISCED Level 3, vocational \\
\hline Germany & ISCED Level 6, vocational & ISCED Level 3, vocational \\
\hline Ireland & ISCED Level 5 & ISCED Level 4 \\
\hline Israel & ISCED Level 5 & ISCED Level 3 \\
\hline Japan $^{1}$ & ISCED Level 5 or 6 & \\
\hline Luxembourg & ISCED Level 5 or 6 & \\
\hline Mexico & ISCED Level 6 & ISCED Level 2 and training \\
\hline
\end{tabular}




\begin{tabular}{l|l|l}
\hline \multicolumn{1}{c|}{ Country } & Teachers & Assistants \\
\hline New Zealand & ISCED Level 6 & \\
\hline Norway & ISCED Level 6 & ISCED Level 3 \\
\hline Poland ${ }^{2}$ & ISCED Level 7 & \\
\hline Portugal & ISCED Level 7 & \\
\hline Slovak Republic & ISCED Level 3 & ISCED Level 3, vocational \\
\hline Slovenia & ISCED Level 6 & \\
\hline Switzerland & ISCED Level 6 & \\
\hline
\end{tabular}

1. Data does not cover daycare centres and integrated centres for early childhood education and care.

2. A master's or equivalent degree is not a prerequisite, but most ECEC teachers enter the profession with this level.

Notes: Data refer to 2018. ISCED Level 2 = lower secondary education; ISCED Level 3 = upper secondary education; ISCED Level $5=$ shortcycle tertiary; ISCED Level 6 = bachelor's degree or equivalent; ISCED Level 7 = master's degree or equivalent.

Source: OECD (2020[19] $)$ Education at a Glance 2020: OECD Indicators, https://doi.org/10.1787/69096873-en and OECD "Quality beyond Regulations" database.

StatLink तilst https://doi.org/10.1787/888934249490

\section{Learning from countries: Increasing the number of qualified staff}

Several countries have employed a range of strategies to increase the number of qualified teachers over time, such as setting higher standards, incentive mechanisms, or offering workplace education opportunities for staff working in ECEC.

In Australia, since 2012, higher workforce requirements have been progressively introduced. Centre-based services with children in pre-primary education are required to employ at least a qualified teacher, and additional requirements (two qualified teachers) hold for some large settings. Furthermore, requirements cover both teachers and assistants: half of the staff must hold or be working towards at least a short-cycle tertiary qualification (ISCED Level 5), and the other half must hold or be working towards at least a post-secondary qualification at ISCED Level 4. In line with increasing regulatory requirements, the qualification of the ECEC workforce in Australia has increased over recent years.

In Canada, many provinces and territories have recently set new standards for initial education. For example, in the province of Nova Scotia, the curricula of post-secondary programmes have been updated to meet the adopted new standard on learning outcomes. The province also introduced a process of recognition of prior learning to provide individuals working for ten years or more in the ECEC field the opportunity to demonstrate they have acquired the necessary knowledge and skills to obtain an ECEC qualification.

In Ireland, new qualification requirements have been introduced in past years, as well as incentives for centres to hire ECEC staff with higher qualifications. Teachers (so-called "room leaders" in the Early Childhood Care and Education programme) are now required to have an ISCED Level 5 diploma at the minimum, but centres with teachers who hold a university degree (ISCED Level 6) in early childhood receive higher funding. The proportion of settings in the Early Childhood Care and Education programme with graduate teachers has increased in the last decade, rising from $20 \%$ in $2012 / 13$ to over $50 \%$ in 2018/19. For all staff who work directly with children, the minimum requirement is a major award in ECEC at ISCED Level 4.

In addition to incentives or regulations to raise the education level of the ECEC workforce, defining standards for initial education, such as on its content or inclusion of a practical component, can be an effective means of ensuring quality and consistency across programmes (Box 3.2). 


\section{Box 3.2. Ensuring quality and consistency across initial education programmes through standards}

In Australia, the Children's Education and Care Quality Authority determines the qualifications required for staff included in mandated staff-to-child ratios, including educational level, early years focus, practicum and curriculum content. Approved qualifications for teachers must have an appropriate pedagogical focus and provide professional experience with children aged birth to five. For vocational qualifications, the programmes must comply with national quality standards for training and assessment. Standards are developed through a collaborative process with the sector and industry groups.

In Ireland, Professional Awards Criteria and Guidelines for initial education programmes for teachers (at ISCED Level 6) were developed in 2017 and 2018 to improve the quality and consistency of degree programmes. The development of these criteria included consultation of higher education specialists and practitioners. The adherence of the programmes to the criteria is being assessed in 2021. For major awards at ISCED Levels 4-6, additional descriptors that define standards of knowledge, skills, and competencies will be incorporated, beginning in September 2021.

In Japan, there are national standards for the core curriculum for initial education programmes, including standards regarding subjects and required credits. The national standards are developed and improved with the involvement of scholars in the field of ECEC, officials of administrative facilities, ECEC staff and relevant professional associations. The core curriculum for initial education programmes aims to ensure consistency across programmes nationwide and to support quality.

In Canada, most provinces and territories' governments (7 out 13) provide standards for initial education programmes. For example, in Ontario, initial education institutions must be approved by Ontario's College of Early Childhood Educators so that graduates are recognised as qualified staff. In Newfoundland and Labrador, the standards define minimum requirements on content, length and practicum placements. New Brunswick adopted standards for initial education in 2018. In Quebec, to be considered as "qualified", staff must have completed a specific programme (Diploma of Collegial Studies in Early Childhood Education) that includes a general education component and a training component specific to early childhood. These programmes have to be approved by the Quebec Department of Education and Higher learning.

\section{Integrating work-based learning into initial education}

Work-based learning during initial education for ECEC professionals is associated with quality in ECEC. The international literature has long highlighted the important role played by work-based training for sustaining situated and contextual-based learning (Balduzzi and Lazzari, 2015[20]; Flämig, König and Spiekermann, 2015 [21]). A common characteristic of work-based learning is the combination of theory and practice, supporting the development of knowledge and skills that are at the core of the ECEC profession (Ärlemalm-Hagsér, 2017[22]; Oberhuemer, 2015[23]; Lohmander, 2015[24]). Extended placement periods in ECEC settings during initial preparation may allow prospective staff to live the culture of practice, and to combine theoretical and experiential learning, helping them to critically reflect on their own practice (Balduzzi and Lazzari, 2015[20]). As prospective staff engage in hands-on activities and deal with challenges of everyday practice, they are provided with opportunities to build and apply new knowledge in real-life situations (Kaarby and Lindboe, 2016[25]). Additionally, observing teacher-child interactions within real-life situations has been shown to foster sensitive and rich interactions with children (Romo-Escudero, LoCasale-Crouch and Turnbull, 2021[9]; Fukkink et al., 2019[26]). 
TALIS Starting Strong has looked into key features of initial education programmes across a number of countries, finding that initial education programmes that included practical placements in real work settings also covered more areas than staff programmes that did not have such a practical dimension (OECD, $\left.2020_{[2]}\right)$. These findings suggest that work-based learning can not only contribute to bridging theory and practice in ECEC, but also to broadening their curricular contents.

Despite the international recognition of the importance of work-based learning for prospective ECEC professionals, studies that investigate the content and delivery of initial preparation programmes are still relatively scarce. The Quality beyond Regulations policy questionnaire asked whether a practicum is a required content of initial training for teachers and assistants. Results show that a practicum is required in most settings covering children aged 3 to 5 , as well as in most of those for ages 0 to 5 , but they are less frequent in settings for children aged 0 to 2 (Figure 3.2, Table C.3.1). On the other hand, it is far less common to include a practicum in initial education for assistants.

\section{Figure 3.2. Practicum requirements as part of ECEC professionals' initial education and training}

Percentage of settings that require a practicum, by age group and staff type, 2019

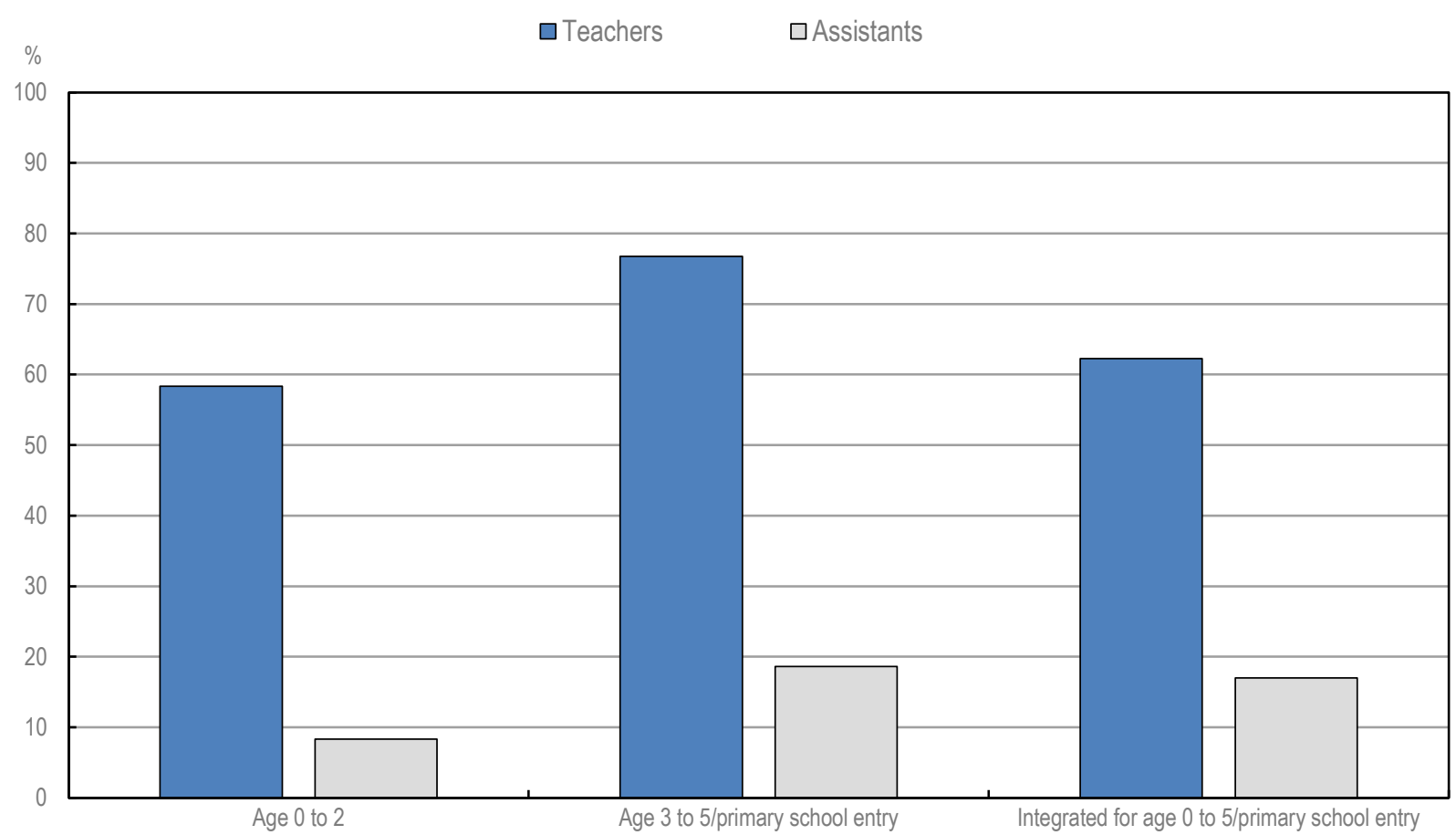

Notes: The percentage in each age group is based on the total number of observations/settings within the age group, including settings classified as "not applicable" or "missing". Information on settings and categories of staff included for each country and jurisdiction and classification according to standardised age groups is provided in Annex $A$.

Source: OECD "Quality beyond Regulations" database.

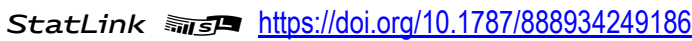




\section{Learning from countries: Integration of work-based learning into initial education}

In Australia, initial education programmes both for teachers and assistants include workplace-based learning to ensure that students acquire professional experience within an ECEC service. Students are required to develop and demonstrate their skills in real settings, through a strong co-operation between initial education institutions and ECEC settings. In addition to providing regular placement opportunities for students, ECEC settings also provide feedback and input into the development of initial education materials.

In Ireland, since 2017, the initial education programmes for staff are required to offer supervised practice placements, with a minimum of $35 \%$ of the overall duration of the course. Practice placements include a variety of settings to cover the full 0 to 6 age range. A survey conducted in 2015 to assess the satisfaction of staff with their initial training found that many of them felt there was a need for greater standardisation of the practicum to address its duration, content, supervision and assessment. This finding fed the development of guidelines for initial preparation. The Professional Award-type Descriptors for ISCED Levels 4 and 5, entering into force in 2021, will require participants to undertake a minimum of 150 hours per annum of professional practice, covering the work with both children aged 0 to 2 and older children. The workplace-based learning is designed to offer a variety of learning opportunities, including observation and self-assessment and application of theory and knowledge to practice.

\section{Breadth of the content of initial education programmes}

Working with young children requires specialised skills and content knowledge on a variety of subject and development areas. Building a robust base of knowledge across a variety of subjects is key for ECEC professionals to successfully cope with the practice challenges. Findings from TALIS Starting Strong show that the breadth of training of ECEC staff is positively associated with attitudes and practices related to process quality (OECD, 2020[2] $)$. In all participating countries, pre-primary staff who covered more areas in both their initial and recent training report adapting their practices more to children's needs and interests. Staff sense of self-efficacy for supporting child development and learning is also higher among staff who covered a greater number of areas in their training (OECD, 2020[2]).

The Quality beyond Regulations policy questionnaire asked countries whether it is a requirement or common practice for teachers to cover specific content in order to obtain the minimum qualification in key areas such as child development, child health, curriculum and pedagogy, playful learning, classroom management, diversity, transitions and family and community engagement.

At least $80 \%$ of the content areas considered in the questionnaire are required to be included in teachers' initial education and training programmes in the majority of participating countries and jurisdictions (12 out of 19) that set content requirements in ECEC settings for children aged 3 to 5/primary school entry. Australia, Germany, Poland and Canada (Nova Scotia) reach 100\%. Belgium (Flanders), the Czech Republic, Denmark, Japan, the Slovak Republic and Turkey reach or surpass $90 \%$ coverage. Israel, Luxembourg and New Zealand cover approximately $50 \%$ of the content. In the remaining countries and jurisdictions, teachers' initial education and training programmes cover less than half of the content (Figure 3.3). There are several reasons for this lower coverage. In some countries, there is no requirement on the content of initial training, but it is common practice to include several of these areas (e.g. Portugal). In Luxembourg, initial training programmes for teachers are not specific to ECEC, and therefore, there is no requirement to cover these areas. Some countries have included a wide range of settings in their responses to the Quality beyond Regulations policy questionnaire, such as settings for after-school activities (e.g. Luxembourg and Switzerland) that are not considered to have an education objective by other countries, which also contributes to differences in requirements of initial education and training programmes for staff. Concerning assistants, Australia requires coverage of $100 \%$ of the contents, but other countries with available data require a less broad coverage of areas than for teachers. 
Figure 3.3. Breadth of content required as part of ECEC professionals' initial education to obtain the minimum qualification

Average across settings of the percentage of content areas required to be included, among those included in the Quality beyond Regulations questionnaire, by age group, 2019
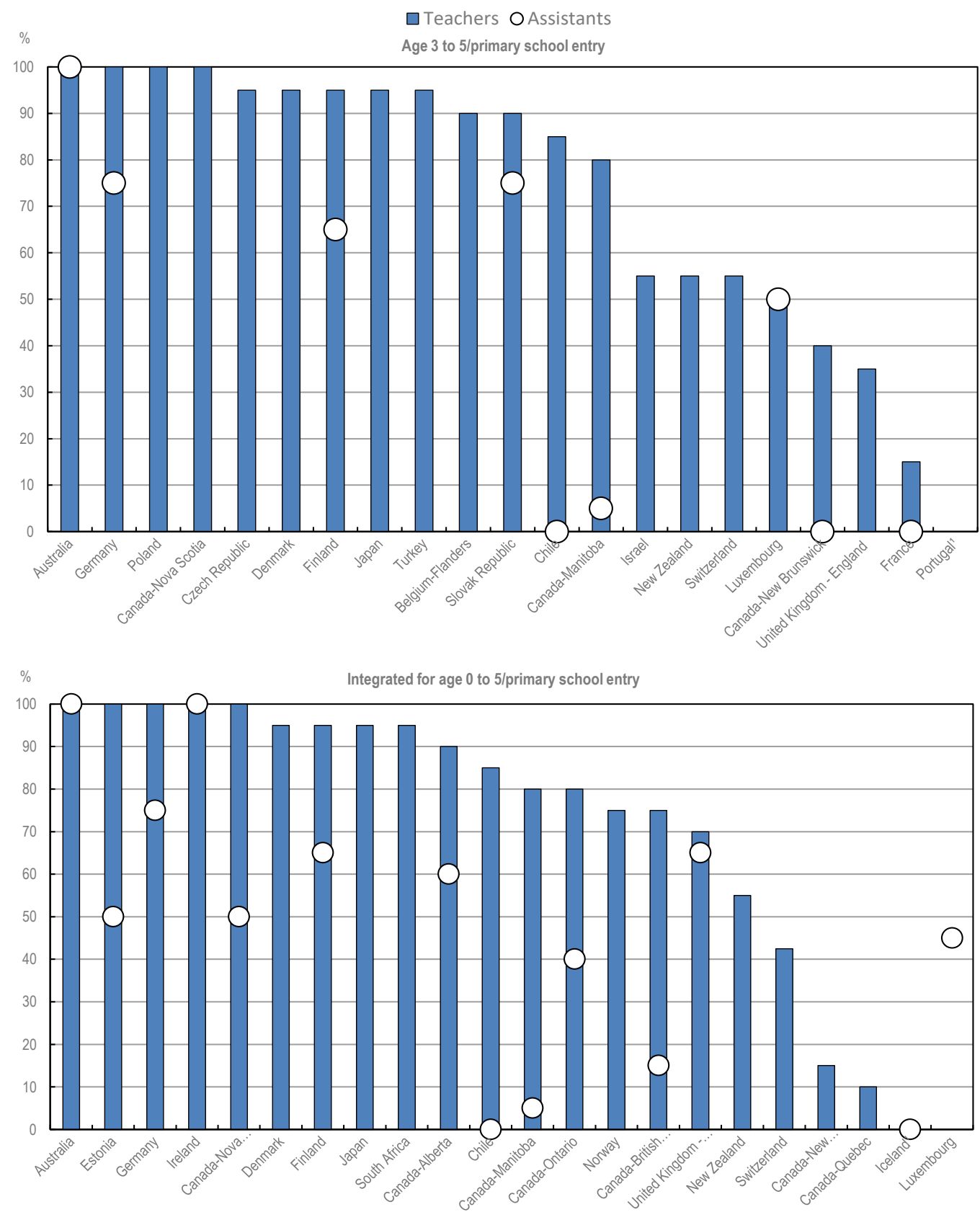

1. No content is required for initial education.

Notes: The breadth of content refers to the percentage of content required among 20 items listed in the Quality beyond Regulations policy questionnaire within the following key areas: child development, child health, curriculum and pedagogy, playful learning, classroom management, diversity, transitions and family and community engagement. In countries with multiple settings within an age group, the breadth of content required as part of initial education represents the average across settings in that age group.

Information on settings and categories of staff included for each country and jurisdiction and classification according to standardised age groups is provided in Annex $A$.

Source: OECD "Quality beyond Regulations" database.

StatLink הत्गाS https://doi.org/10.1787/888934249205 
Similarly, in settings for children aged 0 to 5/primary school entry, at least $80 \%$ of the content areas are included in teachers' initial education and training programmes in the majority of participating countries and jurisdictions that set content requirements (14 out of 19). Regarding assistants, Australia and Ireland require coverage of $100 \%$ of the content, and other countries have a smaller content coverage.

In settings for children aged 0 to 2 , in all countries and jurisdictions with available data that set content requirements, at least $70 \%$ of the considered content areas are covered in teachers' initial education programmes for teachers and a smaller percentage for assistants (Figure C.3.1).

Most initial education programmes in participating countries and jurisdictions include aspects related to child development, be it as a requirement or a common practice (Figure 3.4). Most training programmes for teachers include playful learning aspects, such as facilitating play, and facilitating creativity and problem solving. Regarding curriculum and pedagogy, it is frequent to find initial education programmes covering learning theories, facilitating learning in arts, literacy and oral language, science and technology, and mathematics/numeracy, but less common on aspects related to implementing the curriculum framework. Regarding diversity issues, most training programmes for teachers include working with children from diverse backgrounds and with children with special needs, but it less common that programmes address issues related to dual or second-language learners. Areas such as working with parents from diverse backgrounds are commonly covered across settings, while linking ECEC and home-learning activities is one of the least covered topics.

Content requirements of initial education for assistants are, in comparison to teachers, less broad, with programmes having less than $20 \%$ of the considered areas being required and $30 \%$ of them being required or common practice. Some of the most commonly covered areas, either through requirement or common practice, are child health and playgroup or group management. In contrast, the least covered areas include learning theories, facilitating learning in science and technology and working with dual or second-language learners. These differences in initial programmes between teachers and assistants reflect differences in roles and responsibilities.

Preparing teachers to work with children with varying needs, interests and cultural backgrounds is important to foster inclusion and equity in ECEC, but it is not systematically covered in initial education programmes. As demands increase on ECEC staff to address diversity, this is an area of training increasingly prioritised in some countries (Box 3.3). 
108

Figure 3.4. Requirements of ECEC professionals' initial education in terms of content areas

Percentage of settings across countries that require specific content or in which specific content is common practice, by staff type, 2019

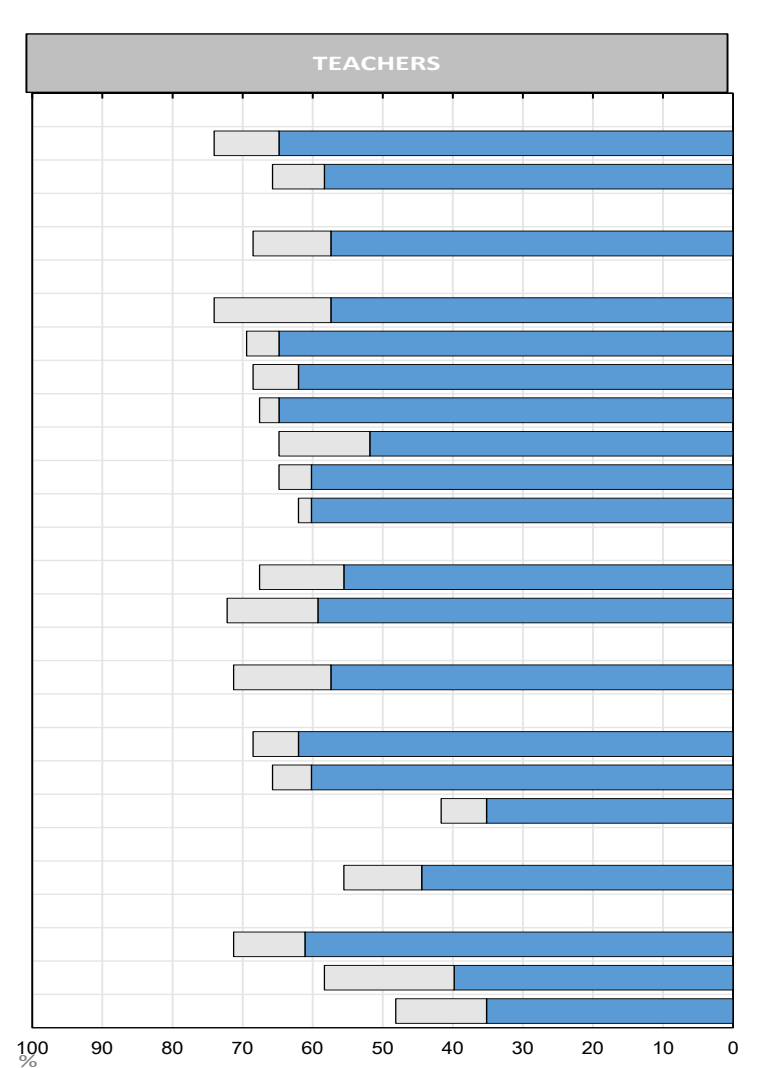

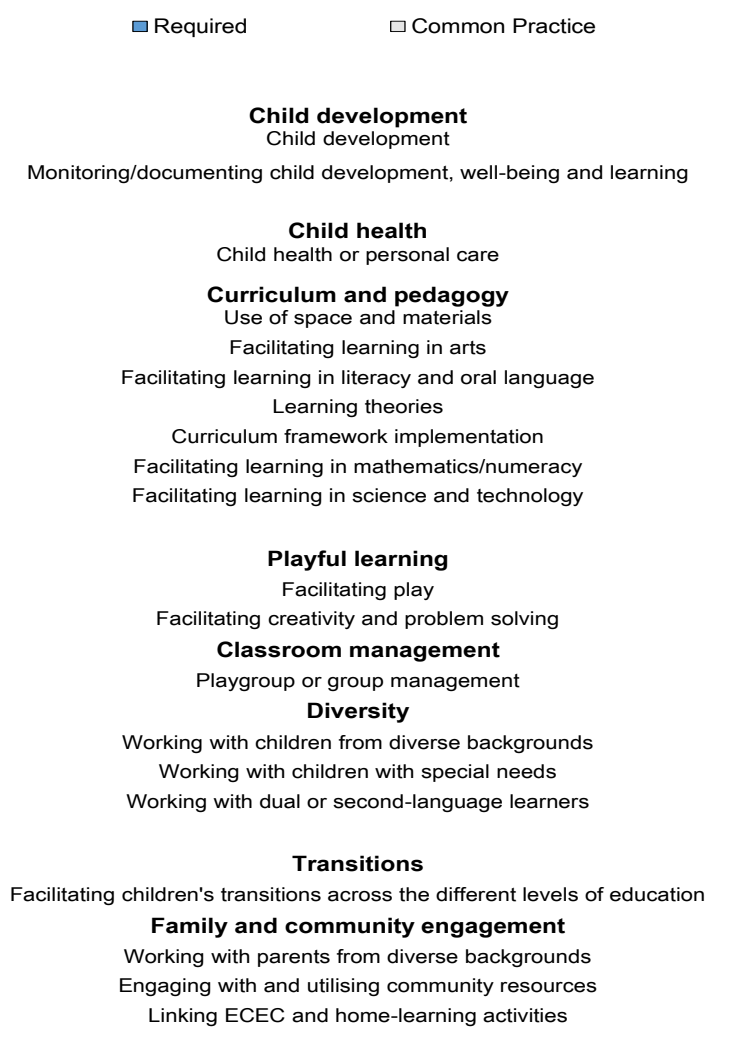

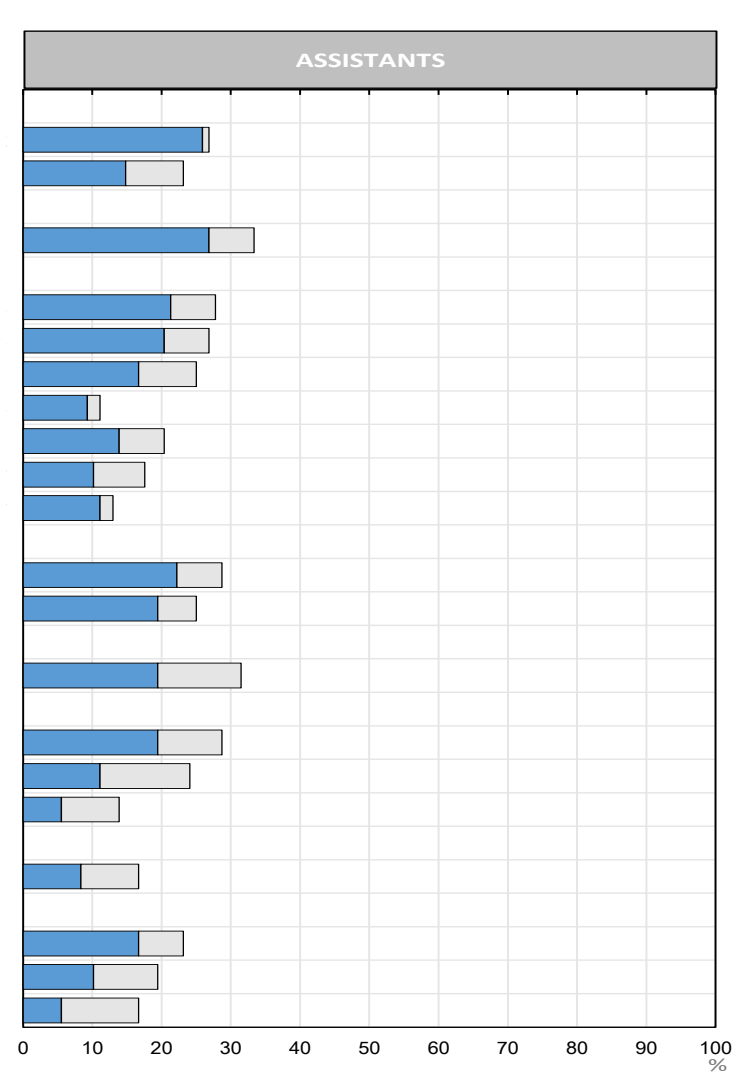

Notes: Countries and jurisdictions were asked to indicate if a specific item is "required", "common practice" or "not regulated/required". This figure only shows content that is required or common practice. Information on settings and categories of staff included for each country and jurisdiction and classification according to standardised age groups is provided in Annex A.

Source: OECD "Quality beyond Regulations" database.

StatLink 部Ist https://doi.org/10.1787/888934249224 


\section{Box 3.3. Supporting cultural diversity and multilingualism through initial education and professional development}

In Australia, teachers are prepared to promote equity and respect for diversity through initial education, with required contents covering several related topics, such as culture, diversity and inclusion, English as an additional language, multicultural education, Aboriginal and Torres Strait Islander perspectives, and socially inclusive practices. There are also several resources to support the inclusion of children from minority backgrounds. For example, in the state of Victoria, a practice guide has been published, "Supporting Bilingualism, Multilingualism and Language Learning in the Early Years", that offers scenarios designed to help staff incorporate children's family languages into daily practice. Additionally, a professional development package is available to support staff in implementing the curriculum framework in remote Indigenous settings. The resource targets staff who speak English as an additional language and is designed to encourage thinking and discussions about how to develop practices aligned with the core curriculum framework.

In Luxembourg, the ECEC system is characterised by its linguistic and cultural diversity, with most children exposed to more than one language from a very early age. A multilingual ECEC education programme for children aged 1 to 4 was introduced in 2017 to help them develop their language skills and be better prepared for a multilingual society and school system. The aims are to ensure an early introduction to the Luxembourgish and French languages, promote the appreciation and inclusion of all family languages, and support collaboration with families and local social and cultural services. ECEC teachers and assistants providing multilingual education receive initial and ongoing training specifically focused on multilingualism. Regular exchange meetings of the pedagogical officers are also organised, where participants can exchange ideas regarding multilingualism. In addition, staff are required to receive a minimum of eight hours of professional development in the field of multilingualism every two years.

In Canada, in many provinces and territories, initial education and professional development programmes are provided to support staff to respect and value diversity, and to recognise the unique needs of linguistic minorities and Indigenous communities. It is also mandatory for initial education programmes to cover working with parents from diverse backgrounds (e.g. in Alberta, British Columbia, Manitoba, New Brunswick, Nova Scotia and Ontario). Candidates learn about families' unique characteristics and are trained to implement family-centred approaches. Additionally, there are several professional development opportunities. For example, Nunavut has developed a centre-embedded professional development programme designed to support the implementation of culturally relevant practices of the Inuit culture. The programme is delivered by experts in Inuit culture and provides staff with opportunities for work-based learning and exchanges with Inuit community members. In Alberta, the programme, Getting Ready for Inclusion Today, provides professional development courses along with coaching to support staff in implementing inclusive practices. In New Brunswick, working with parents from diverse backgrounds is a mandatory component of professional development.

\section{Aligning staff initial education with ECEC curriculum frameworks}

Preparing staff to implement and use a curriculum as part of initial education programmes is crucial to ensuring good curriculum implementation and appropriate pedagogical practices. Across participating countries and jurisdictions, curriculum framework implementation in initial education programmes is largely required for teachers across ECEC settings for all age groups (Figure 3.5). Regarding assistants, the majority of countries and jurisdictions either require it or indicate it as common practice (Figure C.3.2). Still, there are some countries and jurisdictions for which the integration of curriculum framework implementation into ECEC staff initial education programmes is not regulated or required. 
Figure 3.5. Inclusion of curriculum framework implementation in teachers' initial education

Percentage of settings for which the inclusion of curriculum framework in teachers' initial education and training is regulated, common practice or not regulated/required, by age group, 2019

Age 0 to 2

$\square$ Required $\quad \square$ Common practice $\quad \square$ Not regulated or required

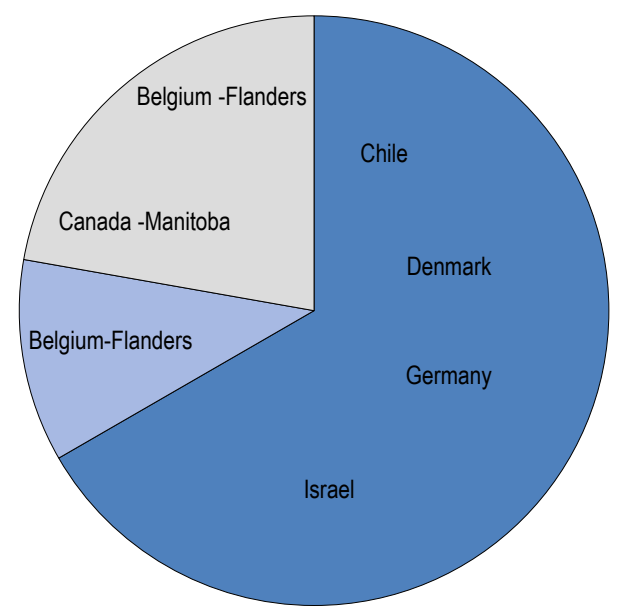

Age 3 to 5/primary school entry

$\square$ Required $\square$ Common practice $\square$ Not regulated or required

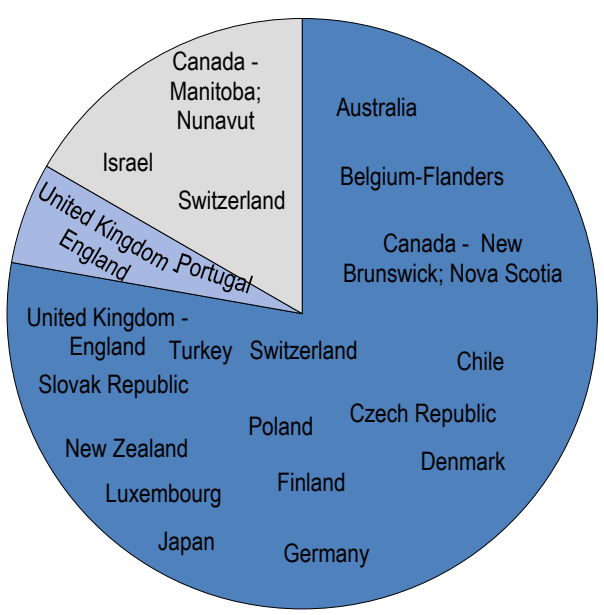

Integrated for age 0 to $5 /$ primary school entry

$\square$ Required $\square$ Common practice $\square$ Not regulated or required

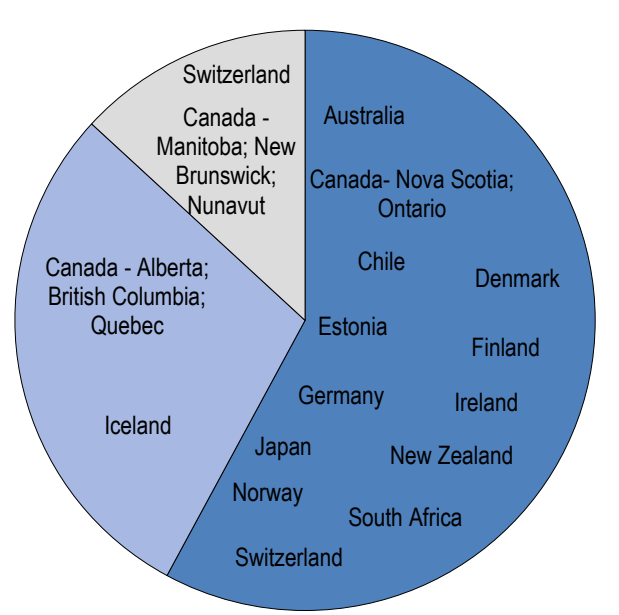

Notes: All countries with information available for settings within a specific age group are represented in the figures. Countries may therefore appear in different categories, representing the different settings. Countries with missing values or not applicable information in all settings in an age group are not shown in the figures. The calculation is based on all settings within a specific age group, including those for which information is not applicable or missing. In countries with multiple settings reported at the sub-national level, when requirements on curriculum implementation are the same across sub-national jurisdictions, only the name of the country is shown, and when specified in different ways, the name of the jurisdiction is also indicated. Information on settings and categories of staff included for each country and jurisdiction and classification according to standardised age groups is provided in Annex A.

Source: OECD "Quality beyond Regulations" database. 
Learning from countries: Incorporating curriculum frameworks in ECEC staff's initial education

In Australia, the curriculum is one of the core contents addressed by initial education programmes for all teachers and assistants. The approved programmes in the ECEC sector are required to offer opportunities for students to learn and understand the ECEC curriculum.

In Canada, in Nova Scotia, New Brunswick, Ontario and Quebec, the curriculum framework is also a required or common practice component of initial education. In some jurisdictions (Newfoundland and Labrador and Alberta), specific professional development courses were provided to ECEC faculty to prepare them to integrate the curriculum framework into the initial education programmes. In Ontario, the initial education programmes for assistants also commonly cover the curriculum framework.

In Ireland, the curriculum framework is not systematically incorporated into the initial professional education programmes of all staff. However, programmes starting in 2021 are required to cover curriculum framework implementation, planning, and assessment. Initial education will cover pedagogical practice aligned with the framework, such as enquiry-based, inclusion, developmentally appropriate practice, and children's individual needs.

In Switzerland, too, the ECEC curriculum is part of the contents covered by the initial education programmes. The programmes include learning opportunities related to pedagogy and all curriculum areas. The initial education institutions were important partners in developing the curriculum, strengthening the connections between curriculum implementation and initial education.

\section{Features of professional development that contribute to process quality}

Professional development is pivotal for ECEC staff to extend and update their knowledge and develop new skills (Hamre, Partee and Mulcahy, 2017 [27]). Ensuring that ECEC staff can engage in diverse and stimulating professional development opportunities is key to assuring the continuity of a high-quality teaching workforce.

Professional development refers to the development of staff knowledge and skills, both through structured trainings and informal means, such as collaboration with colleagues and learning on the job. Structured professional development opportunities, either formal if they lead to qualifications, or non-formal if they do not, include courses, workshops, lectures, coaching or consultation involving experts' feedback. Recent meta-analyses of studies with robust designs have suggested that teachers' participation in professional development initiatives enhances process quality in ECEC settings, namely through the enhancement of teachers' abilities to create close, warm and responsive relationships with children, to prevent and manage behaviour and to stimulate children's thinking, reasoning and language development (Eckhardt and Egert, 2020[14]; Egert, Dederer and Fukkink, 2020[28]; Markussen-Brown et al., 2017[29]; Werner et al., 2016[30]).

Several professional development programmes have been shown to improve teachers' interactions with children (Early et al., 2017[31]; Landry et al., 2014[32]; Williford et al., 2017 [33]). In addition, several studies have shown that there is an impact or association between professional development and teacher well-being, self-efficacy, autonomy, reduced burnout, and a reduction in the odds of mid-year job turnover (Davis, Barrueco and Perry, 2020[34]; Wolf et al., 2018[35]). Professional development can also counteract negative influences of the work environment (Peleman et al., 2018[36]). Recent evidence has also shown that participating in professional development opportunities can buffer the negative effect of teachers' burnout, stress and displeasure with their career (Sandilos et al., 2018[37]; Sandilos, Goble and Schwartz, 
$\left.2020_{[38]}\right)$, with some research suggesting that teachers with lower levels of education can benefit the most from participating in professional development courses (Barros et al., 2018[10]; Early et al., 2017[31]).

\section{The design, content and delivery of professional development}

Features of professional development programmes, such as their duration, delivery format, didactical elements and content focus, are important to understand in terms of their effects on process quality. There is a wide variety of professional development programmes, with several key variables highlighted as influencing process quality (Egert, Dederer and Fukkink, 2020[28]; Peleman et al., 2018[36]; Werner et al., $\left.2016_{[30]}\right)$. Important features include responsiveness to the context, a practical component, opportunities for reflection in real situations, and the inclusion of feedback or individual guidance.

Centre-embedded professional development initiatives can help meet the local needs of professionals (Peleman et al., 2018[36]) and enhance their relevance for professionals' everyday experiences. Embedding professional development in real contexts can better reflect professionals' specific resources, knowledge and beliefs, valuing their diverse competencies and expertise, and better promoting context-specific planning and improvement (Bove et al., 2018[39]; Peleman et al., 2018[36]; Jensen and lannone, 2018[40]). Professional development interventions can also have positive effects when they involve dynamic learning approaches, with a focus on learning in practice and with professionals actively involved in the process (Bove et al., 2018[39]; Peleman et al., 2018[36]).

The inclusion of opportunities for teacher's self-reflection and self-assessment has also been found to be particularly effective, especially for teachers' abilities to support children's thinking and reasoning (Egert, Dederer and Fukkink, 2020[28]). The critical reflection on day-to-day practices can help professionals to integrate practice into theories and goals, increasing their pedagogical awareness and professional understandings, which, in turn, can strengthen educational practices that are responsive to children's needs, potentialities and learning strategies (Bove et al., 2018[39]; Peleman et al., 2018[36]).

Programmes that combine several components (namely a workshop, coursework and individual support) seem to be more effective than programmes that do not, suggesting that combining workshops, courses, and on-site support may enhance quality improvement by offering a variety of individual learning opportunities (Egert, Dederer and Fukkink, 2020[28]; Markussen-Brown et al., 2017[29]). The inclusion of individual support with a feedback component through coaching or mentoring seems crucial (Connors, 2019[41]; Egert, Fukkink and Eckhardt, 2018[42]; Markussen-Brown et al., 2017[29]). Research has also pointed to the importance of the relationship between mentors/consultants and teachers, with better consultant-consultee relationships predicting teacher-child closeness and positive classroom climate (Davis, Barrueco and Perry, 2020[34]). However, centre-embedded models of professional development, such as peer observation or mentoring, remain less common than off-site training activities (OECD, $2020[2])$.

In addition to structured professional development, team collaboration and regular professional exchanges can improve feelings of support and belonging and be a valuable means to implement and transfer newly acquired knowledge (Bove et al., 2018[39]; Resa et al., 2018[43]). Research has shown that regular exchanges within the team are positively related to process quality (Resa et al., 2018[43]). It is possible that regular team meetings, such as discussing, asking for advice and receiving guidance, contribute to the emergence of a collaborative team culture and a good team climate that ultimately supports the daily implementation of newly acquired knowledge and skills (Jensen and lannone, 2018[40]; Vangrieken et al., 2017 [44]). Moreover, preschool teachers appear to consider that they learn the most when collaboration networks between staff are a core practice in their centres (Yin et al., 2019[45]).

As for initial education programmes, the breadth and focus of professional development can matter for process quality. Results from TALIS Starting Strong have indicated that teachers who were involved in a larger number of topics of professional development reported providing more individual support to children 
through adaptive practices, which is indicative of higher process quality (OECD, 2020[2]). Professional development serves mainly to deepen or update areas already included in initial education. In particular, staff trained specifically to work with a diversity of children are more likely to adapt their practices to children's needs and interests, while ECEC staff show moderate confidence in their ability to work with a diversity of children. There is room to develop quality professional development programmes on working with children from diverse backgrounds (see Box 3.3).

Professional development can also be crucial for the implementation of a curriculum framework and the alignment between curriculum and pedagogical practices, especially when a curriculum framework is changed (see Chapter 2). In several countries, various professional development programmes have been put into place that aim to support ECEC staff in implementing the curriculum (Box 3.4).

\section{Box 3.4. Professional development opportunities for curriculum implementation}

In Australia, it is common to provide professional development on curriculum implementation. For example, the state of Victoria supports the implementation of the curriculum framework through practice guides, literature reviews and a range of other resources and professional learning opportunities.

In Ireland, from 2011 to 2013, a nationwide initiative including on-site mentoring visits, cluster group meetings and seminars, helped to support the implementation of the curriculum framework in areas such as raising awareness of the role of children as active learners, the role of parents, and creating high-quality interactions. A more recent professional development programme aims to support staff understanding and implementing the curriculum framework through workshops, on-site support visits by a mentor and practice tasks for staff. Other professional development resources and materials aligned with the national curriculum framework were developed by expert groups, including selfevaluation tools, guides for action planning and examples of pedagogical strategies (e.g. mathematics in everyday experiences). Mentoring supports that use a curriculum framework practice guide, video observations, feedback and staff meetings are also available.

In Canada, it is common to provide professional development on curriculum implementation, particularly when the framework is somewhat recent. In Nova Scotia, for example, mandated professional development provides learning opportunities for reflection, discussion and application of principles and practices promoted in Nova Scotia's curriculum framework. In 2015, New Brunswick embedded a mandatory professional development programme specifically focused on the curriculum framework for all staff employed in licensed ECEC settings. Additionally, pedagogical workshops, local communities of practice and several resources have been put in place.

\section{Learning from countries: Delivery modes of professional development}

In Australia, it is common to offer centre-embedded professional development. To assist settings in the implementation and development of professional development programmes, there is a range of resources and materials provided by the authorities. In the state of Victoria, for instance, additional funding is allocated to ECEC pre-primary centres depending on children's socio-economic background. Funding can be used by ECEC centres for a range of validated programmes that include training for staff on cultural inclusion and trauma-informed practices.

In Canada, in many provinces and territories, early childhood consultants support ECEC settings in quality improvement, especially settings that receive public funding and adopt the quality standards. A variety of intervention models are used, including the use of standardised quality assessment tools to guide assessment and intervention. In Prince Edward Island, Nova Scotia, and Alberta, it is 
mandatory for designated ECEC settings to participate in these consultation programmes. In Quebec, most ECEC settings have access to consultants to enhance the provision quality, who provide a range of supports in order to support the quality of services, such as facilitation of meetings, support to engage with parents and the community, and help on the development of pedagogical tools and design of learning environments. In Ontario, pedagogical networks have been reinforced, and several professional learning resources accessible on line have been developed to respond to the needs of the ECEC sector. In British Columbia, resources have been created for staff interested in self-guided professional development, such as videos and newsletters. In Manitoba, an open-access online platform, functioning as a living textbook with a series of early childhood development modules, supports professional development and complements formal education and training programmes.

In Japan, it is also common for staff to regularly participate in centre-embedded professional development or training provided by respective local governments, universities and ECEC-related organisations through a range of delivery modes, such as guided observation of children, self-reflection and peer learning.

In Luxembourg, because initial education does not focus exclusively on ECEC, professional development is particularly important to support staff in implementing the national curriculum framework. Many different institutions offer a wide range of courses. Centre-embedded professional development has increased over the years, involving the entire staff of the setting. Although most of the professional development is face-to-face, there are also, for example, online courses. It is also common to facilitate exchanges between staff from other sites and promote on-site visits.

\section{Formal recognition of participation in training and assessing the quality of professional development}

The recognition and accreditation of professional development activities can be a valuable means to ensure quality, as it usually involves standards in terms of content, pedagogical strategies and instructor qualifications. Recognised professional development activities can also lead to certificates or diplomas that can bring opportunities for career progression. The Quality beyond Regulations policy questionnaire asked countries and jurisdictions whether there were regulations for formal recognition and accreditation of professional development activities.

Regarding settings for children aged 0 to 2 years, no countries or jurisdictions require formal recognition and accreditation of professional development activities for teachers, although in two (out of eight), this is common practice (Figure 3.6). For assistants, a requirement is in place in one country, Chile, while in the remaining three countries and jurisdictions, there is no regulation or requirement (Figure C.3.3). 
Figure 3.6. Formal recognition and accreditation of professional development activities for teachers

Percentage of settings for which formal recognition and accreditation of professional development activities is required, common practice or not required or regulated, by age group, 2019

Age 0 to 2

$\square$ Required $\quad$ cCommon practice $\square$ Not regulated or not required

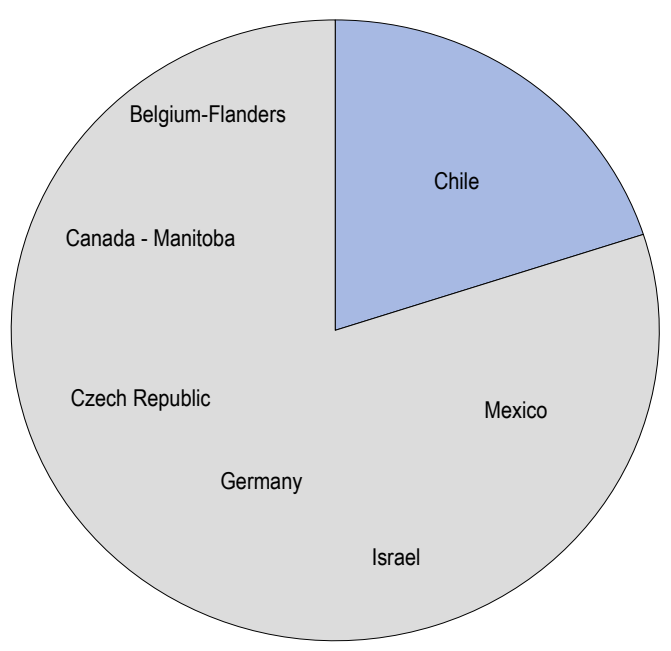

Age 3 to 5/primary school entry

$\square$ Required $\square$ Common practice $\square$ Not regulated or not required

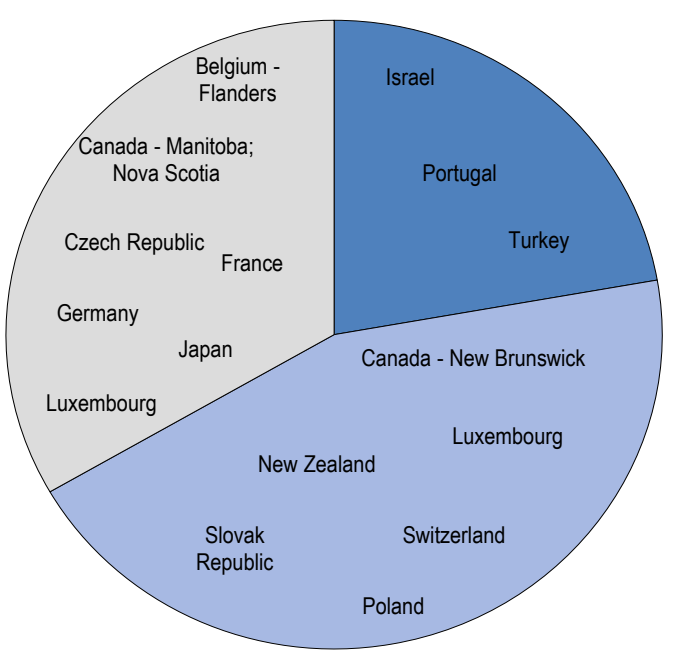

Integrated for age 0 to 5/primary school entry

$\square$ Required $\square$ Common practice $\square$ Not regulated or not required

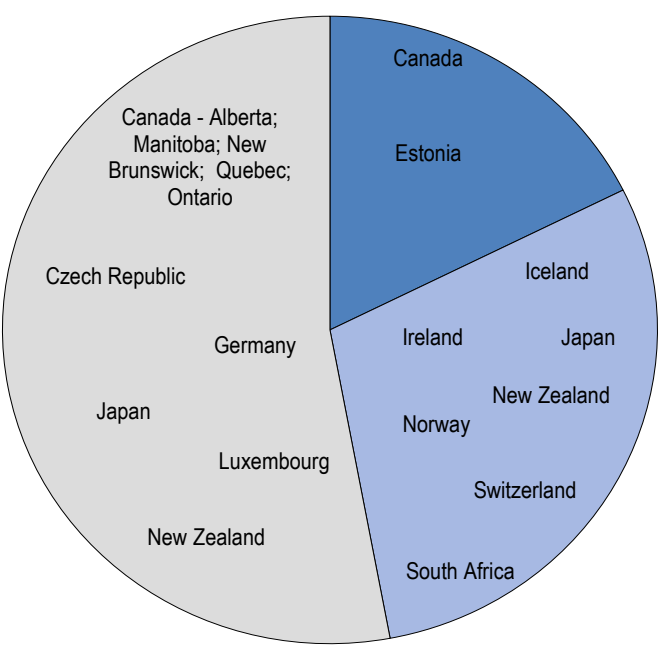

Notes: All countries with information available for settings within a specific age group are represented in the figures. Countries may therefore appear in different categories, representing the different settings. Countries with missing values or not applicable information in all settings in an age group are not shown in the figures. The calculation is based on all settings within a specific age group, including those for which information is not applicable or missing. Information on settings and categories of staff included for each country and jurisdiction and classification according to standardised age groups is provided in Annex A.

Source: OECD "Quality beyond Regulations" database. 
Regarding settings for children aged 3 to 5/primary school entry, formal recognition and accreditation of professional development activities for teachers are required in 3 out of 17 countries/jurisdictions, namely Israel, Portugal and Turkey. For example, Portugal provides formal accreditation of professional development activities for teachers working in the public sector through a national agency. Turkey also regulates formal accreditation of professional development. Concerning assistants, formal recognition or accreditation are common practice in New Zealand and the Slovak Republic.

Regarding settings for children aged 0 to 5/primary school entry, formal recognition and accreditation of professional development activities for teachers are required in 2 out of 19 countries/jurisdictions, namely Canada and Estonia. For assistants, in Canada (British Columbia) and in one setting in New Zealand, it is regulated. For example, British Columbia requires that all ECEC assistants continue to work towards their ECEC credential by completing a minimum of one course in a recognised early childhood development programme within their five-year certificate period. The accreditation of the programmes is at the central level.

The Quality beyond Regulations questionnaire also asked whether there were regulations or it is common practice to assess the quality of professional development. Assessment of the quality of professional development is mainly not regulated, but it is common practice for teachers in a number of participating countries and jurisdictions for settings for children aged 3 to 5 or 0 to $5 /$ primary school entry, but less so for settings for children under the age of 3 (Figure 3.7). The quality assessment of professional development for assistants is, in general, less prevalent than for teachers (Figure C.3.4). 
Figure 3.7. Assessment of the quality of professional development for teachers

Percentage of settings for which assessment is regulated, common practice or not regulated/required, by age group, 2019

Age 0 to 2

$\square$ Regulated

$\square$ Common practice $\quad \square$ Not regulated or not required

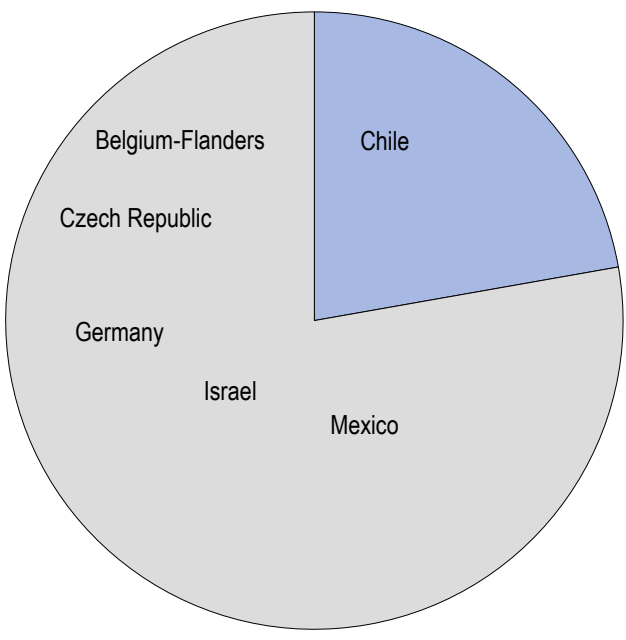

Age 3 to 5/primary school entry

$\square$ Regulated $\square$ Common practice $\square$ Not regulated or not required

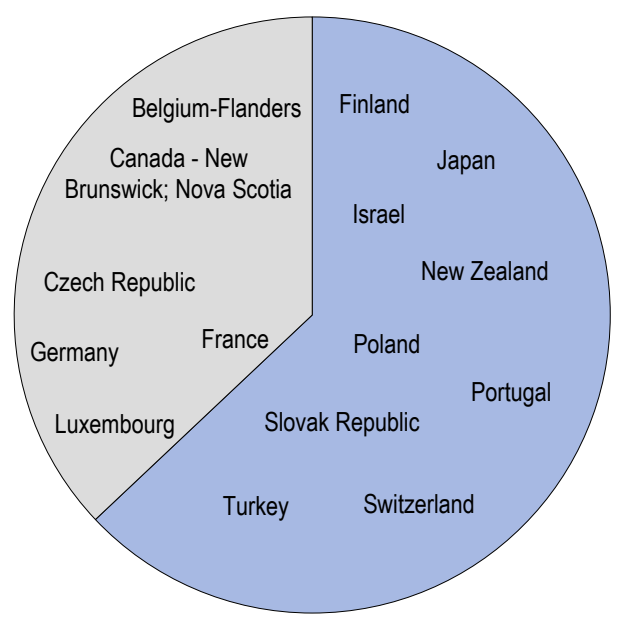

Integrated for age 0 to $5 /$ primary school entry

$\square$ Regulated $\square$ Common practice $\square$ Not regulated or not required

Notes: All countries with information available for settings within a specific age group are represented in the figures. Countries may therefore appear in different categories, representing the different settings. Countries with missing values or not applicable information in all settings in an age group are not shown in the figures. The calculation is based on all settings within a specific age group, including those for which information is not applicable or missing. Information on settings and categories of staff included for each country and jurisdiction and classification according to standardised age groups is provided in Annex A.

Source: OECD "Quality beyond Regulations" database.

StatLink त्ञाता https://doi.org/10.1787/888934249281 


\section{Learning from countries: Requirements to participate in professional development}

While most participating countries and jurisdictions do not regulate the recognition and accreditation of professional development activities or the assessment of quality, several of them have requirements to participate in ongoing professional development activities. Countries may set a minimum of hours of participation in professional development or specific contents and topics, as, for instance, when a new curriculum is being introduced.

In nine provinces of Canada, there are minimum requirements for professional development. For example, in Newfoundland and Labrador, Prince Edward Island, New Brunswick, Nova Scotia and British Columbia, ECEC staff are required to attend professional development to renew their certifications. In New Brunswick, new staff working in licensed ECEC settings must attend professional development specific to implementing the curriculum framework. In Quebec, home-based ECEC providers are required to complete six hours of professional development annually, with an additional requirement that half of the required hours focuses on child development and on the curriculum framework.

In Japan, required professional development includes training for newly appointed and mid-career teachers in public pre-primary settings. In 2009, the system for renewing educational personnel certificates was introduced with the goal to update pre-primary teachers' knowledge and skills. Under this system, pre-primary teachers attend regulated courses and lectures provided by universities and other training institutions once every ten years to renew their certificates.

In Luxembourg, the introduction of compulsory hours of professional development has aimed to ensure that professional development is aligned with the curriculum framework. Goals and contents of professional development programmes are required to align with the curriculum.

In Switzerland, required professional development is used to introduce new topics and subject areas, namely, to implement a new curriculum (see Chapter 2), according to priorities set by cantons and local authorities. These courses are often subsidised or are free of charge.

\section{Setting the conditions for participation in professional development activities}

Participation in professional development is influenced by several conditions, such as funding opportunities and the use of incentives (Schilder, Broadstone and Leavell, 2019 [46]). Work environment features, such as a positive organisational climate, agency in decision making, and time for professional development, are likely critical to staff participation in professional development (Bayly et al., 2020[47]; Bove et al., 2018[39]; Connors, 2019[41]). A respectful and trusting environment can be important for professionals to make the most out of professional development (Bayly et al., 2020[47]). Resources and time to fit the professional development programme into their schedules can impact responsiveness and the effectiveness of professional development interventions (Bayly et al., 2020[47]). Without financial support and incentives (Mowrey and King, 2019 $9_{[48]}$ ), or without releasing time or using inflexible schedules, it can be hard for staff to engage in professional development. According to findings from TALIS Starting Strong, the three main barriers to participating in professional development across participating countries are: not enough staff to compensate for absences when attending training; cost; and conflicts with work schedules (OECD, 2020[2]).

Granting release time during regular working hours for professional development activities can encourage greater engagement in professional development activities (OECD, 2020[2]). Across settings for children aged 3 to 5/primary school entry, releasing time for teachers to attend professional development is a common or required practice in most participating countries and jurisdictions. It is less frequent in settings for children aged 0 to 2 and 0 to 5/primary school entry (Figure 3.8). Teachers in France, Portugal, the Slovak Republic and Turkey are supported by time entitlements. For assistants, time incentives to participate in professional development activities are not regulated or required in the majority of participating countries and jurisdictions (Figure C.3.5). 
Figure 3.8. Time incentives for teachers to participate in professional development activities

Percentage of settings for which time incentives are regulated, common practice or not regulated/required, by age group, 2019

\section{Age 0 to 2}

$\square$ Required

$\square$ Not regulated or not required

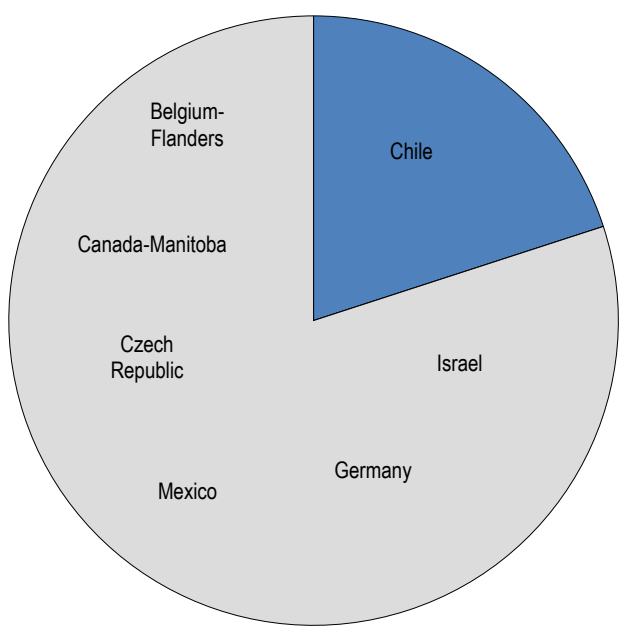

Age 3 to 5/primary school entry

$\square$ Required $\quad \square$ Common practice $\quad \square$ Not regulated or not required
Integrated for age 0 to $5 /$ primary school entry

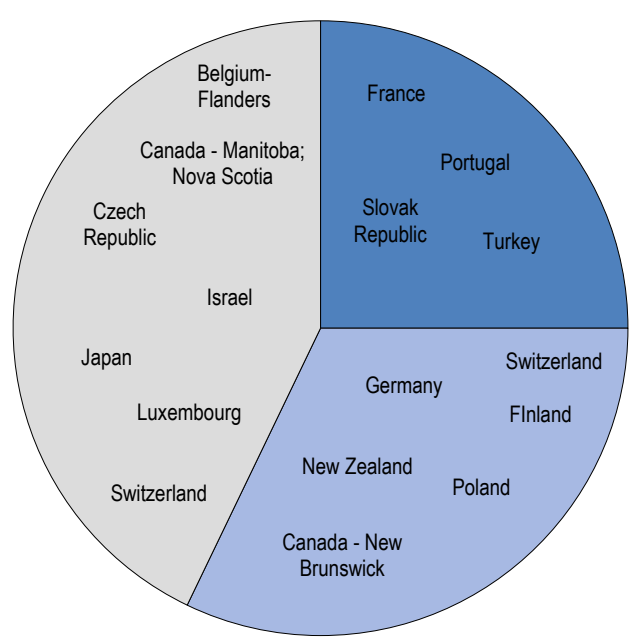

$\square$ Required $\square$ Common practice $\square$ №t regulated or not required

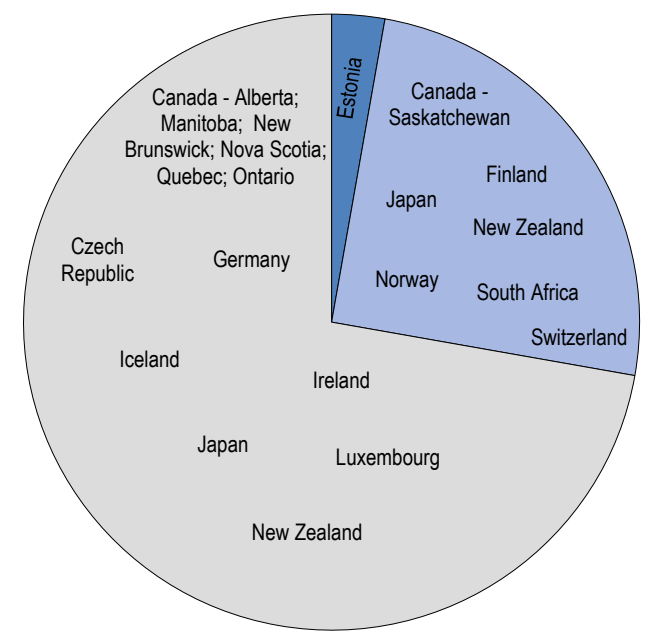

Notes: All countries with information available for settings within a specific age group are represented in the figures. Countries may therefore appear in different categories, representing the different settings. Countries with missing values or not applicable information in all settings in an age group are not shown in the figures. The calculation is based on all settings within a specific age group, including those for which information is not applicable or missing. Information on settings and categories of staff included for each country and jurisdiction and classification according to standardised age groups is provided in Annex A.

Source: OECD "Quality beyond Regulations" database. 


\section{Learning from countries: Providing financial incentives to support participation in professional development}

Offering adequate financial support can be crucial to support staff in their investments in professional development (OECD, 2020[2]). This support can be, for example, covering the costs related to professional development. Developing flexible, professional programmes that enable working and training at the same time can also facilitate participation (OECD, 2020[2]).

In Canada, provinces' and territories' governments provide several types of support for participation in professional development, which may be financial, in-kind, or funding to ECEC settings. For example, in British Columbia, professional development funding is available to support both teachers and assistants who are experiencing barriers to maintaining the required professional development hours to ensure their credentials. Funding is available for, but not limited to, tuition, books, tutoring, travel and occasional childcare costs. In Manitoba, a workplace pre-service training model has been introduced for teachers employed in the regulated ECEC sector. The setting receives funding so that the candidate can attend the training for 2-3 days per week and continue to receive their regular wages. The programme has helped to retain qualified staff in centres. In Quebec, licensed ECEC settings receive a subsidy to determine the type of professional development aligned with staff needs. Alberta offers several grants to both teachers and assistants so that they can attend approved conferences and workshops.

In Japan, it is common for staff to receive reimbursement and coverage of costs associated with official professional development.

\section{Assessing professional development needs and barriers to participation}

The aim of assessing professional development programmes is to determine their effectiveness and relevance. As programmes are designed for staff with different types of initial preparation, working in different roles and with different levels of experience, assessment of the programmes is important to ensure that coherent pathways for skills development are offered (OECD, 2020[2]). In addition, designing such pathways calls for the assessment of staff needs and the barriers to participation in professional development.

Experts have long emphasised that one key aspect for the effectiveness of professional development interventions is the alignment between professional development and professionals' needs and interests (Bove et al., 2018[39]; Peleman et al., 2018[36]). Professional development that targets staff needs can be pivotal for making it meaningful and relevant for participants. Several studies have shown, in fact, that teachers find it important for professional development programmes to address their needs, advocating for training opportunities relevant to their everyday practices (Barnes, Guin and Allen, 2018[49]; Linder et al., 2016 $\left.{ }_{[50]}\right)$. However, analyses using the TALIS Starting Strong data found a positive relationship between receiving training and perceived needs for further professional development $\left(O E C D, 2020_{[2]}\right)$. This might reflect the effectiveness of training in stimulating the interest of staff to improve their knowledge and skills in this area, including by increasing awareness about the complexity of the topics. Better understanding staff needs and interests, while also aligning the supply of professional development with policy objectives, can be a starting point to develop professional development that is both meaningful and stimulating.

The delivery of professional development also needs to address some of the barriers to participation. Proposing programmes that are meaningful to staff is important, but other barriers, such as programmes' geographical location and costs, beyond the need to find time, also play a big role (Linder et al., 2016[50]). Like needs and interests, barriers to professional development can be diverse; they can relate to logistics, working conditions, personal factors, or a combination of all of the above. Assessing barriers regularly and in the specific context can be another important step to developing professional development initiatives likely to engage staff. 
The Quality beyond Regulations questionnaire asked whether, for both teachers and assistants, the assessments of needs, barriers to participation and quality of professional development are required, common practice or not regulated. The assessment of staff professional developmental needs is not often regulated across participating countries and jurisdictions. It is, however, common practice for teachers in a number of countries and jurisdictions, particularly for those working in settings with children aged 3 to 5/primary school entry (Figure 3.9). This is less the case for assistants (Figure C.3.6).

\section{Figure 3.9. Assessment of teachers' professional development needs}

Percentage of settings for which assessment is regulated, common practice or not regulated/required, by age group, 2019

Age 0 to 2

$\square$ Regulated $\quad$ ¿Common practice $\quad \square$ Not regulated or not required

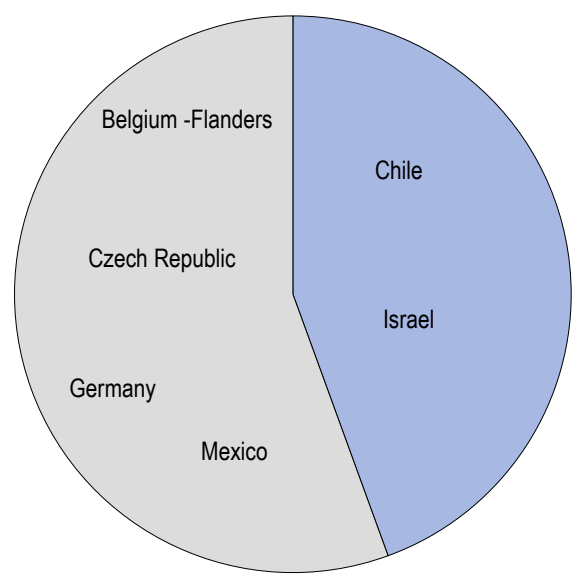

Age 3 to 5/primary school entry

$\square$ Regulated $\square$ Common practice $\square$ Not regulated or not required

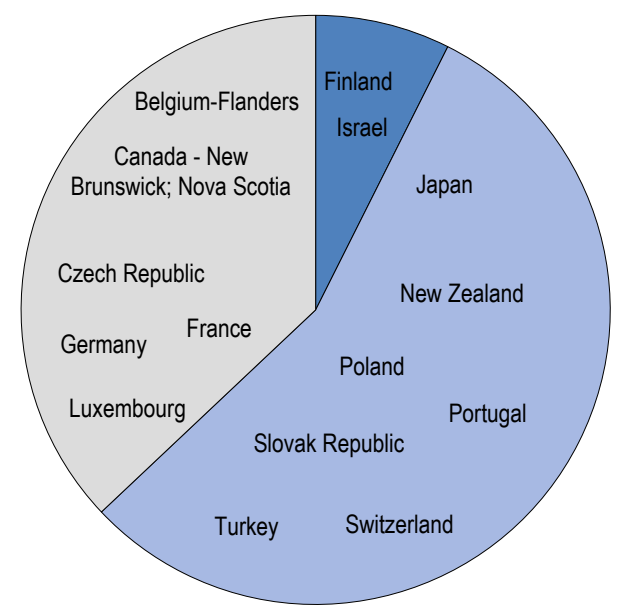

Integrated for age 0 to $5 /$ primary school entry

Notes: All countries with information available for settings within a specific age group are represented in the figures. Countries may therefore appear in different categories, representing the different settings. Countries with missing values or not applicable information in all settings in an age group are not shown in the figures. The calculation is based on all settings within a specific age group, including those for which information is not applicable or missing. Information on settings and categories of staff included for each country and jurisdiction and classification according to standardised age groups is provided in Annex A.

Source: OECD "Quality beyond Regulations" database.

StatLink 部Is] https://doi.org/10.1787/888934249319 
Similarly, the assessment of barriers to participation in professional development is mainly not regulated or not required (Figure 3.10). It is common practice in a small number of countries for teachers. For assistants, barriers to participation in professional development is mainly not regulated and very rarely common practice (Figure C.3.7).

\section{Learning from countries: Monitoring tools for assessing professional development needs}

Relying on different sources of information can ensure that relevant professional development opportunities are available to meet staff needs, although different approaches may need to be co-ordinated. Assessment of staff needs can be done at the level of the ECEC setting, at a national or regional level and more generally through monitoring systems targeting ECEC settings and staff.

In Ireland, regulatory and inspection systems have been progressively changed to strengthen quality assurance, including on issues related to professional development. Education-focused inspections were introduced for pre-primary education settings, which among other things, assess the need for professional development in many areas. Inspectorates help to identify challenges and areas of need and make specific recommendations to support quality improvement through professional development. Agreements are in place with the national quality development service to provide support to ECEC settings. In addition, regular updates on regulatory compliance are provided to initial education institutions. At the national level, national agencies monitor professional development programmes related to the curriculum framework.

In Luxembourg, based on staff self-assessment needs and joint discussions, ECEC leaders are responsible for defining the training courses that are important and necessary. In the last three years, for example, the number of centre-embedded professional development courses has increased significantly as a result of self-assessment processes. In addition, because of assessed needs in curriculum implementation, professional development opportunities have grown for an increased number of subject areas. At the regional level, visits by regional officers are carried out to monitor the implementation of the national curriculum framework and to make recommendations related to professional development.

In Switzerland, staff and leaders in each setting select topics for professional development according to their self-assessed needs. Regular exchanges between experts and staff, facilitated by professional associations, also contribute to assessing professional development needs in the field. For instance, based on professional exchanges and identified needs, an ECEC association has introduced new professional development courses. Additionally, at the regional level, inspection visits may identify professional development needs that drive new professional development initiatives in the canton or commune. The city of Zurich, for example, based on identified needs, has developed a professional development programme for both teachers and assistants that includes topics related to the curriculum, in addition to cross-sectional topics, such as infant education and care, educationally-oriented work and collaboration with parents. 
Figure 3.10. Assessment of barriers to teachers' participation in professional development

Percentage of settings for which assessment is regulated, common practice or not regulated/required, by age group, 2019

Age 0 to 2

$\square$ Regulated

$\square$ Common practice

$\square$ Not regulated or not required

$\square$ Regulated $\square$ Common practice $\square$ Not regulated or not required

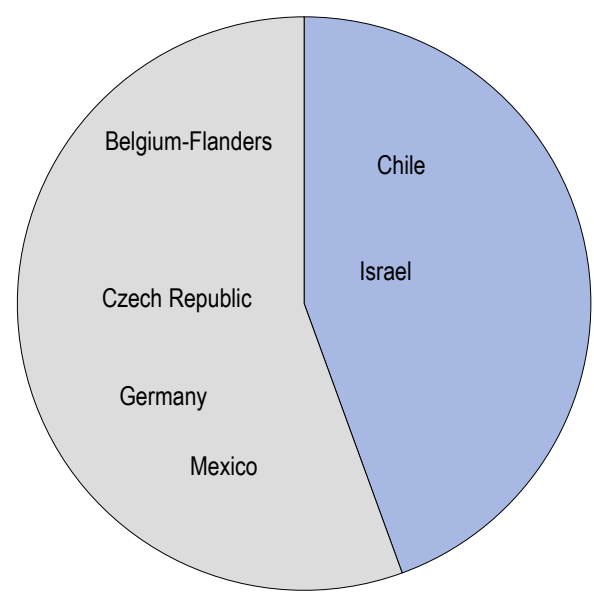

Age 3 to 5/primary school entry

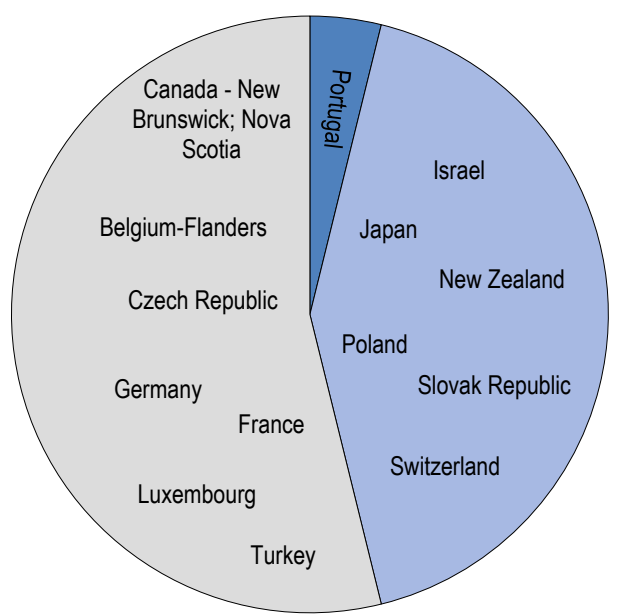

Integrated for age 0 to 5/primary school entry

$\square$ Regulated $\quad \square$ Common practice $\square$ Not regulated or not required

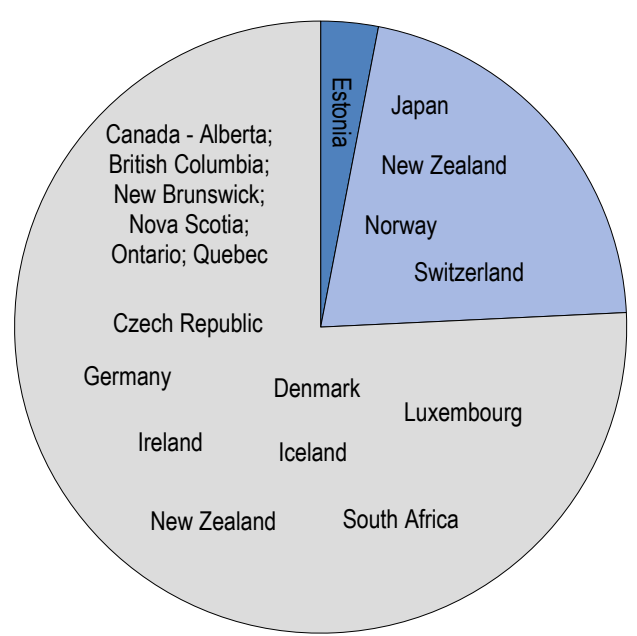

Notes: All countries with information available for settings within a specific age group are represented in the figures. Countries may therefore appear in different categories, representing the different settings. Countries with missing values or not applicable information in all settings in an age group are not shown in the figures. The calculation is based on all settings within a specific age group, including those for which information is not applicable or missing. Information on settings and categories of staff included for each country and jurisdiction and classification according to standardised age groups is provided in Annex A.

Source: OECD "Quality beyond Regulations" database.

StatLink त्ञाजा https://doi.org/10.1787/888934249338 


\section{Features of working conditions that contribute to process quality}

Staff working conditions have an impact on staff well-being, in particular on their emotional well-being, which in turn has an effect on their practices with children and their performance at work. Overall, staff working conditions and well-being can be important drivers of process quality. The importance of staff working conditions for process quality is now well established in the scientific literature and across a wide variety of contexts. In a nutshell, the evidence shows that better working conditions, such as salaries, a positive organisational climate and well-being at work, go hand in hand with higher process quality (Penttinen et al., 2020[51]; Hu et al., 2017[52]; Hu et al., 2017[53]; Shim and Lim, 2019[54]).

Working conditions include various aspects, such as earnings, job security and career prospects, workload, and the quality of the working environment at the ECEC centre. Working conditions contribute to the demands employees are exposed to (i.e. workload, number of children in the group or classroom) and the resources they have at their disposal (i.e. professional autonomy, training) or the rewards they receive for their efforts (i.e. salaries, career progression) (OECD, 2020[2]). A lack of reciprocity between effort and resources or reward can lead to stress, while good alignment between the two contributes to staff well-being (Bakker and Demerouti, 2007[55]; Bakker and Demerouti, 2016[56]). Research shows that ECEC staff's emotional well-being is related to the quality of their interactions with children (de Schipper et al., 2008). Furthermore, working conditions and well-being determine the quality of the job (Cazes, Hijzen and Saint-Martin, 2015 $[57])$, which might, in turn, be a reason for candidates to join the sector, and for existing staff to stay or leave, finally determining the capacity of the sector to retain high-quality staff.

\section{Earning and contractual status}

Salaries are one crucial component of working conditions. Research provides supporting evidence that salary is important for attracting and retaining ECEC staff. Several studies also find a relationship between salaries and the quality of staff's interactions with children, with better-paid staff having more sensitive

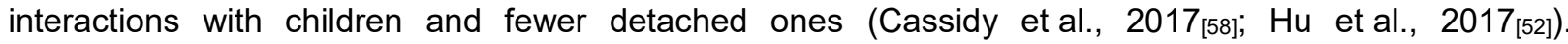
This relationship has also been found in the case of home-based settings (Eckhardt and Egert, 2020[14]). On top of the salary itself, it seems that teachers' perceptions regarding the fairness of their wage are also positively correlated with process quality (Cassidy et al., 2017[58]).

Results from TALIS Starting Strong further show that staff's low satisfaction with salaries associates with stress and disengagement with work (OECD, 2020[2]). In public institutions, the statutory salaries of pre-primary teachers are similar to those of primary teachers in many OECD countries, but not all of them (Figure 3.11). However, these data do not provide the full picture of salaries in the sector. Assistants' salaries can be low and not necessarily regulated, and there may also be differences in salaries between the private and public sectors. Finally, there is a lack of comparable data across countries on salaries of staff working with children under the age of three. 
Figure 3.11. Pre-primary teachers' statutory salaries at different points in teachers' careers

Annual statutory salaries of staff in public institutions based on typical qualifications at different points in staff careers, in equivalent USD, converted using purchasing power parity, 2019

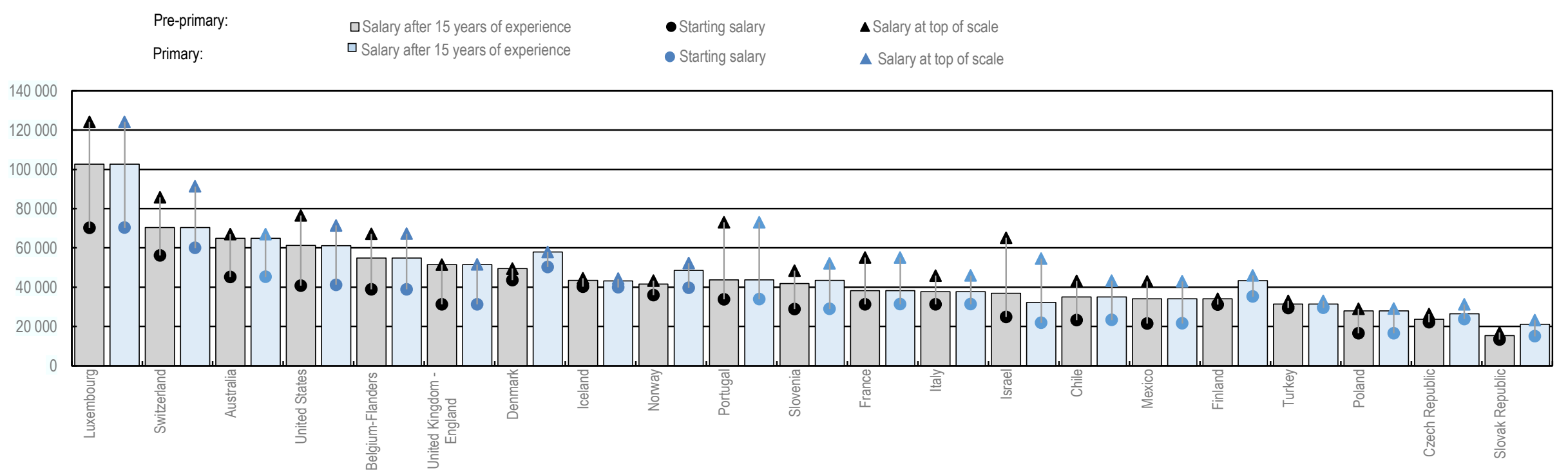

Note: Data are not available for Canada, Estonia, Germany, Ireland, Japan and New Zealand for pre-primary education.

Source: OECD (2020[19]), Education at a Glance 2020: OECD Indicators, https://doi.org/10.1787/69096873-en. 
Job security, understood as a high probability to maintain employment, is an important reward for staff work (OECD, 2020 [2] $)$ and is a major determinant of individual well-being (Cazes, Hijzen and Saint-Martin, $\left.2015_{[57]}\right)$. Job security can help attract new staff to the sector. The contractual status and, in particular, having permanent employment, contribute to job security. Permanent contracts can help retain existing staff in the sector or in ECEC centres, preventing staff turnover, which is a common challenge in the ECEC

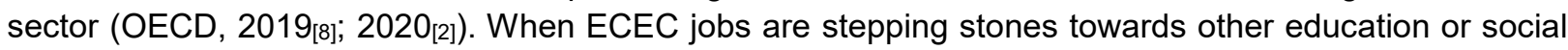
jobs, the ECEC sector can benefit from good candidates but might encounter difficulties in ensuring stable, high-quality services because of high turnover. This issue can be addressed, to some extent, by employment with permanent contracts.

The Quality beyond Regulations policy questionnaire asked countries and jurisdictions about policy measures in place concerning staff contract types. In the vast majority of settings, there are no policy measures or regulations related to the contractual conditions for teachers and assistants (Figure C.3.8). These measures are in place in approximately $15 \%$ of settings for children aged 0 to 2 and 0 to 5 , and in less than $25 \%$ of settings for children aged 3 to 5 . However, ECEC staff may fall under general labour market conditions that are not necessarily reflected in the Quality beyond Regulations questionnaire. Data from TALIS Starting Strong show that among participating countries, between $70 \%$ in Chile to $90 \%$ of ECEC staff in Norway have a permanent contract (OECD, 2019 $\left.{ }_{[8]}\right)$.

\section{Career progression opportunities}

Opportunities for career progression are another important aspect of working conditions that are likely to affect the attraction and retention of the workforce. Career progression can help staff remain engaged with the profession and feel that their efforts are rewarded, which can improve job satisfaction and work-related well-being (OECD, 2020[2]). However, in the ECEC sector, as in the school sector, traditional careers are often "flat", with few opportunities for advancement or diversification, and staff who would like to progress in their career might choose to leave the job. Progression can involve salary increase, new responsibilities through changing roles, such as changes from assistants to teachers or teachers to leaders, or specialisation in certain tasks along the professional career.

In many countries, salaries after 15 years are very similar to those at the beginning of an ECEC professional's career. There are possibilities, however, for salary progression in some of the settings in Belgium (Flanders), Israel, Luxembourg, Portugal, Switzerland and the United States (see Figure 3.11). Policies can support career progressions by setting measures and regulations for promotions and increased responsibilities adapted to the organisation of the ECEC sector and its different roles.

The Quality beyond Regulations policy questionnaire asked whether countries and jurisdictions have measures or regulations to support promotions or wage increases associated with staff performance. In most settings, participating countries and jurisdictions reported that there were no measures to support promotions for teachers, and even less so for assistants (Figure 3.12, Figure C.3.9). Countries may, however, not have reported on measures covering the whole education workforce or the public sector, and not specifically for ECEC staff. Regarding teachers, Australia, Chile, France, Japan, New Zealand, the Slovak Republic and Switzerland have measures to support career progression schemes in some of the settings. Regarding assistants, such measures are in place in some of the settings in Australia, Chile, France, Portugal and the Slovak Republic. 


\section{Learning from countries: Measures to support promotions or wage increases}

In Australia, teachers and assistants can progress in their careers through salary increases based on their work performance and length of service. Regulations on working conditions and salaries are set either nationally or based on state requirements.

In Finland, career progression is under the responsibility of municipalities that set systems for salary increases based on staff performance.

In France, teachers can reach higher positions and leading roles, such as school directors or educational advisers. Staff can also progress to specialised teaching roles, for instance, for working with children with additional needs.

In Japan and Switzerland, teachers and leaders in the public sector can be promoted or have an increase in salary according to their work performance.

The recognition of skills acquired on the job through formal systems can also facilitate career progression (OECD, 2020[2]). For instance, in Canada, in Nova Scotia, a recognition-of-prior-learning process for staff is in place. The initiative has developed a competency profile that specifies the expected skills and knowledge staff should demonstrate, and the assessment is based on exams and scenario-based interviews. In Quebec, there are also opportunities for formal recognition of prior qualifications, especially for staff having acquired some experience outside Quebec in order to address labour shortages. 
Figure 3.12. Measures in place to support promotions or wage increases associated with teacher performance

Percentage of settings in which these measures or regulations are in place, by age group, 2019
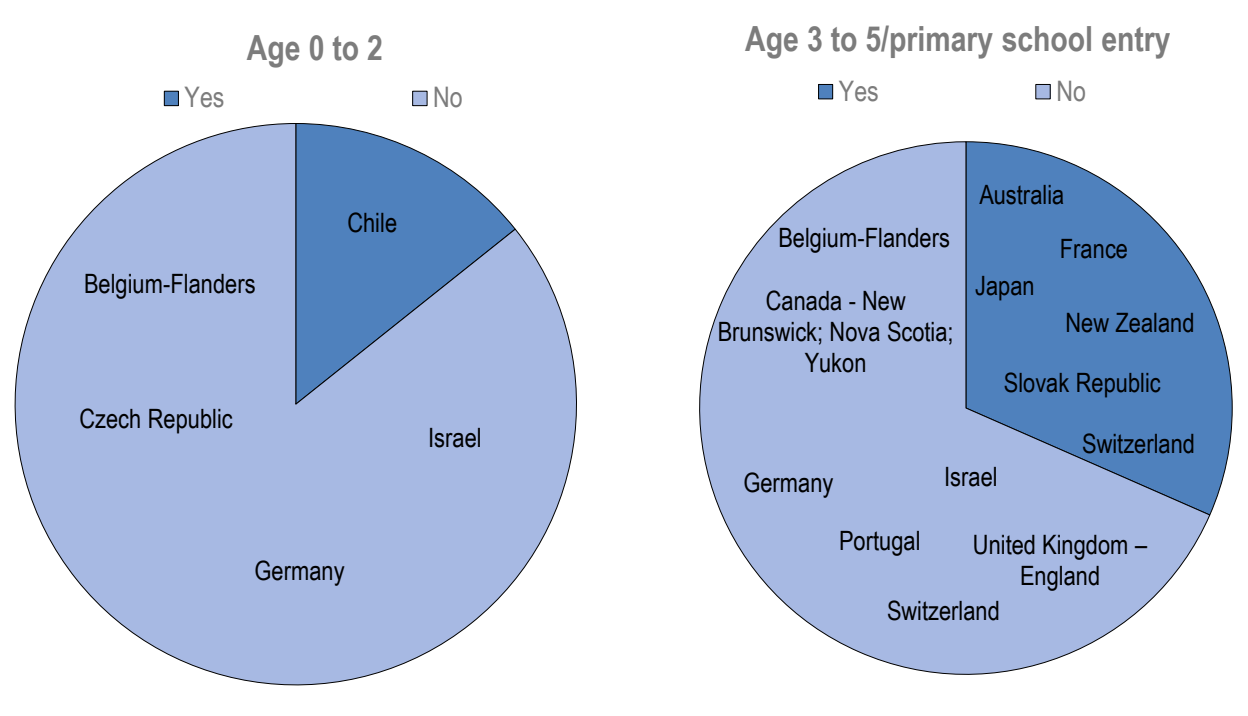

Integrated for age 0 to $5 /$ primary school entry

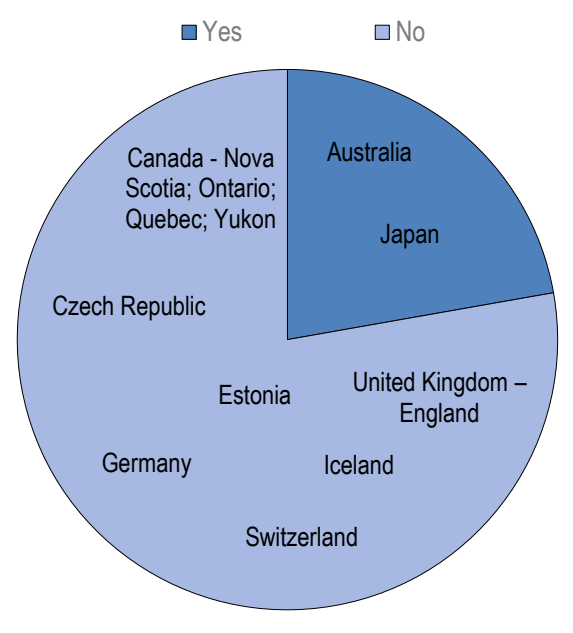

Notes: All countries with information available for settings within a specific age group are represented in the figures. Countries may therefore appear in different categories, representing the different settings. Countries with missing values or not applicable information in all settings in an age group are not shown in the figures. The calculation is based on all settings within a specific age group, including those for which information is not applicable or missing. Information on settings and categories of staff included for each country and jurisdiction and classification according to standardised age groups is provided in Annex A.

Source: OECD "Quality beyond Regulations" database. 


\section{Allocated time to perform various tasks}

The quality of a working environment also includes non-economic aspects of jobs, such as the nature and content of the tasks at hand and working-time arrangements (Cazes, Hijzen and Saint-Martin, 2015[57]). A heavy workload with multiple ongoing tasks that demand persistent physical, psychological or emotional efforts can lead to less engagement and commitment, with detrimental effects on classroom practices (Ansari et al., 2020[59]). There is empirical evidence suggesting that excessive demands and work overload (i.e. high demand, not enough time, short of assistance) are negatively associated with process quality (Aboagye et al., 2020[60]; Aboagye et al., 2020[61]; Chen, Phillips and Izci, 2018[62]).

In the ECEC sector, staff's work includes a variety of responsibilities and activities that go beyond working directly with children, including individual planning or preparing play and learning activities; collaborating and speaking with colleagues and parents or guardians; documenting children's development, well-being and learning; attending professional development activities; and administrative tasks. The allocation of hours to different tasks to ensure that staff can devote sufficient time to each one, including tasks without children, is important for staff well-being (OECD, 2020[2]).

The Quality beyond Regulations policy questionnaire asked countries and jurisdictions whether staff are given protected time to carry out seven different types of tasks to be performed without children. Teachers, across settings for all age groups, are more likely to have protected time than assistants for all tasks assessed, with the differences being substantial in most tasks (Figure 3.13). For teachers, protected time is more frequent in settings for children aged 3 to 5 , with $40-50 \%$ of them having protected time for the majority of tasks, and less so in settings for children aged 0 to 5 , with $30 \%$ of teachers or less having protected time for the various tasks. Among the activities considered, there is not much variation, except for laundry and cleaning, which is rarely accompanied with protected time, even for settings for children aged 0 to 2 (Figure C.3.10).

\section{Figure 3.13. Activities for which ECEC staff are given protected time}

Percentage of settings in which staff are given protected time separate from their contact time with children for the following activities, by age group and staff type, 2019

Age 3 to $5 /$ primary school entry

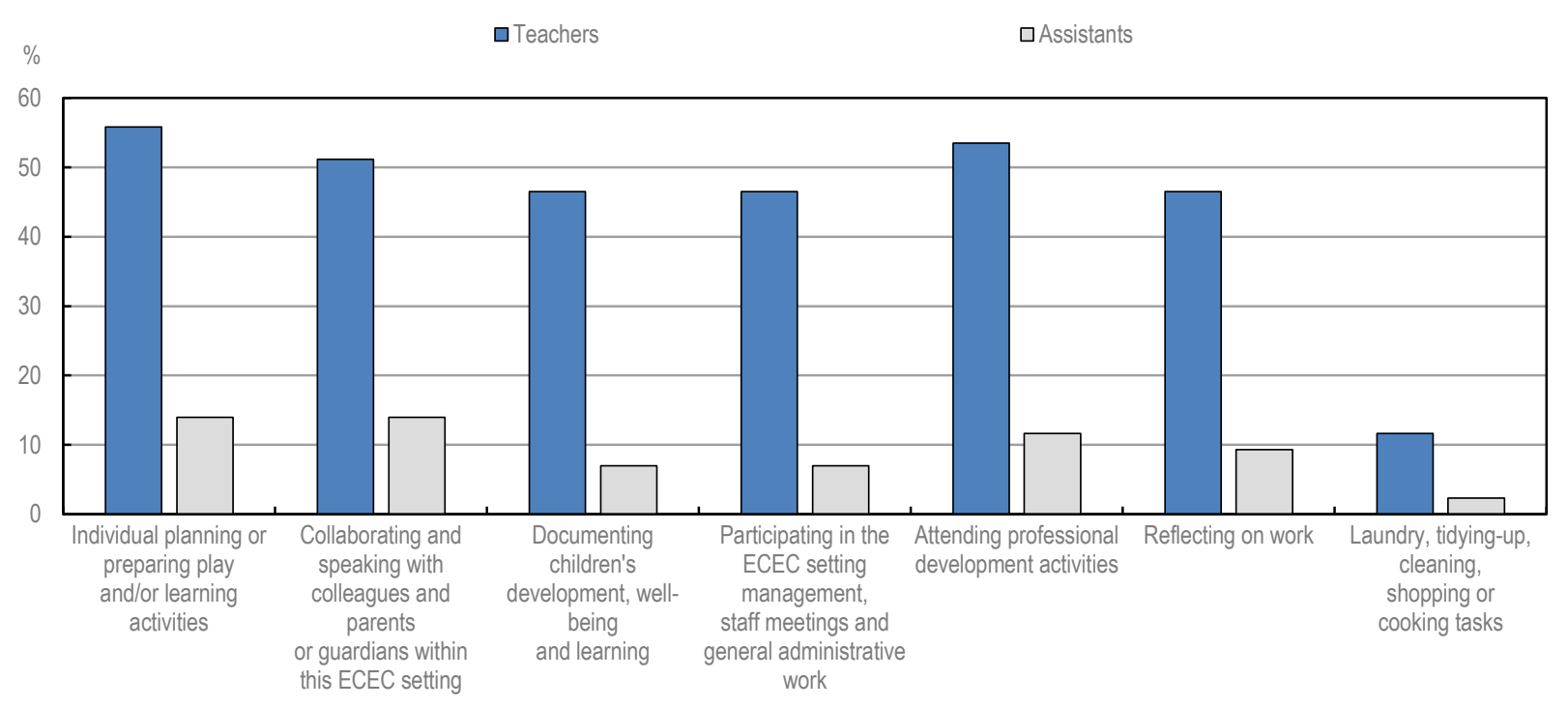


Integrated for age 0 to $5 /$ primary school entry

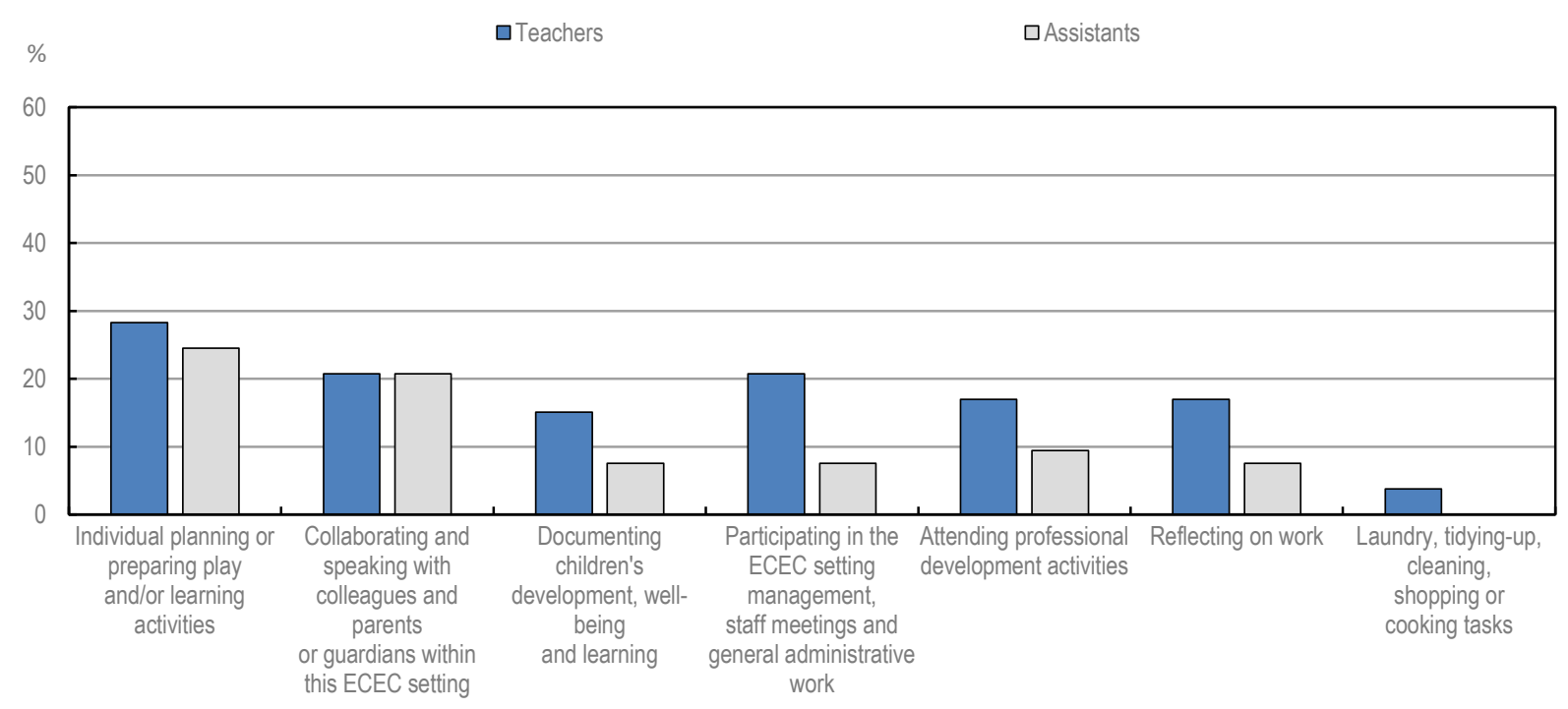

Notes: Calculations include all settings within an age group.

Information on settings and categories of staff included for each country and jurisdiction and classification according to standardised age groups is provided in Annex $A$.

Source: OECD "Quality beyond Regulations" database.

StatLink 제 Sh https://doi.org/10.1787/888934249395

Countries and jurisdictions differ in their regulations with regard to protecting time for activities to be performed without children. Some have policies to protect time for a wide range of activities without children. This is the case for settings for children aged 3 to 5 in the Czech Republic, Finland, Luxembourg, Poland, Portugal, the Slovak Republic and Turkey for teachers, and in the Czech Republic, Luxembourg and the Slovak Republic for assistants as well. In settings for children aged 0 to 5, protecting time for a wide range of activities without children is in place in Estonia, Finland, Luxembourg and Norway for teachers, and in Luxembourg for assistants (Figure 3.14, Figure C.3.11). 
Figure 3.14. Extent of protected time for activities without children

Percentage of tasks (among the seven considered tasks) for which staff are given protected time separate from their contact time with children, by age group and staff type, 2019

Age 3 to 5/primary school entry

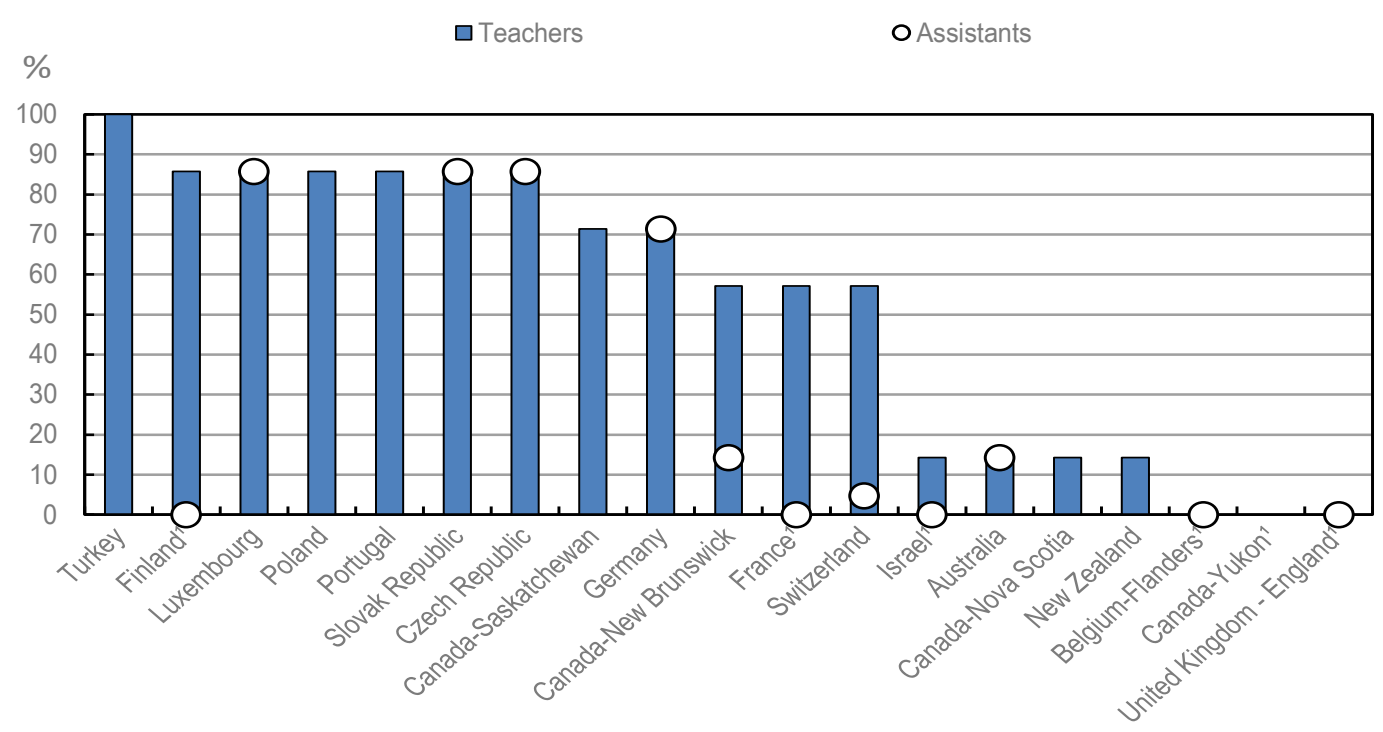

Integrated for age 0 to 5 /primary school entry

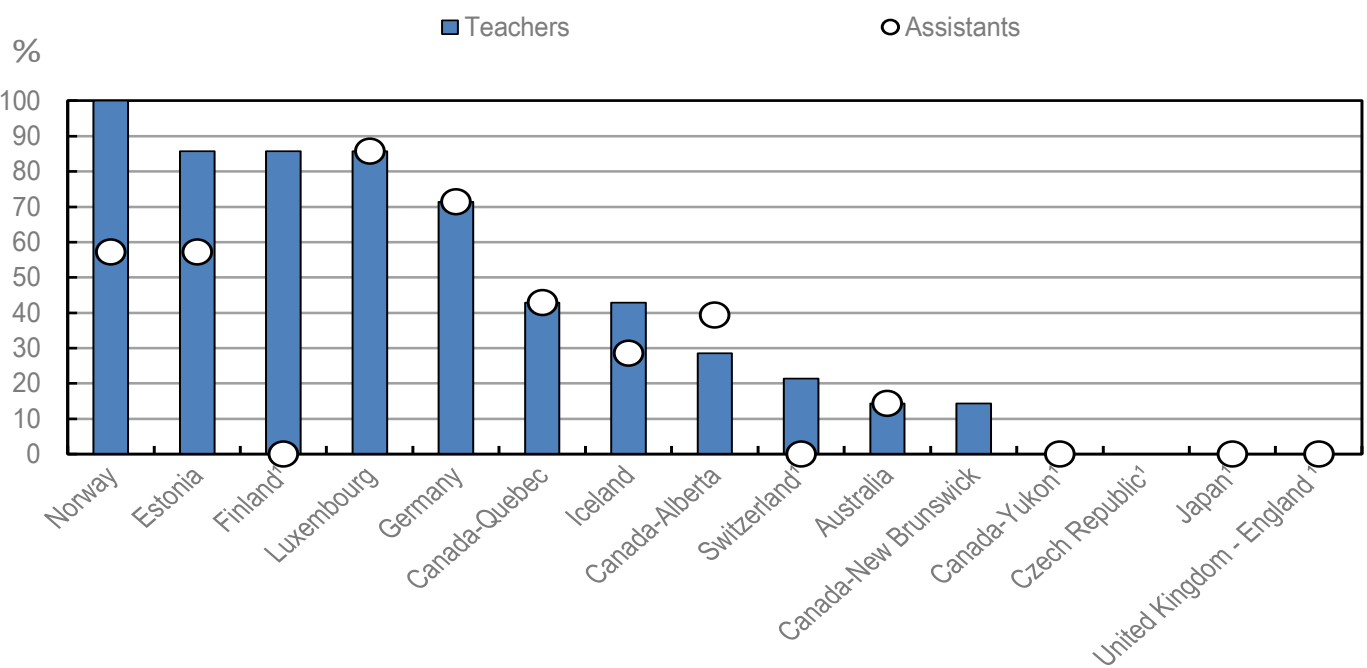

1. Percentage of tasks for which staff are given protected time is $0 \%$.

Notes: The percentage of tasks is based on a list of seven tasks, namely: individual planning or preparing play and learning activities; collaborating and speaking with colleagues and parents or guardians within this ECEC setting; documenting children's development, well-being and learning; participating in the ECEC setting management, staff meetings and general administrative work (including communication, paperwork and other clerical duties); attending professional development activities; reflecting on work; laundry, tidying-up, cleaning, shopping or cooking tasks. For countries with multiple settings for the same age group, the average percentage is displayed. In countries with multiple settings within the same age group, the average percentage across settings is taken. Settings for which information is not applicable or missing are not taken into account. Information on settings and categories of staff included for each country and jurisdiction and classification according to standardised age groups is provided in Annex A.

Source: OECD "Quality beyond Regulations" database.

StatLink त्ञाज https://doi.org/10.1787/888934249414 


\section{Features of leadership that contribute to process quality}

Leadership is pivotal for organisations' success and a key driver of potential change and quality improvement in educational settings. Leaders can help build a climate of trust, collaborative and caring relationships, and a sense of belonging (Brinia, Poullou and Panagiotopoulou, 2020[63]; Heikka, Halttunen and Waniganayake, 2018[64]). It is expected that leaders act as promoters of the quality of ECEC settings, providing resources and conditions for staff to develop high-quality practices. Findings from TALIS Starting Strong show that in centres in which leaders set a clear vision, staff report a stronger sense of self-efficacy (OECD, 2020[2] $)$. Importantly, effective leadership can play a significant role in staff engagement in professional development initiatives (Jensen and lannone, 2018[40]; Keung et al., 2020[65]; Page and Waniginayake, 2019[66]).

Leadership practices can focus on pedagogical dimensions (e.g. staff-child interactions, staff motivation for achieving the centre goals, community and parental/guardian engagement), as well as on management and administrative tasks (e.g. hiring staff, managing budgets) (Daniëls, Hondeghem and Dochy, 2019[67]; Douglass, 2018[68]). While different dimensions of leadership are important for quality, pedagogical leadership, depending on the context and situation, can play an important role in shaping everyday classroom practices (Halpern, Szecsi and Mak, 2020[69]). Recent research suggests that pedagogical leadership practices that strategically focus on children's educational processes and foster trust, collective understanding and responsibility for excellence, are related to high-quality, teacher-child interactions (Ehrlich et al., 2019[3]).

A literature review has highlighted that a leader's ability to communicate and maintain good relationships with his/her staff and the community, providing frequent feedback and recognising accomplishments, are key factors for effective leadership (Daniëls, Hondeghem and Dochy, 2019[67]). Additionally, leaders should take into consideration staff needs and expectations, providing them with opportunities for skill development, while creating adequate work conditions through the establishment of a respectful, trusting and safe environment (Bove et al., 2018[39]; Page and Eadie, 2019 ${ }_{[70]}$ ).

Research also suggests that leadership shared or distributed among staff members is related to staff well-being and more positive conceptions of child development, which, in turn, can be important for quality classroom practices and children's development (Keung et al., 2020[65]). When leaders nurture trust and foster a collective understanding towards excellence and improvement, the relationships among staff are stronger, and staff is more willing to work together, with direct links to higher levels of process quality (Ehrlich et al., 2019 $\left.{ }_{[3]}\right)$. Similarly, results from TALIS Starting Strong show that centres' shared leadership, in which staff are encouraged to have a say in important decisions, is positively associated with staff attitudes linked to process quality in ECEC settings (OECD, 2020[2]).

\section{Education requirements and recognition of prior learning}

ECEC leaders' initial preparation can support their engagement in pedagogical leadership and help them build a shared understanding of effective leadership (Myran and Masterson, 2020[71]). Higher professional status and qualifications can help attract qualified candidates. Importantly, it can also shape leaders' ability to reflect upon their pedagogical leadership, as well as their attitudes about the quality of pedagogical leadership, and can thus impact their involvement in effective leadership practices (Fonsén and Soukainen, 2020[72]; Myran and Masterson, 2020[71] $)$ Results from TALIS Starting Strong show that, in several countries, leaders whose initial preparation focused on early childhood and/or pedagogical leadership report engaging more frequently in pedagogical tasks, suggesting that initial training can be supportive of effective leadership (OECD, 2020[2]).

The Quality beyond Regulations policy review gathered data on centre leaders' minimum educational requirements in different settings (Figure 3.15). Across participating countries and jurisdictions, the most prevalent qualification requirement for leaders is a tertiary education (ISCED Level 6). Around $70 \%$ of 
settings for children aged 0 to 2 have minimum requirements of an ISCED Level 6 level, contrasting with roughly $40 \%$ of settings for children aged 3 to 5 and less than $20 \%$ for the 0 to 5 age group. Regarding the latter, minimum requirements seem to vary considerably across countries and jurisdictions, with $20 \%$ requiring no minimum qualification. To put it differently, settings for children aged 0 to 2 appear to require a higher level of qualifications for becoming a centre leader, compared to settings for other age groups, with age-integrated settings for ages 0 to 5 having the lowest minimum qualification requirements.

\section{Figure 3.15. Minimum educational requirements for ECEC centre leaders}

Percentage of settings across countries for which the following minimum educational requirements are in place, by age group, 2019

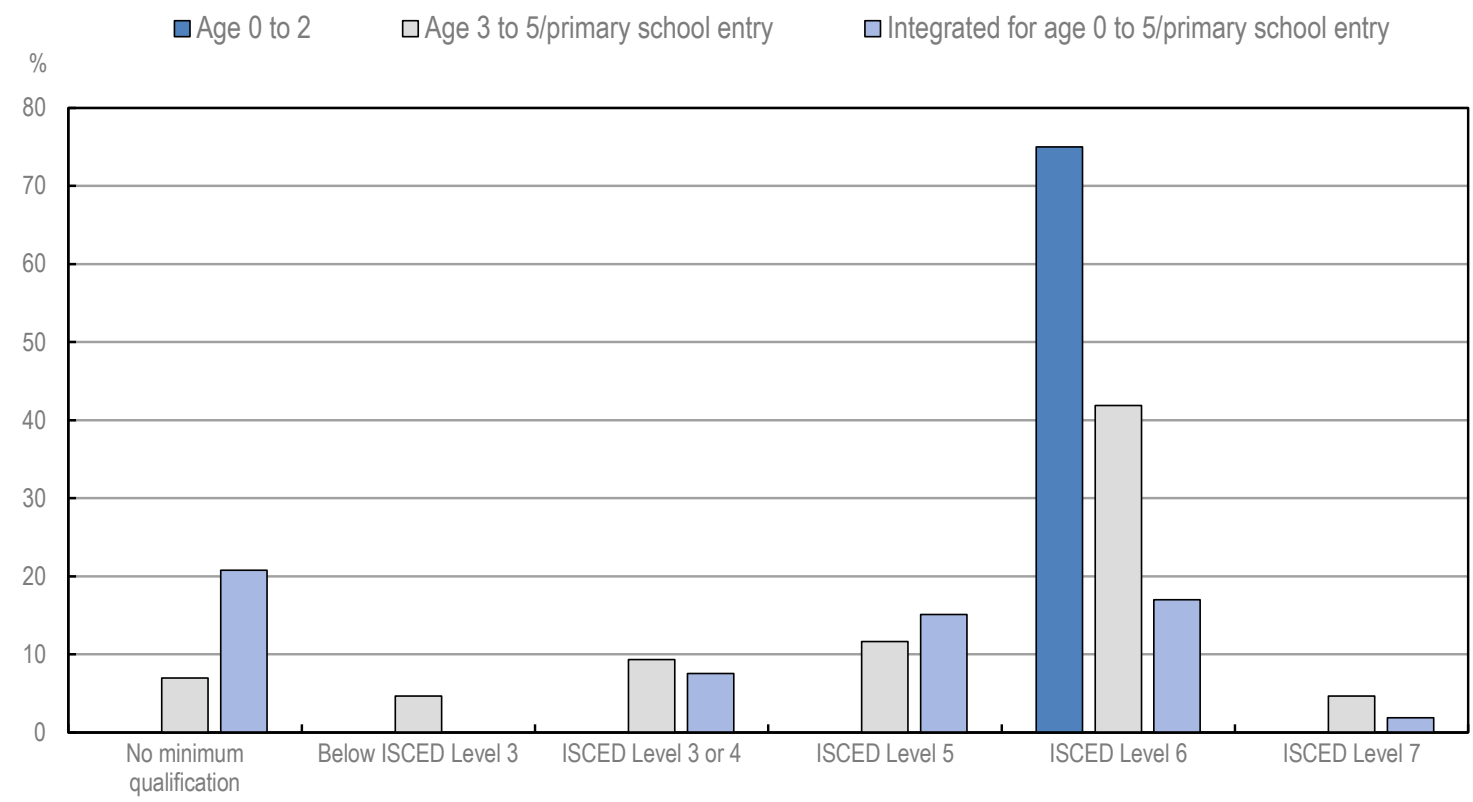

Notes: Calculations include all settings within an age group.

Information on settings and categories of staff included for each country and jurisdiction and classification according to standardised age groups is provided in Annex A.

Source: OECD "Quality beyond Regulations" database.

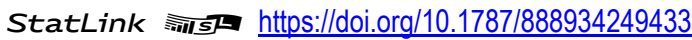

ECEC centre leaders may often start their careers from different positions. Possibilities to meet qualification requirements by recognising prior experience and learning can facilitate career trajectories for ECEC staff and help recruit high-quality leaders with different types of experience. In more than half of settings for children aged 0 to 5 and nearly one-third of settings for children aged 0 to 2 and children aged 3 to 5 , leaders can demonstrate they have the necessary experience and knowledge to act as leaders (Figure C.3.12). 


\section{Learning from countries: Conditions to become an ECEC centre leader}

In Australia, providers are responsible for nominating leaders and verifying the adequacy of their qualifications and prior experience. To assist them, the Australian Children's Education and Care Quality Authority provides the list of approved ECEC qualifications.

In Canada, most provinces and territories (10 in 13) have specific requirements for leaders. In some provinces and territories, requirements include both qualification levels and prior experience in ECEC.

In Japan, too, leaders are required to have adequate qualifications and working experience, although in some cases, a professional can become a leader based on his/her prior experience.

In Luxemburg, for settings for children under the age of three, the bachelor's level is the minimum qualification level for leaders. However, in settings with fewer than 40 children, a qualified teacher can also become a leader. Additional requirements to become a leader include a minimum amount of previous experience in ECEC or education. In settings for older children, teachers elect a committee and its president. The president has some management tasks but no hierarchical authority as this is the responsibility of the regional director. The requirements for becoming a regional director is a master's qualification (ISCED Level 7).

\section{Content areas for leaders' initial training}

ECEC centre leaders are called upon to perform a variety of tasks, from the pedagogical to the administrative, and engage in interactions with staff, parents and several institutions. The breadth in terms of the content of leaders' training is an important aspect of preparing them for their multiple roles. This is also an important policy lever to make the most of leadership in the ECEC sector.

The Quality beyond Regulations policy questionnaire asked whether it is required or common practice for leaders to have been trained in a number of areas as part of their initial training. Pedagogical leadership is the area that is the most frequently required as part of leaders' training, but it is required in less than $30 \%$ of the settings (Figure 3.16 ).

Pedagogical leadership is central for leaders to affect the quality of staff's interactions with children and parents. Pedagogical leadership is either required or common practice as part of initial education for centre leaders in most countries and jurisdictions with available data for settings for children aged 0 to 5 , settings for children aged 3 to 5 and in a bit more than half of the settings for younger children (Figure 3.17).

Other topics covered in initial education programmes for leaders in more than one-quarter of settings are: promoting equity and diversity; collaborating with parents; providing effective feedback; leadership research and theory; and use of data to improve the quality of ECEC (see Figure 3.16). Still, the breadth of content required in initial programmes varies greatly across countries and jurisdictions, with some countries requiring more than $90 \%$ of content items (Czech Republic, Estonia, Finland, Slovak Republic and South Africa) and others requiring only nearly $30 \%$ of them (France, Norway, Portugal and the United Kingdom [England]) (Figure C.3.13). 
Figure 3.16. Content requirements for leaders' initial training

Percentage of settings across countries that require specific content or in which specific content is common practice, 2019

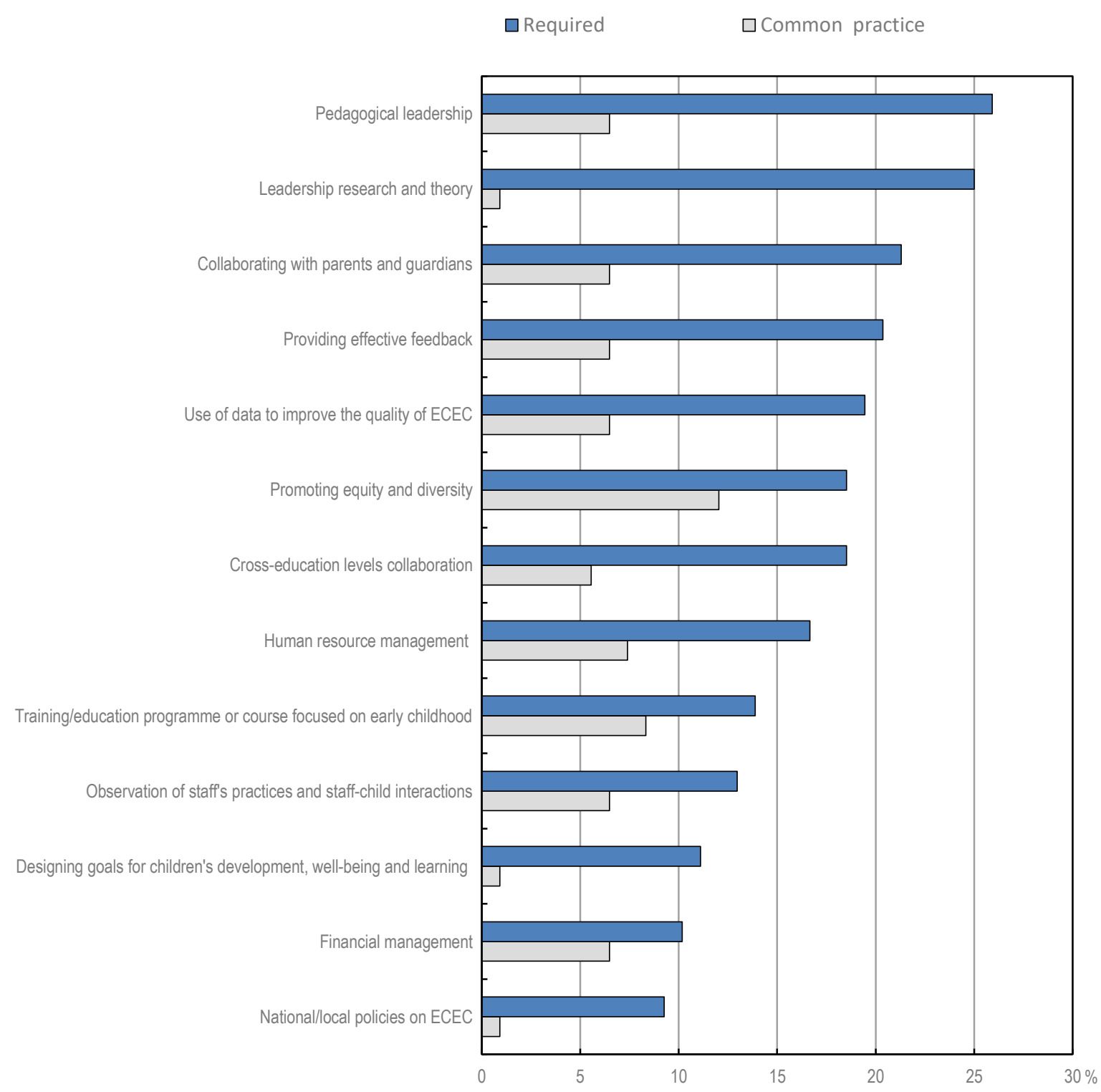

Note: Calculations include all settings across age groups. Information on settings and categories of staff included for each country and jurisdiction and classification according to standardised age groups is provided in Annex A.

Source: OECD "Quality beyond Regulations" database.

StatLink הत्tis https://doi.org/10.1787/888934249452 
Figure 3.17. Pedagogical leadership as a content requirement of leaders' initial training

Percentage of settings for which pedagogical leadership is regulated, common practice or not regulated/required as part of initial training, by age group, 2019

\section{Age 0 to 2}

$\square$ Required $\quad \square$ Common practice $\quad \square$ Not regulated or required

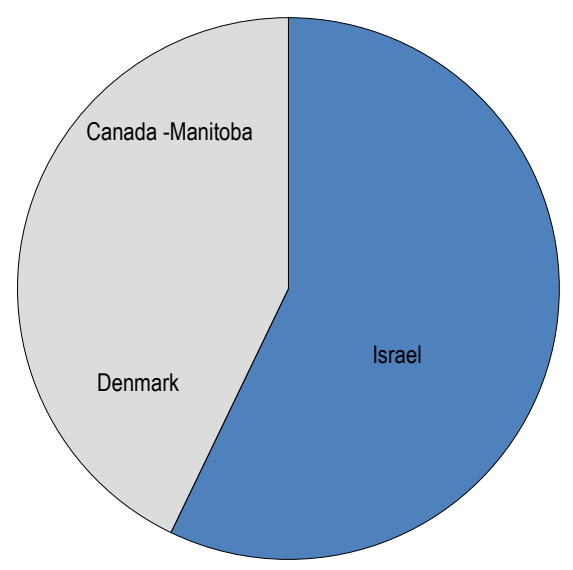

Age 3 to 5/primary school entry

$\square$ Required $\square$ Common practice $\square$ Not regulated or required

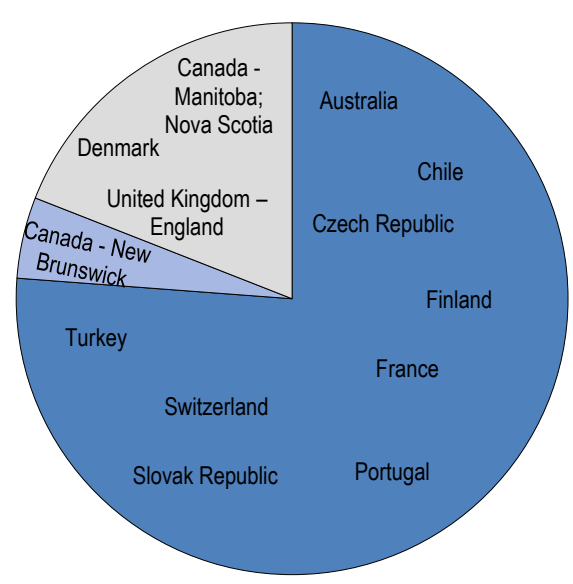

Integrated for age 0 to $5 /$ primary school entry

$\square$ Required $\square$ Common practice $\square$ Not regulated or required

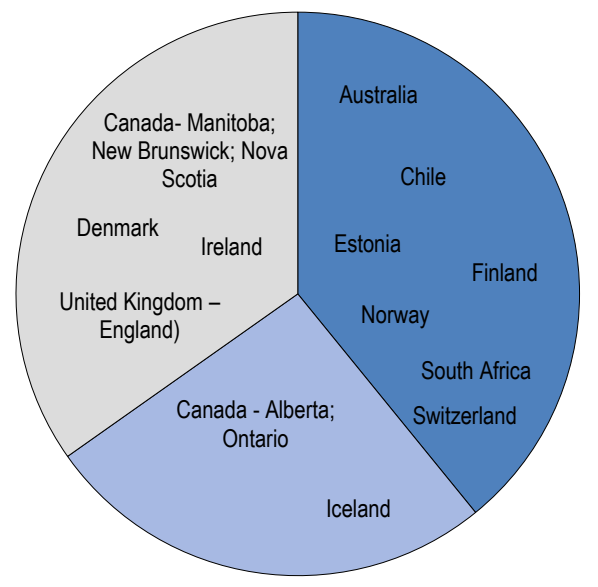

Notes: All countries with information available for settings within a specific age group are represented in the figures. Countries may therefore appear in different categories, representing the different settings. Countries with missing values or not applicable information in all settings in an age group are not shown in the figures. The calculation is based on all settings within a specific age group, including those for which information is not applicable or missing. Information on settings and categories of staff included for each country and jurisdiction and classification according to standardised age groups is provided in Annex A.

Source: OECD "Quality beyond Regulations" database. 


\section{Leaders' professional development}

Besides initial training, leaders need to develop their skills and knowledge through professional development, which can favour changes in the ideas and practices of ECEC leaders. Professional development can promote a shift in leadership approaches, positively impacting leaders' abilities to facilitate and implement developmentally appropriate strategies (Daniëls, Hondeghem and Dochy, 2019[67]; Page and Eadie, 2019[70]; Myran and Masterson, 2020 [71]; Vijayadevar, Thornton and Cherrington, 2019[73]).

Engaging leaders in professional development can be a key lever of quality improvement as it provides updated tools to handle tasks in rapidly changing environments (Douglass, 2018[68]; Elomaa et al., 2020[74]; Myran and Masterson, 2020[71] $)$. Research has shown that professional development can provide concrete tools and information that helps leaders to refine their practices while also contributing to their continuous reflection and improvement (Elomaa et al., 2020[74]; Myran and Masterson, 2020[71]).

Findings from the TALIS Starting Strong show that, in the nine participating countries, nearly all leaders participated in some form of professional development in the 12 months prior to the survey (OECD, $\left.2020_{[2]}\right)$. In most countries, at least three-quarters of leaders participated in a professional development course or an in-person seminar. Like for staff, professional development can help revisit and update knowledge and skills acquired in initial education. When asked about their need for professional development, leaders indicate that knowledge and understanding of current national/local policies on ECEC is an important area for additional training. Knowledge and understanding of new developments in leadership research, the use of data for improving quality and the design of centre goals are further priorities for professional development identified by leaders themselves.

\section{Learning from countries: Professional opportunities for leaders}

In Australia, leaders are supported through ongoing professional development and additional training opportunities. There are guidelines and resources to support the work of leaders, offering practical advice, research evidence and opportunities for reflection. For example, in the state of New South Wales, free professional development and support are available for providers and management teams of eligible services. The programme includes several resources and tools, such as face-to-face visits, online training modules and workshops. In the state of Victoria, a programme for quality improvement (the Victorian Kindergarten Quality Improvement Program) includes two phases, the first one on leadership and the second one on educational practices. The programme involves collaborative professional learning workshops, in-service mentoring and guided selfassessment, online communities of practice and networking opportunities.

In Canada, across several provinces and territories, leaders participate in networks through nongovernmental professional ECEC organisations. For example, the national Canadian Child Care Federation's "Member Council" includes leaders from all provinces and territories. In British Columbia, a Professional Development Hub was created to provide freely accessible online learning as a way to increase access to professional development opportunities. In Nova Scotia, a new model has been put in place, in which leaders attend professional development prior to staff, so that leaders can provide coaching and mentoring to their staff. The programme is freely delivered and is designed to foster a shared understanding among staff and leaders of the concepts underlying the curriculum, namely the value of relationship building and play-based learning.

In Luxemburg, most settings require ECEC leaders to attend professional development programmes on pedagogy and management. Additional professional opportunities are provided every year or twice a year, including supervision sessions on teamwork. Leaders are also encouraged to collaborate with staff and leaders from other ECEC settings through regular exchanges and participation in transnational projects. 
In Switzerland, there are specific professional development courses for leadership in ECEC. Certified training courses include pedagogical and management modules, such as the educational quality of everyday life in the ECEC setting and management issues. Leaders also have the opportunity to reflect their own practice through supervision modules.

\section{Policy pointers}

This section provides policy pointers for countries to support process quality through policies targeted to the ECEC workforce and identifies strategies that build on the information presented in this chapter.

\section{Increase the quality standards and improve other features of initial education programmes for ECEC staff}

Staff who are well prepared through high-quality initial education programmes are better able to sustain enriching and stimulating interactions with children than lower-qualified staff. Qualification requirements vary considerably among participating countries, especially for teachers. Increasing qualification requirements in countries where they are low can raise the status of ECEC professionals and help attract stronger candidates to the sector. Raising qualification requirements, however, needs to be accompanied by providing possibilities for existing staff to meet the new requirements through training and recognition of prior learning.

Beyond qualification requirements, several features of ECEC staff initial education programmes matter for process quality. As discussed in this chapter:

- Work-based learning provides opportunities to bridge theory and practice and apply new knowledge in everyday practices. The integration of work-based learning in initial education is not systematic across participating countries and jurisdictions, and settings and could be better regulated.

- The breadth of the content of initial education programmes is important, with the need to include specialised knowledge on young children, as well as content on a variety of subjects around pedagogy, play diversity, transitions, and family and community engagement. The breadth of the content of initial education programmes varies substantially across countries and jurisdictions, and topics such as family and community engagement can be better integrated.

- Another crucial aspect for raising the quality of initial education programmes is to ensure that staff are prepared to adequately implement and use the curriculum framework and appropriate pedagogical practices. Although curriculum framework implementation in initial education programmes is largely required, still, it is not systematically incorporated.

- Raising the quality of ECEC staff initial education programmes involves defining clear guidelines or standards for these programmes, accreditation mechanisms for all programmes, and creating feedback loops between outcomes of the monitoring of ECEC settings and quality requirements for ECEC staff initial education programmes.

Furthermore, the results discussed in this chapter show that requirements for assistants are much less comprehensive than for teachers. Most countries do not have education requirements for this category of staff; work-based learning is rarely required for assistants initial education programmes; and the breadth of content of these programmes is smaller than for teachers. Defining quality standards for initial education programmes for assistants aligned with their roles and responsibilities could also help attract high-quality candidates to the profession and be a step toward the definition of career progression pathways for this category of staff. 


\section{Support professional development for all staff}

Professional development is pivotal to support ECEC staff in the update of their knowledge and skills and to promote the continuity of a high-quality workforce. Granting time and funding to increase access and staff engagement in professional development can be crucial to ensuring the responsiveness and effectiveness of professional development interventions. Although releasing time for teachers to attend professional development is a common or required practice in most settings that work with children aged 3 to 5/primary school entry, it is less frequent in settings for children aged 0 to 2 and 0 to $5 /$ primary school entry. Providing flexible time arrangements for both teachers and assistants can increase the likelihood of staff participation in professional development. Likewise, protecting time for activities without children, especially those that involve exchanges with colleagues, can lead to informal learning. Teachers have protected time for these activities in less than half of ECEC settings and for an even smaller proportion of settings for assistants. Because of the nature of the ECEC staff job, regulations around working time are important to ensure that staff have the time to learn and reflect on their jobs. In addition, compensating for staff absence and removing barriers related to financial costs can support staff's investment in professional development.

Ensuring quality in professional development programmes is complicated given the very diverse provision of training. As in other sectors, the monitoring of the quality of these programmes is not systematic. Similarly, participation in a professional development programme generally does not lead to a certificate. Strengthening the monitoring of the quality of professional development programmes could accompany regulations on protected time to participate and possible financial incentives. Ensuring that programmes are accredited and can lead to certificates or credits can facilitate the development of career pathways for staff.

\section{Ensure that working conditions help attract and retain high-quality professionals}

Supporting professional development for all staff and ensuring that they have time to perform the many aspects of their jobs, as discussed in this chapter, are important aspects of the working conditions that policies can shape. In addition, improving salaries and opportunities for career progression can be a long-term objective to improve staff retention and the capacity of the ECEC sector to attract good candidates. Such an objective would accompany policies that focus on raising the quality of initial education and professional development to ensure that the quality of the workforce and wages are aligned in the long term.

\section{Develop a shared understanding of how leadership can best support quality in ECEC centres and facilitate leaders' professional development}

Leaders play a key role in improving quality in ECEC settings, particularly by sharing their knowledge and skills with ECEC staff on their practices, engaging with parents, and managing the centre, including by ensuring adequate financial and human resources. The Quality beyond Regulations policy questionnaire asked about regulations and practices concerning the training of ECEC centre leaders. Many participating countries and jurisdictions were unable to provide information on these aspects. This reflects that leadership in ECEC has not received much attention so far, either from research or from policies.

ECEC leaders need to be trained to perform the various aspects of their work. Requirements or common practices to include areas of knowledge in the initial training of leaders are relatively rare, although training in pedagogical leadership is the area that is the most commonly required across settings. Policies can better ensure that ECEC leaders are prepared for the various aspects of their work through high-quality training programmes. Developing clear profiles for leaders with skills requirements, well-defined responsibilities and adequate wages would also offer career perspectives to ECEC staff. 


\section{References}

Aboagye, M. et al. (2020), "Managing conflictual teacher-child relationship in pre-schools: A preliminary test of the job resources buffering-effect hypothesis in an emerging economy", Children and Youth Services Review.

Aboagye, M. et al. (2020), "Finding something good in the bad: the curvilinear emotional demand-conflict teacher-child relationship link", Early Child Development and Care, pp. 1-18.

Ansari, A. et al. (2020), "Preschool teachers' emotional exhaustion in relation to classroom instruction and teacher-child interactions", Early Education and Development, pp. 1-14.

Ärlemalm-Hagsér, E. (2017), "Student teachers' workplace-based learning in Sweden on early childhood education for sustainability: Experiences in practice settings", International Journal of Early Childhood, pp. 411-427.

Bakker, A. and E. Demerouti (2016), "Job demands-resources theory: Taking stock and looking forward”, Journal of Occupational Health Psychology, Vol. 22/3, pp. 273-285, http://dx.doi.org/10.1037/ocp0000056.

Bakker, A. and E. Demerouti (2007), "The job demands-resources model: State of the art", Journal of Managerial Psychology, Vol. 22/3, pp. 309-328, http://dx.doi.org/10.1108/02683940710733115.

Balduzzi, L. and A. Lazzari (2015), "Mentoring practices in workplace-based professional preparation: a critical analysis of policy developments in the Italian context", Early Years, pp. 35:2, 124-138.

Barnes, J., A. Guin and K. Allen (2018), "Training needs and online learning preferences of early childhood professionals”, Journal of Early Childhood Teacher Education, pp. 114-130.

Barros, S. et al. (2018), "The quality of caregiver-child interactions in infant classrooms in Portugal: The role of caregiver education", Research Papers in Education, Vol. 33/4, pp. 427451, https://doi.org/10.1080/02671522.2017.1353676.

Bayly, B. et al. (2020), "Leveraging self-determination theory to understand which preschool teachers benefit most from a professional development intervention", Journal of Early Childhood Teacher Education.

Bjørnestad, E. et al. (2019), "Interaction quality in Norwegian ECEC for toddlers measured with the Caregiver Interaction Profile (CIP) Scales", Scandinavian Journal of Educational Research, http://dx.doi.org/10.1080/00313831.2019.1639813.

Bove, C. et al. (2018), "How does innovative continuous professional development (CPD) operate in the ECEC sector? Insights from a cross-analysis of cases in Denmark, Italy and Poland", European Journal of Education 53, pp. 34-45.

Brinia, V., V. Poullou and A. Panagiotopoulou (2020), "The philosophy of quality in education: A qualitative approach", Quality Assurance in Education: An International Perspective, pp. 6677. 
Cadima, J., C. Aguiar and M. Barata (2018), "Process quality in Portuguese preschool classrooms serving children at-risk of poverty and social exclusion and children with disabilities", Early Childhood Research Quarterly, pp. 93-105.

Cassidy, D. et al. (2017), "Teacher work environments are toddler learning environments: Teacher professional well-being, classroom emotional support, and toddlers' emotional expressions and behaviours", Early Child Development and Care, Vol. 187/11, pp. 16661678.

Castle, S. et al. (2016), "Teacher-child Interactions in Early Head Start classrooms: Associations with teacher characteristics", Early Education and Development, Vol. 27/2, pp. 259-274, https://doi.org/10.1080/10409289.2016.1102017.

Cazes, S., A. Hijzen and A. Saint-Martin (2015), "Measuring and Assessing Job Quality: The OECD Job Quality Framework”, OECD Social, Employment and Migration Working Papers, No. 174, OECD Publishing, Paris, https://dx.doi.org/10.1787/5jrp02kjw1mr-en.

Chen, S., B. Phillips and B. Izci (2018), "Teacher-child relational conflict in Head Start exploring the roles of child behaviour, teacher stress, and bias, and classroom environment", Early Child Development and Care, pp. 1174-1186.

Connors, M. (2019), "Pathways to quality: From internal program supports to early educators' practice", Early Education and Development, pp. 569-589.

Daniëls, E., A. Hondeghem and F. Dochy (2019), "A review on leadership and leadership development in educational settings”, Educational Research Review, pp. 110-125.

Davis, A., S. Barrueco and D. Perry (2020), "The role of consultative alliance in infant and early childhood mental health consultation: Child, teacher, and classroom outcomes", Infant Mental Health Journal.

Douglass, A. (2018), "The role of relationships: An exploratory study of early childhood educators earning a bachelor's degree", SAGE Open, http://dx.doi.org/10.1177/2158244019837830.

Early, D. et al. (2017), "Improving teacher-child interactions: A randomized controlled trial of Making the Most of Classroom Interactions and My Teaching Partner professional development models", Early Childhood Research Quarterly 38, pp. 57-70.

Eckhardt, A. and F. Egert (2020), "Predictors for the quality of family child care: A metaanalysis", Children and Youth Services Review.

Egert, F., V. Dederer and R. Fukkink (2020), "The impact of in-service professional development on the quality of teacher-child interactions in early education and care: A meta-analysis", Educational Research Review.

Egert, F., R. Fukkink and A. Eckhardt (2018), "Impact of in-service professional development programs for early childhood teachers on quality ratings and child outcomes: A metaanalysis", Review of Educational Research, pp. 401-433.

Ehrlich, S. et al. (2019), "Early education essentials: Validation of surveys measuring early education organizational conditions", Early Education and Development, pp. 540-567.

Elomaa, M. et al. (2020), "Directors' stress in day care centers: Related factors and coping strategies”, International Journal of Educational Management, pp. 1079-1091. 
Flämig, K., A. König and N. Spiekermann (2015), "Potentials, dissonances and reform initiatives in field-based learning and mentoring practices in the early childhood sector in Germany", Early Years, pp. 211-226.

Fonsén, E. and U. Soukainen (2020), "Sustainable Pedagogical Leadership in Finnish Early Childhood Education (ECE): An Evaluation by ECE Professionals.", Early Childhood Education Journal, pp. 213-222.

Fukkink, R. et al. (2019), "Training interaction skills of pre-service ECEC teachers: Moving from in-service to pre-service professional development", Early Childhood Education Journal, pp. 497-507.

Halpern, C., T. Szecsi and V. Mak (2020), “'Everyone can be a leader': Early childhood education leadership in a center serving culturally and linguistically diverse children and families", Early Childhood Education Journal.

Hamre, B., A. Partee and C. Mulcahy (2017), "Enhancing the impact of professional development in the context of preschool expansion", AERA Open.

Heikka, J., L. Halttunen and M. Waniganayake (2018), "Perceptions of early childhood education professionals on teacher leadership in Finland", Early Child Development \& Care, pp. 143156.

$\mathrm{Hu}$, B. et al. (2017), "Are structural quality indicators associated with preschool process quality in China? An exploration of threshold effects", Early Childhood Research Quarterly, pp. 163173.

Hu, B. et al. (2019), "Global quality profiles in Chinese early care classrooms: Evidence from the Shandong Province", Children and Youth Services Review, Vol. 101, pp. 157-164, http://dx.doi.org/10.1016/j.childyouth.2019.03.056.

Hu, B. et al. (2017), "Preschool expenditures and Chinese children's academic performance: The mediating effect of teacher-child interaction quality", Early Childhood Research Quarterly, pp. 37-49.

Jensen, B. and R. lannone (2018), "Innovative approaches to continuous professional development (CPD) in early childhood education and care (ECEC) in Europe: Findings from a comparative review", European Journal of Education, pp. 23-33.

Kaarby, K. and I. Lindboe (2016), "The workplace as learning environment in early childhood teacher education: An investigation of work-based education", Higher Education Pedagogies, pp. 106-120.

Keung, C. et al. (2020), "Kindergarten teachers' perceptions of whole-child development: The roles of leadership practices and professional learning communities”, Educational Management Administration \& Leadership, pp. 875-892.

Landry, S. et al. (2014), "Enhancing early child care quality and learning for toddlers at risk: The responsive early childhood program", Developmental Psychology, pp. 526-541.

Linder, S. et al. (2016), "A mixed-methods investigation of early childhood professional development for providers and recipients in the United States", Professional Development in Education, pp. 123-149. 
Lohmander, M. (2015), “Bridging 'the gap' - linking workplace-based and university-based learning in preschool teacher education in Sweden", Early Years, pp. 168-183.

Manning, M. et al. (2019), "Is teacher qualification associated with the quality of the early childhood education and care environment? A meta-analytic review", Review of Educational Research, Vol. 89/3, pp. 370-415, https://doi.org/10.3102\%2F0034654319837540.

Markussen-Brown, J. et al. (2017), "The effects of language-and literacy-focused professional development on early educators and children: A best-evidence meta-analysis", Early Childhood Research Quarterly, pp. 97-115.

Mowrey, S. and E. King (2019), "Sharing experiences together: Within- and across-sector collaboration among public preschool educators", Early Education and Development, pp. 1045-1062.

Myran, S. and M. Masterson (2020), "Training early childhood leaders: Developing a new paradigm for professional development using a practice to theory approach", School Effectiveness and School Improvement.

Oberhuemer, P. (2015), "Parallel discourses with unparalleled effects: Early years workforce development and professionalisation initiatives in Germany", International Journal of Early Years Education, pp. 303-312.

OECD (2020), Building a High-Quality Early Childhood Education and Care Workforce: Further Results from the Starting Strong Survey 2018, TALIS, OECD Publishing, Paris, https://dx.doi.org/10.1787/b90bba3d-en.

OECD (2020), Education at a Glance 2020: OECD Indicators, OECD Publishing, Paris, http://dx.doi.org/10.1787/69096873-en.

OECD (2019), Providing Quality Early Childhood Education and Care: Results from the Starting Strong Survey 2018, TALIS, OECD Publishing, Paris, https://dx.doi.org/10.1787/301005d1en.

Page, J. and P. Eadie (2019), "Coaching for continuous improvement in collaborative, interdisciplinary early childhood teams", Australasian Journal of Early Childhood, pp. 270-284.

Page, J. and M. Waniginayake (2019), "Early childhood educational leaders in Australia: Tensions and possibilities in leadership preparation and capacity building", International Studies in Educational Administration, pp. 23-36.

Peleman, B. et al. (2018), "Continuous professional development and ECEC quality: Findings from a European systematic literature review”, European Journal of Education, pp. 9-22.

Penttinen, V. et al. (2020), "Relations between kindergarten teachers' occupational well-being and the quality of teacher-child interactions", Early Education and Development.

Raikes, A. et al. (2020), "Measuring quality of preprimary education in Sub-Saharan Africa: Evaluation of the Measuring Early Learning Environments scale", Early Childhood Research Quarterly, pp. 571-585.

Ratner, H. et al. (2018), "Creating communities: A consortium model for early childhood leaders", Teacher Development, pp. 427-446. 
Resa, E. et al. (2018), "The role of professional exchange in improving language-related process quality in daycare centres", Research Papers in Education, pp. 472-491.

Romo-Escudero, F., J. LoCasale-Crouch and K. Turnbull (2021), "Caregiver ability to notice and enact effective interactions in early care classroom settings", Teaching and Teacher Education.

Sandilos, L. et al. (2018), "Does professional development reduce the influence of teacher stress on teacher-child interactions in pre-kindergarten classrooms?", Early Childhood Research Quarterly, pp. 280-290.

Sandilos, L., P. Goble and S. Schwartz (2020), "Burnout and teacher-child interactions: The moderating influence of SEL interventions in Head Start classrooms", Early Education and Development, pp. 1169-1185.

Schaack, D., V. Le and C. Setodji (2017), "Home-based child care provider education and specialized training: Associations with caregiving quality and toddler social-emotional and cognitive outcomes", Early Education and Development, Vol. 28/6, pp. 655-668, https://doi.org/10.1080/10409289.2017.1321927.

Schilder, D., M. Broadstone and S. Leavell (2019), "Characteristics of early care and education collaboration associated with success", Early Education and Development, pp. 1029-1044.

Shim, S. and S. Lim (2019), "The influence of Korean preschool teachers' work environments and self-efficacy on children's peer play interactions: The mediating effect of teacher-child interactions", Early Child Development and Care, pp. 1749-1762.

Slot, P. et al. (2018), "Structural and process quality of Danish preschools: Direct and indirect associations with children's growth in language and preliteracy skills", Early Education and Development, pp. 581-602.

Sosinsky, L. and W. Gilliam (2011), "Assistant teachers in prekindergarten programs: What roles do lead teachers feel assistants play in classroom management and teaching?", Early Education \& Development, Vol. 22/4, pp. 676-706.

Vangrieken, K. et al. (2017), "Teacher communities as a context for professional development: A systematic review", Teaching and Teacher Education, pp. 47-59.

Vijayadevar, S., K. Thornton and S. Cherrington (2019), "Professional learning communities: Enhancing collaborative leadership in Singapore early childhood settings", Contemporary Issues in Early Childhood, pp. 79-92.

von Suchodoletz, A. et al. (2020), "Investigating quality indicators of early childhood education programs in Kosovo, Ukraine and Finland", International Journal of Early Years Education, pp. 1-17.

Wang, S., Y. Hu and J. LoCasale-Crouch (2020), "Modeling the nonlinear relationship between structure and process quality features in Chinese preschool classrooms.", Children and Youth Services Review.

Werner, C. et al. (2016), "Do intervention programs in child care promote the quality of caregiverchild interactions? A meta-analysis of randomized controlled trials", Prevention Science, pp. 259-273. 
Williford, A. et al. (2017), "Teacher engagement in core components of an effective, early childhood professional development course: Links to changes in teacher-child interactions.", Journal of Early Childhood Teacher Education, pp. 102-118.

Wolf, S. et al. (2018), "Measuring and predicting process quality in Ghanaian pre-primary classrooms using the Teacher Instructional Practices and Processes System (TIPPS)", Early Childhood Research Quarterly, pp. 18-30.

Yin, H. et al. (2019), "Professional learning communities count: Examining the relationship between faculty trust and teacher professional learning in Hong Kong kindergartens", Teaching and Teacher Education, pp. 153-16.

\section{Notes}

1. The International Standard Classification of Education (ISCED) provides a comprehensive framework for organising education programmes and qualifications by applying uniform and internationally agreed definitions to facilitate comparisons of education systems across countries. For further information, see http://uis.unesco.org/en/topic/international-standard-classificationeducation-isced. 


\section{Annex A. Reference tables}

Table A.A.3 of the present annex is a web table and found in Annex C of the report.

Table A A.1. Overview of ECEC curriculum frameworks and reference numbers for tables and figures, 2019

\begin{tabular}{|c|c|c|c|}
\hline Country & Name of the curriculum framework & $\begin{array}{l}\text { Reference } \\
\text { number }\end{array}$ & $\begin{array}{l}\text { Standardised age group covered } \\
\text { (Age range) }\end{array}$ \\
\hline Australia & Belonging, Being \& Becoming: The Early Years Learning Framework for Australia (EYLF) & 1 & $\begin{array}{l}\text { Integrated for age } 0 \text { to } 5 / \text { primary } \\
\text { school entry }\end{array}$ \\
\hline \multirow[t]{2}{*}{ Belgium - Flanders } & $\begin{array}{l}\text { Decision of the Flemish Government of } 27 \text { May } 1997 \text { on determining the developmental aims and attainment targets of } \\
\text { regular elementary education }\end{array}$ & 1 & Age 3 to $5 /$ primary school entry \\
\hline & A pedagogical framework for childcare for babies and toddlers & 2 & Age 0 to 2 \\
\hline Canada - Alberta & Flight: Alberta's Early Learning and Care Framework & 1 & $\begin{array}{l}\text { Integrated for age } 0 \text { to } 5 / \text { primary } \\
\text { school entry }\end{array}$ \\
\hline Canada - British Columbia & Early Learning Framework & 1 & $\begin{array}{l}\text { Integrated for age } 0 \text { to } 5 / \text { primary } \\
\text { school entry }\end{array}$ \\
\hline \multirow[t]{2}{*}{ Canada - Manitoba } & Early Returns: Manitoba's Early Learning and Child Care Curriculum Framework for Infant Programs & 1 & Age 0 to 2 \\
\hline & $\begin{array}{l}\text { Early Returns: Manitoba's Early Learning and Child Care Curriculum Framework for Preschool Centres and Nursery } \\
\text { Schools }\end{array}$ & 2 & Age 3 to $5 /$ primary school entry \\
\hline \multirow[t]{4}{*}{ Canada - New Brunswick } & Curriculum maternelle & 1 & Age 3 to $5 /$ primary school entry \\
\hline & Curriculum éducatif Services de garde francophone du Nouveau-Brunswick & 2 & $\begin{array}{l}\text { Integrated for age } 0 \text { to } 5 / \text { primary } \\
\text { school entry }\end{array}$ \\
\hline & Kindergarten Curriculum & 3 & Age 3 to $5 /$ primary school entry \\
\hline & New Brunswick Curriculum Framework for Early Learning and Child Care -English & 4 & $\begin{array}{l}\text { Integrated for age } 0 \text { to } 5 / \text { primary } \\
\text { school entry }\end{array}$ \\
\hline Canada - Nova Scotia & Capable, Confident, and Curious: Nova Scotia's Early Learning Curriculum Framework & 1 & $\begin{array}{l}\text { Integrated for age } 0 \text { to } 5 / \text { primary } \\
\text { school entry }\end{array}$ \\
\hline
\end{tabular}




\begin{tabular}{|c|c|c|c|}
\hline Country & Name of the curriculum framework & $\begin{array}{l}\text { Reference } \\
\text { number }\end{array}$ & $\begin{array}{l}\text { Standardised age group covered } \\
\text { (Age range) }\end{array}$ \\
\hline Canada - Ontario & How Does Learning Happen? Ontario's Pedagogy for the Early Years & 1 & $\begin{array}{l}\text { Integrated for age } 0 \text { to } 5 / \text { primary } \\
\text { school entry }\end{array}$ \\
\hline Canada - Quebec & Accueillir la petite enfance & 1 & $\begin{array}{l}\text { Integrated for age } 0 \text { to } 5 / \text { primary } \\
\text { school entry }\end{array}$ \\
\hline \multirow[t]{2}{*}{ Canada - Saskatchewan } & Essential Learning Experiences & 1 & Age 3 to 5/primary school entry \\
\hline & Play and Exploration: Early Learning Program Guide & 2 & Age 0 to 2 \\
\hline \multirow[t]{2}{*}{ Chile } & Curricular Bases of Early Childhood Education & 1 & $\begin{array}{l}\text { Integrated for age } 0 \text { to } 5 / \text { primary } \\
\text { school entry }\end{array}$ \\
\hline & Framework for Good Teaching at Early Childhood Education & 2 & $\begin{array}{l}\text { Integrated for age } 0 \text { to } 5 / \text { primary } \\
\text { school entry }\end{array}$ \\
\hline Czech Republic & Framework Educational Programme for Pre-primary Education (FEP PE) & 1 & Age 3 to $5 /$ primary school entry \\
\hline Denmark & The pedagogical curriculum & 1 & $\begin{array}{l}\text { Integrated for age } 0 \text { to } 5 / \text { primary } \\
\text { school entry }\end{array}$ \\
\hline Estonia & National Curriculum for the Preschool Child Care Institution & 1 & $\begin{array}{l}\text { Integrated for age } 0 \text { to } 5 / \text { primary } \\
\text { school entry }\end{array}$ \\
\hline \multirow[t]{2}{*}{ Finland } & National Core Curriculum for Early Childhood Education and Care & 1 & $\begin{array}{l}\text { Integrated for age } 0 \text { to } 5 / \text { primary } \\
\text { school entry }\end{array}$ \\
\hline & National Core Curriculum for pre-primary education & 2 & Age 3 to $5 /$ primary school entry \\
\hline France & Pre-elementary education: an only cycle, fundamental for the success of all & 1 & Age 3 to $5 /$ primary school entry \\
\hline Germany - Bavaria & $\begin{array}{l}\text { The Bavarian Framework for Early Education (for children aged } 0 \text { to school entry) (BayBEP) including a short summary } \\
\text { of the Bavarian Guidelines for Education (BayBL) }\end{array}$ & 1 & $\begin{array}{l}\text { Integrated for age } 0 \text { to } 5 / \text { primary } \\
\text { school entry }\end{array}$ \\
\hline Germany - Berlin & Bridging Diversity - an Early Years Programme & 1 & $\begin{array}{l}\text { Integrated for age } 0 \text { to } 5 / \text { primary } \\
\text { school entry }\end{array}$ \\
\hline Germany - Brandenburg & Principles of elementary education & 1 & $\begin{array}{l}\text { Integrated for age } 0 \text { to } 5 / \text { primary } \\
\text { school entry }\end{array}$ \\
\hline $\begin{array}{l}\text { Germany - North Rhine- } \\
\text { Westphalia }\end{array}$ & $\begin{array}{l}\text { Principles of education for children aged } 0 \text { to } 10 \text { in child-daycare-facilities and primary schools in North Rhine- } \\
\text { Westphalia }\end{array}$ & 1 & $\begin{array}{l}\text { Integrated for age } 0 \text { to } 5 / \text { primary } \\
\text { school entry }\end{array}$ \\
\hline Iceland & The Icelandic national curriculum guide for preschools & 1 & $\begin{array}{l}\text { Integrated for age } 0 \text { to } 5 / \text { primary } \\
\text { school entry }\end{array}$ \\
\hline Ireland & Aistear - the Early Childhood Curriculum Framework & 1 & $\begin{array}{l}\text { Integrated for age } 0 \text { to } 5 / \text { primary } \\
\text { school entry }\end{array}$ \\
\hline Israel & Frameworks specific to different learning areas & 1 & Age 3 to $5 /$ primary school entry \\
\hline
\end{tabular}


148

\begin{tabular}{|c|c|c|c|}
\hline Country & Name of the curriculum framework & $\begin{array}{c}\text { Reference } \\
\text { number }{ }^{1}\end{array}$ & $\begin{array}{l}\text { Standardised age group covered } \\
\text { (Age range) }\end{array}$ \\
\hline \multirow[t]{3}{*}{ Japan } & National Curriculum Standards for Kindergarten & 1 & Age 3 to $5 /$ primary school entry \\
\hline & National Curriculum Standards for Day Care Centre & 2 & $\begin{array}{l}\text { Integrated for age } 0 \text { to } 5 / \text { primary } \\
\text { school entry }\end{array}$ \\
\hline & National Curriculum Standards for Integrated Centre for Early Childhood Education and Care & 3 & $\begin{array}{l}\text { Integrated for age } 0 \text { to } 5 / \text { primary } \\
\text { school entry }\end{array}$ \\
\hline \multirow[t]{2}{*}{ Luxembourg } & National Curriculum for pre-primary and primary education. & 1 & Age 3 to $5 /$ primary school entry \\
\hline & National Reference Framework for non-formal education for Children and Youth & 2 & $\begin{array}{l}\text { Integrated for age } 0 \text { to } 5 / \text { primary } \\
\text { school entry }\end{array}$ \\
\hline \multirow[t]{2}{*}{ Mexico } & A good start & 1 & Age 0 to 2 \\
\hline & $\begin{array}{l}\text { Key learnings for integral education. Preschool education. Plan and study programs, didactic orientations and } \\
\text { evaluation suggestions }\end{array}$ & 2 & Age 3 to $5 /$ primary school entry \\
\hline \multirow[t]{2}{*}{ New Zealand } & Early childhood curriculum & 1 & $\begin{array}{l}\text { Integrated for age } 0 \text { to } 5 / \text { primary } \\
\text { school entry }\end{array}$ \\
\hline & Early childhood curriculum language nests & 2 & $\begin{array}{l}\text { Integrated for age } 0 \text { to } 5 / \text { primary } \\
\text { school entry }\end{array}$ \\
\hline Norway & Framework Plan for Kindergartens & 1 & $\begin{array}{l}\text { Integrated for age } 0 \text { to } 5 / \text { primary } \\
\text { school entry }\end{array}$ \\
\hline Portugal & Curricular Guidelines for Preschool Education & 1 & Age 3 to 5/primary school entry \\
\hline Slovak Republic & State educational program for pre-primary education in kindergartens & 1 & Age 3 to $5 /$ primary school entry \\
\hline \multirow[t]{2}{*}{ Slovenia } & Kindergarten Curriculum & 1 & $\begin{array}{l}\text { Integrated for age } 0 \text { to } 5 / \text { primary } \\
\text { school entry }\end{array}$ \\
\hline & Kindergarten Curriculum for adapted programmes for preschool children & 2 & $\begin{array}{l}\text { Integrated for age } 0 \text { to } 5 / \text { primary } \\
\text { school entry }\end{array}$ \\
\hline South Africa & The South African National Curriculum Framework for Children from Birth to Four & 1 & $\begin{array}{l}\text { Integrated for age } 0 \text { to } 5 / \text { primary } \\
\text { school entry }\end{array}$ \\
\hline
\end{tabular}




\begin{tabular}{|c|c|c|c|}
\hline Country & Name of the curriculum framework & $\begin{array}{l}\text { Reference } \\
\text { number }^{1}\end{array}$ & $\begin{array}{c}\text { Standardised age group covered } \\
\text { (Age range) }\end{array}$ \\
\hline \multirow[t]{5}{*}{ Switzerland } & Concept for family childcare pedagogy & 1 & $\begin{array}{l}\text { Integrated for age } 0 \text { to } 5 / \text { primary } \\
\text { school entry }\end{array}$ \\
\hline & Curriculum (kindergarten, primary, secondary) & 2 & Age 3 to 5/primary school entry \\
\hline & Guidelines for day care of children from kindergarten to primary school age & 3 & Age 3 to $5 /$ primary school entry \\
\hline & Orientation framework for ECEC & 4 & $\begin{array}{l}\text { Integrated for age } 0 \text { to } 5 / \text { primary } \\
\text { school entry }\end{array}$ \\
\hline & Quality in centre-based childcare & 5 & $\begin{array}{l}\text { Integrated for age } 0 \text { to } 5 / \text { primary } \\
\text { school entry }\end{array}$ \\
\hline \multirow[t]{4}{*}{ Turkey } & Education Program for $0-36$ Months & 1 & Age 0 to 2 \\
\hline & Special early childhood education program & 2 & Age 0 to 2 \\
\hline & Preschool Education Program & 3 & Age 3 to $5 /$ primary school entry \\
\hline & Special preschool education program & 4 & Age 3 to 5/primary school entry \\
\hline United Kingdom - England & Early Years Foundation Stage Framework & 1 & $\begin{array}{l}\text { Integrated for age } 0 \text { to } 5 / \text { primary } \\
\text { school entry }\end{array}$ \\
\hline
\end{tabular}

1. A numeric correspondence is provided to facilitate the reading of tables and figures.

Source: OECD "Quality beyond Regulations" database.

StatLink 제s ht htps://doi.org/10.1787/888934249547

Table A A.2. Overview of age groups covered by ECEC settings and types of provision of ECEC settings, 2019

\begin{tabular}{|c|c|c|c|c|}
\hline Country & Setting & Actual ages covered & $\begin{array}{c}\text { Standardised age group covered } \\
\text { (Age range) }\end{array}$ & $\begin{array}{r}\text { Type of provision } \\
\text { (Public, Private) }\end{array}$ \\
\hline \multirow[t]{3}{*}{ Australia } & Long day care & \multirow{2}{*}{0 to 5 years } & \multirow{2}{*}{$\begin{array}{l}\text { Integrated for age } 0 \text { to } 5 / \text { primary } \\
\text { school entry }\end{array}$} & \multirow{2}{*}{ Public/Private } \\
\hline & Family day care & & & \\
\hline & Preschool/Kindergarten & 3 to 5 years & Age 3 to 5/primary school entry & Public/Private \\
\hline \multirow[t]{3}{*}{ Belgium - Flanders } & Pre-primary education & 2.5 to 6 years & Age 3 to 5/primary school entry & Public/Private \\
\hline & Centre-based childcare & \multirow[t]{2}{*}{0 to 2.5 / 3 years } & \multirow[t]{2}{*}{ Age 0 to 2} & \multirow[t]{2}{*}{ Public/Private } \\
\hline & Home-based childcare & & & \\
\hline
\end{tabular}


150

\begin{tabular}{|c|c|c|c|c|}
\hline Country & Setting & Actual ages covered & $\begin{array}{c}\text { Standardised age group covered } \\
\text { (Age range) }\end{array}$ & $\begin{array}{r}\text { Type of provision } \\
\text { (Public, Private) }\end{array}$ \\
\hline \multirow[t]{4}{*}{ Canada - Alberta } & Approved family day homes & $\begin{array}{l}\text { Infants, toddlers, preschool aged, and } \\
\text { school aged children }\end{array}$ & \multirow[t]{4}{*}{$\begin{array}{l}\text { Integrated for age } 0 \text { to } 5 / \text { primary } \\
\text { school entry }\end{array}$} & $\begin{array}{l}\text { Non-profit or for- } \\
\text { profit }\end{array}$ \\
\hline & Day care & Infants less than 12 months to 5 years & & $\begin{array}{l}\text { Non-profit or for- } \\
\text { profit }\end{array}$ \\
\hline & Early Learning and Child Care (ELCC) Centres ( $\$ 25 /$ day pilot program) & Infants less than 12 months to 5 years & & Non-profit \\
\hline & Preschool & 19 months to 5 years & & $\begin{array}{l}\text { Non-profit or for- } \\
\text { profit }\end{array}$ \\
\hline \multirow{5}{*}{$\begin{array}{l}\text { Canada - British } \\
\text { Columbia }\end{array}$} & Family Child Care & 0 to 12 years & \multirow{5}{*}{$\begin{array}{l}\text { Integrated for age } 0 \text { to } 5 / \text { primary } \\
\text { school entry }\end{array}$} & \multirow[t]{5}{*}{ Public/Private } \\
\hline & Group Care & $\begin{array}{l}\text { Under } 36 \text { months; } 30 \text { months to } 5 \text { years; } \\
\text { school age }\end{array}$ & & \\
\hline & In-Home Multi-Age Child Care & 0 to 12 years & & \\
\hline & Multi-Age Child Care & 0 to 12 years & & \\
\hline & Preschool & 30 months to 5 years & & \\
\hline \multirow[t]{3}{*}{ Canada - Manitoba } & Infant Early Learning and Child Care & 12 weeks to 2 years & Age 0 to 2 & Public/Private \\
\hline & Nursery School & 12 weeks to 6 years & $\begin{array}{l}\text { Integrated for age } 0 \text { to } 5 / \text { primary } \\
\text { school entry }\end{array}$ & Public/Private \\
\hline & Preschool Early Learning and Child Care & 2 to 5 years & Age 3 to 5/primary school entry & Public/Private \\
\hline \multirow[t]{2}{*}{$\begin{array}{l}\text { Canada - New } \\
\text { Brunswick }\end{array}$} & Early learning and childcare facilities/Garderie éducative & Infants to 12 years & $\begin{array}{l}\text { Integrated for age } 0 \text { to } 5 / \text { primary } \\
\text { school entry }\end{array}$ & Private \\
\hline & Kindergarten/Maternelle & From age 5 prior to December 31st & Age 3 to 5/primary school entry & Public \\
\hline \multirow[t]{3}{*}{ Canada - Nova Scotia } & Centre-based & \multirow[t]{2}{*}{0 to 12 years } & \multirow{2}{*}{$\begin{array}{l}\text { Integrated for age } 0 \text { to } 5 / \text { primary } \\
\text { school entry }\end{array}$} & \multirow[t]{2}{*}{ Private } \\
\hline & Family Home & & & \\
\hline & Pre-primary & from 4 years & Age 3 to $5 /$ primary school entry & Public \\
\hline \multirow[t]{3}{*}{ Canada - Nunavut } & Daycare & 0 to 6 years & \multirow{2}{*}{$\begin{array}{l}\text { Integrated for age } 0 \text { to } 5 / \text { primary } \\
\text { school entry }\end{array}$} & Public \\
\hline & Family Day Home & 0 to 12 years & & Private \\
\hline & Preschool & 3 to 5 years & Age 3 to 5/primary school entry & Public \\
\hline \multirow[t]{3}{*}{ Canada - Ontario } & EarlyON Child and Family Centres & 0 to 6 years & \multirow{3}{*}{$\begin{array}{l}\text { Integrated for age } 0 \text { to } 5 / \text { primary } \\
\text { school entry }\end{array}$} & Public \\
\hline & Licensed child care centres & \multirow[t]{2}{*}{0 to12 years } & & Public/Private \\
\hline & Licensed home child care agencies/providers & & & Public/Private \\
\hline
\end{tabular}




\begin{tabular}{|c|c|c|c|c|}
\hline Country & Setting & Actual ages covered & $\begin{array}{c}\text { Standardised age group covered } \\
\text { (Age range) }\end{array}$ & $\begin{array}{r}\text { Type of provision } \\
\text { (Public, Private) }\end{array}$ \\
\hline \multirow[t]{4}{*}{ Canada - Quebec } & Childcare centre (CPE) & \multirow[t]{2}{*}{0 to 4 years } & \multirow{3}{*}{$\begin{array}{l}\text { Integrated for age } 0 \text { to } 5 / \text { primary } \\
\text { school entry }\end{array}$} & \multirow[t]{3}{*}{ Private } \\
\hline & Daycare centre & & & \\
\hline & Home childcare services & 0 to 4 years & & \\
\hline & Maternelle & $\mathrm{m}$ & Age 3 to $5 /$ primary school entry & Private \\
\hline \multirow[t]{2}{*}{$\begin{array}{l}\text { Canada - } \\
\text { Saskatchewan }\end{array}$} & Licensed Child Care Facilities & 0 to 12 years & $\begin{array}{l}\text { Integrated for age } 0 \text { to } 5 / \text { primary } \\
\text { school entry }\end{array}$ & Public \\
\hline & PreKindergarten & 3 to 4 years & Age 3 to 5/primary school entry & Public \\
\hline \multirow[t]{3}{*}{ Canada - Yukon } & Child Care Centre Program & \multirow[t]{2}{*}{0 to 12 years } & \multirow{2}{*}{$\begin{array}{l}\text { Integrated for age } 0 \text { to } 5 / \text { primary } \\
\text { school entry }\end{array}$} & \multirow[t]{2}{*}{ Private } \\
\hline & Family Day Home Program & & & \\
\hline & School Age Program & grade 1 to 12 years & Age 3 to $5 /$ primary school entry & Private \\
\hline \multirow[t]{7}{*}{ Chile } & Public Kindergarten & 0 to 3 years & \multirow[t]{2}{*}{ Age 0 to 2} & Public \\
\hline & Public funds, delegated administration Kindergarten & 0 to 3 years & & Private \\
\hline & Government-dependent private preschools and schools & 4 to 5 years & \multirow[t]{3}{*}{ Age 3 to $5 /$ primary school entry } & Private \\
\hline & Public preschools and schools & 4 to 5 years & & Public \\
\hline & Schools for speech and language difficulties & 3 to 5 years & & Private \\
\hline & Private Kindergarten & 0 to 5 years & $\begin{array}{l}\text { Integrated for age } 0 \text { to } 5 / \text { primary } \\
\text { school entry }\end{array}$ & Private \\
\hline & Private preschools and schools & 3 to 5 years & Age 3 to $5 /$ primary school entry & Private \\
\hline \multirow[t]{4}{*}{ Czech Republic } & Setting for children under 3 years of age & 0 to 3 years & Age 0 to 2 & Private \\
\hline & Children's group & 1 to 6 years & $\begin{array}{l}\text { Integrated for age } 0 \text { to } 5 / \text { primary } \\
\text { school entry }\end{array}$ & Public \\
\hline & Nursery school (kindergarten) & 2 to 6 years & \multirow[t]{2}{*}{ Age 3 to 5/primary school entry } & Public \\
\hline & Basic school (preparatory class) & 6 to 7 years & & Private \\
\hline \multirow[t]{4}{*}{ Denmark } & Kindergarten & 3 to 5 years & Age 3 to $5 /$ primary school entry & Public/Private \\
\hline & Nursery & \multirow[t]{2}{*}{0 to 2 years } & \multirow[t]{2}{*}{ Age 0 to 2} & \multirow[t]{2}{*}{ Public/Private } \\
\hline & Home-based day care & & & \\
\hline & Integrated day care & 0 to 5 years & $\begin{array}{l}\text { Integrated for age } 0 \text { to } 5 / \text { primary } \\
\text { school entry }\end{array}$ & Public/Private \\
\hline
\end{tabular}


152

\begin{tabular}{|c|c|c|c|c|}
\hline Country & Setting & Actual ages covered & $\begin{array}{l}\text { Standardised age group covered } \\
\text { (Age range) }\end{array}$ & $\begin{array}{r}\text { Type of provision } \\
\text { (Public, Private) }\end{array}$ \\
\hline Estonia & Preschool Child Care Institution & 1.5 to 7 & $\begin{array}{l}\text { Integrated for age } 0 \text { to } 5 / \text { primary } \\
\text { school entry }\end{array}$ & Public/Private \\
\hline \multirow[t]{4}{*}{ Finland } & Early education centre (EEC) & \multirow[t]{2}{*}{10 month to 7 years } & \multirow{2}{*}{$\begin{array}{l}\text { Integrated for age } 0 \text { to } 5 / \text { primary } \\
\text { school entry }\end{array}$} & \multirow[t]{2}{*}{ Public/Private } \\
\hline & Family day care (FDC) & & & \\
\hline & Open ECEC activities & 0 to 7 years & $\begin{array}{l}\text { Integrated for age } 0 \text { to } 5 / \text { primary } \\
\text { school entry }\end{array}$ & Public/Private \\
\hline & Pre-primary education & 6 years & Age 3 to $5 /$ primary school entry & Public/Private \\
\hline France & Preschool & 3 to 6 years & Age 3 to 5/primary school entry & Public/Private \\
\hline \multirow[t]{5}{*}{ Germany } & ECEC centre for all age groups $0-6 /$ school entry & 0 to 6 years/school entry & $\begin{array}{l}\text { Integrated for age } 0 \text { to } 5 / \text { primary } \\
\text { school entry }\end{array}$ & Public/Private \\
\hline & ECEC centre for children under 3 & 0 to 3 years & Age 0 to 2 & Public/Private \\
\hline & ECEC centre for children over 3 to $6 /$ school entry & 3 to $6 /$ school entry & Age 3 to $5 /$ primary school entry & Public/Private \\
\hline & Family day care & 0 to 6 years & $\begin{array}{l}\text { Integrated for age } 0 \text { to } 5 / \text { primary } \\
\text { school entry }\end{array}$ & Public/Private \\
\hline & Pre-primary classes & 5 to 6 years/school entry & Age 3 to $5 /$ primary school entry & Public/Private \\
\hline Iceland & Preschool & 0 to 6 years & $\begin{array}{l}\text { Integrated for age } 0 \text { to } 5 / \text { primary } \\
\text { school entry }\end{array}$ & Public/Private \\
\hline Ireland ${ }^{1}$ & Centre-based & 0 to 5 years & $\begin{array}{l}\text { Integrated for age } 0 \text { to } 5 / \text { primary } \\
\text { school entry }\end{array}$ & Private \\
\hline \multirow[t]{4}{*}{ Israel } & Kindergartens & \multirow[t]{2}{*}{3 to 5 years } & \multirow[t]{2}{*}{ Age 3 to 5/primary school entry } & \multirow[t]{2}{*}{ Public/Private } \\
\hline & Ultra-Orthodox settings & & & \\
\hline & Day care centre & 3 months to 3 years & \multirow[t]{2}{*}{ Age 0 to 2} & \multirow[t]{2}{*}{ Public/Private } \\
\hline & Family day care centre & $\begin{array}{l}6 \text { months to } 3 \text { years ( } 3 \text { to } 6 \text { months with } \\
\text { medical approval) }\end{array}$ & & \\
\hline \multirow[t]{3}{*}{ Japan } & Kindergarten & 3 to 5 years & Age 3 to $5 /$ primary school entry & Public/Private \\
\hline & Day care centre & 0 to 5 years & $\begin{array}{l}\text { Integrated for age } 0 \text { to } 5 / \text { primary } \\
\text { school entry }\end{array}$ & Public/Private \\
\hline & Integrated Centre for Early Childhood Education and Care & 0 to 5 years & $\begin{array}{l}\text { Integrated for age } 0 \text { to } 5 / \text { primary } \\
\text { school entry }\end{array}$ & Public/Private \\
\hline
\end{tabular}




\begin{tabular}{|c|c|c|c|c|}
\hline Country & Setting & Actual ages covered & $\begin{array}{l}\text { Standardised age group covered } \\
\text { (Age range) }\end{array}$ & $\begin{array}{r}\text { Type of provision } \\
\text { (Public, Private) }\end{array}$ \\
\hline \multirow[t]{4}{*}{ Luxembourg } & Education and Care Service & 4 to 6 years & Age 3 to $5 /$ primary school entry & Public/Private \\
\hline & Nurseries & 0 to 4 years & $\begin{array}{l}\text { Integrated for age } 0 \text { to } 5 / \text { primary } \\
\text { school entry }\end{array}$ & Public/Private \\
\hline & Pre-primary year 1 & 3 to 4 years & \multirow[t]{2}{*}{ Age 3 to 5/primary school entry } & \multirow[t]{2}{*}{ Public/Private } \\
\hline & Pre-primary years 2 and 3 & 4 to 6 years & & \\
\hline \multirow[t]{2}{*}{ Mexico } & Early childhood educational development (ISCED Level 1) & 0 to 2 years & Age 0 to 2 & Public \\
\hline & Pre-primary education & 2.8 to 5.11 years & Age 3 to $5 /$ primary school entry & Public/Private \\
\hline \multirow[t]{5}{*}{ New Zealand } & Education and Care & \multirow[t]{2}{*}{0 to 5 years } & \multirow{2}{*}{$\begin{array}{l}\text { Integrated for age } 0 \text { to } 5 / \text { primary } \\
\text { school entry }\end{array}$} & \multirow[t]{2}{*}{ Private } \\
\hline & Home-based & & & \\
\hline & Kindergarten & 2 to 4 years & Age 3 to $5 /$ primary school entry & Private \\
\hline & Language nest & 0 to 5 years & \multirow{2}{*}{$\begin{array}{l}\text { Integrated for age } 0 \text { to } 5 / \text { primary } \\
\text { school entry }\end{array}$} & \multirow[t]{2}{*}{ Private } \\
\hline & Playcentre & 0 to 5 years & & \\
\hline \multirow[t]{2}{*}{ Norway } & Kindergarten & 1 to 5 years & \multirow{2}{*}{$\begin{array}{l}\text { Integrated for age } 0 \text { to } 5 / \text { primary } \\
\text { school entry }\end{array}$} & \multirow[t]{2}{*}{ Public/Private } \\
\hline & Family kindergarten & 1 to 5 years & & \\
\hline \multirow[t]{4}{*}{ Poland } & Kindergartens & 3 to 6 years & \multirow[t]{4}{*}{ Age 3 to 5/primary school entry } & \multirow[t]{4}{*}{ Public/Private } \\
\hline & Preschool classes in primary schools & 3 to 6 years & & \\
\hline & Preschool units & 3 to 6 years & & \\
\hline & Preschool centres & 3 to 6 years & & \\
\hline Portugal & Centre-based ECEC for children aged 3+ & 3 t0 6 years & Age 3 to 5/primary school entry & Public/Private \\
\hline Slovak Republic & Kindergarten & $3-6$ years & Age 3 to 5/primary school entry & Public/Private 2 \\
\hline \multirow[t]{2}{*}{ Slovenia } & Kindergarten & 11 month to 6 years & $\begin{array}{l}\text { Integrated for age } 0 \text { to } 5 / \text { primary } \\
\text { school entry }\end{array}$ & Public/Private \\
\hline & Care for preschool children & 0 to 6 years & $\begin{array}{l}\text { Integrated for age } 0 \text { to } 5 / \text { primary } \\
\text { school entry }\end{array}$ & Public \\
\hline South Africa & Age-integrated centre-based & 0 to 4 years & $\begin{array}{l}\text { Integrated for age } 0 \text { to } 5 / \text { primary } \\
\text { school entry }\end{array}$ & Public/Private \\
\hline \multirow[t]{5}{*}{ Switzerland } & Regular centre-based ECEC & 0 to 5 years & \multirow{2}{*}{$\begin{array}{l}\text { Integrated for age } 0 \text { to } 5 / \text { primary } \\
\text { school entry }\end{array}$} & \multirow[t]{2}{*}{ Private } \\
\hline & Family childcare ECEC & 0 to 4 years & & \\
\hline & Kindergarten & 4 to 6 years & \multirow[t]{3}{*}{ Age 3 to 5/primary school entry } & Public \\
\hline & After-school care & 4 to 12 years & & Public \\
\hline & Playgroup & 3 to 4 years & & Private \\
\hline
\end{tabular}


154

\begin{tabular}{|c|c|c|c|c|}
\hline Country & Setting & Actual ages covered & $\begin{array}{l}\text { Standardised age group covered } \\
\text { (Age range) }\end{array}$ & $\begin{array}{r}\text { Type of provision } \\
\text { (Public, Private) }\end{array}$ \\
\hline \multirow[t]{4}{*}{ Turkey } & Independent kindergarten & 3 to 5 years & \multirow[t]{4}{*}{ Age 3 to 5/primary school entry } & \multirow[t]{4}{*}{ Public/Private } \\
\hline & Nursery classroom & 4 to 5 years & & \\
\hline & Practice classroom & 3 to 5 years & & \\
\hline & Special education preschool & 3 to 5 years & & \\
\hline \multirow[t]{4}{*}{$\begin{array}{l}\text { United Kingdom - } \\
\text { England }\end{array}$} & Group-based (private or voluntary providers) & 0 to 5 years & $\begin{array}{l}\text { Integrated for age } 0 \text { to } 5 / \text { primary } \\
\text { school entry }\end{array}$ & Private \\
\hline & $\begin{array}{l}\text { School-based providers with reception classes (may also include nursery } \\
\text { provision for younger children) }\end{array}$ & 3 to 5 years & \multirow[t]{2}{*}{ Age 3 to 5/primary school entry } & Private \\
\hline & Maintained nursery schools & 2 to 5 years & & Public \\
\hline & Childminders & 0 to 11 years & $\begin{array}{l}\text { Integrated for age } 0 \text { to } 5 / \text { primary } \\
\text { school entry }\end{array}$ & Public \\
\hline
\end{tabular}

1. Ireland: Data on Ireland relates to centre-based provision for children aged between 0 and primary school entry. It does not include:

a) Home-based provision, which is currently (2021) outside the scope of regulation and on which very little data is available.

b) Provision within primary schools (either junior/senior infant classes or Early Start classes). While the compulsory school age in Ireland is 6 , children generally start school before their 6 th birthday. Participation in infant classes in schools is possible from 4 or 5 years old, and a limited number of children attend Early Start classes or specialist provision for children with disabilities before the age of 4. While before the compulsory school age, this provision within schools is not part of mainstream ECEC provision, and provision in infant classes is categorised as ISCED Level 1.

2. Slovak Republic: Including church kindergarten.

Source: OECD "Quality beyond Regulations" database.

StatLink 게이 https://doi.org/10.1787/888934249547 


\section{Annex B. Technical annex}

Data informing the Starting Strong VI: Supporting Meaningful Interactions in Early Childhood Education and Care report and the accompanying Starting Strong: Mapping quality in early childhood education and care website were derived from two principal sources, developed specifically for the Quality beyond Regulations policy review carried out between 2018 and 2021:

1. A policy questionnaire distributed to the OECD's Early Childhood Education and Care (ECEC) Network.

2. Complementary country background reports (CBRs) completed by countries that provided additional support to the project.

\section{Policy questionnaire}

\section{Administration of the policy questionnaire}

Between April and October 2019, the OECD ECEC Network administered the Quality beyond Regulations policy questionnaire, collecting data from 26 countries for the reference year 2019 (Table A.B.1.).

Guided by the project's data collection framework, and following a glossary provided by the OECD Secretariat, the substantive sections of the questionnaire collected information on the following areas:

- background information on settings and curricula

- curriculum and pedagogy

- initial education, professional development and working conditions of the ECEC workforce

- contextual information (e.g. governance, standards and funding).

Following the administration of the policy questionnaire, the OECD Secretariat reviewed responses from participating countries, and, in co-operation with the OECD ECEC Network, streamlined the data, organising them along a set of indicators. These indicators are presented as part of a multidimensional map of quality in ECEC in the present Starting Strong VI publication and the accompanying website Starting Strong: Mapping quality in early childhood education and care. All sets of indicators are available for download from the accompanying website at https://quality-ecec.oecd.org.

The indicator development was guided by the members of the OECD ECEC Network and discussed at the meetings of the network between May 2020 and March 2021. Individual data tables for the sets of indicators were shared with and verified by participating countries and jurisdictions. 
Table A B.1. Countries and jurisdictions having responded to the policy questionnaire

\begin{tabular}{c|l|l}
\hline Australia & Chile & Luxembourg \\
\hline Victoria & Czech Republic & Mexico \\
\hline Belgium ${ }^{1}$ & Denmark & Norway \\
\hline Flemish community $_{\text {Canada }}$ & Estonia & New Zealand \\
\hline Alberta & Finland & Poland \\
\hline British Columbia & France & Portugal \\
\hline Manitoba & Germany & Slovak Republic \\
\hline New Brunswick & Bavaria & Slovenia \\
\hline Nova Scotia & Berlin & South Africa \\
\hline Nunavut & Brandenburg & Switzerland \\
\hline Ontario & North Rhine-Westphalia & Turkey \\
\hline Quebec & Iceland & United Kingdom ${ }^{1}$ \\
\hline Saskatchewan & Ireland & England \\
\hline Yukon & Israel & \\
\hline
\end{tabular}

1. Countries that responded to the questionnaire only at jurisdictional level.

Note: Not all countries and jurisdictions responded to all questions and for all types of settings.

Source: OECD "Quality beyond Regulations" database.

\section{Scope of the policy questionnaire}

Given the goal of providing internationally comparative data, the policy review focused on collecting national data from all participating countries. However, for federal systems, information was also collected on sub-national jurisdictions within countries.

Within countries and jurisdictions, the policy questionnaire collected data for all settings belonging to countries' regulated ECEC systems, regardless of type, funding, opening hours or programme content.

To address questions around workforce development, countries were asked to report on their policies based on the structure of their ECEC system, that is integrated for children aged zero to five, or split for children under the age of three and children aged three to five/primary school entry. Countries were asked to report on three main categories of staff: teachers, assistants, and leaders.

For further details on the scope of the policy review and questionnaire, please consult the Reader's Guide.

\section{Application of standardised age groups to settings and curricula}

Standardised age groups were allocated to the different curricula and settings to facilitate the use of information, to enable comparisons across age groups within and across countries (or jurisdictions), and to ensure consistency with the development of ECEC indicators as part of other OECD databases such as Education at a Glance.

The same standardised age groups were attributed to curricula and settings based on the following rules:

- Age 0 to 2: if the majority of years of a setting or curriculum target or cover ages 0 to 2. This includes settings or curricula which start after 0 years (e.g. 12 weeks, 3 months, etc.) and end up to age 3.

- Age 3 to 5/primary school entry: if the majority of years of a setting or curriculum target or cover ages 3 to 5 . This includes settings or curricula which start earlier than age 3 (e.g. 2.5 years) or later than age 3 (e.g. 4 years).

- Integrated for age 0 to 5/primary school entry: if a setting or curriculum target or cover ages below and above the cut-off point of 3 years to a similar extent (e.g. 0 to 12 years). 


\section{Application of "not applicable" and "missing" information}

Information classified by countries or jurisdictions as "no, not regulated or not required", "not applicable" (a), or "missing" $(\mathrm{m})$ was checked against explanatory notes provided by countries and sometimes reclassified within these three categories to ensure comparability of information across countries. For instance, where a particular type of staff (e.g. leaders or assistants) is not employed in a particular setting, the information is consistently classified as "not applicable" across indicators. Similarly, where no external monitoring process for curriculum implementation is in place, information on related items, such as the frequency of inspection or the methods used, is classified as "not applicable". In situations where countries left items in their questionnaire response either blank or ticked the response category "information is not available", comments provided by countries were taken into account for the interpretation of the data.

\section{Aggregation of information across different curricula and settings within countries and jurisdictions}

Information was aggregated for each indicator where information was the same within the standardised age groups. No information for different curricula or settings was aggregated across different standardised age groups. However, given the number of curricula and settings in some countries, a standardised age group could still entail different settings or curricula with different information.

For the use of the data in comparative figures and tables, both in the publication and on the accompanying website, information was sometimes aggregated across settings and curricula, within the same age groups. This generated one item per country and age group. The following rules were applied:

- For indicators based on binary response options (e.g. "yes" or "no"), a category was applied for a specific standardised age group if it applied consistently to all settings or curricula within that age group (e.g. "yes" or "no"). Where information differed across settings or curricula within a certain age group, this was indicated by the category "differs across curricula" or "differs across settings". For items with multiple response options (e.g. "required", "common practice", "no"), similar rules were applied as for items with binary response options.

- For indicators based on the calculation of a percentage of response categories that applied for a curriculum or setting (e.g. "breadth of policy measures in place to improve working conditions"), the simple value is shown where information is the same across settings or curricula within a specific standardised age group. Where information differs, a country average was calculated across curricula or settings within the same standardised age group.

Concerning the treatment of "missing" and "not applicable information in these aggregations:

- For items based on binary or multiple response options, "missing" or "not applicable" information was not taken into account and the aggregation was based only on the curriculum or setting with available information. In case countries or jurisdictions indicated both "not applicable" and "missing" information for different curricula or settings within the same standardised age group, the information is shown as "not applicable".

- For items based on the calculation of a percentage of response categories, "missing" or "not applicable" information was not taken into account, and the country value for that standardised age group represents the simple average of the remaining settings.

- As a consequence of these treatments, if information on the main setting or main curriculum framework within an age group is missing, the aggregations might reflect policies for settings or curriculum frameworks that cover a minority of children.

For some indicators (namely those providing information on levels of governance), the classification "shared responsibility" or "multiple authorities" was applied in the following cases: 
- When more than one level of governance was specified for one curriculum or setting (e.g. Central and Regional), the information was classified as "shared responsibility"/"multiple authorities".

- When information was the same for different curricula or settings within the same standardised age group, the aggregation was simply that category. That can be one particular level (e.g. Central), or "shared responsibility"/"multiple authorities".

- When information was different across curricula or settings within the same standardised age group, this was indicated as "shared responsibility" (e.g. responsibilities are shared for developing the curriculum for different curricula within a standardised age group).

In brief, "shared responsibility"/"multiple authorities" within standardised age groups was used, both when different authorities are responsible for a task for the same curriculum or setting, and when different authorities are responsible for a task for different curricula or settings. Curricula or settings with "missing" or "not applicable" information were not taken into account.

\section{Visualisation of indicators in the report and accompanying website}

Calculation of percentage of curricula or settings:

- When information is presented by standardised age group, the percentage was calculated considering the whole set or total number of observations in this age group in the denominator (including curricula and settings classified as "not applicable" or "missing").

- When information is presented for all curricula or settings without breakdown by standardised age groups, the percentage is based on all curricula or settings across all standardised age groups. Curricula or settings for which information was "not applicable" or "missing" were included in the denominator.

Presentation of countries in figures:

- All countries with information available for curricula or settings within a specific age group are represented in the figures. Countries may therefore appear in different categories, representing the different curricula or settings.

- Countries with "missing" or "not applicable" information in all curricula or settings within a standardised age group are not shown in the figures.

\section{Treatment of sub-national data}

Similar procedures (application of standardised age groups, aggregation of information across curricula or settings within the same age groups) were implemented for countries providing sub-national information.

The nature and extent of the data does not allow to calculate national data from information provided at the sub-national level for most of the indicators. However, for indicators based on the calculation of a percentage of response categories, an average was calculated in each standardised age group as described above for the individual jurisdictions. In a second step, an average for the country level was calculated based on the averages of the jurisdictions for some figures.

\section{Country background reports}

Complementary country background reports (CBRs) were provided by six countries: Australia, Canada, Ireland, Japan, Luxembourg and Switzerland. These background reports responded to a common set of issues and questions, following a standardised framework developed by the OECD Secretariat and reviewed by participating countries, to facilitate comparative analysis and to maximise knowledge-sharing opportunities. All country background reports are available on the following website: https:/loe.cd/3N6. 


\section{Glossary of key terms}

Accreditation (in ECEC settings): Refers to a process in which ECEC service providers, training providers or staff undergo an evaluation of their service, programme provision, or teaching/caring practices, by an external institution (such as an accrediting body) to confirm whether they meet a certain set of regulations or standards.

Assistants: Refers to ECEC staff whose role is to provide support to the teachers or lead staff member with a group of children. They usually have lower qualification requirements than teachers, ranging from no formal requirements to, for instance, vocational education and training.

Child-centred (beliefs, attitudes and practices): Refers to staff approaches and views which assume that learning is an active and co-operative process where children develop their own solutions to given problems.

Children's development, learning and well-being: Refers to children's academic and socio-emotional development, including children's cognitive and non-cognitive development, which helps in the acquisition of skills, abilities, competencies, values and attitudes necessary for children to know themselves, build and maintain relationships with others, engage with life's joys and complexities, and meet challenges in everyday life. Sometimes referred to as outcomes.

Common practices: Refers to any known practices or policies implemented in the last school year in the jurisdiction concerned (based on research, studies, evaluations, reports, data or other documents/reliable sources).

Curriculum/Curriculum framework: Curriculum frameworks are overarching documents setting out the principles, standards, guidelines and approaches that could be used by ECEC staff to foster children's development, learning and well-being. Curriculum frameworks may be broad, aiming to achieve several goals, embracing varied pedagogical approaches, covering several age groups or addressing only a particular age group. The implementation of curriculum frameworks is tightly linked with pedagogy, which can denote the theoretical foundation of a curricular approach. Both curriculum and pedagogy are important drivers of process quality and need to be embedded in staff's initial education and training and professional development.

ECEC: Refers to early childhood education and care. It includes all arrangements providing care and education for children under compulsory school age, regardless of setting, funding, opening hours or programme content (see also ECEC setting).

(ECEC) Centre leader: Refers to the person with the most responsibility for the administrative, managerial and/or pedagogical leadership at the ECEC centre. As part of the leadership role, centre leaders may be responsible for the monitoring of children, the supervision of other staff, contact with parents and guardians, and/or the planning, preparation and carrying out of the pedagogical work in the centre. Centre leaders may also spend part of their time working with the children. Sometimes referred to as Principal.

ECEC provider: Refers to the organisation that provides early childhood education and care services as its main objective. This can be a public institution as well as a private company, or a non-profit organisation.

ECEC quality: A multidimensional concept covering structural characteristics and process quality. Conceptualisations cover global aspects (such as warm climate), and domain-specific stimulation in learning areas such as literacy, emerging mathematics and science. (See Structural quality, Process quality).

ECEC setting: Refers to the place where early childhood education and care [ISCED Level 0] is delivered. Most settings typically fall into one of the following categories: 
Home-based ECEC: licensed home-based ECEC. Home-based settings refers to early childhood education and care that is provided in a home setting rather than a centre. These settings may or may not have an educational function and be part of the regular ECEC system. The minimum requirements defined for home-based settings vary widely across countries. Registered homebased setting providers are accredited to take care of children in their own homes.

Regular centre-based ECEC: more formalised ECEC centres typically belong to one of these three sub-categories:

Age-integrated centre-based ECEC for children from birth or one-year-old, up to the beginning of primary school: can be called kindergarten, preschool, or pre-primary, and offer a holistic pedagogical provision of education and care (often full-day). To an increasing degree, these settings are linked to the educational system.

Centre-based ECEC for children aged 0-2: often called "crèches", these settings may have an educational function, but are typically attached to the social or welfare sector and associated with an emphasis on care.

Centre-based ECEC for children aged 3+: often called kindergarten or preschool, these settings tend to be more formalised and linked to the education system. Many of them are part-time and provided in schools, but they can also be provided in designated ECEC centres.

ECEC staff: Refers to individuals whose professional activity involves the care and transmission of knowledge, attitudes and skills to children enrolled in an ECEC setting. This definition does not depend on the qualification held by the ECEC staff or on the delivery mechanism. ECEC staff may include teachers, educators, assistants or staff working with individual children, among other categories (see also Teacher and Assistant).

Governance: Refers to the systems and standards through which organisations control their educational activities and demonstrate accountability for continuous improvement of quality and performance.

Induction activities: Refers to activities designed to introduce new ECEC staff or teachers into the ECEC or teaching profession, and to support experienced staff or teachers who are new to a setting.

Inspection: Refers to the process of assessing (inspecting, investigating) the quality and/or performance of institutions, staff, services, and programmes by those (inspectors) who are not directly involved in the ECEC settings being monitored, and who are usually specially appointed to fulfil these responsibilities.

Integrated system: Refers to a system in which the responsibilities for ECEC services are under one (leading) authority (at the national and/or regional level), e.g. the education ministry, ministry of social welfare or another authority. Those responsibilities may stretch from curriculum development to standardsetting, monitoring or financing.

Interactions: Refers to all relationships that take place in the ECEC context and comprise ECEC process quality (see Process Quality). It includes inter-personal interactions and interactions with space, objects and materials.

Child-to-child (peer) interactions in ECEC: All interactions that take place among children in ECEC. Quality peer interactions allow children to experience feelings of belonging and confidence and to build friendships, and have a positive impact on children's well-being and socio-emotional outcomes.

Child-to-staff interactions: Refers to all the proximal processes between children and staff, which include social, emotional, physical and instructional aspects, and contributes to the ECEC climate. Collaborative, responsive, stimulating and supportive interactions between staff and children contribute to creating a positive climate and welcoming atmosphere. 
Child-to-space and materials interactions: Apart from interpersonal interactions, process quality also includes interactions with space, objects and symbols. The child's experience is mediated through complex interactions with multiple agents, including people, space, objects and cultural tools. These relations have an important role in shaping children's daily experience at the centre.

Child- to-parents interactions: Positive child-to-parents interactions (outside and inside the play- or classroom) include good communication, warm and emotionally supportive relations, acceptance and displays of love, such as praise and scaffolding. These interactions allow children's attachment and bonding with parents.

Child-to-communities interactions: Relationships that children develop with people, neighbourhoods and institutions surrounding them. The experience of the child is enriched when the ECEC centre fosters and supports real-life interactions with the outside world (e.g. parks, museums, swimming pools, greeting in the neighbourhood). These experiences benefit children's knowledge and social-emotional skills, giving opportunities for interaction with more and more diverse people.

ISCED: The International Standard Classification of Education (ISCED) is the reference classification for organising education programmes and related qualifications by education levels and fields. The classification was revised in 2011, and is referred to as ISCED 2011 (see OECD/European Union/UNESCO-UIS, 2015, http://dx.doi.org/10.1787/9789264228368-en).

ISCED 0 (or early childhood education): Refers to early childhood programmes that have an intentional education component and aim to develop cognitive, physical and socio-emotional skills necessary for participation in school and society. Programmes at this level target children below the age of entry into ISCED level and are often differentiated by age.

ISCED 01 - Early childhood educational development: Provides educational content designed for younger children (in the age range of 0 to 2 years). The learning environment is visually stimulating and language rich, and fosters self-expression with an emphasis on language acquisition and the use of language for meaningful communication. There are opportunities for active play so that children can exercise their co-ordination and motor skills under supervision and in interaction with staff.

ISCED 02 - Pre-primary education: Designed for children from age 3 years to the start of primary education. Through interaction with peers and educators, children improve their use of language and their social skills, start to develop logical and reasoning skills, and talk through their thought processes. They are also introduced to alphabetical and mathematical concepts, understanding and use of language, and are encouraged to explore their surrounding world and environment. Supervised gross motor activities (i.e. physical exercise through games and other activities) and play-based activities can be used as learning opportunities to promote social interactions with peers and to develop skills, autonomy and school readiness.

ISCED 1 (or primary education): Designed to provide a sound basic education in reading, writing and mathematics and a basic understanding of some other subjects. Primary education usually begins between the ages of 5 and 7 , and has a typical duration of six years.

\section{Learning areas}

Creative thinking (learning area): Development of children's capacities and competencies to generate ideas and feelings, use imagination and convey thoughts and experiences in many forms of expression, including artistic skills (e.g. painting, drawing, handicrafts) and musical skills (e.g. singing, playing an instrument, recognising songs). It also refers to children's capacity to observe and reflect, explore independently, and search for their own answers and solutions.

Language and literacy development (learning area): Development of children's productive and receptive language skills at all levels: syntax (ability to form sentences), morphology (ability to form 
words), semantics (understanding the meaning of words/sentences), phonology (awareness of speech sounds), pragmatics (how language is used in different contexts), and vocabulary. Also refers to children's (precursor) literacy skills, that is to say, all the skills related to reading and writing, such as recognising and writing letters and words, understanding pictures, etc.

Motor skills (learning area): Development of both fine and gross motor skills and awareness of one's own body. Fine motor skills include small movements such as drawing and writing or putting on one's shoes. Gross motor skills are large movements like walking and kicking, running and cycling.

Natural science (learning area): Development of children's interest and abilities in understanding the various cycles in nature, as well as in the development of scientific knowledge; the ability to question scientific phenomena and to draw conclusions about scientific subjects. It also refer to the development of awareness of how science and technology shape and affect our material, intellectual and cultural environments and the ability to understand that we all are a part of nature's cycles. These skills also allow an individual to make simple predictions, ask why, comprehend cause and effect, sort, and understand the common properties of living beings.

Numeracy (learning area): Development of children's ability to reason and to apply simple numerical concepts and understand numbers. Basic numeracy skills consist of knowing and recognising space, shapes, location and direction, the basic properties of sets, quantity, order and number concepts, time and change, being able to count, to comprehend fundamental mathematics like addition, subtraction, multiplication and division.

Physical education (learning area): Development of knowledge and awareness of their own body, as well as the development of the ability to perform complex muscle and nerve acts that produce movements, the ability to co-ordinate the body.

\section{Levels of government}

Central: Refers to the authorities responsible for ECEC at the highest level of governance in a country. Depending on the governance structure of the country, these authorities may or may not exert the key power of decision over ECEC policies and implementation. Also referred to as the national government.

Regional or sub-regional: Refers to decentralised level of governance. It is located at state or province level in the vast majority of countries, and may be referred to as communities, Länder, cantons, states, etc. Regional authorities in federal countries are often responsible for ECEC in their particular region.

Local: Refers to the government responsible for the local jurisdiction, located at city/town level in the vast majority of countries, e.g. municipality, district, commune, etc. In some countries, the municipalities take the main responsibility for ECEC settings and primary schools.

Practicum: Refers to the part of pre-service (initial) training where the learner applies the theoretical knowledge in practice.

Pedagogy: Pedagogy outlines the respective strategies and techniques implemented by ECEC staff to provide opportunities for young children's development within a particular social and material context. It involves staff's pedagogical knowledge, but also the way the knowledge is applied and the practices are implemented in interaction with children, and in response to children's requests and interests. Pedagogy can also denote the theoretical foundation of a curricular approach. Thus, pedagogy is considered to both inspire and support curriculum, having a direct effect on children's experiences and interactions in ECEC. Both curriculum and pedagogy are important drivers of process quality and need to be embedded in staff's initial education and training and professional development. 
Pedagogical leadership: Refers to the part of an ECEC centre leader's role that focuses on oversight of pedagogical practice in the setting. This includes actions that a leader takes, or delegates to others, to facilitate or enhance the planning, preparation and carrying out of the pedagogical work in the centre.

Pedagogical approach: Refers to the interactive process between teacher and children and to the learning environment, including the set of strategies and techniques implemented to provide opportunities for children's development in skills, attitudes and dispositions within a particular social and material context.

Constructivist/interactive (pedagogical approach): Refers to an approach that views learning as an active exchange between the child and environment that progresses in 'stages', with adults and peers providing important stimulus in learning. Based on the idea that learners construct new ideas/concepts based on their existing knowledge.

Developmentally appropriate practices (pedagogical approach): Refers to a balance of childinitiated learning and guidance from staff members. The approach provides a wide range of different activities, which are carried out in groups, or independently. The approach focuses on socio-emotional, physical and cognitive development. All practices are based on i) theories of child development; ii) individual needs; and iii) the child's cultural background.

Didactic/direct instruction (pedagogical approach): Refers to a classic method of learning with mainly teacher-initiated activities including repetition. This approach normally follows highly academic programmes, which put emphasis on literacy and numeracy skills.

Experiential education (pedagogical approach): Refers to an approach that focuses on the emotional well-being and the level of involvement of children. It emphasises satisfying children's basic needs so that they feel at ease and self-confident, allowing them to act spontaneously and to be concentrated, interested and fascinated.

Outcome-based education/performance-based education (pedagogical approach): Refers to an approach that sets specific aims and strategies for teachers to achieve outcomes for children, e.g. literacy and numeracy skills, specific subject knowledge, IQ scores as well as child's socioemotional and soft skills such as motivation to learn, creativity, independence, self-confidence, general knowledge and initiative.

Readiness for school (pedagogical approach): Refers to an approach that puts emphasis on preparing children for primary school, e.g. by developing children's early literacy and mathematics development. The pedagogy shows an alignment with primary schooling.

Social pedagogy (pedagogical approach): Refers to an approach that stresses content and quality of practice rather than assessing children's achievement levels. It highlights the importance of dialogue between adults and children, as well as creative activities with discussions and reflections.

Play: Refers to a naturally spontaneous, creative, socio-cultural process where children engage and interact with others and the world around them. Playful learning or use of play for learning are considered different to play initiated and controlled by children as players (also sometimes referred to as free play), which is connected to a constructivist approach to ECEC.

Private setting: Refers to a setting administered/owned directly or indirectly by a non-governmental organisation or private person/organisation (church, trade union, business or other concern). Private settings may be publicly subsidised or not. Private non-publicly-subsidised settings receive no funding from the public authorities and are independent in their finances and governance. Private publicly-subsidised settings operate completely privately but receive some or all their funding from public authorities -if more than $50 \%$ of their core funding comes from government agencies, they can be considered government-dependent private ECEC settings. 
Process quality: Refers to the nature of the daily classroom and centre experiences of children in ECEC and concerns the more proximal processes of children's experiences in their programme. Process quality includes all the proximal processes of children's everyday experience: in addition to the interactions between children and ECEC staff, process quality concerns the interactions among children and the interactions of children with parents, the community and space and materials. While written curricula are considered a structural aspect, the actual activities provided in the ECEC centre are an aspect of process quality. The implementation of written curriculum is a central factor in the configuration of the child's daily experience at the ECEC centre. Interactions between adults (staff-to-staff, parents and community) are also relevant factors influencing ECEC process quality, but they are not considered to be at the centre of the ECEC daily experience from the perspective of the child.

Public settings: Refers to an ECEC centre managed by a public education authority, government agency, or municipality.

Recognition of previous learning (RPL): Refers to an assessment process that allows obtaining or upgrading prior qualifications and/or experience in order to work as an ECEC teacher.

Self-assessment/evaluation: Refers to the process in which an ECEC setting reflects on their own performance regarding the accomplishment of certain goals or standards, or a process in which staff members reflect on their own skills and capabilities as a way to monitor progress, attain goals and foster improvement. Staff self-assessment practices can also be part of a larger monitoring procedure conducted by an external institution.

Staff-child ratio: Refers to the number of children per full-time member of staff. This can be a maximum (regulated) number, which indicates the maximum number of children that one full-time member of staff is allowed to be responsible for; or it can be an average: the average number of children a full-time staff member can be responsible for. Ratios can be either for main staff only (such as teachers or caregivers), commonly reported as teacher-child or teacher-student ratios, but can also include auxiliary staff, such as assistants.

Structural quality in ECEC: Refers to the distal factors that are typically regulated, such as children-tostaff ratio, group size and staff training/education, and create the framework for the experiences of children in ECEC. These characteristics are not only part of the ECEC location in which children participate, but also part of the environment that surrounds the ECEC setting, e.g. the community. Structural factors are an important precursor to the overall domain of process quality and to its subdomains. Also structural features generally have indirect effects on children's development, learning and well-being (through its influence on process quality). Structural quality is partly determined by legislation, policy and funding and is a major factor in the macroeconomic costs of ECEC. See Process Quality.

Teacher and comparable practitioners: Refers to pre-primary and primary education teachers. They are the individuals with the most responsibility for a group of children at the class- or playroom-level. They may also be called pedagogues, educators, childcare practitioners or pedagogical staff in pre-primary education, while the term teacher is almost universally used at the primary level.

Staffs' working time: Refers to the specified total number of hours per week, including contact and noncontact time, as stipulated by the regulations, to earn their full-time salary.

Contact time: Actual contact time is the annual average number of hours that full-time staff spend with children in activities that have an educational component, including overtime. It refers to net contact time as stated in regulations, excluding preparation time and periods of time formally allowed for breaks.

Non-contact time: Refers to the component of staff's working time other than contact time directly working with children (e.g. preparation, professional development, and consultation with parents). 
Transitions: Refers to a change process that children go through from one educational stage to another over time. This can include horizontal and vertical transitions. Horizontal transitions involve children's transitions during their everyday lives between, for instance, a pre-primary education setting or primary school and an after-school centre. Vertical transitions refer to the transitions between different educational settings, such as between an ECEC setting and primary school. Transitions might also refer to children's transitions between the home-learning environment and the ECEC setting. Also relates to transition practices of staff that intentionally attempt to support children during their transition period across settings, and to training that seeks to prepare staff for their work on transitions (e.g. co-operation with parents, attitudes and reflection on transitions).

Working conditions: Refers to staff working hours, workload and wages, among others. 


\section{Annex C. List of tables available on line}

The following tables are available in electronic form only.

Chapter 2. Curriculum frameworks, pedagogy and process quality in early childhood education and care

https://doi.org/10.1787/888934249509

\begin{tabular}{l|l}
\hline Figure C.2.1 & Specification of developmental and learning goals in curriculum frameworks covering children aged 0 to 2 \\
\hline Figure C.2.2 & Scope of stakeholders' involvement in the design of curriculum frameworks covering ages 3 to 5 \\
\hline Figure C.2.3 & Scope of stakeholders' involvement in the design of curriculum frameworks covering ages 0 to 2 \\
\hline Table C.2.1 & ECEC curriculum frameworks legal status and coverage, 2019 \\
\hline Table C.2.2 & Developmental/learning goals stated in curriculum frameworks \\
\hline
\end{tabular}

\section{Chapter 3. Workforce and process quality in early childhood education and care}

https://doi.org/10.1787/888934249528

\begin{tabular}{l|l}
\hline Figure C.3.1 & Breadth of content required as part of ECEC professionals' initial education to obtain the minimum qualification (age 0 to 2) \\
\hline Figure C.3.2 & Inclusion of curriculum framework implementation in assistants' initial education \\
\hline Figure C.3.3 & Formal recognition and accreditation of professional development activities for assistants \\
\hline Figure C.3.4 & Assessment of quality of professional development for assistants \\
\hline Figure C.3.5 & Time incentives for assistants to participate in professional development activities \\
\hline Figure C.3.6 & Assessment of assistants' professional development needs \\
\hline Figure C.3.7 & Assessment of barriers for assistants' participation in professional development, by age group \\
\hline Figure C.3.8 & Policy measures and regulations concerning the contract type of staff, by staff type \\
\hline Figure C.3.9 & Measures in place to support promotion or wage increase associated with assistants' performance \\
\hline Figure C.3.10 & Activities for which staff are given protected time \\
\hline Figure C.3.11 & Extent of protected time for activities without children \\
\hline Figure C.3.12 & Recognition of prior learning to meet qualification requirement for centre leaders, by age group \\
\hline Figure C.3.13 & Breadth of content required as part of leader pre-service training to obtain the minimum qualification, by age group \\
\hline Table C.3.1 & Practicum requirements as part of ECEC professionals' initial education and training \\
\hline
\end{tabular}

\section{Annex A. Reference tables}

https://doi.org/10.1787/888934249547

\begin{tabular}{l|l}
\hline Table A.A.3 & Professionals working in ECEC settings, 2019
\end{tabular}




\section{Annex D. Network member contributors}

Starting Strong $\mathrm{VI}$ is a product of continued collaboration between the OECD Secretariat and the OECD Network on Early Childhood Education and Care. Participants provided country data, country-specific policy information, feedback on drafts, among other contributions.

Participating countries and experts are listed below in alphabetical order.

\begin{tabular}{|c|c|c|}
\hline Country & Name & Organisation \\
\hline \multirow[t]{2}{*}{ Australia } & Craig Bennett & Australian Children's Education and Care Quality Authority \\
\hline & $\begin{array}{l}\text { Amanda Collins } \\
\text { John Mason }\end{array}$ & $\begin{array}{l}\text { Australian Children's Education and Care Quality Authority } \\
\text { Australian Children's Education and Care Quality Authority }\end{array}$ \\
\hline Belgium - Flanders & $\begin{array}{l}\text { Goedele Avau } \\
\text { Bart Bruylandt } \\
\text { Liesbeth Roels } \\
\text { Marie-Hélène Sabbe } \\
\text { Christele Van } \\
\text { Nieuwenhuyzen }\end{array}$ & $\begin{array}{l}\text { Flemish Government Education and Training Department } \\
\text { Flemish Government Education and Training Department } \\
\text { Flemish Government Education and Training Department } \\
\text { Flemish Government Education and Training Department } \\
\text { Growing Up (formerly known as Kind en Gezin) }\end{array}$ \\
\hline Chile & $\begin{array}{l}\text { Paula Guardia } \\
\text { Bárbara Marchant }\end{array}$ & $\begin{array}{l}\text { Ministry of Education, Undersecretary of Early Childhood Education } \\
\text { Ministry of Education, Undersecretary of Early Childhood Education }\end{array}$ \\
\hline Canada & $\begin{array}{l}\text { Tania Brudler } \\
\text { Danielle Dubé } \\
\text { Nicole Gervais } \\
\text { David Hull } \\
\text { Bronwen Lloyd } \\
\text { Diane Lutes } \\
\text { Debra Mayer } \\
\text { Christian Paradis } \\
\text { Suela Sefa } \\
\text { Denise Stone } \\
\text { Jugo Vukojevic }\end{array}$ & $\begin{array}{l}\text { Children's Services, Alberta } \\
\text { Ministère de la Famille, Québec } \\
\text { Canada (CMEC) representative to the OECD ECEC Network, New Brunswick } \\
\text { Council of Ministers of Education, Canada (CMEC) Secretariat } \\
\text { Early Learning and Child Care, Nova Scotia } \\
\text { Early Learning and Development, New Brunswick } \\
\text { Chair of CMEC's Early Childhood Learning and Development Committee } \\
\text { Employment and Social Development Canada } \\
\text { Ministère de la Famille, Québec } \\
\text { Early Learning and Child Care, Nova Scotia } \\
\text { Employment and Social Development Canada }\end{array}$ \\
\hline Czech Republic & Irena Borkovcová & Czech School Inspectorate \\
\hline Denmark & $\begin{array}{l}\text { Lise Bendix Lanng } \\
\text { Louise Solgård Hvas }\end{array}$ & $\begin{array}{l}\text { Former Division of Early Childhood Education and Care } \\
\text { Ministry of Children and Education }\end{array}$ \\
\hline Estonia & Tiina Peterson & Ministry of Education and Research \\
\hline Finland & Kirsi Alila & Ministry of Education and Culture \\
\hline France & Gilles Pétreault & Ministry of National Education and Youth \\
\hline Germany & $\begin{array}{l}\text { Samuel Bader } \\
\text { Fabienne Becker-Stoll } \\
\text { Ute Jansen } \\
\text { Nicole Klinkhammer } \\
\text { Evelyn Kubsch } \\
\text { Jana Pampel } \\
\text { Christa Preissing } \\
\text { Eva Reichert- } \\
\text { Garschhammer } \\
\text { Carolyn Seybel } \\
\text { Bettina Stobbe } \\
\text { Daniel Turani }\end{array}$ & $\begin{array}{l}\text { German Youth Institute } \\
\text { State Institute of Early Childhood Research (IFP) } \\
\text { Ministry for Children, Family, Refugees and Integration - North Rhine-Westphalia } \\
\text { German Youth Institute } \\
\text { Senate Department for Education, Youth and Family } \\
\text { Senate Department for Education, Youth and Family } \\
\text { Berlin Institute for Quality Development in the Early Years (BeKi) } \\
\text { Senate Department for Education, Youth and Family } \\
\text { German Youth Institute } \\
\text { Ministry for Education, Youth and Sport - Brandenburg } \\
\text { German Youth Institute }\end{array}$ \\
\hline Iceland & $\begin{array}{l}\text { Ragnar F. Ólafsson } \\
\text { Björk Óttarsdóttir }\end{array}$ & $\begin{array}{l}\text { Directorate of Education - Talis Starting Strong Survey matters } \\
\text { Ministry of Education, Science and Culture }\end{array}$ \\
\hline
\end{tabular}




\begin{tabular}{|c|c|c|}
\hline Ireland & $\begin{array}{l}\text { Philip Crosby } \\
\text { Toby Wolfe }\end{array}$ & $\begin{array}{l}\text { Department of Education } \\
\text { Department of Children, Equality, Disability, Integration and Youth }\end{array}$ \\
\hline Israel & $\begin{array}{l}\text { Noa Ben-David } \\
\text { Michal Carmel } \\
\text { Inbal Ron Kaplan } \\
\text { Varda Malka } \\
\text { Merav Turgerman }\end{array}$ & $\begin{array}{l}\text { JDC Israel } \\
\text { Ministry of Labour, Social Affairs and Social Services } \\
\text { RAMA } \\
\text { Ministry of Labour, Social Affairs and Social Services } \\
\text { Ministry of Education }\end{array}$ \\
\hline Japan & $\begin{array}{l}\text { Kiyomi Akita } \\
\text { Satoshi Aritaki } \\
\text { Fumiko Honda } \\
\text { Takuro Horikawa } \\
\text { Masafumi Ishikawa } \\
\text { Riyo Kadota } \\
\text { Hirokazu Kobayashi } \\
\text { Koki Matsumoto } \\
\text { Sachiko Nozawa } \\
\text { Kayo Sawada } \\
\text { Nagisa Shimada } \\
\text { Kenta Shizume } \\
\text { Chie Takatsuji }\end{array}$ & $\begin{array}{l}\text { Gakushuin University } \\
\text { Ministry of Health, Labour and Welfare } \\
\text { Cabinet Office } \\
\text { Ministry of Education, Culture, Sports, Science and Technology } \\
\text { Ministry of Education, Culture, Sports, Science and Technology } \\
\text { Seinan Gakuin University } \\
\text { Ministry of Education, Culture, Sports, Science and Technology } \\
\text { Ministry of Education, Culture, Sports, Science and Technology } \\
\text { University of Tokyo } \\
\text { Ministry of Education, Culture, Sports, Science and Technology } \\
\text { Ministry of Education, Culture, Sports, Science and Technology } \\
\text { Ministry of Health, Labour and Welfare } \\
\text { Ministry of Health, Labour and Welfare }\end{array}$ \\
\hline Luxembourg & $\begin{array}{l}\text { Christine Konsbruck } \\
\text { Georges Metz } \\
\text { Flore Schank } \\
\text { Claudia Schroeder } \\
\text { Claude Sevenig }\end{array}$ & $\begin{array}{l}\text { Service National de la Jeunesse (SNJ) } \\
\text { Service National de la Jeunesse (SNJ) } \\
\text { Ministry of Education, Children and Youth } \\
\text { Ministry of Education, Children and Youth } \\
\text { Ministry of Education, Children and Youth }\end{array}$ \\
\hline Mexico & $\begin{array}{l}\text { María del Carmen Campillo } \\
\text { Pedrón } \\
\text { Susana Escamilla } \\
\text { Hernández } \\
\text { José Iván Quezada López }\end{array}$ & $\begin{array}{l}\text { Ministry of Public Education } \\
\text { Ministry of Public Education } \\
\text { Ministry of Public Education }\end{array}$ \\
\hline New Zealand & $\begin{array}{l}\text { Nancy Bell } \\
\text { Siobhan Murray }\end{array}$ & $\begin{array}{l}\text { Ministry of Education } \\
\text { Ministry of Education }\end{array}$ \\
\hline Norway & $\begin{array}{l}\text { Ida Erstad } \\
\text { Tove Mogstad Slinde }\end{array}$ & $\begin{array}{l}\text { Directorate for Education and Training } \\
\text { Ministry of Education and Research }\end{array}$ \\
\hline Poland & Witold Zakrzewski & Ministry of National Education \\
\hline Portugal & $\begin{array}{l}\text { Liliana Marques } \\
\text { Helder Pais }\end{array}$ & $\begin{array}{l}\text { General Directorate of Education } \\
\text { General Directorate of Education }\end{array}$ \\
\hline Slovak Republic & Viera Hajdúková & Ministry of Education, Science, Research and Sport \\
\hline Slovenia & $\begin{array}{l}\text { Janja Cotič Pajntar } \\
\text { Barbara Kresal Sterniša } \\
\text { Nada Požar Matijašič }\end{array}$ & $\begin{array}{l}\text { National Education Institute } \\
\text { Ministry of Education, Science and Sport } \\
\text { Ministry of Education, Science and Sport }\end{array}$ \\
\hline South Africa & $\begin{array}{l}\text { Sara Maja } \\
\text { Vuyelwa Ntuli }\end{array}$ & $\begin{array}{l}\text { Department of Basic Education } \\
\text { Department of Basic Education }\end{array}$ \\
\hline \multirow[t]{2}{*}{ Switzerland } & $\begin{array}{l}\text { Andrea Faeh } \\
\text { Veronika Neruda } \\
\text { Franziska Vogt }\end{array}$ & $\begin{array}{l}\text { St. Gallen University of Teacher Education } \\
\text { Swiss Conference of Cantonal Ministers of Social Affairs (SODK) } \\
\text { St. Gallen University of Teacher Education }\end{array}$ \\
\hline & \multicolumn{2}{|c|}{ The Swiss contribution was produced with the financial support of the Jacobs Foundation Switzerlanc } \\
\hline Turkey & $\begin{array}{l}\text { Aynur Arslan } \\
\text { Seval Kuday } \\
\text { Tuncai Morkoç }\end{array}$ & $\begin{array}{l}\text { Ministry of National Education } \\
\text { Ministry of National Education } \\
\text { Ministry of National Education }\end{array}$ \\
\hline United Kingdom - England & $\begin{array}{l}\text { Charlotte Clarke } \\
\text { lan Ward }\end{array}$ & $\begin{array}{l}\text { Department for Education } \\
\text { Department for Education }\end{array}$ \\
\hline
\end{tabular}





\section{Starting Strong}

\section{Starting Strong VI}

\section{SUPPORTING MEANINGFUL INTERACTIONS IN EARLY CHILDHOOD EDUCATION AND CARE}

Children's learning, development and well-being are directly influenced by their daily interactions with other children, adults, their families and the environment. This interactive process is known as "process quality", and leads to a key question - which policies set the best conditions for children to experience high-quality interactions in early childhood education and care (ECEC) settings?

This report discusses five main policy levers and their effect on process quality, focusing particularly on curriculum and pedagogy, and workforce development. It presents indicators covering 26 countries and jurisdictions, 56 different curriculum frameworks, and more than 120 different types of ECEC settings. 